Portland State University

PDXScholar

$1-1-1979$

\title{
Institutional economics and urban political economy
}

Forrest Clinton Blodgett

Portland State University

Follow this and additional works at: https://pdxscholar.library.pdx.edu/open_access_etds Let us know how access to this document benefits you.

Recommended Citation

Blodgett, Forrest Clinton, "Institutional economics and urban political economy" (1979). Dissertations and Theses. Paper 849.

https://doi.org/10.15760/etd.849

This Dissertation is brought to you for free and open access. It has been accepted for inclusion in Dissertations and Theses by an authorized administrator of PDXScholar. Please contact us if we can make this document more accessible: pdxscholar@pdx.edu. 
FORREST CLINTON BLODGETT

\author{
A thesis submitted in partial fulfillment of the \\ requirements for the degree of \\ DOCTOR OF PHILOSOPHY \\ in \\ URBAN STUDIES
}

Portland State University

1979

(C) FORREST C. BLODGE IT

Reproduced with permission of the copyright owner. Further reproduction prohibited without permission. 
TO THE OFFICE OF GRADUATE STUDIES AND RESEARCH:

The members of the Committee approve the thesis of Forrest Clinton Blodgett presented August 2, 1979.

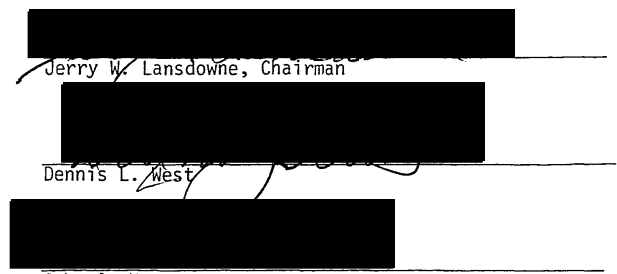

John A. Hanson

APPROVED:

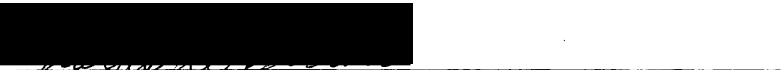

Charles D. Bolton, Acting Dean, School of Urban Affairs

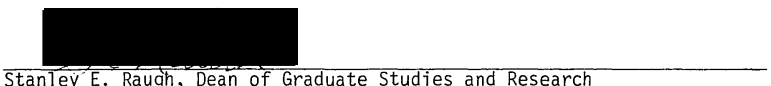

Reproduced with permission of the copyright owner. Further reproduction prohibited without permission. 


\section{ACKNOWLEDGMENTS}

One is left with a sense of enormous debt after completion of an enterprise of this magnitude. What commences as an individual tour de force ends with the humble realization that one's accomplishment--if, incieed, it is an accomplishment--is solidly founded on the works of all the scholars whose names fill his footnotes and bibliography, the colleagues and friends who gave constructive advice and assisted with the logistical details of producing the finished manuscript, and the family members who endured hardship and solitude and yet encouraged progress.

Some persons stand out as meriting special thanks because their contributions were more direct and they more keenly infiuenced the final product. Such persons include Dr. John Hodges, Emeritus Professor of Economics at the University of Missouri, who gave valuabie criticism of the first drafts of this manuscript and under whose tutorage I first Tearned of Vebien, Cominons, and Ayres; Dr. Jerry Lansdowne, Professor of Urban Studies at Portland State University, who guided me through the Tabyrinth of political theory; Dr. John Hanson, who insisted that I keep the "urtian content" up front, and thereby helped improve the final product over what it would otherwise have been; or. Denny West, who performed the rites that initiated me into urban scholarship; and Dr. Hohad Toulan, Dean of the School of Urban Affairs at Portland State University, whose adnonishments kept ne at the task, and whose patience and forbeararice allowed me time to finish it. 
And, of course, Kathryn Erickson, a typist with the productivity of an IBM line-printer, the patience of a thermostat, the precision and accuracy of an electronic calculator, and a heart of pure gold, has my profound thanks for producing the final manuscript as well as parts of the first draft.

Likewise, I am grateful for that corps of readers--Dr. Hi1degard Kurz, Hazen Morse, Dorothy Wondree, and Dorothy Adkins--who discovered and made possible the correction of typographic errors and my errors of form.

Finally, I owe a personal and special gratitude to my wife, Bery, who endured many hours of discussion while ideas were forming, many hours of solitude while ideas were committed to writing, many hours before the typewriter producing much of the first draft, and many hours encouraging and sometimes driving me to produce copy. 
TABLE OF CONTENTS

PAGE

ACKNOWLEDGMENTS ..............................

CHAPTER

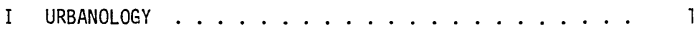

Urban Context ................. 2

Institutional Economics . . . . . . . . 7

Time Period of Analysis

Ends and Means

Ceremonialism

Technology

Orthodox Economics . . . . . . . . . 18

Urban Pluralism . . . . . . . . . . . . 22

Collective Action

Interest-Group Politics

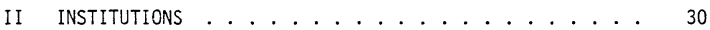

Institutions and Groups.......... 30

Origins of Institutions . . . . . . . . 33

Social Functions of Institutions ........ 40

Institutional structure . . . . . . . . 45

Classifications of Institutions ...... 50

Institutions and Urban Areas ........ . . 57

III URBAN CONTINUUM ................. 61

Life Processes and Temporal Setting . . . . . . 62

Homo Mensura

Temporal Setting

Reproduced with permission of the copyright owner. Further reproduction prohibited without permission. 
II URBAN CONTINUUM (Continued)

Causes, Effects, and Means ......... 68

Present Effects of Past Causes

Effects and Means

Ends, Means, and Process ............

Natural or Artificial Selection

Alternative Ends and Limited Means

On-Going Life Processes

IV

CEREMONIALISM AND THE URBAN PAST . . . . . . . . 102

The Transmission of Cultural Beliefs . . . . . 105

Origins of Cultural Beliefs . . . . . . . . . 112

Totems and Taboos................. 121

The Mythical Past . . . . . . . . . . . . 124

Mystical Justifications . . . . . . . . . 129

Ritual and Role-Playing ............ 132

Ceremonialism and Law . . . . . . . . . 137

Summary ................... 140

V CEREMONIALISM AND URBAN CHOICES . . . . . . . . . . 144

Ceremonialism and Institutional Structure.... . 145

Institutional Structure

Rank and Status

Rank and Technical Competence

Ceremonialism and Socialization ......... 167

Ceremonialism and Social Control . . . . . . 175

Ceremonial Exchange

Ceremonial Gift-Giving

Ceremonialism and Social Choices . . . . . 187

VI TECHNOLOGY ......................... 194

Reproduced with permission of the copyright owner. Further reproduction prohibited without permission. 
VI TECHNOLOGY (Continued)

Technology and Tools ............. 196

Tools and Goods

Tools and Skill

Tcols and Productivity

Tools and Human Effort . . . . . . . . . 212

Power Devices

Transmission Devices

Control Devices

Thought Devices

VII TECHNOLOGICAL DYNAMISM ............. 239

Technological Continuity . . . . . . . . . 240

Technology and Science

Cumulative Synthesis

Technological Cross-Fertilization

Technological Change .......... . . 250

- Tools and Change

Technology and Cities

Technology and Urbanization

Technology and Ceremonialism . . . . . . . 277

Innovation of New Technology

Ceremonialism and Innovation

VIII TECHNOLOGICAL PROGRESS . . . . . . . . . . . 299

Institutional Change--Technology

and Internal Economies . . . . . . . . . 301

The Heavy Plow

Triennial Field Rotations

The Heavy Horse

Urbanization--Technology and External Economies . . 322

Distribution of Urban Settlements

Rural to Urban Migration

Urban Growth

Technology and Progress............ 341

Reproduced with permission of the copyright owner. Further reproduction prohibited without permission. 
IX URBAN VAlUATIONS ............................. 347

Values and Welfare............ 351

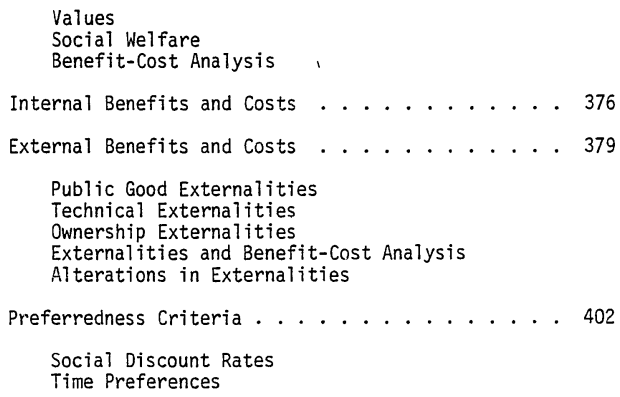

Benefit-Cost Analysis and Welfare . . . . . . 412

X URBAN PLURALISM ............... 421

Collective Action . . . . . . . . . . . . 424

Conflicts of Interests

Ceremonial Norms

Changing Ceremonial Norms

Interest-Group Politics . . . . . . . . . . 446

Law and Sovereignty

Interest Groups and the Law

XI CONCLUSION ...................... 474

Summary of Major Points . . . . . . . . . . . 474

Institutional Economics

Valuations

Pluralism

Institutional Economics and Pluralism . . . . . 486

Institutional Economics and Urban Affairs . . . . 489

Reproduced with permission of the copyright owner. Further reproduction prohibited without permission. 
XI CONCLUSION (Continued)

Institutional Economics and Urban Affairs

(Continued)

Technology and Urbanization

Urbanization and Ceremonialism

Institutional Economics . . . . . . . . . 496

Economic Theory

Contemporary Institutional Economics

SOURCES CONSULTED

540

Reproduced with permission of the copyright owner. Further reproduction prohibited without permission. 


\section{CHAPTER I}

URBANOLOGY

The emergence of a complex and highly urbanized industrial society has inspired great study of urbanization and urban phenomena by social scientists. Unfortunately, most social scientists study urbanology within the relatively narrow confines of their particular disciplines. Sociologists concentrate on urban phenomena arising out of human-group relationships, while political scientists concentrate on units of urban government and intergovernmental relations. Likewise, economists study urbanology from a market perspective while geographers tend to concentrate on urban location theory and historians are concerned about the history of urbanization. Moreover, urban planners and research specialists are principally practitioners who receive and attempt to apply the resulting fragments of theory to their professional practices. There has been altogether too little cross-tell between the academic disciplines, and thus little advancement toward a wholistic theory of urbanology.

On the other hand, there have been some productive efforts to apply theories from one discipline to the study of another discipline--notably, group theory from sociology and elements of marginalism from economics are being applied to aspects of political science. But this is on a somewhat ethereal level with only marginal integration across disciplines. Some of the hybrid results of this kind of academic crosspollination have only recently been applied in any meaningful way to urbanology. The point is that progress toward a more wholistic theory 
of urbanology seems all too slow under the circumstances.

The major contention of this work is that some progress toward such a wholistic theory might be made by integrating institutional economic theory and elements of the more orthodox economic theory with aspects of pluralist theory from political science and relating the resulting whole in an urban context. This chapter is the first and introductory chapter in a work which attempts that synthesis. In the way of introducing the work, this chapter explains what is meant by "urban context," and it briefly traces out the theories involved in the synthesis.

\section{URBAN CONTEXT}

The title of this work, Institutional Economics and Urban Political Economy, implies that institutional economics and political economy have some kind of unique and exclusive relationship to urban affairs. It is the purpose of this section to disabuse the reader of any such notion and to explain the context in which the word "urban" is used. Neither institutional economics nor political economy is uniquely or exclusively related to urban phenomena. Rather, both subjects were founded and expanded on much more general planes.

Institutional economics is based on anthropological methodology, and it seeks to analyze and describe the cultural antecedents to human economic interaction at all levels. Likewise, political economy attempts to rationalize political behavior in economic terms and economic behavior in political terms. Political economy is therefore as applicable to international and national affairs as it is to state and local affairs. The point is that both bodies of theory apply to all kinds of social 
interaction--international, national, state, local, institutional, fraternal, familial, and interest-group as well as urban.

Acknowledging that neither institutional economics nor political economy is uniquely or exclusively urban, it is no less true that the scopes of both subjects do include urban affairs. It is therefore possible to study urban affairs from the institutional economic point-ofview or from the vantage point of political economy. Or it is possible to view the latter two subjects with an urban perspective. Hopefully, this study will take each of these points-of-view at appropriate times so that the reader will sometimes find urban affairs elaborated from the position of institutional economics or political economy, and the latter will sometimes be illuminated from an urban point-of-view.

Having said that, it remains necessary to clarify the so-called urban context. There does not appear to be any general agreement as to what is meant by the adjective urban--what should properly be included and what should be excluded. Some persons proceed on the restrictive assumption that urban affairs means only those matters which take place exclusively within urban boundaries. Others believe that the term urban affairs is broad enough to include any phenomenon which has urban consequences or is itself a consequence of urban-related activities.

The restrictive assumption is at least partly based on a fallacious analogy. It is observed that urban areas themselves are physically distinguished from other areas by political and geographic boundaries. It follows by analogy that any activity described by the adjective "urban" should likewise be boundaried. That is, if an activity is truly urban, then it must take place inside the boundaries of a city, vis-a-vis any and all other areas outside of urban boundaries.

Reproduced with permission of the copyright owner. Further reproduction prohibited without permission. 
However, urban areas do not exist in perfect isolation from other so-called non-urban areas. Nor do urban phenomena take place isolated in some kind of vacuum from other so-called non-urban phenomena. Indeed, no urban area is self-sufficient. It is always a part of a much larger whole, and the urban and non-urban areas are interdependent entities. To be sure, urban areas are distinguished from other geographical environs. But the urban areas are distinguished only in relation to such other environs, and they are connected by transportation and communication facilities to those environs--both urban and non-urban.

Moreover, commercial as well as other social interaction takes place between the interconnected parts. Thus, changes in agricultural productivity which takes place in rural areas affect adjacent urban centers through the resulting changes in the prices of agricultural goods. And urban events which alter the supply of manufactured agricultural inputs or consumer goods and services purchased by the families of agricultural employees affect the rural or non-urban environs. Indeed, one is hard pressed to find a matter in the course of human affairs which does not bear consequences of some sort for cities.

It should be clear that this writer disagrees with the restrictive assumption and adheres to the assumption that the term urban affairs includes any phenomenon which has urban consequences or is itself a consequence of urban-related activities. This clarification is necessary because the reader may sometimes find the subject at hand only indirectly or remotely related to urban affairs. This is partly because the work builds from economic and political theories of social interaction that are more general in character before applying the theories in the more specific urban context. Nevertheless, the nexus to urban phenomena 
are there whel the relationships are studied in an anthropological time frame.

For example, the American labor movement is used in the next chapter to illustrate an institutional cycle. The connection bet:!een a labor movement and urban affairs is not immediately obvious, and some would insist that any connection between the two is very tenuous at best. However, a moment's refiection recalls that labor movements arise out of the turmoil of imperfectly competitive labor markets, and the latter emerged with the industrialization which spawned large-scale enterprises employing masses of labor. It is here that the connection between labor movements and urban affairs becomes clear. Industrialization is a uniquely urban affair. Indeed, at least one wave of urbanization in industrial nations was powered by the so-called industrial revolution-a recent phase of the on-going technical revolution which has set mankind quite apart from other anomaly. Labor movements are aspects of industrialization, and they are therefore uniquely urban phenomena as well.

Another example appears in Chapter III where the ends-means continuum, a crucial component of institutional economic theory, is illustrated in terms of the Roman establishment and subsequent development of the city of London, England. One might, of course, use any human artifact or collection of such works to illustrate the ends-means continuum. However, it is especially appropriate to use a city as the vehicle to describe the theory because cities are the epitome of civilized society, and they are all at once the physical results and the major repositories of human creative genius.

Chapters IV and $V$, dealing with ceremonialism (the practice by which institutions discharge their social functions), explores some of 
the ancient roots of the myriad of institutions which comprise a city. Not all of the institutions examined can be called exclusively urban institutions, but neither can they be excluded from any study of urban institutions. For example, a primary human institution, the family, exists in both urban and rural settings. It cannot, therefore, reasonably be excluded from any serious study of institutional matters in either urban or rural settings. Moreover, Chapter IV gives some insight into how the institutional structure eventually adapted ceremonialism to permit the feudal cities of antiquity to emerge.

Chapters VI, VII, and VIII on technology would at first seem to deal with purely rural affairs. However, the urban relevance of those chapters lies in the relationships between technology and agriculture, between agricultural productivity and urbanization, and finally between technological advance and urban function and form. The argument is made in those chapters that the revolutions which incrementally advanced civilization from preliterate and prehistorical folk societies to preurban folk communities, from the latter to feudal cities, and from feuda? cities to industrial cities were precipitated by technological changes which first increased agriculturai production in each case. The increased productivity in agriculture created food surpluses and pari passu emancipated some members of the community from primary and rurat employments and enabled them to specialize in secondary or urban activities such as transportation, commerce, security, manufacturing, etc.

Finally, the essence of the last few content chapters is that cities are arenas in which human groups interact in the choice of social ends and in the allocation of means to attainment of the chosen ends. The interaction operates to reconcile the tensions between ceremonial 
constraints and technological opportunities, and the result is institutional change. Cities are inimitably suited as habitations of humangroup interactions because cities are concomitantly the creatures of and the principal domiciles for human institutions. They are likewise the abodes of the people who populate institutions and who interact through groups.

The point is that the connections between urban affairs and that which follows may at times appear remote and obscure to the reader. It is only by viewing the subject in light of very long-run effects that the urban relevance becomes clear. And that relevance achieves clarity with the understanding embodied in the foregoing assumption--that matters not narrowly construed as urban frequently have urban consequences, and clearly urban matters often have consequences far beyond the bounds of cities. The urban context, then, construes the term urban affairs as broad enough to include such remote but related matters.

\section{INSTITUTIONAL ECONOMICS}

The first of the theories dealt with here is institutional economics. Institutional economics is a uniquely American contribution to the field of economics. Two of its founders are Thorstein Veblen and John R. Commons. 1 Institutional economics enjoyed substantial currency prior to World War II, but it suffered decline in the face of the socalled new economics of John Maynard Keynes. However, it is once again becoming popular as a research and publication field, and the works of Veblen and Commons in particular have spawned a whole school of new or neo-institutionalists within the field of economics.

The seminal literature of institutional economics exists in 
fragments and is distinguished by a remarkable lack of correspondence. This is not true of any one piece of Veblen's writing, each of which is a gem of literary excellence. But there is no writing which integrates Veblen's thoughts into a single, coherent theory. While the ambitious and prolific work of Commons possesses better overall continuity and roundness--especially his last statement on theory, The Economics of Collective Action--it is unnecessarily repetitive and filled with vast, redundant abstractions and special terminology to represent matters better described, in the opinion of this author, using commonly understood terms.

Moreover, the works of Commons and Veblen are not in agreement on some fundamental and crucial points. Subsequent scholars have made little effort to reconcile the differences so that the modern student can be presented with a coherent, consistent, and integrated body of institutional theory. While a studied and exhaustive reconciliation of differences between Veblen and Commons is an ambitious and worthy enterprise, it is outside the scope of this work. Rather, the goal at hand is simply to bring the theories into sufficient correspondence to achieve the purpose described at the outset--namely, to relate institutional economic theory to pluralist theory from political science and relate the whole to urban affairs.

The technique used to achieve consistency between the fragments of institutional economic theory is simply to use those parts which are essentially in agreement, to use those parts which this author believes are most valid where there is conflict and where the material is needed to round out the whole theory, and to ignore any remaining part which is not particularly applicable. Accordingly, a major part of this paper is 
given over to systematizing institutional economic theory. The following few paragraphs are a brief outline of the main tenets of that theory as understood by this writer. The first part is a clarification of applicable time-period assumptions. The second part describes the endsmeans continuum or the temporal institutional setting. And the last two parts describe the Veblenian theories of ceremonialism and what C. E. Ayers chooses to call technology.

\section{Time Periods of Analysis}

An anthropological approach to social interaction in general and economics in particular, institutional economics views social arrangements in what this writer likes to call the very long run. In this sense, the ideas of institutional economists tend to receive greater approbation from historians, anthropologists, and sociologists than from more orthodox economists. Indeed, institutional economists are viewed as somewhat necessary but anomalous appendages by more traditionminded members of the profession. And, as specialists in psychiatry must first be medical doctors, so institutional economists must first establish their competence in orthodox bodies of economic theory.

Orthodox economic theory does not now concern itself with the institutional very long-run. Rather, it recognizes three other analytical time periods--the very short-run, the short-run, and the long-run. The chief feature which distinguishes one time period from the other is the economist's assumptions about variability in the supply of productive inputs. In the very short-run, the supply of all productive resources for the end product under study is assumed to be fixed so that supply of the product to the market is limited to whatever can be 
produced with the resources physically on hand in that time period. It is therefore impossible to either increase or decrease supply of the product to the market in that time period.

Absolutely fresh broccoli, available within any given week, is a commodity which may be in relatively fixed supply so that the price is primarily a function of demand. It is not usually possible within the week (the very short run) to increase the supply because of the growth cycle of broccoli. The broccoli available during the week took approximately seventy days from sowing to harvest. If it is cut too early the edible yield will be small and unpalatable. If it is cut too late it will be in flower and unsuitable for the table. It must be harvested, marketed, and consumed during its prime week for the very best results. Its supply can be neither increased nor decreased by any significant amount within the very short run comprising its prime week. Thus, if the demand for absolutely fresh broccoli that week is high in relation to its rigid supply it will command a high price. On the other hand, the price may have to decline below cost in order to clear markets before spoilage if the market demand is very low in relation to the fixed supply. However, some resources are assumed to be variable in the short run while other inputs are assumed to remain fixed. Capital goods (or producers' durables), the level of technology, and the land are examples of resources which are generally assumed to be in fixed supply in the short run. Land and capital goods do not become physical components of the products in the production of which they are employed. On the other hand, man hours of labor and intermediate goods which lose their identities in and become a part of the final product are assumed to be variable in the short run. Thus, supply of the product may be increased or 
decreased to meet changes in market demand to the extent of the changeability of the variable inputs and their technical substitutibilities for fixed resources--for example the extent to which additional man hours may be substituted for equipment hours.

Operation of a food-processing plant illustrates the economic short run. During off-harvest seasons, the plant processes only those fruits and vegetables which could be held over from the previous harvest in some temporary storage medium. The plant characteristically operates with a sma:11 permanent staff working a normal forty-hour week (five consecutive eight-hour days). Moreover, the company will vacation its permanent staff during the off-harvest seasons. In other words, it chooses to reduce its off-season operations by increasing its ratio of capital to labor. It accomplishes this by reducing the units of variable input (man hours and produce in process) used with the units of fixed input (permanent equipment and the real estate that houses the plant). This has the effect of decreasing the total cost of variable inputs while leaving the total cost of fixed inputs unchanged.

However, as fresh fruit and vegetables commence to arrive at the plant early in the harvest season, the company will start hiring temporary help to handle the accelerating input of produce. As the season wears on and the fresh produce backlogs, the company may increase its hours of operation--first by going to a seven-day work week and paying overtime rates to its employees and then by hiring temporary starf and scheduling additional operating shifts. In other words, the company chooses to increase its operations during harvest season by decreasing its ratio of capital to labor. It accomplishes this by increasing the units of variable input (man hours and produce in piocess) used with the 
units of fixed inputs (equipment and real estate). This has the effect of increasing the total cost of variable inputs while leaving the total cost of fixed inputs unchanged in the short run.

Al1 productive resources are assumed to be variable in the economic long run. While this assumption does not mean that the supply of all existing inputs is infinitely elastic, it does mean that technical substitutibility between existing and potential inputs is variable. Thus, a way will be found in the long run to produce any economic good for which there is a market demand at a price sufficient to cover all costs of production.

If, in the food-processing plant example, the company found that it could not process all vegetables and fruits available in its producticn area during the year, and if it could not supply the market demand for its output, then it might find it profitable to expand its plant-that is, to increase its short-run fixed inputs to meet the higher output expectations. This is a lorig-run consideration--a time-period during which all inputs, including capital goods and real estate, are considered to be variable. In expanding its plant, the company will likely purchase more land and more equipment embodying the newest technology. This should enable the company to substitute capital goods for man hours of labor insofar as the newer and better machines can be operated with fewer people. Thus, the company can now achieve higher levels of output per man hour of input. It is said to be taking advantage of increasing returns to scale by increasing its scale of plant and reducing its longrun average cost of output.

Economists study market phenomena--supply, demand, price, etc.-under the different states of resource variability assumed in economic 
time periods. Their tacit assumption is always that the antecedent and current or assumed states of institutional arrangements will not changeeven in the long run. It is application of the time-worn ceteris paribus to social elements which orthodox economists treat as exogenous to the markets they are studying. For this reason, orthodox economists will study the effects on quantities and prices of changes in what is called the quoefficient of technical substitutibility between two inputs. That is, they study the effects within the market as an institution. They ignore the effects of technical change on the market as an institution as well as the effects on other institutions which make up the social system of which the market is a part.

On the other hand, institutional economists believe that economic phenomena are products of institutional systems and that markets, as orthodox economists see them, will exist subject always to iristitutional constraints. Attention of the institutional economist is therefore concentrated on the institutional milieu in which markets exist. In other words, the institutional economist is concerned not just with market phenomena according to orthodox theory, but with the feed-back effects of market activities on institutional arrangements as well. He is concerned as well with the economic ways in which society uses and changes its uses of material devices and the ways in which society's use and changes in use of material devices structures and restructures society itself.

While the orthodox economic time periods are necessary, they are not sufficient by themselves to accommodate the institutional frame-ofreference. The economic long-run is simply not long enough to observe the feed-back effects of technical change on social arrangements. Institutional changes of a substantial sort are social revolutions, and they

Reproduced with permission of the copyright owner. Further reproduction prohibited without permission. 
take centuries and sometimes millennia to occur. At least one more time period is required to observe institutional change. It is, of course, the very long run--an anthropological time period of sufficient duration to study the institutional changes which result from economic and quasieconomic activities.

The very long run is, then, the principal time period of institutional economic analysis. It often takes the analysis back in time to the dawn of mankind's existence on earth--a time when there were no cities as, they are known today, and when human groups were primitive family bands, the members of which lived short, hard, and frugal lives. Within that perspective the work at hand draws heavily from that of Clarence E. Ayres, a second generation institutional economist. ${ }^{2}$ Ayres joined the ceremonial and technological components of institutional economics from Veblen with the idea of an ends-means continuum described by John Dewey. The following is a very brief outline of the elements of institutional economic theory which will be elaborated in remaining chapters.

\section{Ends and Means}

According to Dewey, social interaction takes place in a temporal setting--a longitudinal dimension in time which is called an ends-means continuum, a continuum of on-going life processes. If the continuum is divided into two parts, a past and a future, then the present is the boundary between the two. Ail that exists in the present is the effects of causes which lie in the past. These present effects are also the means, the resources, to ends which lie in the future along the continuum. $^{3}$

Reproduced with permission of the copyright owner. Further reproduction prohibited without permission. 
Ends are states of affairs which lie in the future and which exist in the present only as human contemplation. Some ends-in-view may be alternative insofar as some competing ends may be exclusive. That is, selection and attainment of one set of ends may absolutely preclude the possible attainment of the competing end. This is because means are either too scarce to permit all sets to be secured, or the alternative sets of ends may be incongruous.

Ends are not ends-in-themselves, but once attained become means to on-going ends which lie farther in the future along the continuum. Ends have value because people, through institutions, set them out as desired, and means have value in part because they are instrumental in achieving desired future ends. The crucial questions raised by the concept of the ends-means continuum are, how and why are particular ends-to-be-achieved selected from an array of competing possible ends? And against what criterion and how are means selected and organized for the attainment of the selected ends?

\section{Ceremonialism}

Part of the answer to the foregoing questions according to Veblen and Ayres is found in the practice of ceremonialism. Ceremonialism is an institutionalized practice, and it involves the conferring and validation of status upon members of society. ${ }^{4}$ The technique is instrumental in the social-control functions of institutions--the socialization and the transmission of culture needed to preserve stability throughout society.

Ceremonial values are based on the cultural beliefs which descend to the present from the past. They are transmitted by the myths, 
legends, dramas, and literature which extol tribal triumphs of the past and the mystical powers of ancestors. The legends about those triumphs are pervasive and are used to transmit the totems and taboos of culture-the "right" ethical and aesthetic values to hold. Such values connote social order and status. People are thus taught from their infancy the systems of status which descended to them from their tribal pasts. Through ceremonialism they come to understand and accept their positions in society and the roles they must play. Likewise, they come to accept the mana, the mystical potency attaching to each social rank, and to recognize the distinctions between their ranks and the ranks of others, both above and below them in the social structure.

People are also taught how to acknowledge rank and validate status in ceremonial exchanges or transactions, ceremonial gift giving, and ceremonial destruction of goods. And they learn the grave consequences and the sanctions imposed for failure to learn and conform to the prescribed modes of ceremony. Finally, the cultural beliefs or tribal legends, the totems and taboos, and the mana of rank and status, are constantly reinforced by the mystical ceremonies and they are reconstructed throughout peoples' lifetimes by the awe-inspiring dramas, graphic arts, literature, and religious liturgies of their cultures. All of this socialization is accomplished by institutions attempting to perpetuate established value systems. And insofar as ceremonialism is successful as the socializing mode of institutions, it augurs toward structure and stability in society.

Ceremonialism is necessarily backward-looking in terms of the endsmeans continuum. It links present arrangements with the causal conquests of the past, and it prescribes the successful methods of the past as the

Reproduced with permission of the copyright owner. Further reproduction prohibited without permission. 
best ways to organize means to achieve future ends. Likewise, those ends are measured as desirable or undesirable in terms of the values descended from the past. The ceremonial aspect of society extends the past forever into the future never changing and never ending. Such is the mucilage of society in modern as well as primitive societies.

\section{Technology}

However, institutions rise and some even decline, and society and social ways do sometimes change from generation to generation. The question is, what causes such changes in the face of the powerful backwardurging of ceremonialism? The answer, according to Veblen and Ayres, is found in the social effects of new technologies, where technology is simply that quality of a tool that enables it to reduce or be substituted for human effort in the creation of any good or service having human value. ${ }^{5}$ Technique, the human propensity and skill to employ particular technologies, aims to convert ends to means as a pervasive and on-going process. This process is continuous, dynamic, progressive, and futureoriented. 6

The innovation of new technologies tends to be unstabilizing to institutional environmerits because the innovation of new technologies organizes means (divides labor) and opens ways of distributing social products in ways differing from the ceremonially-prescribed methods descending from the institutional past. Moreover, new technologies often radically change even the ends selected to be achieved because some ends formerly beyond the available means are brought within reach by the new technologies. New technology therefore opens opportunities to change prior existing social status and ceremonial systems of rank, and 
it affords new avenues of social mobility--avenues toward higher status for some and diminished status for others.

The ensuing environment is, of course, fraught with conflict between those persons who wish to preserve the ceremonial values upon which their ranks and statuses are founded and those persons who stand to gain in position and status by the innovation of new technology. Thus there is an endless struggle between the tradition-bound and backward-clinging forces of ceremonialism and the progressive and forward-leaning forces of technology, both as to choices between competing future ends and the alternative ways of organizing means toward the attainment of the selected ends.

How much of known new technology is actually innovated depends upon the relative strength of ceremonialism--or, in other words, the strength of institutional values and institutional resistance to change. Insofar as new technology is innovated, certain ceremonial aspects of institutional value systems wither and become quaint cultural vestiges of the past--but never without anomy and social upheaval. ${ }^{7}$ The question is, by what means does society reconcile the tensions between ceremonialism and new technologies as the future ascends to the present and fades into the past in an endless continuum of on-going life processes?

\section{ORTHODOX ECONOMICS}

The answer to the foregoing question is found in techniques for weighing values and for balancing those measured values in some sort of matrix, the outcome of which is social choice--choices that do or do not lead to the innovation of new technologies. These techniques are found principally in orthodox economic theory and in political theory-- 
particularly pluralist political theory.

Ralph Barton Perry has made convincing arguments to show that anything about which a person or group of persons has concern possesses value. ${ }^{8}$ A definition as broad as Perry's admits valuations across an infinite range, and therefore a myriad of competing values and conflicting interests. In other words, values perceived by persons and institutions are as multifarious and disparate as society is pluralistic, and there is no simple or direct method to structure and weigh competing values in selecting ends and ways of organizing means toward achieving those ends.

The problem is to resolve those conflicting interests in a selection of sociar ends and an allocation of means which somehow maximizes social welfare. Such resolution involves optimizing in the allocation of social means to the creation of social welfare. Vilfredo Pareto describes an efficient allocation as one in which means have been allocated such that it is impossible to improve anyone's welfare without adversely affecting the welfare of another. ${ }^{9}$ J. R. Hicks and Nicholas Kaldor argue that social welfare can be improved, even though a Pareto-optimal allocation of means exists, if social product is redistributed in such a way that those persons losing welfare value their losses less than those persons who gain welfare value their gains. ${ }^{10}$

Kenneth Arrow's "possibility theorem" asserts that there are some conditions of choices under which no market or political arrangements will necessarily define, much less achieve, a social-welfare function amenable to Paretian measurement. ${ }^{11}$ Nevertheless, the Pareto criteria remain a compelling ideal to be as nearly achieved as possible. However, any movement toward that ideal should be based soundly on 
empirically accurate valuations. Valuations function to weigh costs and benefits, where benefits are the human satisfactions achieved by securing particularly desirable sets of ends, and costs are the alternative ends foregone to achieve those benefits.

Both costs and benefits may possess either internal attributes (aesthetic, private, divisible, personal, visceral, etc.) or external attributes (ethical, institutional, public, indivisible, collective, etc.) or part internal and part external attributes. Economists have shown how goods and services (and outcomes) which possess only internal benefits and costs may be efficiently provided through the pricing mechanisms of free markets. Such goods are viewed as so-called private goods.

Francis Bator and others have argued convincingly that goods and services (and outcomes) which possess substantial external benefits or costs cannot be efficiently provided through free markets because the goods are not divisible. ${ }^{12}$ Once such goods have been produced, no one can be excluded from enjoying the benefits or suffering the costs arising from their production. Goods possessing substantial externalities are therefore collective goods or public goods. Since public goods cannot be divided, they cannot be packaged and sold in consumer units. And since each person values his benefits and costs differently, there is no way to discover the true magnitude of the benefit or cost any person experiences with public goods. Persons, therefore, tend to "free ride" in the consumption of public goods by understating their benefits and overstating their costs. Goods possessing substantial externalities must be provided wholly or in part under some other institutional arrangement than free markets. ${ }^{13}$

The usual alternative arrangement to free markets for allocating Reproduced with permission of the copyright owner. Further reproduction prohibited without permission. 
public goods is some variation of government institutions and the electoral process. Whatever institutional arrangement is set upon, some technique for weighing social benefits and social costs is needed. The technique enjoying currency in recent years is "benefit-cost analysis." Mishan and others have described the process and some of the issues involved. 14

The issues surrounding cost-benefit analysis raise substantial doubt as to its accuracy in valuing public goods. The problems surround the following questions:

- Which costs and benefits will be included in the analysis?

- Which are internal and which are external?

- What pecuniary values will be assigned to external costs and benefits?

- What social discount rate will be used to discount future benefits and costs back to present values?

- Over what useful life will the future benefits and costs be discounted?

- What is to be maximized or minimized in the outcome?

- And the most important question of all, which institutional values will reign over the processes deciding these questions? Clearly, the cost-benefit analysis of any potential public activity can lead to many different conclusions depending on how the foregoing questions are answered, and they can be answered any number of ways. Despite its obvious 1 imitations, cost-benefit analysis appears to be the best tool available for evaluating alternative public ends. All of which points up the problem--values as perceived by persons and institutions are multifarious and disparate, and there is no simple or direct 
method to structure and weigh competing values regarding ends and means. How, then, does society reconcile the tensions between ceremonialism and technology in selecting ends and in organizing means?

\section{URBAN PLURALISM}

The answer is found in institutional changes that are brought about through collective action and interest-group politics. Theories of collective action are components of institutional economic theory, and they are the original products of John R. Commons. Theories regarding interest-group politics stem from contemporary political theory. The two bodies of theory attempt to explain how institutions adjust to unstabilizing social aberrations through changes in custom and law.

Collective Action ${ }^{15}$

According to Commons, conflicts of interests rise between "going concerns" (institutions) over the present and future uses of scarce resources. Resources are scarce because of property rights, and the conflicts of interests are resolved through "transactions" that affect interinstitutional changes in property rights. Transactions take place within the limits of custom and law operating as "working rules." At the same time any transaction involves establishment of the particular working rules that will govern the exchange with which it deals. Thus, customs change as working rules change and become routinized through transactions.

Transactions are classified by Commons as bargaining transactions, rationing transactions, and managerial transactions. Bargaining transactions are voluntary arrangements between going concerns of

Reproduced with permission of the copyright owner. Further reproduction prohibited without permission. 
approximately equal powers, and they tend to be juridical in nature. Rationing transactions involve legislative powers, and they take place between collective superiors and legal subordinates. They are, for the most part, involuntary. Managerial transactions involve executive powers in which involuntary actions arise out of decisions about organized uses of properties and other rights previously established out of bargaining or rationing transactions.

All transactions involve conflicts of interest arising from scarcity, interdependency of interests arising from the need for exchange, and order arising from a need for working rules to facilitate exchange. Transactions function to convert conflicts of interests to interdependencies of interests. And collective action, through the power of transactions, creates and changes the working rules--unorganized custom, organized custom in the form of common law, and the codified laws of nation-states, including constitutional, statutory, and administrative laws.

Parties to a transaction include the social organizations between which property rights are to be exchanged, the best alternative exchange on both sides, and collective action operating through custom and law. Bargaining power in a transaction is the right to deny others the future uses of properties. It is seldom equal between the going concerns involved in transactions; however, any exercise of bargaining power is legal so long as the transaction is completed within the parameters of custom and law. This defines what Commons calls "reasonable value"-whatever bargaining power is allowed in custom and law.

The dynamism of this process is in the relationships between transactions, customs, and laws. Transactions are structured by custom and 
law, while law slowly changes to conform to custom, and custom evolves out of the routine practice of transactions. Such determinations establish and change property rights and thus the power relationships between going concerns in transactions. The legal foundations of governments are in the natures of the predominant forms of transactions in the governed societies--bargaining transactions (juridical power), rationing transactions (legislative power), and managerial transactions (executive power).

Interest-Group Politics

As customs evolve out of the routine practice of transactions, law slowly changes to conform to the evolving customs. How changes in the law come about in an industrial democracy is explained by the pluralist theory of politics. Much has been written since World War II about the group basis of politics, in which group theory from the field of sociology has been applied to the study of political interactions. The fruits of that union are pluralist political theory. ${ }^{16}$ Pluralist theory does much to explain how political stability is maintained by the interaction of interest groups in which groups are free to form and dissoive coalitions with other groups in support or opposition to issues about which people feel strongly enough to create, join, leave, and dissolve interest groups.

According to Dewey, any social activity involves at least two groups, those directly involved in the activity, and those indirectiy affected for good or bad by the activity. Those persons who are indirectly affected and who perceive their interests involved in the activity will organize to protect those interests. Dewey called the

Reproduced with permission of the copyright owner. Further reproduction prohibited without permission. 
organized interest a public, and insofar as the public commissions agents to operate in its behalf regarding the activity, there exists the institution of government. ${ }^{17}$

Earl Latham, a political pluralist writing somewhat later, argued that social activities take place in groups. ${ }^{18}$ A11 values cherished by people are realized through groups. There are a great many accommodations made through group interactions--the common and the universal, the diverse and the particular. Latham included both privately and publicly organized groups in his observations.

According to Latham, groups are in constant motion and it is through group interaction that the rules of government are made and changed, and the community is governed. Groups organize, as Dewey said, to concentrate power and to use that power to come to terms with their environments. So-called official groups are those organized as public, and they function to provide levels of compromise in writing the rules (laws) for other groups. This is, of course, accomplished in the United States under the Constitution by the various branches and levels of governments--legislative, executive (including the myriad of administrative and regulatory agencies) and the judicial branches, as well as federal, state, and local levels of governments.

The whole idea is that consensus can be reached, the laws can be created and changed, and human welfare can be enhanced through smal1group interactions in which individuals are free to join or leave any group, and any group is free to form coalitions with other interest groups in support or opposition to any action or issue. In this way, a public-interest equilibrium results from public opinion and the interaction of opposing forces. Equilibrium is maintained by the

Reproduced with permission of the copyright owner. Further reproduction prohibited without permission. 
interaction alone and no outside authority is needed to maintain stability.

Thus, the tensions between ceremonialism and technology are reconciled through transactions between going concerns in which the transactions change working rules, and the working rules alter customs according to the collective action theories of John R. Commons. Moreover, laws are changed by interest-group interactions to conform to evolving customs according to political pluralist theories. Finally, the result is very long-run changes in the institutional system while social stability is maintained.

This chapter has introduced the work at hand as a partial synthesis of institutional economic theory and political pluralist theory and the application of the results to urban affairs. The chapter sets forth the assumption that urban phenomena cannot be effectively studied in isolation of other phenomena. That is, any event that has urban consequences or is itself the consequence of urban activities is appropriately a subject of study by urbanologists. This is followed by a brief outline of the institutional economic theories, the orthodox economic theories, and the political pluralist theories that are components of the synthesis. The next chapter, Chapter II, is a brief review of selected social science literature on institutions. The review is undertaken to define the word "institution" in a way that will serve throughout the remaining chapters. The remaining chapters are elaborations of the foregoing theories in the context of urbanization and urban affairs.

Reproduced with permission of the copyright owner. Further reproduction prohibited without permission. 


\section{END NOTES, CHAPTER I}

${ }^{1}$ Thorstein Veblen, The Theory of The Leisure Class (New York: The Macmillan Co., 1899); The Theory of Business Enterprise (New York: The New American Library, 1958); The Portable Veblen, The Essence of the Work and Thought of One of America's Great Original Minds, ed. by Max Lerner, (New York: The Viking Press, 1948). John R. Commons, Legal Foundations of Capitalism (Madison: University of Wisconsin Press, 1957); Institutional Economics, Its Place in Political Economy, 2 vols. (Madison: University of Wisconsin Press, 1961); Economics of Collective Action (Madison: University of Wiscons in Press, 1970). Both Veblen and Commons were prolific writers. The cited works comprise those which are of most importance to this paper. Veblen and Commons share the distinction of founding institutional economics with Wesley C. Mitchel1. However, Mitche17's work is not so important to the field, and he is well known in other fields of economics.

${ }^{2} \mathrm{Cl}$ arence E. Ayres, The Theory of Economic Progress: A Study of The Fundamentals of Economic Development and Cultural Change (New York: Schoken Books, 1962).

3 John Dewey, Experience and Nature (New York: Open Court Publishing Co., 1925); "Theory of Valuation," International Encyclopaedia of Unified Science, Voi. II (Chicago: University of Chicago Press, 1939).

${ }^{4}$ Veblen, Theory of the Leisure Class. Ayres, Theory of Economic Progress, pp. 155-76.

${ }^{5}$ Veblen, Theory of Business Enterprise. Ayres, Theory of Economic Progress, pp. 105-24, 177-202.

${ }^{6}$ Jacques Ellul, The Technological Society, trans. by John Wilkinson (New York: Random House, Inc., 1964).

${ }^{7}$ Sebastian de Grazia, The Political Community; A Study of Anomie, (Chicago: University of Chicago Press, 1948).

8 Ralph Barton Perry, General Theory of Value (Cambridge: Harvard University Press, 1926).

${ }^{9} V i 1$ fredo Pareto, Manuel d'Economie Politique, 2d ed. (Paris: Girard, 1927).

10J. R. Hicks, "The Foundations of Welfare Economics," Economic Journal, XLIX (September, 1939), 699-712. Nicholas Kaldor, "Welfare Propositions of Economics and Interpersonal Comparisons of Utility," Economic Journa?, XLIX (September, 1939), 549-52.

${ }^{11}$ Kenneth J. Arrow, Social Choice and Individual Values, $2 d$ ed. (New Haven: Yale University Press, 1963); "A Difficulty in the Concept of Social Choice," Journal of Political Economy, LVIII (1950), 328-46. 
12 Francis M. Bator, "The Anatomy of Market Failure," The Quarterly Journal of Economics, LXXII (August, 1958), 351-79.

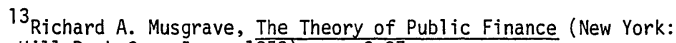
McGraw-Hill Book Co., Inc., 1959), pp. 3-27.

$14 \mathrm{E}$. J. Mishan, Cost-Benefit Analysis, new and expanded edition (New York: Praeger PubTishers, 1976). A. R. Prest, and R. Turvey, "Cost-Benefic Analysis; A Survey." Economic Journal, LXXV (December, 1965), 683-735.

$$
15
$$

Commons, Economics of Collective Action.

16 Pluralist theory has evolved over a long period. So-called "philosophical pluralists" emerged in Great Britain between 1900 and 1925. The analytical pluralists were or are a United States phenomenon. It is this latter group to which this paper refers. The early works of the analytical pluralists include: James Madison, "No 10, The Union as a Safeguard," Federal ist, in Vol. 43, Great Books of the Western World, ed. by Robert M. Hutchins, et al., 54 vols. (Chicago: Encyclopaedia Britannica, Inc., 1952), pp. 49-53. Arthur F. Bentley, The Process of Government (Chicago: University of Chicago Press, 1908). John Dewey, The Public and Its Problems (Denver: Alan Swallow, n.d.). E. Pendleton Herring, Group Representation Before Congress (Baltimore: Johns Hopkins University Press, 1929). Walter Lippman, The Phantom Public (New York: Macmillan, 1929). E. E. Schattschneider, Politics, Pressures and the Tariff (New York: Prentice-Ha11, 1935). David B. Truman, The Governmental Process (New York: Alfred A. Knopf, Inc., 1951). Earl Latham, The Group Bas is of Politics (Ithaca: Cornel1 University Press, 1952).

$$
\begin{aligned}
& { }^{17} \text { Dewey, Public and Its Problems. } \\
& { }^{18} \text { Latham, Group Basis of Politics. }
\end{aligned}
$$




\section{CHAPTER II}

\section{INST ITUTIONS}

The word "institutional" appears frequently in the preceding chapter, and the word "institution" is in daily common usage. Most persons have a good notion what the word means. However, a good word definition of "institution" remains elusive, and social scientists are not in complete accord on a precise definition. This chapter attempts to develop a definition of "institution" which will serve throughout the remainder of this work. In pursuit of such a definition, the first section examines the relationship between institutional and non-institutional groups. The next few sections examine respectively the origins of institutions, their social functions, their structures, and the attempts to classify them. The last section loosely relates institutions to urban areas and poses several questions which will occupy the remaining chapters.

\section{INSTITUTIONS AND GROUPS}

Political science contemplates the distribution and application of social power--the capacity of one agent or coalition of agents to control the powers and direct the actions of other agents and groups--in the authoritative allocation of values. In so doing, political theorists tend to treat interest groups as more or less homogeneous and of approximately equal power. That is, they tend to ignore intergroup differentials--although criticism over recent years has caused political 
scientists to reexamine these and other simplifying assumptions which undergird pluralist theories.

The assumption of approximate intergroup homogeneity is a crucial weakness of pluralist theory. It seems clear enough that there are striking differences in power between groups. A group is defined as "two or more people between whom there is an established pattern of psychological interaction /s such that the aggregation/ is recognized as an entity by its own members and usually by others because of its . . . collective behavior." ${ }^{1}$ This definition may be applied to any human aggregation from an entire civilization to a whole society, a nationality, a municipality, a neighborhood or other community, or simply two persons. Clearly the power of a community consensus to expand a city park located in the neighborhood is weak as compared to the remaining members of the much larger municipality who do not wish to expand the park under any circumstances. Thus, the magnitude of the aggregation is relevant in some sense to a group's magnitude of power.

Of equal importance is the relative positions of groups regarding particular social issues. Even groups with approximately equal numbers of members enjoy or suffer inequalities of power simply because of their relative positions regarding the issues of their collective concerns. For example, groups which support an established or institutionalized practice generally need not exert much power to justify continuation of the practice. That is, the position itself may possess the power because of the institutional nature of the practice. On the other hand, groups which seek changes to such established practices must usually exhaust every power at their disposal in advocacy for change.

The issues of slavery and civil rights in the United States are Reproduced with permission of the copyright owner. Further reproduction prohibited without permission. 
cases in point. Despite the Declaration of Independence, which loudly proclaimed in 1776 that "all men are created equal," and the revered Bill of Rights to the U. S. Constitution, which guarantees certain human freedoms, the then existing institution of black slavery persisted until 1865. It ended then only after a bloody Civil War anu ratification of the Thirteenth Amendment to that Constitution.

Likewise, the Fourteenth Amendment and a variety of Civil Rights laws in the 1870's failed to operationalize the rights of freedmen, or former slaves, until the landmark Supreme Court decision, Brown et al vs Board of Education of Topeka et al in 1954. That case released a veritable landslide of pent-up and bitter protest from black citizens who had tolerated discrimination at the hands of whites, based in part upon the prior inferior social status of slavery. These protests were met with angry and often violent reactions from whites, many of whom may go to their graves believing that black people are inferior and whites superior. Discrimination continues even now in spite of recent Civil Rights Acts. The point is that the powers of institutionalized practices and beliefs doggedly persist even when they are demonstrably bankrupt and great human suffering has been spent in the advocacy for change. 2

Perhaps of even greater importance is the relative character of the groups regarding particular social issues. That is, groups of approximately equal numbers of members possess unequal powers because of differences in their essential characteristics. For example, the officials of a municipal government--the mayor, members of the city council, city manager, city engineer, city planner, and members of the planning commission--will generally possess more collective power to decide land-use issues for their community than any other interested group

Reproduced with permission of the copyright owner. Further reproduction prohibited without permission. 
because the municipal government has unique characteristics, vis other interest groups.

The quality which distinguishes the municipal government from other groups in this simple example is its institutional character. That is, it possesses some of the coercive powers of the institution of government, powers which it may apply to community land-use issues as well as to a wide range of other municipal issues. And these particular institutional powers are not generally shared with other groups immediately interested in the issues over which the institution enjoys province. Thus, institutional groups generally possess crucial and decisive powers regarding issues because of characteristics which distinguish them from non-institutional groups.

Institutional groups are therefore unique and distinguished from other social groups with sufficient significance to make them objects of especially concentrated study. Research into the nature of institutions has occupied sociologists for more than a hundred years and some economists for more than seventy-five. While it is intended to dwell here on the work of economists, it seems appropriate at the outset to summarily review some of the more significant conclusions of other social scientists regarding institutions--notably sociologists and cultural anthropologists. Much has been written by those scholars which illuminates some of the essential character of institutions--their origins, social functions, structures, methods of operation, and classifications. What follows at this point is an ontological exploration of institutions out of which will emerge a concise and hopefully clear definition of institutions which will serve throughout the remainder of this work.

Reproduced with permission of the copyright owner. Further reproduction prohibited without permission. 


\section{ORIGINS OF INSTITUTIONS}

Social scientists have differing perspectives as to the origins of institutions. Institutions have "come- out of mores," according to Sumner, where mores are folkways, which are commonly understood to enhance social welfare, and the breaches of which are more severely and formally punished than breaches of ordinary folkways. Ordinary folkways are popular habits, the breaches of which are punished informally by avoidance, exclut sion, or ostracism. Likewise, Veblen vaguely defines institutions as clusters of habits and customs--ways of doing and thinking about things-that are sanctioned by long practice and by approval of the community. ${ }^{3}$

The custom by which a groom carries his bride over their first threshold is a happy little fol kway which is one of a number of ceremonies marking the advent of the couple's matrimony. The practice enjoys the universal approbation of the community, but the state of matrimony will not be dissolved nor will the groom suffer more than verbal chastisement if he omits it from the ceremonial steps to the nuptial chamber. However, the admonition "thou shalt not commit adultery" is an example of a more which has been codified into the laws of most nations as inimical to the institution of monogamous matrimony--an institution which has grown out of that and other related mores. Persons who breach those mores are generally subject to formal sanctions which may be pressed by the injured spouse, or brought by the state, or both.

On the other hand, Chapin believes that institutions arise out of the fundamental needs of mankind. According to this view, institutions come into existence because they stabilize the behavior of people who are striving to deal with such fundamental needs as fear, hunger, and

Reproduced with permission of the copyright owner. Further reproduction prohibited without permission. 
sex. Matrimony once again provides an example of an institution which stabilizes social relations in dealing with the human need for sexual expression. It clearly defines the roles of husband and wife and the socially acceptable limits upon their marital and extramarital sexual expressions.

Martindale disputes the biological "needs theory" because institutions are social phenomena and human needs are not immutable prerequisites of social existence. He believes that "group needs" are a more realistic basis for institutions. Among group needs are the need for security, social stability, and perpetuation of the group. These needs necessarily imply constraints upon the liberties of individual members in the interest of the group. ${ }^{4}$

For example, the institution of private property has evolved in part as a guarantee of minority rights for the owners to enjoy the quiet use of that attractive cape-cod cottage down the block along with all of its contents. Perhaps more important, that right also implies the power. to deny their use to all nonowners of those particular properties. While the nonowners probably possess different properties of their own, they are a nonowning majority regarding that particular cape cod and its contents. Private property rights are, of course, reciprocal insofar as the owners of that cape cod join the nonowning majority regarding the properties of others. They therefore tacitly agree to respect the private property rights of others as others have honored their property rights. These institutional arrangements augur toward the stability of intragroup relations in uses of the myriad of nonhuman things which are necessary in some measure for the satisfaction of human needs--both human group needs and the needs of the human individuals who comprise the 
group. 5

Still other social scientists distinguish several periods of institutional development in what is called an "institutional cycle"--(1) incipient organization, (2) efficient functioning, (3) formalism, (4) disintegration, (5) disappearance or reformation. According to this idea, an institution may rise in its incipient phase as a reform movement during a social crisis which demands new techniques for handling social problems. The movement develops leaders, organizational structure, norms (rules or standards of behavior) for dealing with the social issues of its special concern, and the material accouterment necessary for its efficient operation. During its phase of efficient functioning, the institution comes to enjoy legitimacy and prestige and to have the power to direct the actions of others. Eventually, the institution becomes a cherished end-in-itself. Its functionaries grow complacent and reactionary and its structure becomes inflexible during its formal phase. As society progresses, the institution may find itself overtaken and unable to cope in a new and changing social environment. Thus, it disintegrates and disappears, or, if it serves some crucial social purpose, it is drastically reformed during another social crisis.

The rise of labor unionism and the institutionalization of labor organization and collective bargaining in the U. S. illustrates aspects of the institutional cycle. Labor unionism is a modern phenomenon which arose concomitant with modern urbanization from the social crises accompanying what is popularly called the industrial revolution. During the immediate preindustrial age there were no labor unions, and industry and commerce took place between very small business and consuming units in small but often competitive markets. Transactions were direct and

Reproduced with permission of the copyright owner. Further reproduction prohibited without permission. 
face-to-face. The buyer knew the seller and usually the maker as well. The maker was intimately acquainted with whomever he employed. Indeed, he rarely employed more than one or two persons in his enterprise.

It was the belief that atomistic and competitive markets would make the most efficient allocation of resources and distribution of income that could be achieved. These beliefs gave rise to a Common Law prohibition against any conspiracy which would restrain trade--that is, to conspiratorially and artificially reduce the supply of goods and services to markets and thereby raise prices and wages above those which would prevail under competitive conditions. The Common Law prohibition against such conspiracies was later codified in the U. S. as the "Sherman Anti-Trust Act of 1890." 6

Likewise, it was believed that there was no need for government regulation of private economic activities so long as competitive markets functioned as they were supposed to. Indeed, government economic intervention was viewed as undesirable intrusion: into the private affairs of citizens. This, coupled with a general distrust of governments resulted in a number of wel1-known limitations on the powers of governments in the U. S. Constitution. One such limitation is Section 10 of Article I which prohibits governments in the United States from enacting any law impairing the obligations of contracts. ${ }^{7}$ This provision and the Common Law and statutory prohibition against conspiracies which restrain trade and commerce effectively barred the organization of labor and collective bargaining in the United States for more than a century.

Agreements between an employer and his employee were, after all, private contracts with which governments could not tamper, according to the Constitution. And is it not true that employees who organize and 
meet to set wages, working conditions, and other matters of employment are conspiring to restrain free and competitive trade in labor markets? These, then, were the pre-industrial institutional arrangements governing employment and wages. Each agreement between an employer and an employee was a separate, private contract arrived at by individual bargaining between the two parties. No ore else was privy to the contract and therefore no one but the two parties could have any cause of action on the contract under the Common Law.

However, the early Nineteenth Century witnessed the first sparks of the industrial revolution in the United States. Social events which mark the succeeding era include the innovation of new power, transportation, manufacturing, and agricultural technologies, the emergency of large-scale corporate enterprises each employing many workers, and the migration of labor from rural areas and agricultural employments to urban areas and manufacturing and service employments. This latter event effectually decreased individual or familial independence and greatly increased social interdependence insofar as the revered family farm produced much of the substance it consumed while the urban family relied entirely upon a wage-earner's buying power to satisfy its consumption needs.

Urban product markets lost their competitive flavor, becoming monopolistic and oligopolistic with large-scale business enterprise. Likewise, urban labor markets lost their competitiveness, becoming oligopsonistic and in some cases monopsonistic with the massing of many workers in urban areas dominated by a few large enterprises. Relationships changed from primary to secondary. Transactions between consumers and producers, and between employers and employees became impersonal and 
took place at arm's length. Thus, employer-managers came to possess great power to dictate wages and working conditions to workers who had little choice but to accept whatever was offered.

As ons might expect, employers took advantage of the situation to exploit labor for private gain. Wages were abysmally low in most areas, working conditions were primitive and working hours were long. The fantastic profits realized from these cost savings were used to further fuel the industrial revolution and to enrich the corporate owners. The institutional arrangements which descended from the preindustrial past were simply not appropriate to the social situations introduced by the industrial revolution. The resulting crises gave rise to the American labor movement and the incipient phase of the institution now known as the labor union. 8

The labor movement was a long, mighty, and often violent struggle for the legitimacy of labor's right to organize and bargain collectively with employers. The movement was met head-on by the intransigence of private businessmen and the formidable juridical powers of the courts upholding the Common Law and the Constitution. Time and space do not permit further elaboration of the long struggle which eventually culminated in the National Labor Relations Act of 1935 (NLRA), the so-called "Magna Carta of Labor." The act formalized the legitimacy of labor organization and collective bargaining, and it marks the beginning of labor unionism's institutional phase of efficient functioning. The Act passed its constitutionality test in 1937 when the Supreme Court handed down its landmark decision "National Labor Relations Board vs Jones and Laugh 1 in Stee 1 Co." ${ }^{9}$

The labor mores which arose with the labor union movement and which Reproduced with permission of the copyright owner. Further reproduction prohibited without permission. 
were not codified in the NLRA were formalized in legislation following the Jones and Loughlin case. Labor unions have become a fact of institutional life in the United States. They have recognized leaders who possess prestige and influence. They have organized structure (the local, the international, the federation, and the convention) and institutional norms (strike, picket, union shop, check-off, collective bargaining, and much more). And finally, they possess the power to direct the actions of others.

It appears that the labor union may now have passed into its formal phase in terms of the institutional cycle. The union has become a cherished end-in-itself--something like motherhood, the Constitution and democratic government in the U. S., all of which stand above serious criticism. All of American 1abor's major objectives stand 1ong achievedthe forty-hour week, paid holidays and vacations, union security, minimum wages, bargaining on all wage and employment conditions, etc. Its structures are inflexible in the face of labor force changes which threaten the foundations of the union movement. Its officers and other functionaries have become complacent and even reactionary at a time when labor's role in inflation, unemployment, and discrimination suggest the need for changes in both the cherished labor mores and union powers at the bargaining table.

What the future may hold for the institution of labor unionism cannot be known. However, if its structural inflexibilities and the complacent and reactionary attitudes of its leaders cause it to be overtaken and unable to cope in new and changing social environments, it will likely disintegrate and disappear. Or, if it continues to serve some crucial social purpose, it will be reformed during the ensuing social

Reproduced with permission of the copyright owner. Further reproduction prohibited without permission. 
crisis. The poirit is simply that the rise of labor unionism and the institutionalization of labor organization and collective bargaining in the U. S. illustrates aspects of the institutional cycle, incipient organization, efficient functioning, formalism, disintegration, and disappearance or reform.

The foregoing ideas do not appear to be alternative theories of the origin of institutions. Rather, they are complementary explanations. Even the apparent dispute over the human needs vs group needs theories seems superficial. Institutions may and probably do arise to meet either or both kinds of needs. At any rate, these explanations are compatible with the idea that institutions come out of mores, or widely understood and held values and with the idea of a so-called institutional cycle. Whatever theory one holds of the origin of institutions, it seems clear that they evolve with or from some particular system of values--whether those values center upon human interaction, material things, or procedures governing human uses of material objects, and whether those values are aesthetic, ethical, technical, or pecuniary in character.

\section{SOCIAL FUNCTIONS OF INSTITUTIONS}

The theory of the origins of institutions is suggestive of the principal function of institutions, that of maintaining social stability. As already noted, Chapin argued that institutions come into existence because they stabilize the behavior of people seeking to satisfy basic needs. Mead stresses the same phenomena, holding that group existence presents each member with a number of similar or identical situations which yield to common responses. These responses are institutional in the sense that institutions represent aspects of group

Reproduced with permission of the copyright owner. Further reproduction prohibited without permission. 
activity that enable members to act adequately by assuming the common group attitude toward those activities. ${ }^{10}$

Likewise, Parsons argues that certainty and stability in social interaction result because institutions are "role integrates" which organize one's expectations in any given social context. ${ }^{11}$ For example, the participants in a common economic transaction will play the roles of buyer and seller. Presumably the buyer wishes to acquire possession and legal title to some object which the seller either owns himself or is selling as an agent of the true owner. The institution of law--more narrowly, commercial or contract law--will govern their transaction. Each party, having knowledge of contract law, will know what is expected of himself and the other party as the transaction proceeds.

They both know that the object of their transaction must have a legal purpose--that is, the contract cannot be undertaken in contemplation of breaking the law. They also know that each must have contractual capacity before the transaction will result in a binding contract. The seller knows that he must make an offer to sell and the buyer knows that he must make an acceptance of the offer in order to reach the agreement (or mutuality of assent) necessary to the contract. Finally, there must be consideration, or something in exchange, given by the buyer to the seller at the time the seller gives over possession of the object to the buyer. Having met all of these conditions, both the buyer and the seller may derart with certainty that all other members of society wi1l honor the outcome of their transaction. ${ }^{12}$

Certainty and stability in social interaction result in this case because the institutions of law and the market have integrated the roles of buyer and seller in their economic transactions. Thus the principal

Reproduced with permission of the copyright owner. Further reproduction prohibited without permission. 
function of institutions is that of maintaining social stability so that members of society might interact with some degree of certainty as to outcomes. Other functions are subsidiary and supportive of this one. There are at least three of these subsidiary functions; exercise social control, socialize persons, and transmit culture.

Institutions are the social groups which exercise social control-the modicum of processes through which society or any social subgroup obtains conformity by its members to its mores or norms of expected behavior. In addition to his many other observations on institutions, Sumner stressed the social-control function. Likewise, John R. Commons, one of the founders of institutional economics, defined institutions in terms of their social-control function--"Institutions are collective action in control, liberation, and expansion of individual action." 13

The preceding description of how the institution of law achieves certainty and stability in social interaction by integrating the roles of buyer and seller in their transaction serves equally well to illustrate the social-control function of institutions. In that case, the institution of law controlled the social interaction by prescribing the essential elements of a binding contract: legality of purpose, contractual capacity, mutuality of assent, and consideration. Social behavior which achieves these elements is reinforced by execution of the contract and consumation of the transaction to the satisfaction of all concerned.

The foregoing emphasizes the regulatory character of social control--the power to prescribe certain social actions, to proscribe other actions, to reward proper behavior and to impose punishments for noncompliance. Clearly members of society must understand and accept their roles and the social norms under which they must play out those roles if 
social control is to be effective and social stability a reality. Thus another function of institutions is socialization--a social-psychological process whereby the personality is conditioned to the folkways and mores and is shaped to fit the social roles it will play in society. It is a process of initiation which commences when a person is born and ends for him when he dies.

For example, the male infant, who possesses certain biological characteristics which distinguish him from the female, immediately commences to learn about his distinctions and the roles he will play because of those distinctions. The first institution to socialize him is the family. The family dresses him in blue and his sisters in pink. The family applies rewards to reinforce behavior which fits the male role in life. He learns that he should expect to one day become a husband, father, and bread-winner. And he is introduced to a myriad of folkways which enforce these roles. Likewise, he is discouraged from behavior which does not comport with the male roles he is expected to assume. This socialization into male roles will be carried on by every other institution in which the maturing male finds himself--the school, the law, the church, the economy, the government, etc. He will, therefore, learn to submit to social control and do his best in his male role to help achieve social stability through institutional processes.

In addition to initiating persons into their roles, socialization also transmits culture from generation to generation. Malinowski alludes to this when he calls institutions the "real units of culture" which organize the activities of people who are attempting to satisfy hasic needs--where culture is a term meaning all socially-acquired behavior patterns that are communicated by symbols. This includes all 
material artifacts of mankind as well as the folkways and mores, or the nonmaterial attributes of society. ${ }^{14}$

One may cite virtually any procedure, or material object generally used by mankind as an example of a culture item which is transmitted from generation to generation through the process of socialization. All the attributes of language, as well as the books, road signs and other physical manifestations of language are examples of cultural transmission, albeit that language also happens to be an institution. Moreover, a 11 language skills are learned. That is, none of the language skills are inherited genetically or arise as normal biological phenomena.

The process by which the culture of any particular language capability is imparted to the young is one of socialization in which the reciprocal roles are those of transmitter and receiver or writer and reader. The socialization commences in the institution of the family and is carried on by the institution of education as well as a variety of other institutions. The result is the transmission of cultural norms by which people may communicate meanings to one another through the use of sound and graphic symbols. The ability to successfully communicate lends itself to certainty and stability in social interaction. It is in and through institutions that society gets it all together--both the material and non-material aspects of culture and all of the values attending thereto. And it is through the socialization process of institutions that culture is transmitted from generation to generation.

In summation, it may be said that institutions function to preserve social stability through exercising social control, socializing persons and transmitting culture. On a higher level of generalization, it may be claimed that institutions are the social guardians of culture and the

Reproduced with permission of the copyright owner. Further reproduction prohibited without permission. 
proper discharge of institutional functions serves to preserve and perpetuate cultural attributes in the society of which the institutions are a part.

\section{INSTITUTIONAL STRUCTURE}

Turning now to institutional structure, it is said that institutions are organized social groups--groups structured so that their purposes are achieved by dividing their functions among members or agents who carry out those functions as individuals or as sub-groups. Sumner distinguishes between an institutional "concept" of socially-sanctioned activities and a "structure" which provides organizational patterns for the realization of the concept. Of course this organized character is not unique to institutions. MacIver defines institutions as established forms of procedure which are characteristic of group activity, while associations are organized groups with structure, identity, and membership. ${ }^{15}$

It seems clear that institutions might be divided into their human and non-human components, as MacIver attempts to do. However, it also seems artificial to refer to the non-human components as the institution, and the human components as something else. An institution is a uniquely human and social phenomena, even though it may involve other cultural attributes. And it is difficult to comprehend how an institution can possess any being or significance without its human components and its social character. Thus, an institution is an organized social group which is united with and employs the established forms of procedure to which MacIver refers.

Terms frequently associated with institutional groups are bureau 
and oligarchy. That is, institutional life is a bureaucratic existence in which the officers or agents of the institution occupy positions or offices and play the roles in society dictated by those offices. Role is behavior expected of an individual who occupies a particular social position in which the behavior is determined by the group or culture of which the person is a member. The positions or offices are generally arranged in some scalar fashion with some offices connoting higher rank and status or greater power than other offices in the institutional structure. 16

The modern business corporation aptly illustrates an economic institution which possesses a scalar bureaucracy. The corporation is a legal individual created by the state through the issuance of a corporate charter. The owners possess shares of stock as evidence of their ownership and of their rights to participate in the election of a board of directors and to receive a share of the net profits of the corporation. The board of directors has the power to name the corporation president, delegate operating authorities to the president, hold him accountable for results stemming from those authorities, and declare the dividends by which the owners--or shareholders--participate in profits of the corporation.

Shareholders and members of the board of directors do not typically engage in the day-by-day management of the corporate business. Rather, this is the function of the person appointed to the position and playing the role of president. He is usually the general agent of the corporation with powers to bind the corporation into contracts with persons and other corporations. The president has an organization consisting of positions occupied by persons who play the roles of subordinate corporate officers and other functionaries. 17

Reproduced with permission of the copyright owner. Further reproduction prohibited without permission. 
The typical small manufacturing firm would probably have four divisions: finance, materials, production, and marketing. Examining only the production division for a moment, the line position titles in descending order of rank, status, and power might include the vice-president for production, the superintendent of plant operations, the plant manager for plant \#2, the plant \#2 swing-shift foreman, the 1 ine $A$ lead foreman on plant \#2 swing shift, and the assembly technician on line $A$ in the plant \#2 swing shift. The persons occupying each of these corporate positions take on the habits of dress and customs of behavior primarily as they perceive their roles and status through the expectations of others, both inside and outside the institution. Thus, the modern business corporation, like other institutions, possesses a scalar bureaucracy.

Insofar as there is bureaucratization and organized structure, it is often claimed that institutions are also oligarchical in that there is control within institutions by the few officers who possess the highest rank. And it follows that these same few officers exercise the institutional powers in interaction with other interest groups over issues of their collective concerns. The point is, that institutional groups are organized social groups, and this characteristic, coupled with other institutional attributes, endows the institution with formidable power in dealing with non-institutional groups or social issues.

Hence, the unique powers of institutions are functions of their strategic positions on social issues and of their essential characteristics. That is, arising from mores, institutions stand to preserve the status quo on any issue while groups opposing the status quo stand to challenge the mores or the fundamental beliefs of most people. Moreover, institutions possess special powers for the preservation of the status

Reproduced with permission of the copyright owner. Further reproduction prohibited without permission. 
quo--or the maintenance of stability and certainty in social interaction. These special powers are crucial to the functioning of institutions exercising social control, in socializing initiates, in transmitting culture, and thus in maintaining stability.

The special powers of institutions are to maintain and prescribe norms of expected behavior, award and reinforce behavior conforming to expectations, proscribe non-conforming behavior, and impose sanctions for non-conforming behavior. In speaking of religion, Dewey writes:

To say it is institutionalized is to say that it involves a tough body of customs, ingrained habits of action, organized and authorized standards and methods of procedure . . . Faith in these ideas, or at least in the catch words which express them, become obligatory, necessary for social salvation; disbelief or indifference is heresy. 8

Noninstitutional groups may possess some capacities to employ these powers as amongst their particular memberships. However, they generally possess no legitimate powers to coerce persons who are not members of their particular groups into compliance with their norms. Indeed, their members are free to unilaterally terminate their relationships with the groups if they find themselves in such disagreement with group norms that they cannot conform. Finally, the sanctions of non-institutional groups are informal in nature: avoidance, exclusion, and ostracism from the group. And these sanctions are rarely significant outside the groups imposing them.

On the other hand, institutions possess the power to prescribe and proscribe behavior of persons who hold no offices inside the institutional bureaucracies but who are members of the society whose culture the institutions preserve and transmit. Moreover, institutions generally possess the power to formally coerce nonconforming persons into

Reproduced with permission of the copyright owner. Further reproduction prohibited without permission. 
adherence with mores, or institutional norms. In the case of the state-one of the political institutions of a nationality--such institutional coercion may achieve the ultimate force, the power to deprive nonconforming members of their lives.

Likewise, institutions award and reinforce conforming behavior by conferring status and the trappings of status upon persons who behave in accordance with the expectations attending the social roles they play. But more important, such conferred status is universaity recognized and acclaimed throughout the society of which the institutions are a part, whereas the status conferred by noninstitutional groups is generally acknowledged only within the groups conferring the status.

For example, one who has managed to comply with all of the requirements is awarded the status of medical doctor. He must first be graduated from a baccalaureate institution, usually with honors, and the completion of a pre-medical curriculum. He must score high on the medical aptitude tests. He must then apply to many medical schools and hope that one will accept him. If he gains admittance, he must complete three or four years of rigorous professional schooling in medicine. The degree of doctor of medicine or medical doctor will be conferred upon him by the institution from which he is graduated if he completes his work successfuliy.

However, he is not yet prepared to practice medicine without restrictions. He must next complete a residency of one or two years at some accredited hospital, after which he must take and pass his medical board examinations. He will then be certified by the state as qualified to practice medicine and he may thereafter play the role of medical doctor without legal restrictions. If he chooses to specialize in some 
narrow field of medicine, he must usually complete some additional professional training and more internship. He may then practice in his specialty as well as in general medicine. He is addressed as "doctor" and he is accorded great admiration and respect by all and envied by many. If he is in the least successful in his practice, he will enjoy the institutional status conferred upon him as well as great prestige, influence, and income for the rest of his iife.

This then is the modus operandi of institutions--they function to stabilize social relations by maintaining the status quo. This is accomplished through the processes of social control, socialization, and culture transmission. These latter functions are carried out through the unique institutional powers of prescribing and proscribing behavior, formally awarding behavior which comports with institutional expectations, and formally punishing nonconforming behavior--all of which is widely recognized, accepted and acclaimed throughout the society of which the institutions are a part.

\section{CLASSIFICATIONS OF INSTITUTIONS}

Having distinguished institutions and institutional groups from noninstitutional groups, it needs to be noted that institutions differ amongst themselves. That is, they are different as to their powers and their cultural attributes. Notwithstanding these differences, al1 institutions perform the functions, possess structures and operate as described above. The distinctions between institutions are therefore differences of magnitude rather than of essential character. These differences have provoked attempts by social scientists to classify institutions.

Reproduced with permission of the copyright owner. Further reproduction prohibited without permission. 
For example, Herbert Spencer advanced a typology of institutions containing three main classes--maintaining and sustaining institutions (marriage and the famity), producing and distributing institutions (the economic system), and regulating and restraining institutions (religion and the government). Anthropologists and others have divided institutions into a primary class and a secondary class. According to this classification, primary institutions are found in all human societies and include marriage, the family, the economic system, and religion. Secondary: institutions are those derived from or functionally amplifying the primary institutions. Secondary institutions are language, art, education, recreation, government, and whatever others one might choose to list. 19

Chapin writes of "diffused" institutions as those which stabilize social behavior throughout a society--language, art, recreation, etc.-and of "nucleated" institutions as those which structure behavior within smaller units of society--the family, the business enterprise, the church, etc. On the other hand, Parsons distinguishes between relational, regulative, and cultural institutions. Relational institutions are those which prescribe reciprocal role expectations. Regulative institutions prescribe socially agreeable ways of striving toward certain ends. And cultural institutions organize a people's cultural orientations. Finally, Martindale sees so-called social institutions which organize the attainment of instrumental values, and cultural institutions which see intrinsic values as ends-in-themselves. 20

The perception of this writer is that classifications of the foregoing sort tend to obscure the essential likenesses of institutions by stressing spurious and fallacious differences. For example, it appears 
that all of the above writers have, in one way or another, confused institutional functions with structures and methods of operation. In this regard, both Spencer and Parsons call one class of institutions "regulating and restraining institutions"--while regulation or social control is a function of a11 institutions.

Likewise, Chapin's classification apparently assumes that the socalled diffused institution of language does not operate to structure behavior in the smaller units of society, the family, school, etc. Or, conversely, that the so-called nucleated institutions possess no capacity to stabilize social behavior throughout society. And finally, Parsons and Martindale write of so-called "cultural institutions" as a class by itself, while it has been shown above that all institutions are repositories and transmitters of culture. The point is, that classifications of institutions of the foregoing sort may serve some narrow purposes, but they also obfuscate the ontology of institutions.

A further point against arbitrary classifications of institutions is that institutions tend to be interdependent and intersupportive. For example, the institution of the family is dependent upon the institutions of marriage, the church, the state, and institutions of the economic system--to say nothing of languagc, law, art, education, and the like-to create the social bonds which unite the couples who are starting the families, to enforce the sets of property and other social arrangements which protect families within society, and to produce and distribute the goods and services which the family needs but cannot produce for itself. Similar institutional interdependencies abound and they greatly enhance the powers of institutions in the discharge of their stabilization functions.

Reproduced with permission of the copyright owner. Further reproduction prohibited without permission. 
Likewise, one person may simultaneously play roles in many institutions. That is, one woman may occupy the position and play the role of wife in the institution of matrimony, of mother in the institution of the famity, of owner, manager, or worker in an economic institution, and city councilwoman in an institution of government, to name only a few of her possible institutional roles. Thus, the interdependencies of institutions is matched by interlocking institutional memberships in which one person will occupy positions and play roles in many institutions.

This institutional interdependency has fostered a number of elitist theories about interinstitutional relationships. For example, C. Wright Mills believes that the oligarchies which control the economy, the government, and the military establishment also control all other groups. This idea is advanced in part as an alternative theory to the theories of political pluralism--which, of course, tend to treat all groups as more or less homogeneous and of approximately equal power. ${ }^{21}$

Control is maintained within an elite group of persons, according to Mills, each of whom has achieved status within the economy, the government, or the military establishment by being male and caucasian, graduating from the right schools, belonging to the correct churches and clubs, living in acceptable neighborhoods in the right cities, and driving the right cars. Moreover, the oligarchy has made it easy, according to Mills, for persons with the proper status to fill positions and play roles in any of three controlling institutions and to shift to other positions, either within one institution or from one institution to another, whenever the situation demands it.

Examples of persons who can and have played roles with high status in several or all of the elite institutions are legion. One who comes

Reproduced with permission of the copyright owner. Further reproduction prohibited without permission. 
immediately to mind is Dwight D. Eisenhower. He graduated from the military academy at West Point, New York. He achieved the highest active military rank attainable in the United States. He retired from the profession of arms to become the president of Columbia University. He returned from there to a military post for a time before seeking and winning election to the presidency of the United States. U. S. Grant, George C. Marsha11, and Douglas MacArthur are among others who accomplished similar transformations after graduation from West Point. ${ }^{22}$

This writer has no particular quarrel with Mills or with most elitist theorists as regards the internal consistencies or the empirical relevancies of their arguments. Nor does he have cause to quarrel with pluralists on either of those two criteria. However, it appears somewhat hyperbolic for elitists to claim that their world view is alternative to pluralism, or for pluralists to argue that there is no elitism operational in a democratic society. ${ }^{23}$

In the first place, one need only admit to imperfections in the political sphere to see that the democracy of pluralism is flawed toward oligarchy in the same way that imperfections in the market place flaw so-called "perfectly competitive markets" toward oligopolistic markets in economic affairs. Mertons alludes to such imperfections when he claims that a11 institutions are not equally supported by all social groups because certain existing institutions may preserve a status quo which is oppressive to some and very beneficial to others. He thus argues that nonconformity may reflect an unreasonable lack of opportunities within the existing institutional fabric of society. ${ }^{24}$

The lack of opportunities to which Mertons alludes derives from unreasonable barriers to access to positions of institutional status and 
power. Many trade and most professional associations function in part to erect and maintain barriers to entry into their skills and professions. The object of these barriers is ostensibly to protect the public from inferior craftsmanship and faulty professional practice. In fact, the real object is all too often to protect the existing craftsmen and professional persons from competition and to restrict the supply of skilled labor and professional services so that persons already admitted to the trade or profession may enjoy oligopolistic or artificially high wages and fees.

This is every bit as true of union apprenticeship programs as it is of admission requirements to the practice of law or medicine. One can hardly argue that intensive special training is not needed to produce skilled medical doctors and competent attorneys. Likewise, one should not be expected to tolerate shoddy workmanship from a plumber or an electrician. The question is not whether there should be training; rather, it is how much training is really necessary to produce quality workmanship and competent professional service.

Competence in most craft skills can be acquired by the average citizen with one year or less of training in an industrial arts school and one additionat year working as an apprentice to a journeyman or master craftsman. But the usual union program calls for a minimum of four years of apprenticeship in the union before advancement to journeyman regardless of other experience or training. The difference amounts to an unreasonable barrier to entry into the trade. Similar differences exist in the artificially protracted requirements for admission to medical and legal practice as well as to other professional vocations. The point is that these unreasonable barriers to entry restrict 
opportunities to otherwise qualified aspirants. And these aspirants thereafter and therefore regard the institutions with skepticism and give them only grudging support.

One may, of course, cite other barriers, many of which are based on more noxious criteria--religious beliefs, racial characteristics, sex, national origin, etc. One may also cite other social imperfections which flaw pluralism toward oligarchy. However, this does not mean that a democratic political system cannot achieve some measure of stability while it allocates values in its usual authoritarian manner any more than similar imperfections in a market system means that the market does not or cannot achieve some measure of market equilibrium while it allocates limited resources to alternative and competing social ends.

But, more important, both elitists and pluralists appear to have committed and compounded some significant errors. Pluralists tend to treat groups as though they were all noninstitutional in character. On the other hand, elitists tend to treat groups as though they are all institutional in character. Neither view squares properly with reality; for there are indeed both institutional and noninstitutional groups, as they have been distinguished here, operating in society. But, as further anaiysis will hopefully show, the concern of both of their operations centers on institutional change. However, it is inappropriate to expand further on that point at this time because that is the subject which occupies the remainder of this work.

Rather, it is appropriate at this point to rationalize this brief search into the ontology of institutions. The purpose has been to establish a suitable working definition of an institution. Drawing from the ideas in the foregoing discussion, the definition of an institution

Reproduced with permission of the copyright owner. Further reproduction prohibited without permission. 
which will serve throughout the remainder of this work is:

An institution is an organized social group which has evolved from and is united with some particular system of cultural values, and it serves through processes of social control to stabilize social interaction by preserving and perpetuating those values in the society of which the institution is a part.

The foregoing look at institutions has drawn principally from the works of sociologists and cultural anthropologists. While institutional economists do not essentially dispute other social scientists, they do possess a unique perspective on the functioning of institutions. Henceforth concentration will be upon that institutional economic perspective.

\section{INSTITUTIONS AND URBAN AREAS}

The close and inextricable relationship between urban affairs and institutions is of particular importance to this paper. Institutions, of course, abound in urban areas. Indeed, nearly all institutions reach their zenith in cities. While the traditional view is that cities exist to house people and the things people need, it is not clear that people need cities solely for domiciliary purposes. Rather, the people are all involved in social interactions under the social control of the institutions which flourish in the cities. In this context, the city's principal raison d'etre may be viewed as to domicile the institutions needed to maintain social stability in a complex society. It seems that people should have little need for cities were this not so.

Moreover, the city itself is a creature of institutions. That is, city government with all of its trappings, educational institutions, and the myriad of family and business institutions from which the former two derive their tax bases and which they regulate in the interest of social stability, are institutions without which the city would have no

Reproduced with permission of the copyright owner. Further reproduction prohibited without permission. 
legitimacy and little or no being.

Hence, it is hoped that some progress toward a more wholistic theory of urbanology might be made by integrating group theory as it has been applied to political science with institutional economic theory and other aspects of traditional economic theory and relating the results to urban affairs. Toward that end, the remainder of this work will explore the following questions:

1. What is the temporal setting of institutions and cities? (Chapter III).

2. How do institutions function in that temporal setting? (Chapters IV - V).

3. What are the underlying causes of institutional instability, change, and discontinuity, and what are the consequences of this to the city? (Chapters VI - VIII).

4. How are institutional values measured in dealing with the stresses leading to institutional change? (Chapter IX).

5. By what processes do societies reconcile the social tensions which lead to institutional change? (Chapter $X$ ).

6. What are the apparent social implications of the conclusions stemming from the foregoing questions? (Chapter XI). 
END NOTES, CHAPTER II

$I_{\text {Henry Pratt Fairchild, (ed.), Dictionary of Sociology and Related }}$ Sciences (Patterson: Littlefield, Adams \& Co., 1964), p. 133.

${ }^{2}$ Thirteenth and Fourteenth Amendments to the Constitution of the United States, in Documents of American History, 5 th ed. Ed. by Henry Steele Commanger (New York: Appleton-Century-Crofts, Inc., 1949), pp. 147-48. Earl Warren, "Brown et al v. Board of Education of Topeka et al," in The Annals of America, Vol. 17 (Chicago: Encyclopaedia Britannica, Inc., 1968), pp. 253-58.

$3_{\text {William Graham Sumner, Fol kways: A Study of the Sociological }}$ Importance of Usages, Manners, Customs, Mores, and Morals (New York: The New American Library, 1960); Veblen, "Races and PeopTes," in Portable Veblen, pp. 297-305; and "The Instinct of Workmanship," in Portable Veblen, pp. 306-23.

${ }^{4}$ Stuart Chapin, Contemporary American Institutions (New York: Harper Bros., 1935), pp. 14-16; Don Martindale, Institutions, Organizations and Mass Society (Boston: Houghton Mifflin $\mathrm{C}_{0 .,}$ 1966), pp. 124-25.

5 "Law of Property," Encyclopaedia Britannica, Macropaedia, Vol. 15 (Chicago: Encyclopaedia Britannica, Inc., 1974), pp. 46-56.

6 "The Sherman Anti-Trust Act, July 2, 1890," in Documents of American History, pp. 136-37.

7 "Section 10, Article I, The Constitution of the United States," in Documents of American History, p. 142.

${ }^{8}$ Thomas C. Cochran and William Miller, The Age of Enterprise: A Social History of Industrial America (New York: Harper and Row, Pub1ishers, 1961), pp. 18-23, 53-66, 228-48, 261-65. Harvey C. Bunke, A Primer on American Economic History (New York: Random House, Inc., 1969), pp. 70-88. U. S. Department of Labor, Bureau of Labor Statistics, A Brief History of the American Labor Movement, 1970. Ed. (Washington, D. C.: U. S. Government Printing office, 1970).

${ }^{9}$ The National Labor Relations Act of July 3 and July 5, 1935 , Statutes at Large, XLIX, 449-55.

${ }^{10}$ George Herbert Mead, Mind, Self and Society, ed. by Charles W. Norris (Chicago: Chicago University Press, 1934), p. 262.

${ }^{11}$ Talcott Parsons, The Social System (Glencoe: The Free Press, 1951), pp. 46-50.

12Len Young Smith, and G. Dale Roberson, Business Law: Uniform Commercial Code, 3d ed. (St. Paul: West Publ ishing Co., 1971), pp 46- 189. 
${ }^{13}$ Sumner, Folkways. Commons, Economics of Collective Action, p. 21.

14 Bronislaw Mal inowski, The Dynamics of Culture Change (New Haven: Yale University Press, 1945), p. 15.

${ }^{15}$ Sumner, Folkways. Robert M. Maciver and Charles H. Page, Society: An Introductory Analysis (New York: Holt, Rinehart and Winston, Inc., 1949), pp. 11-18.

${ }^{16}$ Max Webber, The Theory of Social and Economic Organization, trans. by A. M. Henderson and T. Parsons (New York: Oxford University Press, 1947), pp. 329-47.

${ }^{17}$ Smith and Roberson, Business Law, pp. 787-802.

18 John Dewey, Characters and Events, ed. by Joseph Ratner (New York: Henry Holt \& $(0 ., 1929)$, pp. 799-800. (2 vols.)

19 Herbert Spencer, The Principles of Sociology, vol. 1, 3d ed. (New York: D. Appleton \& Co., 1885), 437-41.

${ }^{20}$ Chapin, Contemporary American Institutions, pp. 14-15. Parsons, The Social system, pp. 46-50. MartindaTe, Institutions, Organization, pp. 124-25.

${ }^{21} \mathrm{C}$. Wright Mi11s, The Power Elite (New York: Oxford University Press, Inc., 1956), pp. 269-96. Floyd Hunter, Community Power Structure (New York: Doubleday, 1963). A7 so see: Robert Michels, Political Parties: A Sociological Study of the 01 igarchical Tendencies of Modern Democracy, trans. by Eden and Cedar Paul (New York: Dover Publications, Inc, 1959).

22 "Eisenhower, Dwight 0.," Encyclopaedia Britannica, Macropaedia, Vol. 6, pp. 514-16." "Grant, Uiys $\frac{\text { ses S., "Encyclopaedia Britannica }}{4}$ Macropaedia, Vol. 8, pp. 278-80. "Marshal 1, George C., "Encyclopaedia Britannica, Macropaedia, Vol. 11, pp. 534-35. "MacArthur, Douglas," Encyclopaedia Britannica, Macropaedia, Vol. 11, pp. 219-220.

${ }^{23}$ The issues surrounding pluralism and elitism are by no means settled. There is a large and growing body of literature on the matter. The relevant works include: Robert Dahl, "A Critique of the Ruling Elite Model," The American Political Science Review, XLVII (June, 1958), pp. 463-69. Nelson W. Polsby, "How to Study Community Power: The Pluralist Alternative," The Journal of Politics, XXII (August, 1960), 474-84. Will iam Kornhauser, "'Power Elite' or 'Veto Groups'," in Culture and Social Character, ed. by Seymour Martin Lipset and Leo Lowentha? (New York: The Free Press, 1961), pp. 252-67. Peter Bachrach and Morton S. Baratz, "Two Faces of Power," The American Political Science Review, LVI (December, 1962), 947-52. Daniel Beel, "The Power Elite - Reconsidered," American Journal of Sociology, (November, 1968), 238-50.

${ }^{24}$ Robert K. Mertons, Social Theory and Social Structure, rev. ed.

(New York: The Free Press, 1957), p. 122.

Reproduced with permission of the copyright owner. Further reproduction prohibited without permission. 
CHAPTER III

URBAN CONTINUUM

The foregoing was an abbreviated, cross-sectional view of institutions out of which a definition of institutions emerged. The view was cross-sectional in the sense that it explored the ontology of institutions as static bodies or as entities at rest. It was like a picture of an object, capturing its essence at some instant in time. The view purposely avoided the dynamics of institutionalism except by implication. It was, of course, implied in the descriptions of institutional characteristics that institutions take actions which are ordered in time. That is, institutions are not in fact static bodies. Rather, they are social mechanisms of choice which operate over time. But this aspect of institutions was not explicitly constructed in the preceding chapter. Henceforth, concentration will be upon the dynamics of institutions and the group and urban environments in which they exist. This is the realm of institutional economics--not uniquely, to be sure, for sociologists and anthropologists have studied the dynamic attributes of institutions. But institutional economists have concentrated their works on these dynamic attributes. And, as economists are inexorably bound to do, they have posited theories about such matters.

The theories of institutional economics have to do with the first four questions raised at the conclusion of the preceding chapter. They have to do with the nature of the institutional environment, its setting on a temporal plane. They have to do with the manner of action and 
interaction of institutions in that environment. And institutional economic theory posits causes of institutional instability, change, and discontinuity. Finally, along with the more traditional theories of economics, they suggest ways of measuring institutional values in dealing with the stresses leading to institutional changes.

While political pluralist theory is in evidence throughout the search of the first four questions because of an inherent paralle1 between institutional economics and pluralism, no effort is made to point out the evidence or explicate the parallelism. Rather, it is in pursuit of answers to the fifth question that pluralist theory is brought into the analysis to solve the institutional dilemma developed in the early chapters by suggesting ways in which societies reconcile the social tensions leading to institutional changes. However, the explicit introduction of pluralist theory must wait until chapter six.

\section{LIFE PROCESSES AND TEMPORAL SETTING}

Returning then to the point at hand, the first institutional economic theory explored here addresses the first question at the conclusion of chapter one--what is the temporal setting of institutions and cities? Stated concisely, the temporal setting of institutions and cities--indeed, of virtually everything--is a longitudinal dimension in chronological sequence called an "ends-means continuum," a continuum of "ongoing life processes." This chapter will deal with the characteristics of the ends-means continuum. But first, it is important to briefly clarify "life processes" and "temporal" in the meanings intended here.

Reproduced with permission of the copyright owner. Further reproduction prohibited without permission. 
Homo Mensura

Turning first to the matter of "life processes," it is observed that man is a living creature in terms of the usual meaning of the word "living." He shares that distinction with the universe of both animate and inanimate biological forms. Mankind, therefore, has a very special interest in life and in anything which acts upon or interacts with life forms. Moreover, mankind has established an order of things in which biological forms are classed higher than geological forms, the animate biological forms are classed higher than the inanimate, and man is classified as the highest animate form--chiefly because of the relatively greater intellectual capacities of his brain--the power of conceptual thought--and the adaptability which this gives him. Thus, man's great adaptability is manifest in the wide range of choices afforded to him by his relatively larger intellectual capacities.

One may, of course, dispute this homocentric order of things with appeals to metaphysical, teleological, or spiritual criteria. However, this writer eschews the opportunity to speculate upon the relative merits of alternative ways of ordering things. Rather, the position assumed here is consistent with the homocentric view. It is homo mensura, a view enunciated by the great sophist, Protagoras, "man is the measure of al1 things." This means that if there is no actor, there can be no choice. If there is no choice, there are no consequences of choice. No consequences means no criticism. And man is, above all else, a critical animal and his criticism focuses on the consequences of choices made by himself and his human cohorts who are taking actions on their choices. ${ }^{2}$ Choice naturally connotes alternative courses of action from which to choose as well as an agent to make the choice. There are some actions

Reproduced with permission of the copyright owner. Further reproduction prohibited without permission. 
in which there are no known alternatives from which man may choose. For example, an unpredictable and cataclysmic celestial aberration which destroys all life environments in the sublunar realm of man might present mankind with no known alternatives. Mankind, along with other life forms, would become extinct in those environments. Such a catastrophe cannot be said to be part of a life process in the homo mensura sense. The agent perpetrating the aberration, the actor, was not man and was not known to man. That is, the situation resulted from a so-called event of nature, a happening over which mankind possessed no known power of control. While there were indeed consequences stemming from the event, the consequences were not relevant because they did not arise from the choices made by man from alternatives which might affect the outcome.

Use of the word "catastrophe" in the preceding paragraph implies that an event resulting in the extinction of life forms on earth would be undesirable. The question is, for whom would it be undesirable? To measure it as undesirable assumes a preconception that 1 ife forms on the planet are desirable. And who or what is most likely to harbor such a preconception? Man, who is heavily invested in life processes, certainly harbors that preconception. Likewise, other forms of intelligent life, insofar as they too might conceptualize survival in such terms, might also harbor that preconception. However, this latter point is rere anthropomorphic speculation. The point is, that valuing outcomes as desirable or undesirable is most likely a subsumption of homo mensura.

One further point about life processes, the alternatives open to human choices have proliferated down the centuries of man's earthly habitation. This is partly due to mankind's ability to organize itself 
and its activities around institutions and urban institutional complexes, and partiy from man's unique tool-using capability. Both of these ideas are more fully developed in succeeding chapters. It is important in passing to acknowledge that both of these abilities arise from mankind's relatively larger intellectual abilities and that they greatly enhance man's adaptability by further widening the range of choices open to him. In summation, life processes are sequences of events involving interactions with matter in any form in which the actor, man, exercises some element of choice, bears the consequences of his choices, and is open to critical analyses of the choices and their consequences. The ends-means continuum is a continuum of on-going life processes in this homo mensura context.

\section{Temporal Setting}

Turning now to the word "temporal," a temporal event or environment must be understood as transitory or temporary, as worldily or sublunary, as secular, and as ordered in time or chronological sequence. Conversely, it is not permanent or eternal, neither spiritual nor ecclesiastical, and not spatial or latitudinal in character. ${ }^{3}$

A temporal event is temporary or transient, not eternal. It occurs in some relationship to other events in which each event is unique in one's awareness of its existence. For example, when one travels from his home to his place of employment, the travel is an event which occurred after some other event in one's awareness--after completing a breakfast of kippered herring and baked tomatoes. It likewise occurred before some other event in one's awareness--before placing his brown bag in a locker and walking to the turret lathe he will tend until coffee

Reproduced with permission of the copyright owner. Further reproduction prohibited without permission. 
break.

The travel was not existential in one's awareness during breakfast, existential perhaps, but not an actual occurrence. Nor was it existential while he was placing his brown bag in the locker, experiential, perhaps, but not an occurrence presently in process. The travel was a transitory event which was existential to the traveler after his breakfast and before his arrival at his work station. It was, therefore, not eternal in terms of the person's present awareness of its actual occurrence.

A temporal event is a worldly or sublunary event rather than a spiritual phenomenon. It is a real thing which can be observed, measured and verified by empirical means. It can be experienced through one or more of the human senses. One can see, hear, touch, smell, or taste the evidence of the event either directly through natural senses or through technical amplification of the evidence so that it is perceptibie to one's naturat senses. ${ }^{4}$ For example, one may measure his rate of speed as he travels from his herring and tomatoes to his turret lathe by observing the rate reflected on his automotive speedometer as he moves between the two. Such observation is one of many pieces of evidence that one is indeed traveling. It is not a spiritual phenomenon insofar as one need not rely solely on his divine faith to verify the evidence of travel (rate of speed, in this illustration).

Likewise, a temporal event is secular, not ecclesiastical. That is, it is not something which can only be verified or interpreted by priests or other ecclesiastics who purport to possess supernatural means by which to verify the existence of the event. For example, one may become convinced of the existence of some divine, omnipotent being 
through litanies, supplications, lamentations, testimonials, and other ceremonial applications by clergymen. While this may become a spiritual reality in one's awareness, it is not temporal within the meaning of that word. 5

Finally, a temporal event is ordered in time or chronological sequence rather than in spatial relationships. One might relate events to one another in space by showing, for example, that breakfast took place at one's domicile while tending a turret lathe took place some distance away at a place of employment. On the other hand, one might relate the events in sequence of their happening--breakfast, travel, tend turret lathe, etc. This latter way of relating events is temporal. The former is spatial. 6

The chronological sequence is longitudinal insofar as the sequence is a chain of events which are related in some ways and which extend into the past in a time continuum. Conversely, a spatial relationship is latitudinal or cross-sectional because it views events either at some point in time or without regard to time or sequence. That is to say, spatial relationships are not dynamic. They are static and they take no account of change-over time. Thus, a temporal environment is dynamic because it is not eternal. It is temporary, transitory, and reflective of change. It is not spiritual, but is sublunary, worldly. It is not ecclesiastical, but is secular. And, it is not a spatial relationship but a chronological one.

Once again, the temporal setting of institutions and cities is a longitudinal dimension in chronological sequence called an "ends-means continuum," a continuum of on-going life processes. The continuum is a setting for human choices involving interaction in the sense of life

Reproduced with permission of the copyright owner. Further reproduction prohibited without permission. 
processes described above. And those choices involve society in the temporal sense also described above. The remainder of this chapter is given over to an elaboration of the ends-means continuum in these contexts.

The elaboration will first divide the continuum into a past, a present, and a future. It will then examine present conditions in terms of the past, the principal idea being that all existing in the present is the effect of causes which lie in the past. It will next examine the present conditions in terms of the future. The principal idea is that the present effects of prior causes are also the means to ends which 1 ie in the future along the continuum. The elaboration will then examine the nature of ends and their relationship to means. Finally, the nature of ends and their relationship to on-going life processes will be explored.

\section{CAUSES, EFFECTS, AND MEANS}

If the continuum is divided into two parts, a past and a future, then the boundary between the two is the present. The present is, of course, the only existential part of the continuum. All that occurred in the past is experiential and the future is expectatial. One essentially spends his life at the boundary between the past and the future. Human real time is the present, a time when the past and the future converge upon one's act of choosing. All else is a great fantasy conjured up out of the pages of history books and the speculations of prophets and urban planners. The aged, whose lives have been spent in the past, often live out the present in fond or remorseful recollection of their past experiences. The young, whose lives are still short and whose life exper iences are few, generally live out the present in anticipation of the 
uncertain future into which their lives extend. Either way, the past is memory and the future is speculation. Only the present is existential.

\section{Present Effects of Past Causes}

While the past is history and only the present is existential, all that exists in the present is the effect of causes which lie in the past along the continuum. Thus, the past and the present are inextricably linked by the milieu of creatures, artifacts, materials, and ideas which descend to the present out of the past. ${ }^{7}$ A moment's reflection reminds one that he himself is an effect of prior causes--the deliberate or accidental sexual union of his mother and father as well as all preceding generations of like unions and a multitude of other events which ultimately led to his conception, birth, and maturation.

Another moment's reflection reveals that one is born into an environment which, like himself, is the effect of prior causes--some of which resulted from planned and deliberate choices and actions by the generations of mankind which preceded him in the world, and some of which were human accidents of chance or so-called events of nature extrinsic to man and over which man possessed no known powers. One can only marvel at the magnitude of the celestial universe, the geological reality of the earth, the majesty of a Mt. Mckinley, the vast emptiness of a Sahara, and the cascading splendor of a Victoria Falls. But these natural wonders did not always exist. They are the effects of who-knows-what causes, but causes nevertheless.

On the other hand, much of civilized man's habitat, and the structures, artifacts, people, and institutions which comprise that habitat, are effects which are more clearly linked to known past causes. In most 
cases, the causes were intrinsic to man. They grew out of human deliberations and resulted in human actions and interactions both with other mankind and with other aspects of the environments in which humans found themselves. A city, any city, is the effect of such past causes.

Take, for example, the modern city of London, England. One who disembarks at Heathrow Airport gives little thought to why or how London came to be the city it is today. He usually accepts it as it is, enjoying the commercial and cultural amenities the city offers and suffering the congestion and other disamenities which are part of metropolitan existence anywhere. And yet, London is the effect of causes which reach back more than two millennia. The city is the result of human deliberations and actions spanning more than 2,000 years of time.

The embryonic city of London was established in the First Century B. C. at the beginning of the Roman occupation of Britain. No doubt the site was a market and perhaps a military post before the Romans occupied it because nature endowed it with a number of attributes which commended it to human use. London lies forty miles inland at one of the last places along the Thames River accessible to deep-draft vessels. Moreover, the city is located at the eastern terminus of a low hill system which extends westward between the lower Midlands in the north and the Salisbury Plain in the south to the Severn River and the Bristol Channel on the west coast. All of which is to say that London occupies a very strategic location in respect to traffic to and from mainland Europe. It commands the most convenient north and south access routes, and it lies astraddle a major water barrier to that access, a barrier which is also a major water route to the English Channel and mainland Europe. 8

Reproduced with permission of the copyright owner. Further reproduction prohibited without permission. 
The Romans were no doubt quick to perceive the natural strategic advantages of the site for they established their seat of government in Britain at what they called Londinium. The Romans built a basilica on land now occupied by Leadenhall Market on what is presently Gracechurch Street leading from London Bridge up to Cornhill. This was the hub of Londinium in Roman times. It is now the center of the financial district of London with the Bank of England, the Stock Exchange, the Royal Exchange, Lloyds of London, and other financial institutions clustered nearby.

The original selection of that particular site as a seat of government and its subsequent transformation for use by financial institutions in modern times reflects the present effects of literally millions of human choices and actions over the intervening millennia. One cannot hope to capture the magnitude of the transformation in such a brief treatise as this. But the choices range from the decision of the Roman governor to establish an institution of government there to the less portentous but very necessary logistical and technical choices by the architects, engineers, and craftsmen who constructed the edifices to house the institutions as well as the choices of the multitude of plain folk and civil servants of every rank to live in London and to work in the institutions located there.

The point is, that the metropolitan amenities and disamenities one experiences as London, England did not emerge in full flower from the thin air in an instant of time. Rather, the present effects one knows as London were caused largely out of human deliberations, choices, and toil extending more than 2,000 years into the past. The principle is that present effects, be they perceived as good or bad, are inextricably

Reproduced with permission of the copyright owner. Further reproduction prohibited without permission. 
tied to the past causes which brought them into existence.

\section{Effects-Means}

The next principle is that the means available in the present, the resources for the attainment of ends which lie along the continuum in the future, are the same present effects of prior causes which occupied the immediately preceding discussion. That is, the future is inexorably built upon the means available in the present. And insofar as those means are the effects of prior causes, the future is inextricably linked to the past. That linkage is through the effects-means which exist in the present at the boundary between the past and the future. ${ }^{9}$

One set of such effects is an understanding of causal relationships themselves. An understanding of those relationships arises from empirical observations and deductive insights which link effects to causes. These descriptions of causal relationships are synthesized into theories which may then be employed to predict future outcomes with some calculable degree of certainty. Theories likewise enable persons to prescribe present actions to effect desired future outcomes. It is by these processual arrangements--description, prediction, and prescription-that knowledge of past causes are instrumental toward achieving future ends. Thus, an understanding of causal relationships is itself an effect-means which may be employed like other means toward achieving ends which 7 ie in the future. ${ }^{10}$

In another example, the city of London was established by the Romans with the end in view or purpose of domiciling the seat of their institution of government in Britain. The means available at that time were the effects of causes which lie along the continuum in the past. 
The strategic advantages of the site were geological obliquities of nature created over millions of years of terrestrial upheaval, erosion, and sedimentation. It remained only for the Roman intelligence to discover it and for her legions to secure it. The legions needed to secure the site were drawn from the far reaches of the empire where their military doctrines and prowess were sharpened in more than two hundred years of sporadic warfare--notabiy the Punic Wars, the Mithridatic Wars, and the Gallic Wars which ultimately brought Caesar and his legions to Britain. The architects and artisans required to improve the site were available from projects in other parts of the empire where they learned their skills after the centuries-old Athenian architectural tradition of the post and lintel, to which the Romans added their monumental arch. The stone, wood, and other materials required for site improvements were no doubt providences of nature in proximity to the site. The institutionalized norms of Roman provincial government were the accreted experiences of their Hellenistic predecessors, embellished by their own experiences in governing the empire from the Caspian Sea to the Straits of Gibralter and from Egypt to Gaul. Finally, like the legionnaires and the architects and artisans, civil servants were available from other parts of the empire where they were sired, reared, and trained in the art of administration. All of these means were the effects of past causes, and they were employed to attain the end in view of creating the domicile of Roman government in Britain. ${ }^{11}$

Effects-means, like those at the time of the Roman establishment of London, possess several attributes which are important to the institutional thesis. The first is that means have value in part because they are instrumental in attaining desired future ends. The second is that,

Reproduced with permission of the copyright owner. Further reproduction prohibited without permission. 
given their instrumental qualities, means have value in part because they are in 1 imited supply in the present. And finally, means are unidirectional as to the ends toward which they are employed.

The first attribute of effects-means, that they have value in part because they are instrumental in attaining desired future ends, is analogous to the demand side of the orthodox economist's partial equilibrium condition in so-called factor markets. That is, the demand for any resource is derived from the demand for the good or service in the production of which the resource will be employed. Thus, if there is no economic demand for an end product, there can be no effective demand for the resources to produce it. Likewise, the intensity of demand for the end product will reflect in the intensity of demand for the resources to produce it. 12

One can easily apply this idea to the effects-means, or resources, in the example of Roman London. The good or service demanded was a domicile for the seat of Roman government in Britain. This arose from the end chosen by the Romans to establish their government in Britain-ignoring any reasons why the Romans might choose to do that. From that decision flowed all of the choices and decisions regarding subsidiary ends--where to locate that government? How to secure the site? How to develop the site, and on ad infinitum? From each decision arose a series of new demands for means, and the values of those means were determined in part by how instrumental they were in attaining the desired future end toward which they would be employed.

However, the foregoing attribute accounts for only part of the value of means. Another part is accounted for by the second attribute-that means which are available in the present are in limited supply.

Reproduced with permission of the copyright owner. Further reproduction prohibited without permission. 
This is, of course, analogous to the supply side of the orthodox economist's partial equilibrium condition in factor markets. Resources will be supplied to those employments which yield the highest incomes or greatest benefits to their owner. And, given an effective demand, those resources which are in the shortest supply will command the highest incomes. However, this goes beyond the point to be made at this time, which is simply, that the means available in the present are limited to whatever effects of past causes exist at the time. ${ }^{13}$

All. of the means described above for Roman London--the site, military legions to secure the site, architects, craftsmen and materials to improve the site, institutionalized norms of Roman provincial government, and civil servants trained in the art of administration--were available in the present as the effects of causes which lie in the past. While they were supplied partly in response to the Roman decision to establish its government in Britain, they were not available in unlimited quantities. Indeed, they were 1 imited both because they were not created in infinite numbers and because some were required to pursue similar enterprises elsewhere in the empire. The principle was fulfilled for the Romans as it was for the empires before theirs and as it has been down all the ages of man. The means available to attain ends which lie in the future are 1 imited to the present effects of past causes.

The last mentioned attribute of effects-means is that means are unidirectional as to the ends toward which they are employed. That is, means which are spent in the achievement of particular ends become embodied in those ends. The spent means yield their identities to the ends toward which they were spent. ${ }^{14}$ In the example of Roman London, the site, materials, and labor of architects and artisans lost their

Reproduced with permission of the copyright owner. Further reproduction prohibited without permission. 
identities in the physical facilities of Londinium. The people who populated Londinium labored in and yielded their identities to the institutions which were domiciled there. And the institutions of the city and the city itself merged their identities with that of Roman government in Britain.

The consequence of this is simply that means or resources which are imprudently allocated to unworthy ends are at least partially wasted An unworthy end is one which yields less social welfare in the homo mensura context per resource-means than a competing and alternative end in view at the time the former was chosen. The allocation is imprudent if the relative social costs and benefits of the foregoing ends-in-view were accurately known before the choice could no longer be retracted without expending resources in the retraction.

Resources are wasted under such circumstances insofar as greater social welfare could have been achieved if the same resource-means had been allocated to the alternative end rendering the greater social benefit. This is analogous to maximizing net social benefits, in the vernacular of the orthodox economist. There are, of course, situations in which one may choose other normative criteria than maximizing net social benefits. However, those options go beyond what is intended here, and they will be considered in a subsequent chapter. It is enough at this point to define waste in these rudimentary terms. 15

The foregoing attributes of effects-means--that means have value in part because they are instrumental in attaining desired future ends, that means which are available in the present are in limited supply, and that means are unidirectional as to ends to be reached--imply a need to economize in the employment of means. They admonish care in avoiding 
waste of needed and 1 imited resources. They argue for full and efficient utilization of available resources. And these normative implications extend logically to another--that great care to be taken in the selection of ends-to-be-attained or reached from the array of ends-in-view so that the selected ends render the greatest possible social welfare in terms of the homo mensura criterion.

\section{ENDS, MEANS, AND PROCESS}

It is appropriate then to take up the nature of ends and to examine their relationships to means and to on-going life processes. Ends are simply possible alternative states-of-being which do not exist in the present but lie in the future along the continuum and are open to human choices. 16 It is important at this point to distinguish between the possible future outcomes of so-called natural phenomena and the possible future consequences of present choices by mankind. Given the homo mensura assumption and certain distinguishing characteristics of mankind, only the latter can be viewed as ends.

\section{Natural or Artificial Selection}

One might imagine a state of nature in which the environment is devoid of human presence and thus of human influence. Pristine forests are rooted in virgin soils, and there is a perfect ecological balance between the vegetation, atmosphere, and animal life in the Eden-1ike environment. The whole scene is an idyllic state in which the ecological balance is thought to be natural because whatever selections occur are made by agents other than man.

There are events, to be sure, which constantly tip the 
environmental equilibrium this way and that way so that minuscule changes are discernible after some time. The established weather pattern might change slightly year by year for some obscure reason so that less vegetation is set before the animate creatures low in the food chain. The change will cause a decline in the population of vegetarians. Some will simply starve to death while the fecundity of survivors will decline and their progeny will be less prolific than they were during more verdant times.

The effects of the famine will reflect all the way to the top of the food chain. Some of the carnivores.will starve for want of edible flesh. Others may perish in conflicts with competitors over whatever flesh and carrion is available. The whole process may bring extinction to some of the weaker species. But, eventually, the natural balance will be restored by the brutal law of survival-of-the-fittest. And, according to this line of reasoning, nature will be strengthened in the process. Moreover, the whole process is correct and proper--primarily because it came out that way without the fettering influences of man. It was so-called natural selection in which the selections were made by agents other than man. 17

This so-called state of nature is one in which future outcomes are the results of natural phenomena. That is, they become actual outcomes because of the present reactions of both geological and biological matter to incipient aberrations in their environments. Moreover, the reactions occur with practically no conscious contemplation by the reactor of possible future consequences. Stated another way, the reactor has no capacity to analyze and therefore no capability to describe causal relationships in situations it faces. Thus the reactor cannot predict probable 
outcomes or prescribe ways of effecting a desired outcome. There are therefore very few or, more likely, no choices for the reactor. Rather, the reactions are in a sense programmed by nature so that if a particular environmental stimulus arises, then a corresponding reaction is initiated and will bring forth a nearly certain predetermined result so long as there is no foreign interference with the reaction process. 18

Take, for example, the common barn swallow, Hirundo rustica, a migratory insectivore. The northern hemisphere perceptibly warms shortly after the earth-track of the sun passes the vernal equinox in its annual sojourn to the cancer equinox. The seeds which have lain dormant during the dark days of winter germinate and thrust tiny roots into the warming earth. The longer and warmer days open the buds on trees and bushes, invite the small green tips of monocots out of the ground and initiate the photosynthetic process that will grow the plants upon which most insects and their larvae feed. ${ }^{19}$ The eggs laid in the fall by the insects which could not hope to survive the bitter winter now respond to the warmth of spring, opening and releasing nymphs and larvae and initiating the metamorphosis which will produce the flying insects upon which the barn swallows feed. 20

As the track of the sun moves closer to the northern equinox, the barn swallows arrive as far north as southern Alaska in the northern temperate zone. Guided by the sun, they have come from the seasonally colder southern hemisphere seeking moderate climates and flying insects suitable to their tastes. The older birds who have migrated before respond to a mating urge by returning to established nests. The young birds, who have migrated for the first time, seek out mates and set about building new nests of mud, dried grasses, animal hair, and feathers 
in which to lay and hatch their eggs. The swallows will take turns setting their eggs so that each mate can respond to pangs of hunger by gathering food in the only way it knows, catching and devouring indigenous insects in flight. After the chicks hatch, the parent swallows spend their days gathering insects in the same way to take back to the gaping beaks that fill their nest.

The days grow shorter after the sun passes the cancer equinox. The whole natural process commences to slow and the insect population declines as the season wears on. By now the chicks have matured and are learning to feed on flying insects just as their parents have done. This combination of factors--shorter days, cooler weather, fewer insects, and matured brood--signals time for migration to the warming climates in the southern hemisphere. The spatial situation is reversed and the swallows leave their nests, flock together, and again guided by the sun, journey to the southern hemisphere. Some flocks fly a distance of 9,000 miles to the southern reaches of Argentina in this migration. 21

The swallows have been primarily reactors in the foregoing episode, responding to both external and internal stimuli. They responded to the changing weather patterns and subsequent ecological transformations by migrating. They responded to the biological urge to mate by nesting, laying, and hatching eggs, and nurturing their young. They essentially sought out environmental conditions which conduced to their welfare. They took natural phenomena as they found them, adapting only to the extent of building a crude nest of indigenous materials in which to fulfill their biological urges to propagate. And when the environment turned adverse with season, the swallows responded by migrating to whence they came. The duration of the future into which the swallows'

Reproduced with permission of the copyright owner. Further reproduction prohibited without permission. 
deliberations consciously projected was very brief, if indeed they projected at ali. ${ }^{22}$ That is, they possessed no analytical capability and they could therefore not describe past causes of present effects, predict future outcomes, or prescribe actions to effect desired future outcomes. Man is, of course, a reactor like other animals. Once conception has taken place, the prenatal events attending a human pregnancy are essentially of the reaction sort. Likewise, the biological processes of physical maturing and aging are genetic reactions to time and other features of environment over which man has only a limited power of control. The foregoing examples focus on stimuli and processes which are biological and intrinsic to the reactor. Man also reacts to some extrinsic stimuli in his environment with little conscious thought to possible future consequences.

But more often, man does deliberate on the probable future outcomes of his present choices. And when his present choices are influenced by his deliberations, man becomes more than a reactor. He is an actor who makes choices from an array of possible future ends. He bears the consequences of his choices and those choices are open to critical evaluations on the basis of their consequences. Man is unique among earthly creatures in terms of his time-span of discretion--the duration of the continuum over which his deliberations and choices project. He possesses the analytical ability to discover and describe causal relationships descending from the past, and he can use the knowledge of those relationships to predict probable future outcomes and to prescribe ways of effecting desirable outcomes. ${ }^{23}$

Thus, the state of nature might be contrasted with a state of man in which so-called artificial selection takes place. The selection is 
artificial, according to this line of reasoning, because the choices are made by man. Man destroys the pristine forests in order to build and heat his houses. He clears the land of all natural vegetation, levels the ground, and tills the virgin soil to plant and cultivate crops for food and fiber. He consumes the food and spins the fiber into yarn which will produce the textiles to fashion his clothing and household fabrics. Eventually, he builds cities here and there to house the myriad of institutions which flourish wherever man abounds. Finally, he builds roads to connect the farms to the cities and the cities to one another.

Many species of animals which formerly foraged the land can no longer survive there. They are driven into other areas, upsetting the "natural balances" in those regions. And man, who now occupies their former habitats, takes measures to keep the natural fauna off his land and out of his cities. On the other hand, man does keep domestic animals on parcels of the land which he holds out of cultivation for use as pasture. But these creatures are not generally capable of surviving without man's maintenance. They are the products of so-called artificial selection, of husbandry choices made by man to more efficiently produce meat for food and animal fiber for textiles.

This latter situation, the so-called state of man, is clearly one in which man is very much involved in the selection process. He has looked upon the primeval region, and in the place of pristine forests he sees a house, barn, and outbuildings surrounded by crop land and pasture. In the place of natural fauna he sees beef and milk cattle, swine, sheep, poultry, and other domesticated creatures grazing between his fences. The images of possible future uses of the land which cross his mind as he contemplates the forest in its natural state are ends-in-view. They

Reproduced with permission of the copyright owner. Further reproduction prohibited without permission. 
are states of being which do not exist at the time and which will not exist unless the man chooses to take up tools and carve his homestead out of the wilderness he sees before him. 24

Clearly, the possible future outcomes of natural phenomena cannot be considered ends in the absence of an actor such as man--one who can visualize a possible state of being which does not exist at the time of the vision, but a state which can be brought into being at some future time only if the actor chooses and couples his choice with appropriate action. While possible future outcomes of natural phenomena are not ends in the absence of an actor such as man, the ultimate fruition of a possible natural outcome becomes an effect of whatever causes brought it into existence as soon as the creative event ascends from the future to the present and passes into the past. And, insofar as the effect may be instrumental to ends perceived by mankind as lying in the future along the continuum, such effects are potential means for man to achieve those future ends.

Moreover, while the possible future outcomes of natural phenomena cannot be viewed as ends in the absence of an actor such as man, such possible outcomes are, in fact, ends-in-view if man looks upon them as among the alternatives from which he may choose. For example, choosing to hold entire regions as wilderness areas in order to pass them to future generations as examples of states of nature is an artificial selection. And, in this sense, all the natural events which take place in those regions are artificial insofar as they would not be taking place were it not for the deliberate social choice and its complementary actions to hold the regions in those uses rather than in other viable, alternative uses. Thus, it can be argued that all sublunar selection is 
artificial so long as an actor such as man inhabits the earth. 25

On the other hand, it can be argued that all of mankind's advancement--some would call it a descent out of a state of nature or a fall from grace $^{26}--i s$, in essence, the acquisition and actualization of ways in which natural outcomes can be deliberately arranged to adapt the environment to a more agreeable habitat for man. For example, at some time in the ancient past, a member or members of the human species discovered how to ignite fires by means initiated by themselves. They found that they: could choose to ignite certain common materials--probably by briskly rubbing them together--at times and places of their choosing. Moreover, they discovered that they could control their fires by containing them in stone and earthen hollows and vessels and by regulating the rate at which combustible materials and air were added to them. Fire thereby became a tool of mankind for heating abodes and cooking food. It subsequently led to a multitude of other techniques employing a variety of fire forms for an even greater variety of human purposes.

Did the human species create the natural phenomenon known as fire? Indeed, did the species create the elements needed to ignite fires? Or, did humans give fire the qualities which make it at once destructive of beings and things and instrumental in adapting the environment to a more agreeable habitat for man? Clearly, the answer is no. A1l of these features accrue to fire naturally. Rather, mankind through analysis simply discovered and described these natural characteristics and acquired and actualized techniques by which fire could be employed as means to future ends selected by humans. Thus man, a creature of nature, is simply employing natural phenomena to secure a balance in nature which conduces toward his own welfare. Damming a stream is no less natural

Reproduced with permission of the copyright owner. Further reproduction prohibited without permission. 
when done by man than when done by a beaver. Both creatures have altered the ecology in the vicinity of the dam in order to adapt the environment to their special needs. According to this line of reasoning, all selection is natural. ${ }^{27}$

The point raised by this seeming diversion from the central argument is the question--is there a real distinction between so-called natural selection and artificial selection? or is the distinction itself specious and artificial? Is it possible that all selection is artificial so long as man inhabits the earth? $0 r$ is it possible that all selection is natural insofar as man is a creature of nature and, in the temporal context, is forever limited to natural constraints no matter what his time span of discretion?

The position of this writer is that the distinction drawn between natural selection and so-called artificial selection is specious and can lead syllogistically to dubious conclusions and thereby to questionable policies. Moreover, this writer tends to the view that all selection is natural. Mankind are creatures of nature. At most they are instruments of nature in the context of on-going life processes. Man discovers qualities about natural phenomena and he devises and employs techniques for applying his discoveries to adapt his environment to a more habitable abode for himself. But he is constrained by nature and can never successfully exceed the parameters of nature for very long, if at a11. In short, man is not supernatural. ${ }^{28}$

How then does one account for the distinctions described above? A first step is to cease conceptualizing selection in terms of the fallacious dichotomy, natural and artificial. Rather, one can treat all selections as natural and distinguish them on the basis of the time-span of 
discretion within the selection agent's capabilities. Man stands quite apart from other mortal agents with this method of classification. All other agents are substantially of the reactor sort, while man possesses the capacities of both reactor and actor. The essential difference is that the latter possesses the capability of visualizing alternate ends as complex states of being which are not in existence and which wil1 not come into existence unless the actor chooses one or another and couples his choice with equally complex series of actions usually carried on over some protracted period of time to bring his chosen state into being.

In summation, ends are possible alternative goals which lie in the future along the continuum and which are open to human choices. They are possible future consequences of present choices by mankind. Possible future outcomes of selections by agents other than man are therefore not ends in this homo mensura context unless they are among the alternatives from which man chooses.

\section{Alternative Ends and Limited Means}

Returning now to the nature of ends, ends possess certain attributes which are of particular importance to the institutional thesis. The attributes are: ends have value because people, through institutions, prize them as desired. Moreover, ends cannot be severed from the means to their attainment. Therefore, some ends-in-view are alternative because means are limited so that only some of the competing ends-in-view are attainable with the available means. Some ends-in-view are alternative because they are exclusive--they are incongruent with other competing ends-in-view. Ends are not ends-in-themselves because, once they are attained, they become means or impediments to on-going ends. 
And finally, on-going life processes are processes which convert ends to means in some continuing fashion.

The first attribute of ends is that ends have value because people, through institutions, prize them as desired. Ends are prized or desired as they show likelihood of satisfying perceived human wants. The human wants may arise from deficits or conflicts which render existing or probable future states of affairs objectionable. Objectionability is of course a relative matter in that one compares alternative possible future states of affairs and ranks them according to their preferredness on the basis of their least objectionability. Thus, the ends are appraised on the basis of their serviceability toward erasing objectionable states of affairs by filling the deficits or resolving the conflicts out of which the human wants arise. ${ }^{29}$

Ends are, in this sense, analogous to consumer goods and services in the orthodox microeconomic theory of product markets. And the behavioral phenomena described above aresimilar to the concept of utility on the demand side of the same microeconomic theory. Economic goods and services are chosen in the economic institution called the market place according to the wants or preferences and the buying powers of people as consumers. The goods and services yield utility or satisfaction by filling deficits which render an existing state of affairs with the deficits less preferred than other expectant or possible states of affairs without the deficits. ${ }^{30}$

These ideas have far greater applicability than to choices in economic institutions alone. Ends have been defined as possible alternative states of being which do not exist in the present but which lie in the future along the continuum and are open to human choices. Ends may

Reproduced with permission of the copyright owner. Further reproduction prohibited without permission. 
therefore repose in what is narrowly defined as the realm of political institutions or in the realm of other institutions than market or political institutions. And in like manner, the valuing of alternative ends, whether by economic, political, or other social institutions, can be done, with some adaptation, in the marginal frame-of-reference of orthodox microeconomic theory. However, this moves ahead of the point to be made here, which is simply that ends have value because people through institutions prize them as desired.

It is possible to illustrate this by relying, once again, on the example of Roman government in Britain. In this case, the question is, why did the Romans choose to establish (select the end) dominion over the Britons? The answer is simple. The Roman world view was of a distinct empire insulated from the barbarians on all sides. This view eventually led to the Gallic Wars and the conquest of western Europe. Britain became a feature of that conquest because the northern coast of Gaul was not secure from raids and pillage by some of the thirty or so barbaric tribes that populated Britain at the time.

Thus, the Roman conquest of Britain was initiated to resolve conflicts which rendered an existing state of affairs more objectionable to the Romans than the future prospect of a secure western frontier populated by conquered and submissive peoples. The choice to secure the submission of the Britons by military means was made by the Roman institution of government during the reign of Emperor $\mathrm{Claudius} \mathrm{I}$. The campaign was prosecuted by Roman military institutions over a period of forty years, touching the reigns of Emperors Claudius, iero, and Domitian. It was successfully concluded by General Agricola during the reign of Domitian. The point at hand is simply that the Roman conquest 
of Britain had value to Romans because Romans, through their institutions, prized that conquest as sufficiently meritorious to allocate substantial means to its prosecution over a span of forty years touching the reigns of three Roman emperors. 31

The second attribute of ends within the institutional framework is that ends cannot be severed from the means to their attainment. This proposition seems so self-evident that it is hardly worthy of statement. However, one often hears persons speak of certain goals as possessing such merit that they should be attained whether or not there are means to do it. Such statements are, of course, based on highly idealistic beliefs--views which lead the ideologue to believe that the relationship between ends and means is so tenuous as to be of no practical consequence. Such views are not realistic inasmuch as ends as outcomes are neither more nor less than the interaction of the ensemble of means which brought them into existence. The obverse side of this is a previous observation that means yield their identities to the ends they achieve. Which is to say that goals, no matter how worthy, cannot be secured without the means to do so. ${ }^{32}$

This idea--that ends cannot be severed from the means to their attainment--coupled with a previous observation leads to the next attribute of ends. The previous observation is that means-resources are limited to the present effects of past causes. Taken together, these two propositions admonish that some ends-in-view are alternative because means are limited so that only some of the competing ends-in-view are attainable with the means available. Ends-in-view are, of course, ends which are discerned by people to be possible of attainment under prevailing circumstances. 33

Reproduced with permission of the copyright owner. Further reproduction prohibited without permission. 
Clearly, there are many ends which qualify as ends-in-view. When taken singly they are possible of attainment under prevailing circumstances. That is, there are available means which might be allocated to their achievement. However, when all ends-in-view are taken together, it is generally discovered that the available means are insufficient to attain all of them simultaneously, or perhaps even seriatim. The paucity of means was elaborated above and will not be further labored here. Suffice it to say that ends-in-view are constrained by available means so that ends compete with one another for selection as ends-to-be-reached. Ends-to-be-reached are ends-in-view which have been set apart as more desired than competing ends. They become ends to the achievement of which some of the scarce means will be ai?ocated. An end-to-be-reached therefore, becomes the coordinating activity around which all other subactivities are organized. Once the choice of a particular end is made from among competing ends-in-view, the selection and organization of appropriate means to attainment of the chosen end follows almost pro-forma. $^{34}$

One may deduce from the preceding observation that ends justify their means. Indeed, this conclusion is unavoidable, notwithstanding the often heard proclamations to the contrary, if the word justify is understood to mean "to supply good grounds" or "to warrant" the employment of the means for the chosen purposes and ways. 35 However, persons who argue that any particular means are justified by the ends they are meant to secure appear to do so either because they have more interest in the employment of those particular means than in the ends they are supposed to achieve (in other words, they contemplate ulterior ends) or because they view the ends-to-be-reached as worthy of attainment at any cost 
(in other words, the ends are viewed as ends-in-themselves). On the other hand, it would appear that persons who vehemently claim that means cannot be justified by the ends toward which they will be employed do so either because they believe that there is little correspondence between ends and means or because they actually believe that there are other means more suitable or that the chosen ends are not worthy. In fact, which combinations of means ought to be employed toward achievement of which particular ends is problematical and is the subject of other chapters in this monograph. All of which does not defeat the pragmatic conclusion that ends justify the means.

There is another reason why some ends-in-view are alternative, and it has nothing whatever to do with paucity of means. The next attribute of ends is that some ends-in-view are alternative because they are exclusive. That is, they are incongruent with other competing ends-inview so that it is simply impossible to attain all sets of such exclusive ends at the same time and place. This is so even if means are sufficiently abundant to do so. ${ }^{36}$

Examples of this abound. One cannot present his actual physical being in two or more spatially different places at precisely the same instant of time. He might place an image of his physical being in many different places instantaneously. Or he might seek to be in different places at different times. But it is quite impossible to place one's actual physical self in two different places simultaneously.

Likewise, one cannot occupy the position and play the role of husband in the institution of matrimony and, at the same time, remain an eligible bachelor in terms of the same institution. At some point both ends may stand open to selection and the means may be available to secure 
either. One may choose to mount a campaign with the end-to-be-reached of wooing an eligible female into marriage. And once he has exchanged nuptial vows with her, he has taken on the role of husband. But after initiation in that position, he is no longer an eligible bachelor. On the other hand, one may eschew every opportunity to involve himself in any activity, the result of which is matrimony. In which event, he cannot honestly play the role of husband in the institution of matrimony. The point is that the two ends are existentially exclusive and they cannot be simultaneously attained.

Another institutional attribute of ends is that ends are not endsin-themselves because, once they are attained, they become means or impediments (or perhaps some of both) to on-going ends. The distinction between ends and means is relational in the temporal sense. It was demonstrated earlier how present means to future ends are the effects of causes which lie in the past. This is the same as stating that the present means are in part the ends or consequences of choices made in the past. Likewise, everything that does not exist in the present but must be brought into existence to serve as means to a further end are ends themselves. 37

This can be traced out in the context of the continuum developed to this point. 'Ar snd-in-view is an intellectual phenomenon. It does not exist except in contemplation. If it is selected as an end-to-bereached, the end becomes expectatial and it is the activity around which immediate means and intermediate ends are organized. As each event which brings the chosen end into existence ascends from the future to the present, the end emerges and becomes existential. And as those events all pass into the past, the residual components of the end which remain in

Reproduced with permission of the copyright owner. Further reproduction prohibited without permission. 
the present, the embodiment of the means which brought the end into being, become the effects of causes which lie in the past. Thus, the continuum has brought the contemplation to consequence. And the consequence may facilitate or impede or both facilitate and impede the attainment of on-going ends.

For example, the founding of the City of London is seen to be a long series of events related to one another in a continuum of ends and means. The coordinating element around which all subactivities, immediate means, and intermediate ends were organized, was the Roman world view of a distinct empire insulated on all sides from raids and pillage by barbarians. This ideal became an end-to-be-reached. The means to that end were the intermediate ends of estabishing dominion over and maintaining peace in all contiguous lands harboring barbarian tribes. This led to the Gallic Wars as Rome allocated immediate means in the form of Roman Legions to the intermediate end of conquering Western Europe, including Britain.

The conquest of Britain achieved an intermediate end and became a means to a further intermediate end, the establishment of a Roman government in Britain with which to maintain the peace. The construction of a domicile for that government was an intermediate end to establishment of the Roman government. And, of course, the City of London was founded with the construction of that domicile. Thus, construction of Roman London became one of the means to establishment of a Roman government in Britain. The establishment of that government became a means to maintaining the peace in Britain, and maintaining peace in Britain became a means to insulating the Roman Empire from pillage by barbarians on its north-western periphery.

Reproduced with permission of the copyright owner. Further reproduction prohibited without permission. 
The foregoing example treated all attained or existential ends as though they were, ipso facto, means to on-going ends. It is sometimes the case that such existential ends are found to be impediments rather than means to some on-going ends. ${ }^{38}$ such a situation may come to pass either because the attained end was selected deliberately to impede some on-going ends, or because there was an inadequate prediction of probable on-going consequences of attaining the selected end. An inadequate prediction might result if the persons choosing ends did so either without sufficient information upon which to estimate the outcomes accurately or because they applied defective theories as to causal relationships, and they therefore drew unrealistic conclusions. Whatever the reasons, it sometimes happens that existential ends are impediments rather than means to some on-going ends.

Suppose, for example, that a person owns some open land on the edge of an older urban area. Suppose further that the urban area is shifting from mixed residential and light commercial use to industrial use. And finally, suppose that the owner chooses to develop the land by constructing private, single-family dwellings to accommodate upper middle-income families, speculating that the proximity to light commercial enterprises might be an inducement for such families to buy residences in the area. What are the likely consequences of the private owner's choice if the established trend toward industrial uses continues on adjacent lands?

The most probable result is that the owner-developer will not succeed in selling his new units to upper middle-income families, if indeed he can sell them at all. ${ }^{39}$ Thus he may not realize sufficient revenue from sales to cover his costs of development, and he may find himself

Reproduced with permission of the copyright owner. Further reproduction prohibited without permission. 
pushed into bankruptcy. The owner's failure could have originated in either inaccurate information about the land-use trend in the area (stemming from indifference on the owner's part, an inadequate estimate of the land-use trends in the area, or a sheer paucity of data) or defective theory as to the causal relationship between the established trend and its most probable effect on the potential future uses of his property. Some would argue that the owner should not be deprived of his folly--that he should be free to make his private market choice and to succeed or fail upon its merits. On the other hand, there are some sound social reasons why his venture should be truncated before losses occur. Insofar as means are unidirectional as to the ends to which they are allocated, they cannot always be economically recovered. Thus, resourcemeans will be wasted because they have been imprudently allocated to the unworthy end of constructing private single-family dwellings in a location which is not suitable for residential purposes. But, perhaps more important, new housing is a very durable product, and it can be expected to remain serviceable for up to twenty years with little maintenance and for much longer with substantial maintenance. Moreover, the cost to reclaim the land from small residential parcels into large industrial units is prohibitive. ${ }^{40}$ Therefore, the housing, as an existential end, stands as an impediment to the on-going end of developing the land for industrial uses, its probable highest use.

Comprehensive urban planning is seen as an effort to avoid problems of the foregoing sort in urban land-use. The plan usually starts with a catalogue of existing land uses and land-use regulations. Based upon explicit assumptions, the plan attempts to project probable demographic and economic changes which will affect future land uses. It then

Reproduced with permission of the copyright owner. Further reproduction prohibited without permission. 
proposes ways of incrementally changing zoning ordinances and other land-use regulations so that land-use transitions occur in an orderly fashion in accordance with some preconceived and explicit notions about what future land-use patterns ought to be and why they should be that way. Finally, the plan is updated periodically to keep it current with changes which take place over time. The comprehensive plan is usually the product of careful deliberations by a city planning staff, a city planning commission, and the elected members of city government. It is usually subject to extensive public hearings before ratification and before any changes are enacted. ${ }^{41}$

In short, comprehensive city planning looks at land-use in a continuum which extends from the past to the future. And it looks at present land-use effects of past cause, at the present effects-means to future ends and at an array of ends-to-be-reached along with the combinations of means which might be organized to their attainment. One of the functions of the plan is to assure with reasonable probability that existential ends become means, not impediments, to on-going ends in urban land use.

\section{On-Going Life Processes}

The foregoing elaboration of the temporal setting of institutions and cities reduces deductively to the proposition that on-going life processes operate to convert ends into means in some continuing fashion. That is why the continuum is called an ends-means rather than a meansends continuum. All means were something else before they were meansresources to on-going ends. They were either the outcomes of phenomena not involving deliberation and selection by man, or they were ends in 
the homo mensura context. ${ }^{42}$

Ends, as ends-in-view, were intellectual phenomena which existed only in the contemplation of members of the human species. They were states of being which did not exist at the time and which would come into being only if the persons contemplating them chose them as ends-tobe-reached and coupled their choices with actions to effectuate the ends. Ends became existential as immediate means and intermediate ends were selected and organized toward securing the ends-to-be-reached. And, in-as-much as ends are not ends-in-themselves, they became means (or impediments or both) to some on-going ends when they became existential. Thus, ends were transformed into means by on-going life processes and on-going life processes operate to convert ends into means in some continuing progression.

In summation, the temporal setting of institutions and cities is a longitudinal dimension in chronological sequence called an ends-means continuum, a continuum of on-going life processes. The setting is one for making social choices of ends-to-be-reached from an array of competing possible ends-in-view and for selecting and organizing immediate means and intermediate ends toward attainment of the chosen ends. Finaliy, the setting is one in which ends are transformed into means in some continuing fashion by on-going life processes. The next two chapters examine the functioning of institutions in this temporal setting as well as the significance this has for cities.

Reproduced with permission of the copyright owner. Further reproduction prohibited without permission. 
END NOTES, CHAPTER III

${ }^{1}$ Richard Carrington, The Mammals, (New York: Time, Inc., 1963), p. 172.

${ }^{2}$ Protagoras, Fragments, quoted in Treasury of World Philosophy, ed by Daggobert D. Runes, (Patterson: Littlefield, Adams, Inc.., 1959), p. 976. Also see Eugene Meehan, The Foundations of Political Analysis; Empirical and Normative, (Homewood: The Dorsey Press, 1971), pp. 14, 152-57.

3The discussion of the word "temporal" follows the definition found in any unabridged dictionary. E.g., Webster's New Twentieth Century Dictionary of the English Language; Unabridged, 2d ed. (New York: The World Publishing Co., 1970), p. 1887.

${ }^{4}$ John Dewey, Essays in Experimental Logic (Chicago: University of Chicago Press, 1917), pp. 231-41, and Logic: The Theory of Inquiry, excerpted in Intelligence in the Modern World, ed. by Joseph Ratner, (New York: Random House, Inc., 1939), pp. 913-24. Meehan, Foundations of Political Analysis, pp. 17-12.

${ }^{5}$ Will James, "...we have a right to believe at our own risk any hypothes is that is live enough to tempt our will." The Will to Believe, excerpted in Introductory Readings in Philosophy, ed. by Marcus G Singer and Robert R. Ammerman, (New York: Chas. Scribner's Sons, 1962), p. 219. This pragmatic approach is contrasted with the instrumental approach of John Dewey. We have a right to believe only that which verified through scientific testing. If it is not proven and cannot be disproven, then the issue or problem remains in the problematical--without solution. A Common Faith, (New Haven: Yale University Press, 1934), passim.

${ }^{6}$ John Dewey, Experience and Nature, excerpted in Ratner, Intelligence in the Modern World, pp. 1039-43, and Experience and Education, excerpted in Ratner, Intelligence in the Modern World, pp. 667-68. Also see Dewey's "The Continuum of Ends-Means," Theory of Valuation, pp. 40-50.

${ }^{7}$ Charles Darwin, The Origin of the Species by Means of Natural Selection, and The Descent of Man and Selection in Relation to Sex, Vol. 49, Great Books of the Western World, 54 vols., ed by Robert M. Hutchins, et al., (Chicago: Encyclopaedia Britannica, Inc., 1952), pp. 596, 597. Dewey, Experience and Nature, pp. 109-11, 114-16.

8"London," Encyclopaedia Britannica, 1974, Vo1. 11, pp. 90-94. "Europe, Geological History," and "Europe, Physical Geography," Encyclopaedia Britannica, 1974, Vol. 6, pp. 1034-35, 1040-42.

${ }^{9}$ Dewey, Theory of Valuation, p. 43.

10 Dewey, Theory of Valuation, pp. 44-58. Meehan, Foundations of Political Analysis, p. 13. 
${ }^{11}$ Edward Gibbon, The Decline and Fall of the Roman Empire, Vols. 40 \& 41, Great Books of the Western World, 54 vols., ed. by Robert M. Hutchins, et al., (Chicago: Encyclopaedia Britannica, Inc., 1952), pp 2, 9. "Britain, Ancient," Encyclopaedia Britannica, 1974, vol. 3, p. 194.

12 Dewey calls this idea little more than a "bad pun," by which he explains that means may be valued intrinsically as well as instrumentally. Theory of Valuation, pp. 27-28. The economics of factor demand is described in any microeconomic textbook. E.g, C. E. Ferguson and J. P. Gould, Microeconomic Theory, 4th ed. (Homewood: Richard D. Irwin, Inc., 1975), pp. 364-420.

${ }^{13}$ The institutional idea of scarcity is consistent with orthodox economic theory. See John R. Commons, Economics of Collective Action, (Madison: University of Wiscons in Press, 1970), pp. 89-96. For a description of the economics of factor supply, see Ferguson and Gould, Microeconomic Theory, pp. 69-75.

${ }^{14}$ Dewey, Theory of Valuation, pp. 35-50.

${ }^{15}$ For a statement of the meaning of "net social benefits," see Arthur F. Schreiber, Paul K. Gatons, and Richard B. Clemmer, Economics of Urban Problems; An Introduction, (Boston: Houghton Miffl in Co., 1971), pp. 16-20.

16 John Dewey defines an end as "an objective of conscious endeavor," Experience and Nature, p. 783, and as an object or forsseen consequence of desire and interest, Theory of Valuation, pp. 28-30, passim.

${ }^{17}$ Darwin, Origin of the Species and the Descent of Man, pp. 40, 42.

${ }^{18}$ Carrington, Mammals, p. 172.

$1{ }^{19}$ Frits W. Went, The Plants, (New York: Time, Inc., 1963), p. 60.

${ }^{20}$ Peter Farb, The Insects, (New York: Time, Inc., 1962), p. 67.

${ }^{21}$ Roger Tory Peterson, The Birds, (New York: Time, Inc., 1963), passim.

${ }^{22}$ Peterson, The Birds, p. 126.

${ }^{23}$ Carrington, The Mamma 1s, pp. 169, 170. Darwin, Origin of the Species and the Descent of Man, pp. 592, 596.

${ }^{24}$ Dewey, Theory of Valuation, pp. 50, 66 .

${ }^{25}$ The idea that all selection by mankind is artificial is a commonly held view. For literature associated with institutional economics, see: Darwin, Origin of the Species and the Descent of Man, p. 596. Commons, Legal Foundations of Capitalism, pp. 375-76. E17ul, The Technological Society, p. 79.

Reproduced with permission of the copyright owner. Further reproduction prohibited without permission. 
p. 596 .

${ }^{26}$ Genesis 3. Darwin, Origin of the Species and the Descent of Man,

27 Dewey has consistently rejected the notion that man is somehow supernatural. Much of his effort in Experience and Nature is given over to the idea that man is very much a part of nature.

${ }^{28}$ Carrington, The Mammals, p. 172. Also see Pierre Teilhard de Chardin, The Phenomenon of Man, trans. by Bernard Wall with an introduction by Julian Huxley (New York: Harper and Row, Publishers, Inc., 1965). Assuming an evolutionary point of view, mankind is found to be to the earth and universe what man's mind is to his own body--a transformation agency promoting "hominization," or expanding what Teilhard calls the "noosphere" (the sphere of mind, vis the biosphere or sphere of life, and the lithosphere or sphere of inorganic matter) in a "noogenesis," as contrasted with a cosmogenesis. Thus, mankind is, to Teilhard, more than a simple part of nature. Mankind is a much advanced agent of nature to carry on the evolutionary process. Cf, Friedrich Nietzsche, "Thus Spake Zarathustra," trans. by Thomas Common, in Treasury of World Philosophy, ed. by Daggobert D. Runes (Paterson: Litt7efield, Adams Co., 1959), pp. 861-66.

${ }^{29}$ Dewey, Theory of Valuation, pp. 33-34, 45, 47. Perry, General Theory of Value.

${ }^{30}$ Ferguson and Gould, Microeconomic Theory, pp. 9-119.

${ }^{31}$ Gibbon, Decline and Fall, p. 2. Julius Caesar made a scouting expedition into Britain in 55 B.C., ostensibly to search for minerals. The actual conquest of Britain for the reasons stated did not commence until 43 A.D. "Britain, Ancient," Encyclopaedia Britannica, 1974, Vol. 3, p. 194.

${ }^{32}$ Dewey, Theory of Vatuation, pp. 26, 29, 35.

${ }^{33}$ The idea that ends are alternative or competing for selection because of scarce resources (means) is a common proposition of orthodox economics. The idea is commonly attributed to Lionel Robbins. An Essay on the Nature and Significance of Economic Science, 2d ed. (London: MacMillan \& Co., 1935), pp. 12-16. The idea is usually found in the introductory chapters of most principles and microeconomic textbooks. E.g., see: Paul A. Samuelson, Economics, 9th ed. (New York: McGrawHi17 Book Co., Inc., 1973), pp. 18-30. Ferguson and Gould, Microeconomic Theory, p. 2.

${ }^{34}$ Dewey, Theory of Valuation, pp. 2, 48-49.

${ }^{35}$ other meanings of the word "justify" which are rejected for the purpose at hand include: To declare free from guilt or blame. To prove or show to be in conformance with law, right, propriety, or duty. To vindicate. To defend or maintain. Webster's Dictionary, p. 993. Dewey appears to be ambivalent on this question. He expresses two views in two different publications written about the same time. In one, he 
says that "the maxim that 'the end justifies the means' is basically the same as the notion of ends-in-themselves . . . for only the conception that certain things are ends-in-themselves can warrant the belief that the relation of ends-means is unilateral, proceeding exclusively from ends to means. Theory of valuation, p. 42. In the other publication, Dewey says that "Means used determine the end actually reached. The end justifies the means only when the means used are such as actually bring about the desired and desirable end." "The Economic Basis of the New Society," in Intelligence in the Modern World, ed. by Ratner, p. 432. This latter statement is precisely the position taken by this writer.

${ }^{36}$ The idea that some ends are alternative because they are incongruent with other competing ends-in-view follows deductively from the assumption of incongruity.

${ }^{37}$ Dewey, Theory of Valuation, pp. 26, 43, 49. Ayres, Theory of Economic Progress, p. 224.

${ }^{38}$ Dewey, Theory of Valuation, p. 43.

${ }^{39}$ The example is consistent with the theory that an established trend in land use toward uses which render higher returns to owners (E.g., from commercial to industrial will continue). R. E. Park and E. W. Burgess, The City (Chicago: Chicago University Press, 1926). Homer Hoyt, The Structure and Growth of Residential Neighborhoods in American Cities, (Washington, D.C.: U. S. Government Printing Office, 1939). Lloyd Rodwin, "The Theory of Residential Growth and Structure," The Appraisal Journal, XVIII (Ju1y, 1950), 295-317. William G. Grigsby, Housing Markets and Public Policy, (Philadelphia: University of Pennsylvania Press, 1963).

${ }^{40}$ Grigsby, Housing Markets, pp. 1, 103-110.

41 Reginald R. Isaacs, "The Dynamics of Urban Renewal," in How to Manage an Urbanized World, Vol. II of Taming Megalopolis, 2 vols, ed. by Eldredge Wentworth, (Garden City: Doubleday \& Co., Inc., 1967), pp. 787-88. Alan Black, "The Comprehensive Plan," in Principles and Practice of Urban Planning, 4 th ed., ed. by William I. Goodman and Eric C. Freund (Washington, D. C.: International City Managers Association, 1968), pp. 349-78.

42 Dewey, Theory of Valuation, p. 50. Ayres, Theory of Economic Progress, pp. 224-30. El1u1, Technological Society, pp. vi, 19-21. 
CHAPTER IV

CEREMONIALISM AND THE URBAN PAST

The second chapter defined institutions in terms of their essential character and the third chapter described a temporal setting in which institutions exist. This chapter will examine the operation of institutions in the setting described in Chapter III. It is first useful to recall the central ideas from the first three chapters. The definition arising from the examination of institutions in the second chapter is:

An institution is an organized social group which has evolved from and is united with some particular system of cultural values, and it serves through processes of social control to stabilize social interaction by preserving and perpetuating those cultural values in the society of which the institution is a part.

The stress here is on cultural values, ways of knowing and doing regarding all manner of social interaction.

The temporal setting of institutions which was described in Chapter III is an ends-means continuum; a continuum of on-going life processes; a setting for human choices. It was found that the continuum consists of a past, a present, and a future. It was argued that all that exists in the present is the effects of prior causes, and that those same effects are the means available in the present to the attainment of ends which lie in the future along the continuum. It was likewise argued that ends are alternative because available means are limited and because some ends are incongruous so that not all competing 
ends-in-view are attainable. Finally, it was argued that ends are not ends-in-themselves. Once they have been attained, ends become means to on-going ends which lie farther in the future along the continuum. Human choices involve the selection of ends-to-be-reached from among ends-in-view, and the allocation of scarce means to the attainment of the chosen ends.

The question is, how do institutions operate in the temporal setting described in Chapter III? An answer to that question is attempted in this and the next chapter. The central idea in these chapters is that institutions achieve social stability and perpetuate their underlying cultural values by influencing social choices, choices involving the selection of ends-to-be-reached from among competing ends-in-view, and choices concerning the allocation of means to the attainment of chosen ends. Moreover, institutional influences in social choices will be consistent with the cultural values out of which the institutions arise and which they are determined to preserve and perpetuate in service to social stability. How, then, do institutions exercise this influence in the temporal setting described in Chapter III?

Institutions discharge their social functions and influence social choices through the practice of ceremonialism. Ceremonialism is an institutional practice for perpetuating cultural values by conferring and reinforcing rank and social status. Ceremonialism is therefore the method by which institutions exercise social control, socialize initiates, and transmit culture, and thereby maintain social stability. Thus, any understanding of the way institutions operate in the temporal setting described in Chapter III comes down to an understanding of ceremonialism.

Reproduced with permission of the copyright owner. Further reproduction prohibited without permission. 
Ceremonialism can best be understood in terms of the attributes of institutions described in Chapter II. Thus, ceremonialism will be related in this chapter to the cultural values. This comes down to explain how ceremonialism is the social technique by which the urban present is related to the institutional past in terms of the ends-means continuum. Chapter $V$ will examine ceremonialism in terms of institutional structure, socialization, and social control. Finally, the operation of ceremonialism in social choices will be examined in the last part of Chapter V. The essence of Chapter $V$ is that ceremonialism is the chain which binds the urban future to the institutional past in terms of the temporal setting of cities described in Chapter III.

The main purpose of this chapter is to explain how the urban present is inextricably 1 inked by ceremonialism to the institutional past in terms of the ends-means continuum. The main ideas are: ceremonialism arises out of cultural beliefs which descend to the present out of the past. Moreover, ceremonialism is the transmission media of those same cultural beliefs. It recounts the ethos of ancestors in dramas, folk history, legends, and myths. Of course, the ancestors are dead and gone, and the cultural beliefs are therefore unalterably fixed. The cultural beliefs take the forms of taboos and totems--mores and traditional things and ways of knowing and doing. The totems and taboos possess a compelling mystique because of their linkages to the ancestors and the past. 1

The following parts of this chapter will examine more closely each of these aspects of ceremonialism and cultural beliefs. The first part will explore the transmission of cultural beliefs, followed in succession by the origin of cultural beliefs, totems, and taboos, and 
the mythical past, mystical justifications, ritual and role playing, and ceremonialism and law. Once again, the thrust of this chapter is the explication of ceremonialism as the chain which binds the urban present to the institutional past in respect to the temporal setting of cities. It is the agency for informing the present with prototypes of human interactions from the past. And insofar as those prototypes become models for present actions, they tend to reduce uncertainty and create social stability by regularizing social intercourse.

\section{THE TRANSMISSION OF CULTURAL BELIEFS}

One cannot know the true origins of cultural beliefs with perfect certainty. He can only say that they originated sometime in the past and that they were transmitted to the present through a variety of media involving language in some form. No doubt, the earliest method of transmission was oral tradition in which the beliefs were transmitted from generation to generation by way of folk legends and tribal myths. The legends were recalled from the memories of parents and conveyed to children in auspicious ceremonies commemorating particularly important events in the lives of ancestors and in the annals of the tribe.

The mystical ceremonies involved role-playing in everything from simple rituals to complex dramas that acted out in symbolic form the events commemorated by the ceremonies. The dialogues usually took the forms of lyrics and other poetic styles which were prescribed by custom, recalled from memory, and expressed in chants, songs, and spoken discourse. The oral expressions were experiences of the human mind recalling the ancestral and tribal events of the past so that they could be transmitted to others and the receptors might come to understand 
and believe the who, the what, the when, the how, and especially the why of the culture.

Written language evolved later to represent the spoken words, and in part to record and preserve the ancient ceremonies so that the cultural legacies of the past might be transmitted with greater fidelity to future generations. Written languages at first took the form of pictures or ideograms representing words, word fragments, or combinations of words in the spoken language. The modern Chinese written language is one comprised of characters which have evolved from ancient word pictures. However, character writing is tedious to learn and burdensome of memory. Thus alternatives evolved to simplify the written language. The Devangari script, in which Sanskrit and Hindi are written, evolved employing symbols to represent whole syllables with each syllable containing both consonants and vowels. The Phoenician script, from which the Greek alphabet developed, was of the syllabic-type employing only consonantz. The Greeks appropriated some of the Phoenician consonantal signs for which there were no Greek sounds to represent Greek vowel sounds. Thereby emerged a wholly phonetic alphabet that was quickly adapted to the uses of most of the Indo-European world.

From the archaic Indo-European languages evolved most of the modern languages. From Latin emerged the romance languages, Italian, French, Spanish, Portuguese, and Romanian. From the Indian and Sanskrit branched Hindustani, Bengali, and the whole range of middle Indian 1anguages. From the Balto-Slavic came Czech, Polish, Russian, Bulgarian, and Lithuanian. And from the Germanic evolved Swedish, Danish, German, Norwegian, Icelandic, Yiddish, Dutch, and modern English. ${ }^{2}$

Language emerged, first in oral expressions and later in written 
form, as an institution in concert with other institutions to help stabilize social interaction. Language augurs toward social stability by reducing the uncertainties of communication--by increasing the assurances of the speaker or writer that the information transmitted is the information received by the recipient, and the assurances of the receiver that the information received was the information transmitted by the speaker or writer. That is, language makes possible the receiving, decoding, recording, recalling, organizing, encoding, and the transmitting of information which could not be intelligently communicated without language. In short, language makes possible transactions or exchanges of a11 sorts between people--exchanges which would be impossible without language.

Early written languages arose from two dominant purposes--to account for commercial transactions and to record and transmit cultural beliefs by way of the folk legends and myths contained in and reinforced by the rituals and ceremonial liturgies of tribal societies. From this latter purpose flowed the great pieces of ancient writing which are extant today; the great Sanskrit texts of the Aryans, the Rg-Veda, the Upanishads, the Bagavad-Gita, the Tantas, and more; the non-Sanskrit texts of the Hindus, the Kabir, the Caitanya, and the Ramakrishna to name only a few; the Torah in the Hebrew texts of Judaism; the Sutras in many languages, containing the Dharmmas of the Buddha, Siddhartha Gautama. And from the Greek and Latin languages survive the enduring tragedies of Aeschylus, Sophocles, and Euripides as well as the comedies of Aristophanes; the epic poems of Homer and Horace, and the Tyrics of Virgil; the histories of Herodotus, Thucydides, and Tacitus, and the biographies of Plutarch; the great oratories of Demosthenes and Cicero;

Reproduced with permission of the copyright owner. Further reproduction prohibited without permission. 
the philosophical works of Plato, Aristotle, Lucretius, Epictetus, and Marcus Aurelius; and the Bible of Christendom. ${ }^{3}$

Upon these ancient works are founded most of the subsequent artistic and philosophic creations of Western Civilization. Examples are, of course, legion. The influence is so pervasive that space in this treatise does not permit an exhaustive development of the point. Nevertheless, one representative example may suffice to show the linkages between kernels of thought in ancient works and the influence of those $i$ deas in elaborations by subsequent artists, authors, and great thinkers.

The Last Supper, the magnificent surrealistic painting by the modern artist Salvadore Dali, hangs in the National Gallery of Art in Washington, D. C. A realistic painting of the same subject was completed by Leonardo da Vinci nearly 450 years earlier on a wall in the refectory at the monastery of Santa Maria della Grazie in Milan, Italy. One views the paintings with marvel at the superb craftsmanship of the artists and with awe at the inspirational messages they convey. The paintings stir deep and abiding emotions in the hearts of Christians who are reminded of the actions and words of Jesus Christ ai the beginning of the Christian era. 4

For in the night in which he was betrayed, he took bread; and when he had given thanks he brake it and gave it to his disciples, saying, take, eat, this is my body which is given for you; Do this in remembrance of me. Likewise, after supper, he took the cup; and when he had given thanks he gave it to them saying, Drink ye all of this; for this is my blood of the New Testament, which is shed for you and for many, for the remission of sins. Do this as oft as ye shal1 drink it, in remembrance of me. 5

History and ceremony record that Christ died upon a cross of crucifixion on the day following the last supper. The meaning of the 
events, the Last Supper and the crucifixion is that God made a sacrificial offering of Christ, his son, that mortal mankind might be redeemed of sins. In the words of one holy book:

All glory be to thee, Almighty God, our heavenly Father, for that thou, of thy tender mercy, didst give thine only Son, Jesus Christ, to suffer death upon the cross for our redemption; who made there (by his one oblation of himself once offered) a fuil, perfect, and sufficient sacrifice, oblation, and satisfaction, for the sins of the whole world. 6

The Holy Eucharist, the ceremony of the Last Supper, has descended to modern times as a sacrificial offering in expiation of trespass or atonement for sins. That is, an exchange takes place between a communicant and God through the intermediation of Jesus Christ in which the communicant gives up some material possession to the body of Christ, the Church, and God gives the communicant full remission of his sins. The entire event is celebrated by a feast in which a victim, Jesus Christ, is sacrificed on an altar to God. The slaughter of a victim symbolizes the just fate of the sinning communicant. God accepts the sacrifice and God and the communicants then consume the body and blood of the victim in commemoration of the event.

The Holy Eucharist, the most holy of all Christian ceremonies, is reenacted each Sunday and on other holy days in most Christian churches throughout the world. Worshipers, playing the roles of Christ's disciples, recite a creed of faith, make an offering--usually in cash-and confess their sins. After absolution in which the worshipers' sins are forgiven, a priest symbolically repeats the actions and words of Christ in consecrating and serving the bread and wine (the symbolic body and blood of Christ). Following a priestly oblation and invocation, the communicants receive and consume the body (the bread) and the blood 
(the wine) of Christ. The priest recites a prayer of thanksgiving and renders a benediction, and the communicants depart content in the belief that the ceremony of exchange has resulted in the complete and unequivocal remission of their sins, whatever they might have been. The ceremony serves to purge the communicants of debilitating feelings of guilt, while reinforcing their commitments to live, however imperfectly, by the teachings of Christ--that is, to play the roles of Christians within the institutional church.

The priests are of course reenacting a ceremony which was instituted by Christ for the Church founded in His name. However, Christ was simply reenacting a much more ancient ceremony--albeit that he endowed the ceremony with a very dramatic variation by placing himself in the role of Issac, Abraham's son, and making himself the immolation victim. Nevertheless, the idea of a sacrificial offering has a much more ancient lineage. For example, read of God instructing Moses approximately 1200 years before the Last Supper:

And the Lord spake unto Moses, saying, If a soul commit a trespass and sin through ignorance, in the holy things of the Lord, then he shall bring for his trespass unto the Lord a ram without blemish out of the flocks, with thy estimation by shekels of silver, after the shekel of the sanctuary, for a trespass offering. And he sha11 make amends for the Harm that he has done in the holy thing, and shall add the fifth part thereto, and give it unto the priest; and the priest sha11 make an atonement for him with the ram of the trespass offering, and it shall be forgiven him. 7

Or consider the actions of the Patriarch Abraham as he carries out the commandments of Yahweh on Mount Moriah nearly 2,000 years before the Last Supper.

And they came to the place which God had told him of; and Abraham built an altar there and laid the wood in order, and bound Isaac his son, and laid him on the altar upon the wood. And Abraham stretched forth his hand, and took the knife to

Reproduced with permission of the copyright owner. Further reproduction prohibited without permission. 
slay his son. And the angel of the Lord called unto him out of heaven and said, Abraham, Abraham; and he said, here am I. And the angel said lay not thine hand upon the lad, neither do thou anything unto him; for now I know that thou fearest God, seeing thou hast not withheld thy son, thine only son, from me. And Abraham lifted up his eyes and looked and behold, behind him a ram caught in a thicket by his horns; and Abraham went and took the ram, and offered him up for a burnt offering in the stead of his son. 8

The sacrificial offering has yet more ancient origins. Indeed, one can trace the practice to its ultimate origin only by speculation. However, reference is made to the sacrifice of victims for many purposes in the most ancient Sanscrit texts of the Aryans, the Indo-European ancestors of the Hindu, Greek, and Roman cultures. The practice was clearly widespread throughout the ancient world several millennia before Christ instituted it as the principal sacrament of His Church. ${ }^{9}$

Thus, ceremonies of sacrificial offerings as atonements for trespasses against cultural codes came into being sometime in the prehistorical era of man. The ceremonies were transmitted by celebrants down the generations of prehistoric man by the actions and oral recitations of chants, hymns, and other spoken discourse. As written languages emerged at the dawn of history, the chants, hymns, and prose of the ancient sacrificial ceremonies were recorded so that they might be transmitted to future generations with greater fidelity. The written texts became media for transmission of the idea of sacrificial offerings as means of atonement. And upon this kernel of thought is erected philosophies, institutions, impressive edifices of worship, codes of ethics, great works of art, and much more.

This is but one set of a boundless number of examples which might be cited to illustrate the point that the institutional practices of ceremonialism arise out of cultural beliefs which descend to the present 
out of the past. The cultural beliefs are transmitted in folk history, literature, works of art, holy symbols, ceremonies, legends, and myths which recount the pathos of ancestors and the ethos of the tribe. And the cultural beliefs inspire the production of art, literature, philosophy, and a myriad of other cultural vestiges, all of which are designed to perpetuate further the cultural beliefs by linking the temporal present to the institutional past.

\section{ORIGINS OF CULTURAL BELIEFS}

Although one cannot know with perfect assurance the ultimate origins of particular cultural beliefs, a notion of those origins can often be deduced from the texts and artifacts by which they were transmitted to the present. A careful examination of those remnants from the past has occupied archeologists, historians, anthropologists, and other scholars for many years. The results of that scholarship reveal much about the origins of certain cultural beliefs, and thus much about the ceremonialism which arises out of those beliefs. ${ }^{10}$

Many cultural beliefs are founded on faith out of the fear and awe of natural forces over which man has no apparent power. Those forces take two general forms--the fear of death and the awe of natural phenomena such as the annual seasons, rain and flood, volcanic eruptions, earthquakes, and the like. The cultural beliefs allay primitive fears by ascribing unexplained phenomena to supernatural forces and rationalizing them in terms of mystical causes. These mythical justifications invoke a spirit world of mystical potencies which act and react upon one another as though they were causally related in some natural way. Therefore, to the primitive mind, they could be 
beneficially manipulated in quasi-causal ways by ceremony and magical ritual. Ceremonial behavior involves just such ritualistic roleplaying according to the dictates of the ancient and traditional totems and taboos which descend to the present out of the past. 11

An early example of the social consequences of the fear of death was discovered in excavations at Chapelle aux Saints, France. The excavations revealed the imaginative thoughts of the primitive Mousterians (a subgroup of Homo neanderthalensis from the upper paleolithic period, ca. 100,000 to 50,000 years ago) regarding death and the needs of the deceased. Several skeletons were found in shallow graves dug into the cave floor. The dead were carefully interred, their heads sometimes resting on stone pillows. The graves were placed near the hearths so the deceased could be warmed by the fires. They were provided with tools and joints of meat, the better to serve their needs after their earthly lives ended.

The terrifying fact of death and its ravages shocked the Mousterians into unexpected and uneconomic directions of human thought. They could not accept the complete cessation of earthiy life, but vaguely imagined that life must somehow continue and that the dead would have need of the food and tools they buried with them. The Mousterians ceremonially tended the dead as an act of faith. Their faith in magical remedies was proportinnate to their perceived helplessness in the face of death. Objective judgments simply gave way to fear and hope and the Mousterians desperately grasped and accepted the nearest explanation at hand while ignoring any reason to believe there could be any other answer. In short, fear was the sire of faith. 12

These kinds of fears augur huge in the early formation and descent Reproduced with permission of the copyright owner. Further reproduction prohibited without permission. 
of the complex of cultural beliefs which survive in modern times. The font of those beliefs was the religion of the ancients. The domestic branch of the religion was founded in a fear of death not unlike that of the Mousterians. Indeed, the religion arose from prehistoric IndoEuropean traditions and traces of it are found in the ancient Aryans and Vedas of the Hindus as well as the classical writings of the Greeks and Romans.

Unable to accept the notion of the cessation of life at death, the ancients believed that the soul continued after death and that it must have a dwelling. Without a tomb, the sou 1 became a wandering spirit seeking the repose it deserved after the labor and anguish of life. It was believed that the untombed soul was disquieted, an evil spirit, delivering pestilence, famine, and disease upon its living descendants, admonishing them to give sepulture to itself and its physical remains.

Thus it was in pursuit of their own peace in life and the assurance of repose and happiness after death that the 1 iving performed the funeral ceremony. That is, their faithful service to the dead reinforced their own convictions that all would not end for them when they themselves died. Rather, their fastidious rituals assured the living that their souls would also continue after death and that their living descendants would perform the ceremonies which would provide the sustenance needed by their souls after death. This mythical belief was a powerful force compelling the living to ceremonially organize their lives to worship and serve their dead ancestors. The deceased ancestors, the manes whose feats were perpetuated among the living by ceremonialism, legends, and myths, were the family gods. The primitive religion of the ancients was a purely domestic institution.

Reproduced with permission of the copyright owner. Further reproduction prohibited without permission. 
Service to the dead, therefore, did not cease with the funeral ceremony. On the contrary, since the soul of the deceased survived death, it had need of food and drink and it was the duty of the living to satisfy that need. Supplying sustenance to the dead was an obligation not to be left to chance or the capricious sentiments of men. Every Greek and Roman household contained a totem, an altar upon which a few coals must always be burning. The fire was called Vesta by the Romans--Vesta, the goddess of the hearth.

The fire existed to warm the manes, the souls of the ancestors, who were buried nearby and to prepare the offerings which would sustain them. It was the sacred duty of the master of each house to maintain the fire without cessation. An extinguished hearth fire was taboo. The fire ceased to burn upon a family altar only when there was no one left to maintain it. An extinguished hearth meant an extinct family to the ancients. 13

The domestic religion of the ancients forbade two families to mingle. The particular religious practices of each family were sacred and unique. Thus each gens, or extended family, occupied its own canton, a family territory surrounding the sacred fire and its structure. This of course limited social intercourse so that the family was no doubt the sole form of society for many centuries. However, the restrictions imposed by the ancient religious beliefs were too narrow to allow families in the emerging civilization to cooperate in the amelioration of inter-gens disputes without bloodshed or in providing common security and material needs. ${ }^{14}$ It therefore became expedient for several families to join in another worship which was common to all of them. This was accomplished without sacrificing any part of the special religions of the 
constituent families. Indeed, it was essentially an expansion of the domestic religion beyond the family. However, it was based on the same precepts which undergirded the antecedent domestic religion of the ancients.

This eventuality led to the formation of what came to be known as a phratry in ancient Greece, and a curia in ancient Rome. It required some enlargement of preceding religious ideas. Members of the constituent families had to accept the common divinity, a divinity that was superior in some respects to those of the households. Once accepted, the worship was founded by the erection of an altar and the lighting of a sacred fire. Like the patron in the domestic worship, a curion presided at sacrifices for the curia. The worship was in all other respects 1 ike that at the domestic altars. It consisted of preparing a repast on the altar and consuming it in common, for the ancients believed that nourishment prepared and consumed in that way established a sacred bond between people which lasted until death. ${ }^{15}$

The tribe came into existence when several curies found it advantageous to join in common association. The tribe was constituted to be a separate society knowing no higher authority. Like the cury and phratry, the tribe was founded by the erection of an altar and the creation of unique divinities--usually men who were deified and called "heroes." The tribe had an annual feast day on which the entire tribe participated in a sacrifice presided over by a tribunus. The tribal worship was like that of the curies which made it up, identical in form to the domestic worships of the constituent households and based upon the same underlying notions. ${ }^{16}$

Finally, a civitus or city was established when two or more tribes Reproduced with permission of the copyright owner. Further reproduction prohibited without permission. 
found it expedient to organize on some common basis. The ancient city was at first a confederation which had to respect the religious beliefs and civil independence of the tribes and curias which made it up. Unlike modern cities which evolve from village to town and from town to city, the ancient city was created by the gods in a single day. Founding a city was a religious event involving the founding men and their gods.

For example, the city of Rome was founded by Romulus on the 21 st of Apri1---probably in the seventh century B. C.--an anniversary which is still celebrated by the residents of Rome. Of course, there were cantons populated by members of Latin and Etruscan tribes already established on and around the seven hills of what has come to be the City of Rome, for Rome was near the frontier between Latium and Etrusca. But a collection of curias and gentes from several different tribes in a common region does not a civitus make. In the modern vernacular, it lacked a corporate charter, and the charter could only be granted by the gods who would live in, protect, and assure the good fortunes of the city for its mortal citizens.

Romulus first consulted the gods for only they could say where the city should be. Being a Latin from the city of Alba, he consulted the gods by observing the flight of birds. The birds indicated that the gods meant Rome to be established on the Palatine. Romulus offered a sacrifice at the top of Palatine Hill. He and his companions built a fire of brushwood, and each man purified himself by jumping through the fire. Romulus then dug a small circular trench which he called mundus, meaning region of the manes. Into this trench he threw a clod of earth which he had carried with him from the city of Alba. Each of his

Reproduced with permission of the copyright owner. Further reproduction prohibited without permission. 
companions likewise cast bits of earth into the trench. Like Romulus, they had brought the earth from the cantons of their fathers.

The purpose of mundus was to bring the domestic gods from their native sepulchers and install them in a tomb at the new urbs. For it was a taboo that one must not desert his manes and the lesser gods, the lares and penates familiaris, and it would be hoped that those gods would not desert their descendants. With the gods properly entombed in their new location, Romulus built an altar and lit a sacred fire to what now were the lares compitalis and penates publici of Rome.

With his head veiled and wearing a white robe, Romulus traced the boundaries of the new urbs or place of civitus by plowing a furrow around it with a copper plowshare drawn by a white bull and a white cow. The furrow was interupted at places where gates (portae) would be installed, for the furrow was sacred and it was a sacrilege to cross it. Romulus' companions followed silently, throwing the clods turned up by the plow back into the enclosure so that none of the sacred earth would remain outside. Finally, a wall was built inside the sacred furrow, and several meters of earth were reserved along each side for religious purposes.

Just as the gens, the cury, and the tribe had its hearth and chief priest, so did the city. The chief priest of the ancient city was called king, and the position and title were inherited in proper patrician fashion by the eldest son upon demise of his father, the king. Worship at the public hearth fire was the basis of his dignity and power. Just as the patron was 211 at once the chief priest, inagistrate, and master of his family, so the king was also the political chief of the city. ${ }^{77}$

Reproduced with permission of the copyright owner. Further reproduction prohibited without permission. 
So pervasive were the powers of the primitive religion that it was many centuries of bloodshed and human anguish before the gods revealed the cury and the tribe to men that they might cooperate beyond their gentes in common interests. And it was doubtlessly many more centuries of bloodshed before the gods revealed how to establish civitus and found urbs at some place to the same end. The new social organizations gained currency then only when their founders in each case left the powers of the patrons undisturbed and emulated the traditional religious trappings and sacrificial offerings of their constituent gentes. That is, antecedent ceremonial behavior continued as before. Likewise, it constrained the new social organizations so that they possessed only the powers allowed to them by the former. Finally, the new social organizations took on and applied the antecedent ceremonial behavior.

The lives of the ancients were dominated by religious experience. Every action brought men into the presence of one or more gods. The gods prevailed at birth, at the sunrise and awakening, at each repast, at every going in and coming out, at and during repose, in war and peace, and at and after death. Indeed, the pantheon of domestic gods arose from the fear of death and a consequent preoccupation with the human soul--with god-in-man, or approximately what Christians think of as the Holy Ghost.

Many of the ancient beliefs about religious worship persist into modern times. The idea of an individual soul for each person is a well known example. The heroes of the ancient tribes are similar to the saints worshipped by some modern Christian denominations. One can find a column dedicated to the hero George Washington at Washington, D. C., a city named after the same hero. Likewise, that city contains temples to 
other national heroes--Thomas Jefferson, Abraham Lincoln, and the unknown soldier to name a few. And how many of the continuous states have cities named after those and other national heroes as well as other cities with streets, parks, and monuments likewise commemorating the national demigods.

The idea of worshipping an omnipotent God, albeit a single and universal god, rather than a pantheon of deceased ancestors, is a well established practice. The worship involves initiation, adoration, thanksgiving, invocation, sacrificial offerings, and the receiving of absolution and benediction in some order and form in most religious denominations. Some sects also hold tenaciously to other ancient, sacred forms. For example, it is a practice of orthodox Judaism to make a fire offering in which an altar fire must be perpetually burning, and a meat offering in which God is believed to consume His portion in the flame and the remainder is to be consumed by the priests and others involved in the worship. ${ }^{18}$ Such is the stuff of the modern institutional church, or synagogue, or mosque, or temple, or whatever.

The point is, that an enormously complex and powerful institutional system founded at least in part upon a human fear of death and other matters over which man has little or no known powers has evolved out of ancient and mostly intuitively validated beliefs. Those beliefs were transmitted to the present by ceremonial practices, and the institutions which have grown out of those beliefs and practices will continue to perpetuate them into the future.

But more than that, those ancient religious beliefs founded as they were upon primitive fears of death, gave rise not just to religious institutions, but to a proliferation of other institutions which also survive in modern times. A further examination of the writings of the 
Greeks and Romans, civilizations from which Western Civilization traces its origins, reveals that the primitive religion established paternal authority, matrimony, private property rights, inheritance, and much more. After enlarging and extending the paternal family to the cury and tribe, that primitive religion exerted its powerfui influence in the formation of and dominion over the ancient city. All of the institutions of the ancient world evolved from it. And the ceremonial remnants of many of those institutions and laws persist into modern times.

\section{TOTEMS AND TABOOS}

The cultural beliefs, upon which ceremonialism are founded, take the forms of what anthropologists call totems and taboos. Totems are physical objects, trees, stones, altars, household objects, animals, etc., which are believed to possess mana, or supernatural powers or to be inhabited by a god or gods which possess such powers. Taboos are approximately analogous to mores as they have been defined elsewhere in this treatise. That is, they are traditionally or divinely prescribed and proscribed modes of behavior. Much of the preceding descriptions of both ancient and modern religious practices are, in fact, descriptions of totems and taboos. The altar, the physical materials of sacrificial offerings, the bread and wine of the Holy Eucharist, and all other socalled sacred materials are totems. Likewise, the prescribed worship ceremonies, as well as such admonitions as the Ten Commandments of the Judeo-Christian code, are taboos.

Much of that which is described in the remainder of this chapter and the next will be found to fit the description of totem or taboo. However, it is intructive to press further the illumination of ancient 
beliefs and their influence on the ceremonialism of modern institutions in terms of totems and taboos. 19

It is thought that the male-dominant household evolved from a distant antiquity. At a predatory and more barbarian stage of culture, women were seized from the vanquished enemy and prized as trophies of war. This gave rise to a form of ownership-marriage in which the male, who had acquired his female trophies by his predatory prowess, was head of the household. However it came to be, the households of ancient Greece and Rome were headed by their senior male menbers. ${ }^{20}$

The ceremonial behavior, the chants and prayers--in short, the taboos--which were part of the domestic religions of the ancients were a patrimony, a sacred tradition which members of the family were forbidden to disclose to persons outside the family. Those taboos were ceremonially passed from father to eldest son. In giving life to his son, a father also gave him the right to continue the ceremonies of the hearth fire, to make the sacrificial offerings, and to speak the sacred prayers. In this way, a mysterious and sacred bond was established between the infant son and all of the manes, lares, and penates, the ancestral gods of the family. The domestic religion was patriarchal, and the father of the household was the high priest, the pater familias who alone possessed the mana or mystical potency needed to carry on and to perpetuate the family worship.

As priest of the hearth fire, the father recognized no superior-not the city, not his officials, nor any other power could change his worship. He was the supreme chief of the domestic religion. He alone possessed the paternal mana to perform all of the ceremonies of the worship as he had seen his father perform them before him. He alone 
was responsible for the perpetuation of the family and its religion. It was his first concern, and from that concern stemmed all of his powers, powers which he shared with no one.

The father was master of the household as well as its magistrate and chief priest. According to the ancient taboos of patrimony, the father had the right to accept or reject a child at its birth. He could repudiate his wife either for sterility or adultery so that the family would become neither extinct nor debased. The wife had no such powers. The father had the right to give his daughters in marriage, and the right to sanctify the marriages of his sons. He had the power to emancipate or exclude a son from the family worship. And he had the right to adopt or to introduce a stranger into the domestic religion. Finally, at his death, he could name a guardian for his wife and children. In short, he had the powers--indeed, the duty--to do anything necessary to perpetuate the family and its domestic worship. ${ }^{21}$

While the powers of modern husbands and fathers are no longer as prodigious as those of the ancient world, it has been only during the last century that those traditional taboos have yielded in any substantial way to liberalizing influences in modern industrial countries. Indeed, husbands and fathers in some countries continue to wield the traditional powers little changed from those of antiquity. Moreover, it is still very much the case in the more liberal nations that the husband and father is the traditional, if only titular, head of the modern household. A wife continues to take her husband's surname, and that name becomes the surname of all acknowledged children sired by the man. When generic reference is made to the human race, it is called "mankind," not womankind. The male-dominant role, which was so 
soundly entrenched in antiquity and before, continues to be reinforced in modern societies in thousands of seemingly insignificant ways.

Many practices of the ancient religious taboos have been integrated into some modern ecclesiastical practices. For example, ordination is a ceremony for transmitting the mystical potency possessed by the bishop or patriarch to the novice priest so that the latter can execute his fatherly function of ceremonially feeding the children of the church. Moreover, this is a vocation of men for only men can possess paternal mana. It is believed that the bishop acquired his mystical powers from his own ordination in which the hands of a previously ordained bishop were laid upon him, and those hands were carrying on a lineage which originated with Jesus Christ Himself and was transmitted through Simon Peter, Christ's apostle and the first bishop of Rome. Only properly ordained priests possess the mana to carry on the worship. ${ }^{22}$ The modern worship ceremony continues to conform to many of the ancient paternal taboos.

The cultural heritage upon which the ceremonialism of paternity has descended out of the past is an ancient taboo based upon the religious beliefs of the ancients--a belief that was founded upon a fear of death. And the ceremonies of modern institutions continue to reinforce and perpetuate the ancient taboos.

\section{THE MYTHICAL PAST}

The totems and taboos possess a compelling mystique because of their linkage to the past. Linkage to the past necessarily means that the the totems and taboos are unalterably fixed because they are founded on the conquests of the ancestors, the legends about whom have become a part 
of the cultural heritage. The beliefs are unalterable because the ancestors are dead, their physical remains interred and their psychic presences resident only in the dramas, folk history, legends, and myths descended from the past. The myths tell it the way it was and one cannot change them. He can only accept on faith the totems and taboos as transmitted.

of course, one may reject and deny the cultural beliefs, but he must bear an enormous cost to do so. Rejection involves denial of the essential beliefs of the society of which one is a part. It consists of denying the myths, folk history, legends, literature, customs and law-in short the ceremonialism which binds together the institutional network of society. It is putting oneself obverse to the values held most sacred by his contemporaries. It is heresy, and it invites social sanctions which include everything from simple avoidance by family and friends to suffering death by fire at a stake erected by one's friends and neighbors.

As a matter of fact, almost everyone conforms in belief and behavior to the taboos and the proper use of totems. Moreover, they do so on the force of intuitive faith with little, if any, understanding of the origins of, the implicit character of, and the behavior called forth by the beliefs they hold. They do so in part because they are social creatures--an idea which is more fully developed later in the following chapter--and peer acceptance requires conforming beliefs and behavior. In short, most persons accept the totems and taboos on faith and on the nearly flawless logic that one's forefathers prospered and brought forth the present happy state of affairs by conducting their affairs in the ceremonially prescribed patterns. One should therefore emulate the ceremonialism of his forefathers if he is to perpetuate his euphoric state. ${ }^{23}$

Reproduced with permission of the copyright owner. Further reproduction prohibited without permission. 
For example, the traditional marriage ceremony descends little changed in character and meaning from that of the ancients. Modern brides and grooms conform to the taboos and the proper uses of totems according to the ancient ceremony. They do so on the strengths of their own faiths in social customs, and usually with no knowledge of the origins or meanings of the customs. They conform to the customs simply because that is the way everyone does things, and because they fear that their union may somehow be blighted if they fail to pay homage to tradition.

The modern marriage ceremony, conforming to tradition, is a sacred event which takes place before an altar. The bride wears a white gown and her head is covered with a veil. The father of the bride gives her to the groom. The ceremony proceeds with incantations, pledges, and prayers by and on behalf of the bride and groom. The bride takes the surname of her husband. The bride and groom light nuptial candles at or near the altar. They share a wedding cake in the presence of family and guests. And the groom carries the bride over their first threshold, taking care that her feet do not touch the threshold.

The modern marriage adheres remarkably to many of the ancient taboos even though some of the underiying beliefs have long been lost to antiquity. The ancient ceremony, like that of the modern ceremony, marks the advent of matrimony in the lives of the bride and groom. However, the institution of matrimony was inextricably related to the domestic religion of the ancients, and it was no doubt one of the first institutions to rise from those religious beliefs. The ancient wedding ceremony was an essential ingredient of the domestic religion for perpetuating the sacred hearth fire and the sacrificial offerings while avoiding intra-family marriage and inbreeding. Thus, each element of 
the ceremony had special meaning to the ancients.

In the ancient world a daughter took part from her birth in the religion of her father. Every day she invoked his sacred fire and offered it libations. His hearth fire was the altar of her gods. More was involved than simply passing from one household to another when a man from another family asked the daughter's hand in marriage. She must be released from the sacred fire of her father and thereafter invoke the gods of her husband, for it is a taboo that one person shall not worship before two different ancestral fires, before two sets of totems. Proper ceremonies were therefore instituted to formalize the binding of a man and a woman in matrimony--to emancipate her from her father's worship and adopt her into that of her husband.

A sacred ceremony of marriage, differing only in modest detail, was practiced throughout the ancient world. It began in the paternal dwelling of the bride. Surrounded by his family and in the presence of the bridegroom, the father of the bride offered a sacrifice at the conclusion of which he sacramentally declared that he gave his daughter to the bridegroom. She was thus severed from all attachments to her paternal hearth and she was free to adopt her new religion.

The bride was attired in white to proclaim her chastity. She wore a veil so that her presence did not offend the domestic gods of the groom before the groom could remove the cause of offense by making them her gods also. Properly attired, the bride was carried to the dwelling by her husband. However, she dared not enter the dwelling on her own accord for she had no right to do so. Her husband must seize her and take her by force into the presence of his gods. She had to resist-although perhaps not too vigorousiy--while her husband raised her in his 
arms and carried her over the threshold, taking care that her feet not touch the threshold, for the threshold was a sacred totem barring strangers from the hearth fire. The bride was sprinkled with lustral water in the presence of her new domestic divinity. Prayers were spoken as she touched Vesta, the sacred flame. Finally, she shared a cake with her husband in the presence of the hearth fire, placing herself in communion with her husband and his family, including the manes, lares, and penates of the family.

It is easy to understand that matrimony under such solemn circumstances must be monogamous. It involved much more than shallow affection or a simple sexual relationship. Husband and wife were united by the compelling bond of the same religious beliefs and by the worship of the same unique gods. But, more than that, the purpose of the union was to produce an acceptable male offspring who would continue the hearthfire and immolations necessary to the sustenance and tranquility of the gods. Those effects were so grave that men did not believe it possible to have more than one wife in each house. And for the same reasons, such marriages were dissolvable only under the most grave circumstances. ${ }^{24}$

The modern wedding ceremony demonstrates that the totems (the regalia and setting) and the taboos (the behavior of the participants) possess a compelling mystique because of their linkages to the past. The modern bride and groom are compelled by the mystique to conform in adornment and behavior to the ancient and unchanging customs. The mystique is compelling because of the couple's faith that adherence to the ancient myths and traditions will somehow bless their union with durability, success, and happiness. The faith is founded on the

Reproduced with permission of the copyright owner. Further reproduction prohibited without permission. 
conviction that the traditional ceremony was mysteriously instrumental in producing those qualities in the matrimonial unions of their ancestors--unions which, after all, produced the present bride and groom. Moreover, the strengths of their convictions are independent of any knowledge of the so-called pagan origins of the totems and taboos.

\section{MYSTICAL JUSTIFICATIONS}

The cultural beliefs which have descended from antiquity to the present are mystical justifications. They are rationalizations invoking a spirit world of mystical potencies which act and react upon one another as though they were causally related in nature. The spirit world is manipulated in quasi-causal ways by traditional rituals. It is thought that one can appeal through prayer, lamentations, and ceremony to omnipotent spirits to use their mystical powers to perpetuate a present euphoria or to cause and bring forth a particularly desirable future state of affairs. Moreover, when the desirable end is achieved, its achievement is attributed to the liturgy and ritual which invoked the spirits to employ their mystical powers on behalf of the ends sought by the mortal liturgists. Failure to achieve the desirable end is rationalized away as a sign from the spirits that the end was somehow unworthy or the means were inadequate. The gods have spoken either way and their mystical message justifies whatever outcome ensues. Likewise, it reinforces the faith of mortals in the mystical powers of their ceremonies--their totems and taboos. 25

For example, the ancient antecedent to the modern marriage ceremony was a supplication to the domestic gods to sanctify and bless the union of a man and woman for the purpose of producing another who would carry 
on the worship. As already noted, a daughter was incapable by reason of her sex to perpetuate the domestic worship. The ceremonies of sacrifice and offering must be performed by a son of the patron. Moreover, a son born of any other union was a bastard and was thereby unworthy of the domestic priesthood--just as Ishmael, son of Abraham and Hagar, was unworthy to sire the Jewish people because Hagar was only Abraham's concubine and the hand-servant of Sarah, Abraham's wedded wife. Rather, the tribes of Israel descended from Isaac, Abraham's son by Sarah, even though Isaac was born after Ishmael. ${ }^{26}$ The point is that the son who is fit to perpetuate the hearth fire and perform the sacrificial offerings must be born of the union sanctified by the gods in the wecting ceremony. of course, even a union sanctified through proper ceremony might fail to produce a male descendant eligible to continue the line. The greatest misfortune that could befall the domestic piety, the dead ancestors whose souls inhabited the hearth fire, was that its line of descendants might end. If this should happen, its fire would be extinguished and the entire ancestral line would pass into oblivion and endless misery. Therefore, a man discharged his debt to his ancestors and assured immortality for himself when his wife delivered him a son who could assume the paternal priesthood, tend the hearthfire, and make the sacrificial offerings.

For these reasons, the ancients believed that a man belonged to his family--not to himself. He was a link in the family chain which connected the ancestors to future descendants who would carry on the domestic worship, and the chain must not be broken by him. A taboo therefore prohibited celibacy. It also permitted--perhaps required-divorce if the wife were sterile. Likewise, it required that a brother 
or other relative be substituted in the husband's place if the latter were sterile, and that a childless widow marry her husband's nearest available relative. A son born of either of these unions was treated as the son of the original husband for purposes of carrying on the domestic worship. All else failing, one last chance to escape extinction was in a ceremony of adoption in which a young male, not the first son of the patron, was admitted to the sacred hearth and placed in communion with the family gods. The ceremony of adoption was a symbolic fiction, namely the ceremonial rebirth of the adoptee into a new 1 ife. ${ }^{27}$

These options to perpetuate the family worship in the face of an inconsummate or barren matrimonial union were more frequent that one might suppose. For example, Augustus (Gaius Octavious), the first emperor of Rome was the adopted son of his great-uncle, Julius Caesar. Moreover, Augustus failed to sire a son in three marriages. He divorced his first wife, Claudia, who was barren, and his second wife, Scribonia, who produced only a daughter. Finally, Augustus adopted his stepson, Tiberius, who was the son of his third wife, Livia, by her divorced husband, Tiberius Claudius Nero. Tiberius became the second emperor of Rome, succeeding Augustus, his father by adoption. ${ }^{28}$

A11 of those arrangements were means to perpetuating the domestic worship in ways suitable to the family gods. But none of the means were undertaken without sacrificial offerings and appropriate ceremonies appeasing the names and invoking the blessings of the läres and penates. It was the belief that a fruitful outcome could not be forthcoming without appealing to the mystical spirits to exert their omnipotence toward the ends sought by the appeliants, whether it be in a ceremony of marriage, divorce, adoption, or emancipation. And if the desired outcome 
was not forthcoming, then the spirits had somehow measured the outcome as unworthy or the means as inadequate. Like Augustus, who was thrice wed and twice divorced, and who finally acquired an heir by adoption, one must petition the gods by other means until they bring forth the desired outcome. But whatever the outcome, the cause is attributed to the mythical gods whose mystical powers were invoked by ceremony.

\section{RITUAL AND ROLE PLAYING}

Ceremonialism involves ritualistic role playing according to the dictates of the ancient taboos. The role attaches to a social position, and the role playing is the ceremonial behavior expected of one who occupies the position. The role, its social rationale, its powers, and its status and rank are prescribed by tradition. The legends and myths surrounding a role are the agents which prime social expectations regarding the role. And when one comes to occupy a social position, he is expected to play the role and perform the rituals required by the position. Moreover, he automatically acquires the status, rank, and powers--or lack of powers--associated with the position. Likewise, persons occupying reciprocal role-playing positions will respond to incumbents according to the same ancient taboos with deference to their own status and rank relative to that of the incumbent. The point is, the ceremonialism involved in role-playing is a make-believe or contrived situation based on mystical justifications descended from the ancient and mythical past. 29

Take, for example, the modern institution of private property. Few institutions have had such pervasive effects on Western Civilization. Private property is the basis of personal wealth. The creation, 
exchange, and preservation of private property and its rights occupy most human activities directly and indirectly most of the time. One's status, rank, and powers are very much affected by his position within the institution of private property--by how much and what kinds of property he and his principals own or do not own. And the role one is expected to play is likewise affected by his position in the institution of private property.

What is not generally understood is that the modern institution of private property is firmly rooted in the domestic religion of antiquity. While modern beliefs about private property depart significantly from those of the ancients, much of the ritual and role playing of the ancients has descended to the present and is evident in modern role expectations. It is therefore instructive to briefly examine the ancient origins of private property and the attending ritual.

A state of propinquity existed between the ancient family, its hearth, and its ancestors. When they established a hearth and buried their deceased members at some place, it was with the intention that the family should always remain there--not for the life of one man but for as long as descendants remained to feed its Vesta and to support its sacred flame by ceremonial offerings. The family was inextricably attached to the altar and the altar was attached to the soil under and around which the ancestors were buried. The concept of domicile followed quite naturally from those circumstances.

The hearth must be isolated from everything foreign to the domestic worship. The worship was an intimate family affair. It was a sacrilege for a stranger to be in sight of the altar when the family worship ceremonies were performed. Thus, a sacred enclosure surrounded the hearth. 
Likewise, no part of the sacred enclosure could be profaned by any other use. Structures could not be joined together. Each family must have its own free-standing dwelling much like the typical modern family dwelling. A family did not build for the lifetime of one man, but for the descendants who would succeed one another generation after generation. The idea of property was easily extended from the domicile and the family tomb to the land which surrounded them. If the family were to survive to carry on the domestic worship, then there must be resources at hand to provide the sustenance, the food, clothing, drink, and other means of livelihood to support the descendants who would repeat the worship ceremonies in future generations. Those means of lifelihood came from the soil. The contiguous lands were therefore a property of the domestic religion. The entire domain was under the watch of the household divinities who, when properly appeased with sacrifices, maintained a benign benevolence so that peace and bountiful harvests would prevail season by season.

The land comprising the domestic domain was bound by a band of sacred soil a few feet in width which was never touched and which was marked by totems or termini of large stones and tree trunks. On appointed days, the father of the family drove victims around his boundaries singing hymns and making sacrifices to his gods that they would continue to bless his properties with good fortune. No power on earth could displace the totem called terminus once it was established and maintained according to the required ceremonies. Indeed, one who overturned a terminus had committed a horrible sacrilege by disturbing a god, a totem, and encroaching upon another family's field. Expiation required immolation of the person responsible and any beasts involved with him.

Reproduced with permission of the copyright owner. Further reproduction prohibited without permission. 
Property was such a pervasive part of the domestic religion that a family could not abandon the former without renouncing the latter. Nor could a family be deprived of its property against the will of its patron. A man might be subjected to servitude to discharge his obligations, but his land could not be sold to the same end. His lands followed him into servitude, but he remained their proprietor. 30

Much about private property has obviously changed since antiquity. The concept of private property was intermingled with that of sovereignty during the medieval period, and it emerged during the Protestant Reformation in a much altered state. Indeed, the institution of private property has been in a more or less constant state of revolution from its beginning. The point stressed here, however, is its remarkable durability, and the property ritual and ceremony which have survived from antiquity.

The ritual expected of persons playing roles involving private property is remarkably unchanged from antiquity. When one becomes a property owner he is thought to have a mystical bond or relationship with the property. It is his to enjoy as he sees fit. Most units of private property are related somehow to domiciliary purposes, and most residential real properties contain free-standing dwellings occupied by single families. The real properties continue to be defined by boundaries marked by totems, or monuments. The owner no longer drives victims around his boundaries singing hymns and making sacrifices to his gods. However, it is still expected that a property owner know and preserve his properties, and, on appointed days, offer his sacrifice to the god of state by paying the taxes assessed on his properties. The state reciprocates by enforcing laws which preserve the owner's quiet use of the properties. And one who encroaches upon another person's 
property can be prosecuted for trespass or conversion. The modern property owner may now be deprived of his property under a variety of circumstances, but usually not without good reason, and only with due process of law in the United States. Finally, one's properties descend to heirs by testament or by process of statute if the owner expires intestate. If the owner dies intestate, the priority of claims by heirs is established in most jurisdictions according to the survivors' blood relationships to the deceased. 31

The modern institution of private property clearly involves ceremonial role playing in accord with many of the taboos which descend from the domestic religion of antiquity. The social rationale for the role, its mystical powers, and the status and rank of one who occupies a roleplaying position within the institution of private property are prescribed by custom and law. The law, legends, and myths surrounding the role of property owner create self-fulfilling expectations in the minds of persons involved with the institution of private property. Persons who occupy positions in the institution are expected to play the roles and perform the rituals attending the positions they occupy.

Literally everyone is involved in some way with the role playing and ritual of the institutional system in the societies of which they are parts. Most persons believe they are executing edicts of the gods or commissions of the state, or mandates of the people, or orders of some other abstract authority in situations that are natural or inevitable, or under the mystical powers of the spirits. In fact, the ceremonialism with which they play their roles is very real, but it is contrived by men. It is make-believe fabricated by men who allay their apprehensions by ascribing unexplained or unexplainable phenomena to supernatural forces 
and rationalizing them in terms of mystical causes. And the role playing employs the ceremonialism by which mortals attempt to manipulate the spirits in quasi-causal ways to perpetuate a tranquil state of affairs.

\section{CEREMONIALISM AND LAW}

The whole matter of institutional class, rank, and status has been obscured by the institution of the state which has codified cultural beliefs in the law. The law, whether it be constitutional, statutory, administrative, case, or common law, grows out of custom and traditional beliefs, and it reinforces those beliefs by placing the enforcement powers of the state behind them. Likewise, the law gives the customs embodied in the law an air of added permanence because it is often more bothersome to change a law to fit evolving changes in custom than to simply let custom evolve as it will. Moreover, the law often speaks with many tongues. There are, after a11, many diverse sources of custom and thus many conflicting customs. There are, therefore, many conflicting laws.

For example, the laws of the ancient city were nothing more than religious rites, prayers, and liturgical directions intermixed with legislative matters. The laws of succession and property were contained in rules for burial, sacrifice, and worship of the dead. In brief, they were simply the codification of prevailing religious beliefs. And those beliefs descended from the past in legends, myths, and folk histories. The laws of the ancients were immutable because they were the work of the gods. New laws might come into being, but the old laws remained even when they conflicted with the new ones. And all laws demanded the same respect.

Reproduced with permission of the copyright owner. Further reproduction prohibited without permission. 
The ancient law remained unencumbered by concerns about justice or equity. Its concern was religion and there was no need to go beyond that. Likewise, the ancient law was mute as to reason. It was above discussion. It was imposed by the gods and men obeyed the law because they saw themselves bound to their gods. The law was holy, and it was a sacrilege to break it. Where there was a common religion, there was a common law.

Legislation, as it is understood in the modern world, never existed among the ancients. The laws simply presented themselves without being sought. As much of the preceding part of this chapter attempts to demonstrate, the laws were the direct and necessary extension of beliefs. A fear of death, belief in the sacred hearth, and the passage of its stewardship from father to eldest son was ail that was necessary to erect the laws of the ancients. The legislator of the ancients was no man; it was the religious beliefs entertained by men. ${ }^{32}$

It seems that much has changed in modern law. Constitutions are enacted by conventions and changed in a variety of ways. Laws are passed as statutes by legislative assemblies. Regulations are written by administrative agencies. And case law pronounces judicial decisions dealing with interpretations of constitutions, statutes, and administrative regulations. Modern practice does not seem to rely upon revelation or law by the gods. Moreover, modern law seems preoccupied with questions of justice and equity.

On the other hand, one might ask by what medium is the law revealed to the legislator, the regulatory commissioner, and the judge? Have these learned persons conjured up their statutes, regulations, and decisions as exercises of sheer intellectual power? On the contrary, 
they have come to their professions usually with great learning in their fields of expertise--which is to say, they have been educated in the cultural beliefs of their societies. Many, if not most, are members of churches and synagogues which have had a hand in shaping their beliefs about right and wrong and about justice and equity. A1l have emerged from school systems bent upon shaping their beliefs in a common direction. And most have attended colleges and universities which have further refined their professional preconceptions about right, justice, and equity. The fact is that all come from a common cultural heritage, and it would be very unusual if the products of their enterprises departed in any significant way from their cultural preconceptions.

If one examines the laws which are products of the legislator, the administrator, and the judge, he finds that they depart as little as possible from antecedent customs. He will find that transgression against most of the commandments given to Moses by God on Mount Sinai are still classed as felonious crimes just as they have been down the intervening centuries. He will find that many statutes are simply the codification of the common law which descended from custom in Great Britain and was adopted in most of the states comprising the United States because the settlers who founded the country were predominantly of the British cultural heritage.

And if one asks from whence arises English common law he finds that the answer is: The common law is simply well-established cultural beliefs which have evolved from antecedent traditions, legends, and myths. Thus the common law contemplates the surviving remnants of the institutions which were founded in antiquity and which descended to the present out of ceremonial practices. The common law is concerned with the 
regulation of interhuman relations within that institutional framework. 33 Moreover, the notions of justice and equity in American jurisprudence as well as those of other nominally Christian nations are very much influenced by Christ's response when the Pharisees asked Him which was the greatest commandment. It may be recalled that Christ replied:

Thou shalt love the Lord thy God with all thy heart, and with a 71 thy soul, and with all thy mind. This is the first and great commandment. And the second is like unto it, thou shalt love thy neighbor as thyself. On these two commandments hang all the law and the prophets. 34

The first half of Christ's reply was in part an admonition to live by God's commandments. Those commandments comprise the law component of justice. The second part was an appeal for equity in justice.

Therefore, on closer examination, it appears that the essence, if not the substance, of modern law remains firmly grounded on godly revelations and that the legislator, the regulator, and the judge are as much the cultural or religious beliefs of modern man as they were of the ancients. It is in that sense that the institution of law raises ceremonialism to its ultimate as the instrument of institutional efficacy.

\section{SUMMARY}

The cultural basis of ceremonialism has been stressed at great length. This was done to soundly establish the point that ceremonialism, the principal technique of institutions in discharging their social functions, both rises out of beliefs which descend to the present out of the past and is a potent mechanism for the transmission of those beliefs. Ceremonialism was therefore found to be the social practice which links the present to the institutional past in terms of the ends-means continuum, the temporal setting of cities. The preceding parts of this

Reproduced with permission of the copyright owner. Further reproduction prohibited without permission. 
chapter cited a number of examples to illustrate and expand on these points. Each illustration selected an institution founded in antiquitylanguage, religion (and its influence on the gentes, cury, tribe, and city), patrimony, matrimony, adoption, private property, and law--and described how many of the ceremonial attributes of the ancient institutions have survived and continue in the ceremonial practices of the modern descendant of those ancient institutions.

In elaboration of these points, it was demonstrated how cultural beliefs are transmitted in folk history, legends, and myths. The legends recount the conquests of ancestors and the annals of the tribe. The beliefs are unalterably fixed because the events out of which they grew occurred in the past, and there is no way of changing accounts of actions which descend from the past.

The cultural beliefs take the form of taboos--mores or traditional and customary ways of knowing and doing. The taboos possess a compelling mystique of their linkage to the tribal past. And they are mystical justifications or rationalizations invoking a spirit world of supernatural powers which act and react upon one another as though they were causally related in some natural way. Those spiritual potencies are manipulated in quasi-causal ways by ceremony and magic ritual.

Finally, ceremonial behavior involves ritualistic role playing in contrived situations according to the dictates of totem and taboo. It is in these ways that ceremonialism is the yarn which knits the urban present with the fabric of antiquity. Ceremonialism informs the present with models of social interaction from the past. Such models augur toward social stability because they regularize present social interactions.

Reproduced with permission of the copyright owner. Further reproduction prohibited without permission. 
END NOTES, CHAPTER IV

${ }^{1}$ The exposition of ceremonial theory in this chapter follows that of C. E. Ayres, Theory of Economic Progress, pp. 155-76. Also see John Dewey, The Quest for Certainty, (New York: Minton Balch, 1929).

2"Language," Encyclopaedia Britannica, vo1. 10, pp. 642-62.

${ }^{3}$ Louis Renou, (ed.), Hinduism, (New York: Washington Square Press, Inc., 1963). Arthur Hertzberg, (ed.), Judaism, (New York: Washington Square Press, Inc., 1963). Richard A. Gard, (ed.), Buddhism, (New York: Washington Square Press, Inc., 1963). The Greek and Roman authors cited are all published in Great Books of the Western World, vols. 4-9, 12-15. The Holy Bible: Containing the 01d and New Testaments: Translated Out of The Original Tongues: And With The Former Transiations Diligently Compared and Revised, by His Majesty's Special Command. (New York: Thomas NeTson \& Sons, n.d.).

${ }^{4}$ Encyclopaedia Britannica, vol. III, p. 354 ; vol. 10, p. 814 .

${ }^{5}$ The Book of Common Prayer and Administration of the Sacraments and Other Rites and Ceremonies of the Church According to the Use of the Protestant Episcopal Church in the United States of America: Together With the Psalter or Psalms of David, (Greenwich: The Seabury Press, 1952), p. 80 . Underling was added by the author to stress certain points in the text.

6 Ibid.

7 Leviticus 5:14-16.

8 Genesis 22:9-13.

${ }^{9}$ Numa Denis Fustel deCoulanges, The Ancient City: A Study on Religion, Laws, and Institutions of Greece and Rome. (Garden City: Doubleday \& Co., Inc., (n.d.), pp. 25-33.

10 decoulanges has made an exhaustive and classic study of ancient literatures for the purpose of tracing ancient cultural beliefs from their origins to fruition in the ceremonialism of institutions. His work is published as The Ancient City. I shall rely on his scholarship as to the authenticity of those sources.

$11_{\text {Ayres, }}$ Theory of Economic Progress, p. $160 \mathrm{ff}$.

12 V. Gordon Childe, Man Makes Himself, (New York: New American Library, i951), pp. 50-5i.

Reproduced with permission of the copyright owner. Further reproduction prohibited without permission. 
13 deCoulanges, The Ancient City, pp. 15-40.

14 Ibid., pp. 110-16.

${ }^{15}$ Ibid., pp. 117-20. The Curion was known as a phratriarch in Greece.

16 Ibid.

17 Ibid., pp. 134-67.

18 Leviticus 6:8-18.

${ }^{19}$ Ayres, Theory of Economic Progress, pp. 164ff. ATso see:

Sigmund Freud, Totem and Taboo in The Basic Writings of Sigmund Freud, ed. by A. A. Bri17, (New York: Random House, Inc., 1938), pp. 807-920.

${ }^{20}$ Veblen, Theory of the Leisure Class, pp. 33-34.

${ }^{21}$ deCoulanges, The Ancient City, pp. 90-91.

22 Book of Common Prayer, pp. 536-48.

${ }^{23}$ Ayres, Theory of Economic Progress, pp. 167-69.

24 deCoulanges, The Ancient City, pp. 42-48. The Roman keeper of the threshold was Limentinus according to Varro. See James George Fraser, Folk-Lore in the 01d Testament: Studies in Comparative Religion, Legend and Law, abridged ed., (New York: Tudor PubTishing Co., 1923), p. 319.

${ }^{25}$ Ayres, Theory of Economic Progress, p. 168.

${ }^{26}$ Genes is $21: 9-14$.

27 deCoulanges, The Ancient City, pp. 48-56. Also see Fraser, Folk-Lore in the 01d Testament, pp. 216-17.

${ }^{28}$ Encyclopaedia Britannica, vol. 2, pp. 368-72.

${ }^{29}$ Ayres, Theory of Economic Progress, p. 156.

30 deCoulanges, The Ancient City, pp. 60-71.

${ }^{31}$ Maurice A. Unger, Real Estate, 5th ed., (Cincinnati: Southwestern Publishing Co., 1975), pp. 283-367.

32 deCoulanges, The Ancient City, pp. 186-93.

${ }^{33}$ Encyclopaedia Britannica, vol. 4, pp. 998-1005.

34 Mat thew 23:37-40.

Reproduced with permission of the copyright owner. Further reproduction prohibited without permission. 


\section{CHAPTER V}

\section{CEREMONIALISM AND URBAN CHOICES}

The preceding chapter related the institutional practice of ceremonialism to the ends-means continuum, the temporal setting of cities, by explaining the origins of urban ceremonialism. The chapter described how urban ceremonialism is founded upon cultural beliefs which descend to the present from the past. Likewise, it stressed the institutional function of transmitting culture and described how ceremonialism is the vehicle by which the institutional system carries out that function. This chapter examines ceremonialism in terms of other functions of institutions. In particular, it explains the relationships between ceremonialism and institutional structure, socialization, social control, and social stabilization. In these latter functions, ceremonialism is found to be the social mechanism which links the urban future to the institutional past in terms of the temporal setting of the city.

The main idea in this chapter is that ceremonialism links the future to the past in regard to the ends-means continuum by influencing choices made in the present of ends which lie in the future, and choices as to the ways of organizing present means to secure the chosen future ends. Ceremonialism will point to choices which tend to be least disruptive to institutional taboos. This follows since ceremonialism is the practice by which institutions maintain social stability. Likewise, ceremonialism will point toward choices which depart the least from customary and traditional ways--in other words, choices which adhere to institutionalized 
ways. This follows because ceremonialism arises from and is the institutional transmitter of the cultural beliefs which descend from the past. In this way, ceremonialism serves to extend the institutional past forever into the future along the ends-means continuum. And it is the continuity of a present and future enlightened by precedents from the past which tends to stabilize social interaction. ${ }^{1}$

\section{CEREMONIALISM AND INSTITUTIONAL STRUCTURE}

A latter part of Chapter IV described how ceremonial behavior involves role playing in social situations contrived in accordance with the ancient taboos. That is, roles and their reciprocal expectations are prescribed by customs which descend from the past. The phenomenon of role playing gives rise to and is the most visible evidence of institutional structure. Thus, the mores and the customary ways of knowing and doing operate through ceremony to structure society into institutional systems of class and rank. And one's status is evidenced by the mystical totems of rank--the physical symbols of rank. The resulting institutional system promotes social stability by creating a structure of social relationships within which persons may relate to one another.

It is thought that rank and status correspond to the technical competence of the persons to whom the rank is assigned. Such correspondence is a feature of the make-believe quality of ceremonialism. The distinctions of class and rank were contrived first and the positions accorded the status of class and rank were thereafter assumed to coincide with technical competence. That is, technical competence was assumed to exist so long as the position and its incumbent fulfilled the canons of ceremonial competence. And ceremonial competence or adequacy is judged, not 
by merit or technical adequacy, but by the ritual which extols the mana of rank and validates status.

\section{Institutional Structure}

An explanation of institutional structure was made in Chapter I, and it need not be repeated here. It needs only to be added that institutional structure arises from the ceremonial role playing carried on by persons in fulfillment of the cultural beliefs which descend from the past. The role playing involves reciprocal role relationships in which a ceremonial action elicits ceremonial responses from persons occupying reciprocal role positions. The responses are likewise consistent with traditional and customary practices in a solidly structured institutional system. The special nature and importance of ceremonial actions and responses is more fully developed later in this chapter.

Reciprocal role relationships imply class and rank. That is, each role pertains to an institutional position which relates in some way to other roles which likewise pertain to other institutional positions. The relative positions may be of the same or different classes--as between two corporate business executives in the institution of private enterprise, or between a corporate business executive and a minister in the institution of religion. And the relative positions may be of the same or different ranks within their respective classes. The preceding example probably illustrates positions of approximately equal rank within respective classes. Positions involving different ranks within their respective classes might be those of a corporate business executive and a production-line assembly man in the institution of private enterprise, or a production-line assemblyman in the institution of private enterprise 
and a minister in the institution of religion.

In fact, class and rank may be defined according to a great veriety of different criteria. In general, classes are thought to be related in a horizontal plane. Thus, class represents relationships between entities with dissimilar characteristics--as between federal, state, and local classes of governments; or between mercantile, industrial, financial, and service classes of business; or between classes of skilled trades such as carpenters, electricians, and plumbers.

On the other hand, rank connotes a vertical or scalar relationship. Thus, rank represents relationships between entities within a class--such as the population size relationships between cities; or the power relationships between officers in state governments; or the levels of skill within a trade, as with apprentice, journeyman, and master carpenters. It must be noted that there is also a vertical dimension to class in that certain social classes may enjoy greater or lesser prestige than other classes. For example, medical doctors as a class may enjoy greater social approbation than plumbers as a class, even though both classes are, in a sense, involved with plumbing.

Another example drawn from the history of the ancients illustrates the ceremonial nature of class, rank, and institutional structure. It is easy to see how inheritance came to be another institution in the social fabric of ancient Greece and Rome. Since the eldest son must continue the ceremonies of the hearth fire after the demise of his father, he must also inherit all of the properties and powers of his deceased father. And since the property could not be divided, only the eldest son inherited it. Nothing changed except the patron. The eldest son continued in his father's place following his father's demise. The inheritance principle

Reproduced with permission of the copyright owner. Further reproduction prohibited without permission. 
was one of primogeniture. The other offspring of the deceased father simply continued with unchanged status under a new chief priest.

The manner of perpetuating the family worship in cases of sterility were noted earlier. It need only be said that the succession passed collaterally to the next eldest son if the oldest son expired before marrying. On the other hand, the succession never passed to a daughter. However, a father could give his daughter in marriage with the requirement that her first-born son belonged to her father for purposes of continuing his domestic worship. ${ }^{2}$

The family, perhaps the earliest institution devised by man, took on special qualities in the ancient world. It is clear that only agnate relationships were important in matters of family, inheritance, and the like. Persons were related to one another who could trace their paternal lineage back to a common patron. Ho other relationship was important in what came to be known as the patrician society of Ancient Rome and the Eupatridae in ancient Greece. Matritineage had no standing whatever. That is, cognate and consanguine relationships which did not also involve the patrilineal feature of agnation were of no consequence in the ancient world.

The combination of agnation and primogeniture gave rise to a structure of family and extended family relationships in patrician society. Clearly, the family patrons were at the head of the structure. Each was master, magistrate, and chief priest of his family. And under the ancient taboos, a patron would sire as many sons as possible in order to increase the assurance that at least one descendant would survive to continue the domestic worship after he joined his manes. However, only the eldest surviving son would inherit the patrimony. While most daughters 
might be given in marriage, the unmarried daughters and other surviving sons remained in the family. The collected patrilineal descendants of the patriarch were known as the gens in Roman society. Families in ancient India and Greece were constituted in the same way.

It is probable that the gens were the only form of original society. Indeed, their members were the aristocracy of the ancient world. They were related by birth. They worshiped the same domestic gods. They could inherit from one another according to the rules of agnation. They had a common tomb, and they had a common family name. Moreover, since they all shared an undivided patrimony, it was necessary that the entire gens should answer for any of its members in matters of debt and wrongs committed against others. Likewise, the gens had to come to the aid of any of its members who were troubled by outsiders. Finally, scattered members of the gens assembled at their family shrine to make annual offerings to their manes, penates, and lares. ${ }^{3}$

of course, not all persons could call themselves patricius even though the ancient societies of which they were a part were patrician. That is, warfare, disease, crime, civil conflicts, and other such events served to extinguish some hearth fires and otherwise permanently separate persons from their domestic gods. There arose, therefore, at least three distinct classes of people in the ancient world who were not patrician members of gentes. Those classes were servants or slaves, clients and plebes.

Persons who knew no paternal hearth fire might enter into the service of a gens. That relationship may have been reciprocal on some basis of mutual need--the patron and his gens for personal and manual services for which the gens could afford to support an outsider, and the outsider 
for the material support and physical security he might receive from the gens in exchange for the services he rendered to it. More likely, the outside persons were trophies of martial conquest who became the slaves and concubines of the patrician members of the gens. However the union was initiated, the servant was in fact the slave of the patrician household because a voluntary servitude which might end at the will of the servant was not in accord with a society of families living in isolation. Moreover, the domestic religion had no toleration of strangers in the ancient family. Rather, the stranger must be initiated into the domestic worship by proper ceremony. Properly admitted, the servant shared in the family religion. He was protected by the family manes and hearth fire. He belonged to the paternal gods and they to him. He took part in the family festivals and worship ceremonies. And he was buried in the family tomb when he died. He lost freedom for himself and his descendants by acquiring a worship. The master, who was also his magistrate and priest, might raise the slave to a freedman or client, but the former slave became a retainer of the family and remained bound by the family worship to the gens and subject to its patron. ${ }^{4}$

Clients, many of whom were freed from slavery by their masters or were offspring of freedmen, were a class inferior to al1 paternal descendants in the gens. Like the slaves, they could not trace their lineage back to a patron no matter how far they might ascend in their genealogy. The meaning of this was that neither the client nor his descendants could inherit a patrimony or its properties, and they could never become proprietors. Indeed, the client possessed and used property and his personal belongings at the pleasure of the patron and subject to the patron's needs. Moreover, while the client took part in the domestic 
religion, sacrifices were offered for him. He could not offer them for himself even though he acknowledged the family gods as his gods and sought their blessings in all that he did. On the other hand, the gens reinforced its clients in their dealings outside the gens just as it reinforced its patrician members. 5

Finally, the lowest class of all was that of the plebes. The plebeians were, in a word, persons without a hearth. They possessed no domestic altars and could petition no family gods to deliver and preserve them in times of tribulation or to bless their transactions and interactions with good fortune. Thus, the plebeian had no extended family, no paternal authority over offspring, no sacred marriage, no right of property, no law, no justice, and no political rights. The plebeian and the patrician were as far apart as religion could place two men. The plebeians had no status in patrician society. They were a despised lot, beyond the veil of religion and thus of the family, society, and law. ${ }^{6}$ Hence, ancient society was rigidly structured in accordance with the taboos of the domestic religion. The patrons capped the structure with their priestly powers. The patrician members of the gens, the blood descendants of the patriarch, were next in rank to the patrons. The clients were $a$ class of free men who, possessing no paternal lineage of their own, worshiped at the hearth of a gens, a family which traced its agnate lineage back to a patron. The servants or slaves of the gens, differing from the clients only in their degree of freedom and servitude, were next in class to the lowest social class. Finally, plebes, who had no part whatever in the domestic religions of the ancients, were the lowest class--if indeed it can be said that they had any standing at all. Such were the institutions which evolved from the domestic religion 
of the ancients. The few institutions described to this point--language, religion, patrimony, matrimony, adoption, and emancipation, domicile and property, law, inheritance and primogeniture, family, patrician aristocracy, slavery, and clientship--were founded on the cultural beliefs of the domestic religion while that religion, a modicum of totems and taboos, was itself founded on a primitive fear of death. The institutions have prevailed--though substantially changed--and have descended out of the ancient past into the present. They have done so on the power of the mystical ceremonies which served to perpetuate the cultural values upon which they were founded. The ceremonies transmitted those values down the generations of descendants into the present, thereby linking the cultural past to the institutional present and future.

The point is that both class and rank are attributes of positions within institutional structures. Those positions rise out of the ceremonial role playing carried on by persons who are fulfilling role expectations created by cultural beliefs. And the cultural beliefs are traditional and customary ways of knowing and doing which were transmitted to present generations by legends, myths, and folk histories.

\section{Rank and Status}

Class and rank connote social status. That is, one who occupies a particular institutional position does so within a class and possesses the rank assigned to that position by the institutional system. The rank and class of the position confer social status on the person who occupies the position. His social status may be the same or higher or lower than the social statuses accorded other positions of different ranks or classes or both ranks and classes.

Reproduced with permission of the copyright owner. Further reproduction prohibited without permission. 
Status is evidenced by the mystical totems of class and rank--the physical and behavioral symbols of class and rank. The symbols are sometimes very discreet habits of speech, customary gestures, and the like. They are sometimes more conspicuous habits of dress, symbols of military rank, place of residence, and kind of automobile owned and operated. Two totems of prestige have persisted from the earliest times. They have taken the forms of conspicuous leisure and conspicuous consumption. The stress is upon the word "conspicuous," which is to say, periods of leisure and levels of consumption which are beyond the means of most people and which are indulged as symbols to others of the honorific status one enjoys by virtue of his class and rank; or more properly, his potency in conspicuously acquiring and consuming goods and services. 7

Modern social attitudes have been warped toward conspicuous leisure and consumption as means of ceremonial expressions by the legends, myths, and folk history which descend out of the past. The myths rise from a more primitive and more barbarian stage of human development--a stage characterized by a predatory life style in which honorific status was accorded to those who inflict injury by strategy or force. The hunterwarrior enjoyed the highest status in such societies because of a division of labor based upon physical strength and prowess. The hunterwarriors were always men because of their superior physical strength and because their strengths were never impaired by childbearing. However, men who were physically weak were not admitted to the exploitative class.

A11 women and men who were unfit for the predatory activities of the exploitative class were members of the drudging class. They were ceremonially barred from the barbarian exploitative class, and they were restricted to the drudging enterprises--activities which were victual, 
logistical, submissive, peacefur, and physical. This involved the industrial and manual vocations of agriculture, housekeeping, cooking, child rearing, weaving, handcrafts, porterage, etc. These activities were vulgar, demeaning, and undignified, and all members of the inferior class were engaged in them in some way.

Those men in the tribe who possessed the strength and prowess were ceremonially initiated into the hunter-warrior class. Their talents were restricted to exploitative enterprises--activities which were barbarian, violent, aggressive, animate, and spiritual. This involved the managerial and non-industrial vocations of governing the tribe, engaging other tribes in warfare, conducting religious ceremonies, and hunting. They were not permitted, even if they were so inclined, to engage in the drudging employments of the tribe. Members of the hunter-warrior class engaged in competitive sports any time they were not involved with other exploitative activities. All activities of the exploitative class were dignified, honorific, and invidious. Only members of the superior class were permitted to engage in the exploitative activities.

The exploitative vocations were social activities which made very little or no material contributions to the welfare of the tribe. On the contrary, with the possible exception of hunting, they all involved material drains on the tribe. They were activities which occupied manpower that might have been employed to increase the material welfare of the tribe. And that manpower occupied domiciles, ate food, wore garments, and demanded personal services, all of which had to be supplied by the drudging class. Moreover, the food they consumed, the garments they wore, and the domiciles they occupied were the best the tribe could supply. That is, they consumed goods conspicuously and their leisure time was 
taken with invidious and honorific games and ceremonies. 8

Many of the totems and taboos of the barbarian cultures have survived to modern times. Chiefs of state, governors, legislators, judges, generals, admirals, popes, bishops, chief executive officers of business corporations, and a host of lesser exploitative functionaries are the modern ceremonial descendants of the hunter-warriors of the barbarian stage of human development. They are modern members of the exploitative class. They occupy their leisure in invidious sports--tennis, golf, hunting, yachting, deep-sea fishing, skiing, etc. All that they do is dignified, honorific, and invidious. And, like their barbarian ceremonial ancestors, they are engaged in activities which make very little or no material contributions to the public welfare, while they receive the greatest economic rewards society can render. In a word, their consumption and leisure are conspicuous and their lifestyles set the mode for the drudging classes. ${ }^{9}$

There seems always to have been an overwhelming propensity for the vulgar classes to emulate those invidious activities of the superior classes which the former regarded as conveying honor and dignity. That is, one is thought to absorb mana and gain honorific status by doing those things which occupy persons of high social esteem. How else does one explain the modern hunting party in which three or four men and sometimes a woman or two spend several hundreds or thousands of dollars each to hazard injury or death from a myriad of probable accidents in traveling to and from and foraging about in the wilderness? They chance possible heart attack from over-exertion; collapse from dehydration, heat prostration, exposure or hypothermia; fall from unimproved trails over precipitous terrain; poisoning from reptiles, insects, toxic vegetation, and 
natural water pollution; and the stray bullets of other exuberant, careless, or drunken hunters. They hazard all of this to acquire a few rounds of game. It is obviously much less costly and dangerous under ordinary circumstances to purchase the same weight of U.S.D.A. choice beef from a local market if one is truly. after quality meat.

In fact, the hunters are only incidentally after the flesh of game. They are actually spending their leisure and their money in a conspicuous way. They are spending in a way which appears to be irrational when measured in a detached economic sense because the pecuniary costs of their expedition far exceed any material benefits they can hope to secure-even if the expedition is fortunate enough to achieve its most ambitious intent. Indeed, the hunters are seeking a benefit which cannot be easily measured in the mundane terms of the market place.

The hunters depart with their minds filled by the image of Ernest Hemmingway attired in a pith helmet and bush jacket, on safari over the grassy veldt below Kilimanjaro, and hunting for trophies for a lodge in Idaho or a plantation in Cuba. Or possibly they envision themselves as Theodore Roosevelt similarly attired, and hunting big game trophies in Africa for the wildlife collection of the Museum of Natural History in Washington. Or they see themselves as a party of hunter-warriors from a primitive culture setting forth with crude weapons into an uncertain wilderness to secure game to feed the tribe during the coming winter. Whatever the image, it is a phantasy etched vividly into their minds by myths and legends, and they are setting out to reenact the hunting exploits of those phantasies. If their expedition fulfills their phantasies, they will return to recall their exploits for friends so that the friends will know that the hunters possessed the means, the potency, to spend their 
leisure and money conspicuously in invidious activities out of which they could realize little or no material gain. In short, the benefit for which they are paying so handsomely is the personal satisfaction of flouting invidious symbols which validate their honorific status.

Hunting was selected to illustrate the ceremonial nature of conspicuous consumption because the actions of a hunter more closely resemble the predatory lifestyle of the lower barbarian cultures to which hunting is akin. In fact, one might as easily select any of the modern forms of participatory recreation--skiing, gambling, back-packing, golf, tennis, horseback riding, etc.--as well as some forms of spectator entertainment in which the reenactment of phantasies is accomplished for the spectator by surrogates. Whatever the form of conspicuous leisure and consumption, it is behavior in which the pecuniary cost is intended to greatly exceed any material benefit that might result for the participants, and in which the nonmaterial benefit is in its use as an invidious symbol of honorific status.

On the other hand, the supply side of recreation and entertainment has fostered profitable and expanding enterprises. There are highly organized (and drudging) institutions devoted to satisfying the demand for the growing numbers of people who are allocating more of their pecuniary means to conspicuous leisure and consumption. For example, hunting has led to the organization of local and national hunt and gun clubs, state fish and game commissions, national fish and wildlife services, as well as the commercial enterprises which manufacture and sell the totems, the hunting materials and equipment, required to engage in the sport. All are involved in some way with preserving and perpetuating the invidious sport--including the licensing and regulation of hunters, the creation and

Reproduced with permission of the copyright owner. Further reproduction prohibited without permission. 
management of hunting preserves, and the propagation of the game which is the ostensible object of the hunting expedition. All of this has emerged out of the propensities of the vulgar classes to emulate the invidious activities of the exploitative classes in the quest for honorific status.

Both conspicuous leisure and conspicuous consumption require substantial economic means. Both are therefore bound to the economic rewards accorded positions of class and rank within the institutional system. A consistency of institutional systems is that one must play the role expected of the position he occupies--that is, he must maintain the honorific status of the position by partaking of leisure and consuming at levels expected of one possessing his rank--and the economic rewards accorded the position are precisely the means required to play the role.

For example, one who has managed to enter a particularly favored social class and ascend to a high rank in that class will be rewarded by the institutional system with the economic means required to maintain himself in accordance with the canons of taste expected of his position. That is, one who was born into and reared as a member of a wealthy family and who manages to inherit a large quantity of productive wealth will possess sufficient income from that wealth to maintain the wealth almost in spite of himself. This is accomplished by the simple expedient of using some of the income to place the wealth under the stewardship of persons who are technically competent to manage it productively. Moreover, the remaining income is available and necessary to finance the conspicuous consumption required to fil1 the hours of conspicuous leisure required to fulfill the status expectations attaching to the class and rank enjoyed (or suffered) by the owner of the wealth.

Reproduced with permission of the copyright owner. Further reproduction prohibited without permission. 
The wealthy heir might be expected to possess a substantial amount of nonproductive property--nonproductive in the sense that it does not enter into the creation of money income, or the income created does not cover the cost to maintain it. For example, he might own a penthouse apartment in Manhatten, a bungalow and yacht in Bermuda, and a ski lodge at Jackson Hole. And he would need a Lear jet to travel between the three and wherever else he might choose to go. He would need automobiles in each location--a chauffeured 1 imousine in New York, a Ferrari in Bermuda, and a Land Rover at Jackson Hole. A small resident staff must be on hand at each location to maintain the properties and to cater the needs of the heir and his guests.

Likewise, the tycoon would devote most of his time to invidious forms of recreation. There would be skiing and hunting from Jackson Hole; yachting, deep-sea fishing, scuba diving, golf, tennis, and sun-bathing in Bermuda; and the theater, cocktail circuit, more golf, handbal1, and business arrangements in New York. To fill his spare time he might make gambling junkets to Monte Carlo and Las Vegas, hunting expeditions to Africa and India, pleasure cruises on the Mediterranean and Aegean Seas, and world tours to places not regularly visited in the course of his other activities.

On the other hand, one who suffers (or enjoys) a state of poverty because of class or rank or both, is sustained by economic rewards which comport with the status accorded him in the institutional system. He possesses very little personal wealth--perhaps only the clothing he and his family wear--and his only income is whatever he can obtain from the wages he can earn in unskilled classes of employment or from private charity and public welfare. There is no surplus for invidious recreation,

Reproduced with permission of the copyright owner. Further reproduction prohibited without permission. 
and his leisure is demeaning in the eyes of others. In both the case of the very wealthy and that of the poverty-stricken, the economic rewards accorded the institutional positions are precisely sufficient to play the roles expected of persons occupying the positions.

Choice of class and rank are not always elective. For example, both men and women are born into the unique and distinctive biological classes of male and female, and it is not usually possible for members of either class to change their memberships to the other classes. Moreover, one is born of particular parents with particular descendants and genetical compositions. These genetic qualities might be manipulated, but there is no presently known way to change them from one order to another. Likewise, one is born at a particular time in the ends-means continuum and at a particular geographical place, and he matures successively through infancy, childhood, adolescence, young adulthood, and aged adulthood. Finally, he expires at a particular geographical place and at a particular time in the continuum. While one may have some choices about this last personal event, he has practically no control over the rest. Each stage of biological development possesses different powers of rank and levels of status, and the direction of movement and the speed with which one passes from one stage to another is beyond his deliberate control.

Excepting cases like the foregoing biological classes and ranks, other barriers to social mobility are ceremonial and they are therefore a part of the institutional system. A rigidly structured institutional system very likely affords few or no opportunities for persons to improve their status by changing their social classes or institutional ranks. The class and rank system of ancient institutions aptly illustrates a 
rigidly structured institutional system.

The family arrangement of the ancients created a system of rank in the patrician family. It has already been stated that the patron held the highest rank and status. Below him in rank and status followed his sons in descending order by age, the eldest of whom held the highest rank next to his father by virtue of his eventual inheritance of the patrimony. After the patron's sons came his grandsons and great-grandsons followed by his brothers, nephews, grand-nephews, etc. in descending order according to their agnate relationships to the patron. The lowest in rank, if they could be said to possess any rank independent of that of their husbands, were the women of the gens, the wives and unmarried sisters, daughters, nieces, etc. of the patron. One entered the patrician class by chance of birth and his rank in the class was also unalterably set by the order of his birth.

Likewise, the class, rank, and status of all other members of ancient society were fixed by the same set of patrician relationships even though the other members were not born into patrician families. This was simply because the patrician class was the aristocracy of the ancient world, and all other social relationships were measured by patrician criteria. At any rate, three other classes existed in the society of the ancients. Their statuses were based upon class, and all three classes were inferior in status to the patrician class. In descending order of status, the three were clients, slaves, and plebes. Again, the status of each class depended upon the relationship of the class to the patrons. And a person became a member of one of the inferior classes either by birth or by calamity. It was possible for a plebe to become a servant or slave and to ascend to client. But there were only two ways 
to become a patrician: by being born the legitimate descendant of a patron or by adoption by a patron. 10

While these barriers to social mobility were very real, they were not created by the gods as the ancients thought. Rather, they were institutional arrangements created and perpetuated through ceremony and role playing by men. This is equally true of social barriers in the descendant institutions of the modern world. They, too, are institutional arrangements created and perpetuated through ceremony and role playing by mankind.

However, most modern societies do contain ceremonially regulated opportunities for their members to improve their social statuses by changing their classes or ranks or both. Insofar as persons achieve greater satisfaction from higher levels of social status, they are incentivated by ceremonial inducements to change toward positions of more favorable classes and higher ranks when the institutional system permits the changes.

The purpose of this portion of the chapter has been to illustrate how one who occupies a particular position in the institutional system enjoys the social status of the class and rank assigned to the position. Status is evident from the invidious symbols traditionally associated with the class and rank of the position, and the person occupying the position is expected to maintain the status of the position by employing the appropriate ceremonial symbols in his role playing.

\section{Rank and Technical Competence}

It is thought that rank and status correspond to the actual merit of the person to whom rank is attributed. Such correspondence is actually a contrived feature of ceremonialism. Distinctions of rank and status 
were established first and thereafter assumed to coincide with technical competence. The person possessing a rank within a class is assumed to possess the technical competence imputed to the position so long as he demonstrates ceremonial adequacy. And ceremonial adequacy is judged by the quality of ritual, not by the merit of the incumbent. The quality of ritual is judged by how closely the role played by the person conforms to the ideal role communicated to the present by tradition and custom. ${ }^{11}$

It is generally believed that rank and status are based upon the actual merit of the person who possesses them by virtue of institutional position. People believe that rank and status were derived from and emerged out of technical competence and meritorious capability, and that the latter were the first and sole criteria determining the former. This idea conjures up a notion that Elizabeth I was the Queen of England during her reign because she possessed the technical qualities most needed at that time--that she was the only person technically qualified to wear the crown and wield the authority of the emerging British Empire. At least she was the most qualified. That is, Elizabeth possessed the rank because she was technically competent.

However, the supposed correspondence between Elizabeth's rank and her merit is another contrivance of ceremonialism. The distinctions of rank and status were established first and were thereafter assumed to coincide with technical competence. The position of English monarch descended out of history to the time of Elizabeth I. It was a wellestablished institution in Great Britain long before Elizabeth was sired by Henry VIII. The office descended from the past and was thought to be a needed and effective institution because it existed. Existing, it had to be filled. Elizabeth ascended the throne simply because she was alive 
and next in line after her sister, Mary I, according to the ceremonial rules of succession, which forces the conclusion that she was fit and competent to reign over the empire because she did. This tempts a further conclusion--almost anyone might have done as well or better. History judges the reign of Elizabeth $I$ in terms of the outcomes supposed to have resulted from her rule. That is, the emergence of England as a formidable world power during and after the reign of Elizabeth is attributed in part to the mystical or royal powers of Elizabeth. Her powers were connected in some mysterious way to the ceremonies by which she received and maintained those powers and to the material objects, the totems, which were the physical evidences of her honorific rank and powers. For example, she was coronated as queen when the crown of England was placed on her head and the scepter and orb of the realm were placed into her hands. All of this was done with appropriate pomp and religious ceremony as with previous and subsequent English monarchs. Likewise, Elizabeth demonstrated ceremonial adequacy in her exercise of state powers in matters of royal court--the use of sword and incantations in elevating heroes and patriots to the peerage, placing the seal of state on treaties and royal decrees, issuing patents and papers of marque, receiving ambassadors from other countries, appointing ministers of state, worshiping in the church of England (which by then the monarch in England headed as we11), and a host of other ceremonial actions. The point is, that Elizabeth's merit and technical ability was judged by how adequate she was in ceremony. And her ceremonial adequacy was measured by how well her behavior conformed to the dictum of custom and the traditional beliefs. ${ }^{12}$

Taking another example, the position of patron, or curion, or

Reproduced with permission of the copyright owner. Further reproduction prohibited without permission. 
tribunus, or king was established first in the ancient world and whoever fulfilled the rubrics of agnation inherited the patrimony and was, ipso facto, technically competent to fill the position, assume the rank, and enjoy the status of the office. The question of technical competence simply never arose. The scion was qualified, according to the gods, solely by fortune of birth. Moreover, his merit was judged, if at all, by how meticulously he adhered to the traditional forms descended from his ancestors in performing the sacrificial offerings and pronouncing the liturgies which were his patrimony. Nothing else mattered. From his relationship to Vesta, the goddess of the hearth, and his paternal ancestors stemmed his powers as chief priest, magistrate, and ruler. ${ }^{13}$

This leaves open the whole question of whether the patron's hokus pokus performed any instrumental or technically redeeming services. It likewise leaves open the question of whether the patrician institutional system in which the patron was accorded such lofty status possessed sufficient redeeming qualities to justify either its initiation and emergence as a powerful force in the forging of Western Civilization, or its enduring longevity down through the generations of man. The fact that it did emerge and has had such prodigious influence on modern institutions is a necessary but not sufficient vindication of the system. One can counter that Western Civilization has somehow managed to evolve in spite of patrician institutional influences.

It is also true of modern institutional systems that the ceremonial distinctions of rank and status were established first and the person who has managed to come into rank is therefore assumed to possess technical competence. For example, so long as a person is more than thirty-four years of age, is a natural-born citizen of the United States, has resided 
within the United States for at least fourteen years, and can somehow convince enough people to vote for him in appropriate primary and general elections, he will become the President of the United States for four years unless he dies before his term expires. There is nothing in this list of qualifications about technical competence. ${ }^{14}$

It is, of course, implied that the people will judge the candidate's competence during the campaign, and that the most desirable--or, more likely, the least undesirable--man will miraculously emerge victorious after the votes have been counted. In fact, the electorate is not judging technical competence at a11. The voters are making their judgements on the basis of the institutional positions the candidate has occupied in the past (what marks of honorific status does the candidate possess?), what he says (do his remarks conform to the cultural beliefs?), and his demeanor (is he dignified or does his appearance otherwise conform to a ceremonially correct image of the office?). In short, the voters will judge his competence on the basis of his apparent ceremonial adequacy. And the misgivings of his detractors notwithstanding, the newly inaugurated president will, all at once, possess a charisma and mystical power which somehow escaped even his most ardent supporters before the election. This part of the chapter has attempted to show how the ceremony of role playing gives rise to an institutional structure of class and rank. While such structure is real, it is contrived. Likewise, the technical competence imputed to class and rank is a contrived feature of ceremonialism. Class and rank and the statuses associated with them evolved first from ancient beliefs, and technical merit was thereafter assumed to correspond to the institutional positions accorded the status of class and rank. Moreover, techniçal adequacy is assumed as long as the incumbent 
person in the position demonstrates ceremonial competence. And ceremonial competence is judged by the rituals of rank--not by merit. Finally, the institutional structure formed by ceremonial role-playing serves to stabilize society by providing a framework for social interaction.

\section{CEREMONIALISM AND SOCIALIZATION}

Ceremonialism, the functional technique of institutions, achieves socialization by conferring rank and status on persons. Socialization helps create social stability by matching persons to institutional roles. Rank and status are conferred within the institutional system according to how well one adheres to the mystical taboos. Ceremonialism can achieve socialization because of the relationship between human emotions-love, fear, frustration, anger, etc.--and the taboos. One gains in moral.stature by strict adherence to code or taboo. One absorbs mana or mystical potency in this way by contact with virtue--with totem. One suffers loss of personal integrity by the unceremonious exposure of transgressing a taboo. Such behavior diminishes mystical potency and one loses face by unvirtuous conduct. ${ }^{15}$

Socialization, a process by which a person is taught to adjust himself to the mores and folkways so that he can be a functioning member of his community, is achieved by the institutional system through ceremonialism. All institutions practice ceremonialism in the discharge of their socialization functions. Ceremonialism accomplishes socialization by conferring class, rank, and status on persons. That is, persons are psychologically conditioned by ceremony to accept role playing positions in the institutional system. They are taught by ceremony the taboos

Reproduced with permission of the copyright owner. Further reproduction prohibited without permission. 
relating to their positions, and they are advanced into those positions with ceremonies appropriate to the classes and ranks conferred by the system.

Recalling the explanation of socialization from the second chapter, it need only be emphasized that the process is carried on by ceremonialism. For example, it commences as soon as the infant wails acknowledgement that the midwife's unceremonious slaps to its backside have provoked breathing. The very next step is usually to ceremonially initiate the child's social existence by giving it a name and recording the name on whatever registry of births is required by law. The innocent and unknowing babe shall ever after be known by that name unless she elects and is able to change it.

In the first moments of life the infant has been ceremonially assigned to several social classes and ranks by the institutional system. If the infant is assumed to be a girl, her birth will most likely be recorded with a female name. She falls in the female class-not the male class. Her initial rank is set by the date and time of her birth. The birth registry will indicate that she is the daughter of her parents, and she is immediately assigned thereby to whatever racial and national classes distinguish them, and to their economic and social ranks. Her place of birth may determine her citizenship. These ceremonial vestitures will remain with her all her life, sometimes enhancing her social relationships, sometimes hindering them, but always ceremonially constraining her within the institutional system.

As the infant gains greater sensory awareness, she wi11 be initiated by awe-inspiring ceremonies into additional classes and ranks. And she will learn by ceremonial practice the behavior expected of her in al1 
manner of institutional situations involving her class and rank. If she lives a more or less normal life in most regions of the United States, she might expect to experience the initiation ceremonies of christening or baptism, registration and advancement in the church or synagogue school, registration and advancement in the Campfire girls, registration and advancement in the public school system, graduation from high school, registration and advancement in college, registration to vote, admission to a sorority, admission to sundry social clubs, college graduation, marriage, registration in social security, registering the births of her own children, licensing to operate a motor vehicle, contract recording, registering titles to properties, employment, court judgements, enrollment in Medicare, retirement, grandmotherhood, death, and burial. No matter of social significance, no change in rank or status, can happen to her without ceremonial acknowledgement.

Each of the foregoing initiation ceremonies will confer status upon her by assigning her to another class or rank in the institutional system. The psychological conditioning carried forth by ceremony will teach her the ceremonial role expectations for each class and rank into which she is advanced. And she will most likely do her best to fulfill those expectations in her role playing. The question is, why is she likely to do her best to fulfill the ceremonial role-expectations of the institutional positions in which she finds herself?

Ceremonialism achieves socialization because of the relationships between human emotions and the mores and folkways. Coupled with the unique intellectual qualities of the human mind, emotions make possible the psychological conditioning of people so that they adjust to the institutional taboos and play their roles accordingly. The range and

Reproduced with permission of the copyright owner. Further reproduction prohibited without permission. 
complexity of human emotions are extensive, and it is beyond the scope of this treatise to attempt a fully enlightened elaboration of them. However, four sets of human emotional situations will illustrate the point. Each set is marked by two polar states. The four sets are: love and hate, confidence and fear, satisfaction and frustration, and tranquility and anger. ${ }^{16}$ Love, which is a strong affection or attachment to another person or group of persons, is generally a pleasurable state that creates dependencies in which the person experiencing love treasures, seeks, and comes to rely on the loved persons both as objects for expressions of love and as reciprocators who reinforce the affections with 1 ike expressions. The affections which bind people together commence to develop in a person from birth. The affection matures during a long period of childhood development in which the child is dependent upon others--principally her parents in the institution of the family--for the satisfaction of most biological needs.

For example, the infant experiences physical discomfort from pangs of hunger. She cannot sleep, and the longer she must go without gratification of her desire for food, the more frustrated she feels. If action to ease the hunger pangs is delayed for some reason, the infant's frustration turns to anger and she cries out for someone to do something about it. When her mother feeds her, her anger fades and her frustration diminishes as her hunger is satisfied. She soon learns to connect the countenance of her mother with the pleasant physical sensations of ingesting milk and satisfying hunger. She comes to depend upon that relationship and each new feeding is another pleasant reinforcement of an emerging affection of the babe for her mother.

In like manner, the child learns to depend on her parents for other Reproduced with permission of the copyright owner. Further reproduction prohibited without permission. 
foods to satisfy her hunger, water to quench her thirst, clothing to protect her from the elements, a domicile to give physical security, a bed in which to satisfy her need for sleep, and physical contact with other persons to gratify her infantile and emerging sexuality.

Thus, affection for others arises initially from the states of confidence, satisfaction, and tranquility created by others in the family institution in meeting one's biological needs while she is in a state of nearly total dependency. Confidence is a pleasant state of full assurance and freedom from fear. Satisfaction is a state of contentment usually achieved when most of one's appetites have been gratified. And tranquility is a state of peace in which one is free from agitation. These states--confidence, satisfaction, and tranquility--are periods of pleasant existence because they are free from physical and emotional tensions. In short, love arises from states of pleasure induced by others. Once the infant associates the receiving of pleasure with the countenances of her immediate family, it is only a short time before she becomes receptive to other influences at their hands. After all, if they possess the power to induce such pleasures, what they think, say, and do is not just important. It is correct. The child therefore becomes receptive to learning from her parents. The learning takes place when the child seeks their praise and avoids their condemnation--when she accepts instruction from them and emulates their behaviors. The parents come thereby to have great power over their daughter and can reinforce certain kinds of behavior by inducing the pleasant states of confidence, satisfaction, and tranquility.

Likewise, the parents can deter other behavior by inducing the painful states of fear, frustration, and anger. These latter states are very 
important to socialization because they excite responses in a person which are useful in conditioning her to accept and play roles in the institutional system. Fear, which is an anxiety and agitation caused by the presence or possibility of an undesirable occurrence, can provoke one into action to forestall the undesirable occurrence Frustration, which is disappointment at failure to gratify desires, can provoke inquiry, introspection, and further action directed at securing satisfaction of the frustrated desires. Anger, which is an intense feeling excited by a real or supposed injury and accompanied by the desire to obtain retribution from the offending party, can provoke one to seek redress of unceremonious behavior.

Human emotional states, when joined with the unique capabilities of the human mind, make it possible for ceremonialism to condition persons psychologically to play their institutional roles correctly. The human intellect is uniquely capable of discovering complex relationships between past causes and present effects. And it can apply the knowledge of those relationships to employ the effects as means to the achievement of ends which lie in the future. Likewise, the human intellect has an equally unique capabiitty of visualizing complex and alternative states of possible future conditions. It can weigh the relative merits of those alternative future ends, select those which appear to be the most desirable to achieve within the means available, and organize the means to achieve the selected future ends.

The young child soon learns which parental responses connote approbation and cause pleasure and which ones mean disapprobation and cause pain. She likewise learns which of her actions precipitate parental approval and praise, and which ones initiate their disapproval and 
condemnation. Thus, she can discover and devise ways to play her role so as to accomplish the former and avoid the latter. That is, she can visualize ends for herself and she can measure their relative merits on the basis of their ceremonial adequacy or their inadequacy according to the cultural values she has learned within the family institution. She is most likely to choose that combination of ends which are within her means and which render the greatest confidence, satisfaction, and tranquility to her. The ends she chooses will, therefore, conform to the ceremonial expectations of the persons for whom she has the greatest affections.

The process of socialization which commenced in the institution of the family continues in every other institution in which the individual finds herself. She simply transfers and adapts the associations she has learned within the family to other institutions. The ceremonial personages of the father, mother, and the brothers and sisters are transferred to the priests and perishioners in the institution of the church; to the city officials and citizens of the city; to the teachers and students in schools; to the managers and workers on the job; and to herself and her husband and children in her own family.

Every other institution carries on the socialization process in the same general way. That is, the institutional system reinforces behavior which conforms to its ceremonial norms and condemns behavior which does not. One aspect of reinforcement involves the conferring of rank and status in the system according to how well one adheres to the mystical taboos. That is, one gains in moral stature by strictly adhering to code. She absorbs mystical potency and achieves confidence, satisfaction and tranquility in that way by contact with virtue. On the other hand, one 
suffers loss of moral stature and experiences fear and frustration by the transgression of a taboo. Such transgression diminishes mystical potency and one suffers loss of face.

The ultimate transference occurs as one substitutes the institution, its totems and taboos, its legends and myths, and its ceremonial vestitures for the persons who nurtured her to maturity and who were the first objects of her love. This occurs when one sees the institutional system as producing confidence, satisfaction, and tranquility. That is, one comes to love the institutional system because it augurs toward social stability in which adherence to institutional norms are perceived as reducing fear, frustration, and anger. When that happens, one wi11 make choices which conform to ceremonially correct institutional taboos.

Clearly, modern techniques for conferring rank and status are continuous with primitive techniques. The human infant of antiquity was as dependent upon her parents as are modern infants. The satisfaction of biological needs were as instrumental in engendering love of parents in the ancient child as in the modern. Likfwise, the influence of parents in the development and maturity of ceremonial beliefs in the ancient child were as great as in the modern. The institution of the family was as important in introducing the ancient child to ceremonialism, class, rank, and status as are modern families to their children. Moreover, while modern institutions may vary in substance from ancient institutions, they are similar in form and the same in essence. They achieve socialization by assigning class and conferring rank and status through ceremony. And socialization creates social stability by advancing persons to ceremonial roles in the institutional system from which they can interact with confidence and certainty.

Reproduced with permission of the copyright owner. Further reproduction prohibited without permission. 
CEREMONIALISM AND SOCIAL CONTROL

There is no clear line between socialization and social control in terms of ceremonialism. The two institutional functions converge on rank and status. Socialization views rank and status in terms of the ceremonies of investiture in which rank and status are conferred on a person as part of the institutional indoctrination process. Its purpose is to initiate persons into the institutional system by convincing them through ceremonies that the positions they occupy and the roles they will play in the system are ceremonially correct for them. It is a way of reducing social dissonance by harnessing individual human energies to the institutional structure or neutralizing them outside the structure.

On the other hand, social control looks to the maintenance of social stability by ceremonially reinforcing the status and rank of persons already established within the institutional system. This is accomplished by the periodic validation of status. Status is validated by the reciprocal acknowledgment of rank in appropriate places and at appropriate times. Such acknowledgment occurs in ceremonial exchange and in ceremonial gift giving. Such practices tend to stabilize a community by keeping its members bound in a network of reciprocal obligations according to their classes and statuses. ${ }^{17}$

\section{Ceremonial Exchange}

Ceremonial exchange is a process by which the statuses of the exchange parties are validated between them. The validation takes the form of mutual acknowledgment of class and rank. This may involve little more than an exchange of salutations which make the acknowledgments in some customary way. However, ceremonial exchange is by no means limited

Reproduced with permission of the copyright owner. Further reproduction prohibited without permission. 
to simple greetings. The more important exchanges acknowledge class and rank by the giving of totems of value and the receiving of other totems of value in exchange. Each party to the exchange occupies an institutional position and possesses the class and rank of his position. How he plays the role of his position in the exchange is prescribed in the law or by ceremonial custom as applied to his position and rank.

Ceremonial exchange facilitates social control by periodically reinforcing the rank and status structure of institutions. It does this by affording opportunities for one to experience acknowledgement of his own status by others and to acknowledge and therefore recall the ranks and statuses of others. It is an institutional feedback mechanism which helps maintain the system. It keeps persons united within a structure of reciprocal obligations. Ceremonial exchange is a practice of long standing, and it has been found to exist in primitive as well as advanced cultures.

The kula ring is a primitive example of ceremonial exchange. It took place among the Tobriand Islanders of Melanesia in the South Pacific. The natives inhabited islands comprising an atoll-1ike ring several hundred miles in circumference. The exchange involved necklaces made of red shells and bracelets made of white shells. The necklaces were exchanged for bracelets in one direction around the islands, and the bracelets were exchanged for necklaces in the opposite direction. Many of the kula totems had names and some had histories. The necklaces and bracelets were durable, but they were neither used as consumption goods nor as a media of exchange outside of the kula ring. Rather, they were used to maintain rank and prestige. ${ }^{18}$

The kula exchange operated over established trade routes and with Reproduced with permission of the copyright owner. Further reproduction prohibited without permission. 
fixed ceremonial patterns. Only a limited number of men could participate in the exchanges, and each man had trading partners on adjoining islands. The partnerships were permanent and they involved mutual trading obligations. The kula trader would travel by canoe to the island next to his in one direction where he would exchange bracelets for necklaces. When he traded with his partner in the opposite direction, he exchanged necklaces for bracelets. Every detail of the exchanges was regulated by custom and traditional taboos. Some exchanges were accompanied with extensive ritual.

Ordinary trading parties accompanied the kula expedition. The latter were involved in the exchange of consumption goods and in other commercial transactions. However, the two forms of activity never intermingled. The commercial trading was done by women and other drudging persons of inferior status. The men involved in the kula exchange never lowered themselves to commercial duties. They were men of invidious leisure. Likewise, they never admitted persons of inferior rank into the kula exchange. The exchange was entirely ceremonial and it served to validate the institutional statuses of the men involved.

The kula exchange validated status in part because of its exclusivity. Only men of the highest ranks were admitted to the ceremonies, and admission was one of the marks of rank. The process of bartering and exchange served to validate the status of trading members because each party to a transaction gave a totem of high value and received another totem of high value in exchange. The exchange was acknowledgement by each trading party of his own status as a giver of mystical potency and the status of the other party as a receiver of mystical potency. Since each party both gave and received mystical potency, the validation was 
completely reciprocal. The kula exchange served to stabilize social relations by binding its elites in a network of reciprocal obligations. The discharge of obligations in the kula exchange served as a veil, if not a reason, for social intercourse of a perhaps more instrumental nature. ${ }^{19}$ Certain aspects of modern commercial or economic exchanges are somewhat akin to ceremonial exchanges. For example, transactions in the common stocks of any of a number of widely held corporations smacks of ceremonial exchange. The investor/risk-bearer is accorded high status in most industrial societies--especially if he is at all successful in his investment strategies. One can attain the institutional rank and status of such a person by simply establishing an account with a stockbroker and by buying and selling stocks through that account.

The buying and selling of corporate securities involves so-called economic transactions in which the buyer places his buy order for a security with his stockbroker. The stockbroker transacts the order and delivers a totem, a receipt, which records the transaction. The investor gives the broker a piece of paper called a check, another totem, in exchange for the receipt. Of course, the receipt is only an interim totem to suffice until the big totem, the certificate of stock, arrives. The mystical potency of the totems exchanged attaches to the recipients in the exchange. ${ }^{20}$

It will be argued that the foregoing transaction was an important economic exchange and that it was one of many similar transactions which are important as a means of raising risk capital for an industrial system. Indeed, that may be true. However, one must seek further. What else has happened in the stock transaction? Clearly, the transaction has validated the status of the buyer as an investor/risk-bearer. Likewise, it 
has validated the statuses of the buying broker, the selling broker, the exchange specialist, the selling party, the corporation and its officers (involved in canceling the seller's stock certificate and issuing the buyer's stock certificate) and a myriad of other persons less directly associated with the transaction.

Moreover, one must inquire as to the true instrumental significance of the stock transaction. Will the economic value exchanged actualiy result in the creation of new capital goods? The answer is, not likely. In fact, in the vernacular of the kula exchange, the transaction simply shifted some ceremonial necklaces and bracelets about in a role-playing situation which had as its object the validation of status. The stock transaction, while very real, is hardly more than a ceremonial exchange, a game in prestige economics. While someone might gain wealth and someone might lose wealth from the transaction, their real gains and losses are in terms of ceremonial rank and status.

There are, of course, a great many other so-called economic transactions which contain traces of ceremonial exchange. The exchange of money as prices for consumer goods in retail markets validates the statuses of purchasers as consumers, vendors as purveyors of goods, and all others associated with the exchange in their own ways. The landlord's status is validated as well as that of the tenant when the latter pays his rent in exchange for his tenancy. Each acknowledges the class, rank, and status of himself and the other party in the transaction. The same is true of employer-employee relationships in which labor is exchanged for wages; government-citizen transactions in which tribute in form of taxes is paid to the state; etc. Each of these exchanges is part of an enormous institutional network of reciprocal obligations which serves to maintain 
unity in a community. And to that end, ceremonial exchange is an instrument of social control which operates to perpetuate social stability.

\section{Ceremonial Gift-Giving}

Another institutional practice of social control is ceremonial giftgiving. Like ceremonial exchange, ceremonial gift-giving is used to validate the statuses of the parties involved. Ceremonial gift-giving involves a donor who gives a gift to a recipient. The gift must be equal to the rank of the donor and appropriate to the rank of the recipient. The recipient is usually expected to reciprocate the gift-giving at some future time--although this may not be the case if the recipient is of very low rank in relation to the rank of the donor. Ceremonial giftgiving validates the status of the donor by demonstrating his powers in giving a gift of value, and it validates the status of the recipient by the donor's acknowledgement of the recipient's rank in the value of the gift given. Ceremonial gift-giving reinforces institutional structure by tying the community together in a web of reciprocal obligations. ${ }^{21}$

A primitive example of ceremonial gift-giving is the potlatch of the Kwakiutl and Haida tribes and other American Indian cultures along the Northwest Pacific coast. The form of potlatch varied with the tribe, but the ceremony had certain general characteristics. The ceremony involved the distribution of gifts to validate social status. The larger and more valuable the gifts distributed, the higher the status of the donor. Likewise, the size of the potlatch gathering reflected the rank and status of the donor. Therefore, guests were invited from a wide territory, and the potlatch accompanied very generous hospitality and sumptuous feasting. Carefut formalities were observed in speechmaking and in the 
distribution of donor properties according to the ranks of recipients. ${ }^{22}$

The potlatch validated the status of the donor by demonstrating his potency in acquiring and giving great wealth. It validated the statuses of recipients because the values of gifts were determined by the ranks of the recipients. The higher the recipient rank, the more mystical potency his gift totems must possess.

of course, potlatch recipients were expected to give their own potlatches when they had accumulated enough properties to do the ceremony justice. It was expected that the recipients would give gifts at their own potlatches which were at least equivalent in mana to the totems they received. Thus, like ceremonial exchange, ceremonial gift-giving involved reciprocity. However, since recipients of low rank and inferior status received gifts of very little value, they rarely reciprocated with their own potlatches.

The potlatch sometimes involved competitive destruction of goods. The object was to validate the statuses of the tribes and their chiefs by demonstrating their capacities to destroy wealth as well as to give it away. The potlatch proceeded as with one involved solely with ceremonial gift-giving. However, the potlatch ended with a huge fire in which all of the donor's remaining properties were destroyed while the guests sat around the fire and watched them burn. Ceremonial destruction of goods was not a widespread practice. It seems to have been an aberration of the gift-giving potlatch.

Almost any event was occasion for a potlatch--marriages, births, and deaths, as well as very trivial matters. The potlatch was not to celebrate the event, but to validate the status of the donor. Therefore, potlatches were geared more to the economic capacity of the tribe than to 
whatever event served as the ostensible occasion to have one. The effect of a potlatch often was to impoverish the donor tribe. It thereafter became necessary for the tribal members to apply their industries to building up the tribal wealth in anticipation of their next potlatch. However, like ceremonial exchange, the potlatch served to unify the participant tribes into a network of mutual obligations. Those obligations no doubt led to other social intercourse of a less ceremonial nature.

The sacrificial offerings which characterized the domestic religion of the ancients were forms of ceremonial gift-giving--as well as forms of ceremonial exchange as with the trespass offerings of Judaism. The gifts were given as offerings to the ancestral gods through the intermediation of Vesta, the goddess of the hearth. Like the potlatch, the sacrificial offerings were feast occasions. However, unlike the potlatch, no guests were invited and no visitors were allowed. Only members of the gens participated in the feast. The sacrificial victim was a totem which acquired mystical potency as it was offered to the gods according to the patrician taboos. It became the meat of the communal feast which bound the members of the gens together and further bound them to their domestic deities. That is, the offering validated the statuses of gens members by acknowledging their kinship and it validated the statuses of the domestic gods in the same way. Finally, the gods were expected to reciprocate by protecting the gens and blessing it with plentitude in peace, and prevalence in adversity. ${ }^{23}$

Ceremonial gift-giving is not limited to primitive cultures. It is a much more widespread practice in so-called advanced cultures than is generally understood. Most of it is harmless enough--even useful in many cases. For example, small remembrances given at parties to 
commemorate birthdays, Christmases, weddings, and the like validate the statuses of both the donor and the recipient in the same sense as in the potlatch even though the gift-giving does not usually impoverish the donors. These modest celebrations usually take place between family members, very close friends, and business partners, and they serve to bind them together in reciprocal role situations within the institution of the family and the extended family. If the extended family is viewed as a worthy institution, then ceremonial gift-giving of the kinship sort ought to be encouraged.

However, the apparently harmless but useful practice of ceremonial gift-giving in the family institution should not blind one to other aspects of its social significance. The social significance of ceremonial gift-giving is in the validation of status and the tacit reciprocal obligations involved. While perhaps useful and relatively harmless within the family institution, these aspects of ceremonial gift-giving raise ethical questions when gift-giving takes place between certain other donors and recipients. Ethical questions arise with giftgiving when the gift involves charity or welfare and when it involves contract relationships and gifts between special-interest groups and agents of governments.

An act of private charity is generally applauded as being a very humanitarian and generous overture on the part of the donor. And, indeed, it may very well be. However, if examined in light of the social dynamics involved, the supposed generosity and humanitarianism might be viewed differently. Insofar as the action validates status, the donor is found to be reinforcing his own status as social superior by giving the gift while the recipient is seen as reinforcing his status as social 
inferior by accepting it. Moreover, the donor's supposed humanitarianism might, in fact, be personal avarice if he is allowed to deduct the cost of his charity from income for tax purposes. Finally, the reciprocity, if any, in this kind of gift-giving must be in the recipient's acceptance of the gift and his acknowledgment thereby of the donor's clearly superior rank and status. This can only be a demeaning experience for the recipient, albeit that he is remunerated for his charity in accepting the gift. Public welfare (that is, accepting income or goods and services from a government on the basis of one's poverty classification) is hardly better, and it might be worse than private charity when viewed in terms of the social dynamics of ceremonial gift-giving. The essential difference between the two is that the donor is a government rather than a private individual. Public welfare, as with private charity, validates the status of the donor as a social superior and the recipient as a social inferior. However, the donor governments act only through agents, and the superior status must attach to the visible persons of governments, to the agents which act for them. The class, rank, and institutional importance of this phenomenon for democratic government should be obvious. Of course, if one does not consider democratic government to be a redeemable feature of the modern world, then the foregoing aspect of public welfare may not be an issue.

Ethical questions arise on at least two other issues surrounding public welfare. The first has to do with the consequence of validating the status of recipients as socially inferior. One must keep in mind that the practice is mandated by the traditions of the hearth fire, the primitive potlatch, and a host of other taboos which have descended in one form or another from prehistoric times. That is, the social control 
powers of ceremonial gift-giving are institutionalized cultural beliefs which are unlikely to change perceptively from generation to generation, whether or not they are socially congruent beliefs. Thus, simply declaring that accepting public welfare because one is poverty-stricken is not demeaning, will not change the cultural beliefs which have descended from antiquity and are so firmly integrated into the institutional system. And those beliefs declare that one who accepts a gift which exceeds his powers and his intentions to reciprocate validates his status as a social inferior. This is not just because others believe it, but because deep in his heart the welfare recipient believes it also. After a11, he accepted the welfare gift on the basis of his poverty in a society that accords high status to wealthy persons.

The problem becomes more pervasive as the welfare recipient comes to accept the inferior status validated by his acceptance of the welfare gift. Acceptance and adjustment to his inferior status will be reinforced each time he accepts another gift of pub1ic welfare. Each time it becomes easier for him to accept the inferior class and rank assigned to him by the institutional system. He will eventually play the role of that class and rank with little or no notion that it could or should be any different.

The second question has to do with the tacit reciprocal obligations of welfare gift recipients. The taboos of ceremonial gift-giving require that the recipient reciprocate in some way consistent with his status and that of the donor. The economic circumstances of the welfare gift recipient make it clear that reciprocation will not involve money or goods and services in the usual sense. Rather, reciprocation can take only one form. That form is political support for the agents of the 
governments tendering the welfare gifts. The conclusion follows that, in terms of the taboos of ceremonial gift-giving, public welfare is a way of purchasing votes in a democratic form of government, and a way of buying acquiescence to government policies in a totalitarian form.

The second classification of gift-giving which raises ethical questions is when the gifts are between certain contracting or potential contracting parties and between members of special-interest groups and the agents of governments. In the former group is the gift-giving between business executives and the union leaders who represent the interests of workers employed by the businesses and between business executives and the purchasing and contracting agents of governments. In the latter group is the gift-giving between members of special-interest groups and the legislative and regulative agents of governments.

Gift-giving of the foregoing sort might be considered as between social equals. Ethical questions therefore come down to the matter of reciprocity. The questions are: what are the tacit reciprocal obligations incurred when an official of the International Brotherhood of Electrical Workers accepts a gift from an electrical contractor whose electricians are members of the brotherhood? What are the tacit reciprocal obligations incurred when a contract administrator in the Department of Defense accepts a gift from a contractor whose contract he is administering? What are the tacit reciprocal obligations incurred when a member of the Labor and Public Welfare Committee of the United States Senate accepts a campaign gift from an officer of the AFL-CIO? What are the tacit reciprocal obligations when a member of the Security and Exchange Commission accepts a gift from a senior partner of a major brokerage fjum on the New York Stock Exchange?

Reproduced with permission of the copyright owner. Further reproduction prohibited without permission. 
It is difficult to see how the donor in each of these cases can have any interest beyond the recipient's tacit reciprocal obligations. And, the recipient's denials notwithstanding, he is almost certain to understand the meaning in his acceptance of the gift. Clearly, giftgiving under any of these and like circumstances raises the spectre of conflicts of interest and possible graft, extortion, and bribery when measured by the taboos of ceremonial gift-giving.

One might extrapolate the policy implications of the deductivelydrawn relationships described above into a great many possible scenarios. However, that moves the discourse beyond the bounds of this paper. Rather, the foregoing situations were described to illustrate the social control possibilities of ceremonial gift-giving. For good or bad, the practice maintains social stability by weaving members of a community into a fabric of reciprocal obligations based upon the ranks and statuses of the members within the institutional system.

\section{CEREMONIALISM AND SOCIAL CHOICES}

The time has come to complete the answer to the second question posed at the end of Chapter I--how do institutions function in the urban temporal setting? It is recalled that institutions were defined in Chapter II, and that the urban temporal setting was described in Chapter III. The present and preceding chapters (Chapters IV and V) proceeded on the premise that institutions discharge their functions of perpetuating cultural values and preserving social stability by influencing social choices. The choices concern which alternative and competing ends shall be achieved and how means shall be allocated to the attainment of the chosen ends. It was posited that institutions 
influence social choices through the practice of ceremonialism--an institutional practice of perpetuating cultural values and beliefs by conferring and reinforcing rank and social status within the institutional system.

This chapter and the preceding: chapter examined the workings of ceremonialism in the discharge of institutional functions. It was argued that ceremonialism is the method by which institutions transmit culture, structure society, socialize members, and exercise social control. Properly executed, these functions serve to discharge the institutional raison d'être--to perpetuate their own cultural values and thereby preserve stability in the larger community of which they are parts. The following four paragraphs summarize the expanded arguments of chapters IV and V.

Ceremonialism arises from the cultural beliefs which descend to the present from the past. Likewise, ceremonialism is the agent for transmitting the cultural beliefs. Ceremonialism recounts the legends and myths of ancestors in literature, drama, and folk history. The cultura? bel iefs are rigidly fixed because the ancestors are dead and buried, and there are no ways of changing the things they did and believed. The beliefs take the form of totems and taboos, or customary and traditional ways. The totems and taboos have an aura of mystique about them because of their linkage to the ancestral past. The beliefs are mythical justifications invoking a supernatural world of mystical potencies which are presumed to be causaliy related in some way. It is thought that these spirits can be manipulated in quasi-causal ways by ceremony to use their mystical powers on behalf of the living. The cultural beliefs tend to stabilize society by giving it precedents to guide human interaction. 
Thus, ceremonialism involves role-playing in social situations which are contrived from the ancient taboos. The taboos operate through ceremony in this way to structure society into institutional systems of class and rank. One's social status is communicated to others by his invidious behavior and by the physical and honorific symbols, the mystical totems, of the rank he possesses. Rank and status is assumed to correspond with technical competence. However, such correspondence is a creation of ceremonialism because the distinctions of class and rank were created first, and the technical reasons-to-be thereafter. Moreover, technical competence is assumed to exist as long as one occupying a position of class and rank demonstrates ceremonial competence. And ceremonial competence is judged by the quality of one's ritual, not by his technical merit. The institutional structure tends to stabilize society by providing a matrix of human relationships in which to carry on social interaction.

Ceremonialism discharges the socialization function of institutions by conferring rank and status on members of society. One is advanced in rank and status according to how well he adheres to the ancient taboos. Ceremonialism has power to accomplish socialization because of the relationship between human emotions and the taboos. One gains in moral standing and he absorbs mana by carefully adhering to the ceremonial taboos. He suffers loss of mana by the unvirtuous violation of a taboo. It is by means of socialization--the conferring of rank and status--that ceremonialism increases social harmony by assigning persons to roles in the institutional system from which they can interact with assurances. Likewise, ceremonialism is the institutional instrument of social control. Ceremonialism reinforces the rank and status of persons already 
within the institutional structure by the periodic validation of status. Status is validated by regular acknowledgments of rank in ceremonial exchanges and ceremonial gift-giving. Both practices involve giving totems of values appropriate to the ranks of the parties involved. And both practices involve reciprocity--immediate quid pro quo in ceremonial exchange, and an obligation for a future quid pro quo in ceremonial giftgiving. The validations of statuses in these ways tend to stabilize a community by occupying its members with a flurry of reciprocal obligations. Ceremonialism is, therefore, the instrument with which institutions perpetuate their own cultural values and maintain social stability. It follows, therefore, that the institutional influence, through ceremony, is applied in social choices to maintain the status quo according to the cultural values out of which the institutions arise. That is, ceremonialism is backward-looking and backward-clinging in terms of the ends-means continuum. Its great powers are exerted to select those ends and organize means to attain the ends which are consistent with institutional, or cultural values. Ceremonialism opposes choices which depart in even minor ways from the descended taboos. ${ }^{24}$ Indeed, the whole ceremonial thrust of culture transmission, socialization, and social control is toward a stable state, a state which is fixed, immobile, unchanging. The practical effect of a successful institutional influence on social choice is to perpetuate ancient customs, traditions, and taboos forever unchanged and unchanging into the future.

of course this has not happened. Institutions have changed. Some have receded or disappeared entirely, and new institutions have emerged to cope with new problems. Indeed, if anything is clear about institutions, it is their lack of continuity. All of the ancient institutions 
described in this and the preceding chapter have changed--many of them radically--between then and now, even though the essence of institutions has remained unchanged. This is a strange outcome in view of the functions of institutions. How is it that institutions which function so powerfully to perpetuate their underlying cultural values and thereby preserve social stability have at least partly failed to fulfill their functions? Why are modern industrial cities different from the cities of artiquity? And why is there instability and sometimes revolution in human societies?

Reproduced with permission of the copyright owner. Further reproduction prohibited without permission. 


\section{END NOTES, CHAPTER V}

${ }^{1}$ The theoretical propositions in this chapter follow the work of Ayres, Theory of Economic Progress, pp. 89-104, 155-76. It al so draws heavily from Veblen, Theory of the Leisure Class.

2 deCoulanges, The Ancient City, pp. 72-85. Fraser cites many cases of ultimogeniture in ancient and prehistoric cultures. However, he concludes that such cases tend to resolve themselves into primogeniture. Folk-Lore in the 01d Testament, pp. 172-204.

3 deCoulanges, The Ancient City, pp. 56-59, 110-16.

${ }^{4}$ Ibid., p. 115.

5 Ibid., pp. 224-29.

6 Ibid., pp. 229-34.

7 Veblen, Theory of the Leisure Class, pp. 60-80.

8 Ibid., pp. 60-87. Melville J. Herskovits, Economic Anthropology; The Economic Life of Primitive Peoples, (New York: W. W. Norton \& Co., Inc., 1965), 461-483, passim. Veb7en, Theory of the Leisure Class, pp. 21-33.

9 Vance Packard, The Status Seekers, (New York: D. McKay Co., 1959).

10 deCoulanges, The Ancient City, pp. 110-34.

${ }^{11}$ Ayres, Theory of Economic Progress, p. 160.

12 Encyclopaedia Britannica, vol. 6, pp. 726-29.

13 deCoulanges, The Ancient City, pp. 90-91, elsewhere, passim.

14 "Section 1, Article II, The Constitution of the United States," in Documents of American History, p. 143.

${ }^{15}$ Gunter W. Remmling and Robert C. Campbell, Basic Sociology; An Introduction to the Study of Sociology, (Totowa: Littlefield, Adams Co., Inc., 1970), pp. 283-95.

${ }^{16}$ Sigmund Freud, An Outline of Psychoanalysis, (New York: W. W. Norton and Co., Inc., 1949), pp. 13-33. Freud deals with the developmental aspect of his theory in terms of his well-known id, ego, and superego. A7 so see John Dewey, Human Nature and Conduct; An Introduction to Social Psychology, (New York: Random House, 1930). 
17 Remmling and Campbe11, Basic Sociology, pp. 94-107.

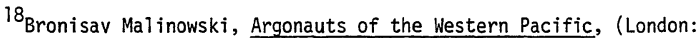
George Routledge \& Sons, Ltd., 1922), pp. 81-104.

19 Exclusion of the nonparticipants validated their statuses as well. Likewise, the commercial exchanges in which the nonparticipants were engaged validated their statuses.

${ }^{20}$ Encyclopedia Britannica, vol. 16, pp. 447-53.

${ }^{21}$ Herskovits, Economic Anthropology, pp. 155-56, 172-73.

${ }^{22}$ George P. Murdock, Rank and Potlatch Among the Haida, (New Haven: Yale University Press, 1936). Helen Codere, "Fighting with Property, a Study of Kwakiut1 Potiatching and Warfare, 1792-1930." Monographs of the American Ethnological Society XVIII (1950), 63, 90-91.

23 decoulanges, The Ancient City, pp. 15-40.

${ }^{24}$ Institutional attempts to preserve the status quo by ceremonially resisting changes in cultural beliefs and values is precisely analogous to the responses to new theories which threaten to supplant or significantly alter the prevailing paradigm of established members of a scientific community. Thomas Kuhn, The Structure of Scientific Revolutions, 2nd ed., (Chicago: University of Chicago Press, 1970), pp. 77-170. 


\section{CHAPTER VI}

\section{TECHNOLOGY}

The preceding two chapters related a theory of social relationships based upon ceremonialism, a practice by which institutions attempt to preserve social stability by perpetuating the cultural beliefs that underlie institutional values. Ceremonialism operates toward those goals by influencing social choices. Ceremonial influences admonish choices of future ends-to-be-reached which are in harmony with the ancient taboos that comprise the cultural beliefs. Moreover, ceremonialism points to methods of organizing present means to future ends in ways that are likewise consistent with the customary and traditional techniques. Ceremonialism is backward-looking and backward-clinging, and it resists anything that threatens to change traditional ways. The continuum effects of ceremonialism are to relate the past to the present and future and to extend the past forever into the future.

And yet it is clear that ceremonialism has not entirely succeeded in either preserving perfect social stability or perfectly perpetuating cultural values. Rather, society has been racked by revolution--sometimes violent and destructive conflagrations and sometimes slow and incremental changes, but a iways changes that undermine confidence in traditional ways of knowing and doing and that precipitate cultural change. Either way, the resulting changes are marked by social instability as people and institutions struggle to adjust to the new and revolutionary realities. The social instability occurs somehow despite institutional 
attempts through ceremonialism to preserve social tranquility.

In like manner, ceremonialism has not been entirely successful in perpetuating unchanged and unchanging cultural beliefs. While there are lingering ceremonial vestiges from antiquity, the present is not a carbon copy of the past. Times have changed, and conditions and methods have changed almost imperceptibly with them. People do not all believe precisely the things their ancestors believed. New institutions have evolved, some have gained greater social significance, others have receded in power, and some have disappeared altogether. The modern industrial city is not exactly like the feudal city. And neither the modern nor the feudal city is the same as the prehistorical folk communities which preceded them.

The question is, what has caused the changes? Why has social instability occurred even while powerful ceremonial forces were operating to preserve it? Why have cultural beliefs changed, and what has provoked institutional discontinuities? Why is the modern industrial city different from the feudal city, and why are the industrial and feudal cities different from the ancient folk villages? An answer to these questions is attempted in this and the next two chapters.

The principal idea in this and the following two chapters is that the innovation of new technologies causes instability in institutional environments because the new technologies organize means in ways that are different from the ceremonially approved methods of the past. New technology often changes even the ends selected to be achieved by bringing some ends within reach that were formerly beyond available means. And it opens opportunities for distributing goods and services in ways differing from the ceremonial past. Thus, the innovation of new 
technologies affords new avenues of social mobility by creating opportunities to change existing ceremonial systems of rank and social status. 1

This chapter will expand on certain crucial aspects of the foregoing ideas. The chapter seeks to discover what technology is. It will explore questions like: How is technology distinguished from and related to technique and human skills? The next chapter will ask from when does technology arise, and how does it come into being? How does it relate to ceremonialism, and how does it affect institutional systems? Finally, how is it related to the ends-means continuum, the continuum of on-going life processes?

\section{TECHNOLOGY AND TOOLS}

The first matter to be settled is the question, what is technology? Technology has been defined generally as applied science having commercial value, or as the practical or industrial arts. There are, of course, much more elaborate definitions, but they all resolve into something like part or all of the above. ${ }^{2}$ These definitions are deficient in several ways. First, they are too general and imprecise. They do not distinguish between human and material aspects of culture. Nor are they specific regarding important distinctive aspects of material culture. Second, the traditional definition of technology gives insufficient attention to the functional aspect of technology. Finally, the social context of technology is virtually ignored in the traditional definition.

The argument is made here that technology is that quality of a tool which enables it to be substituted for human effort in the creation of any good or service having human value. As will be shown, this definition is consistent with institutional economic theory which, alas, also 
does not precisely define technology. ${ }^{3}$ In pursuit of precision, then, it is useful to more carefully consider several components of this definition. For example, what is a tool? What is meant by a good? What does human effort mean in the context of this definition? The question of human value is considered in subsequent chapters.

\section{Tools and Goods}

There are a number of dictionary definitions for the word tool. The definition most suited to its meaning here is that a tool is an implement used by persons to work, shape, form, attach, etc. materials. Another word having close meaning is "machine." A machine is "a structure consisting of a framework and various fixed and moving parts, for doing some kind of work." Others have described a machine as consisting "of three essentially different parts, the motor mechanism, the transmitting mechanism, and finally the tool or working machine. "4 This latter description makes the tool the working part of a machine. On the other hand, the machine serves the tool. That is, its raison d'être is to energize and perhaps control the tool. Thus, any machine is merely an extension of the tool to which it gives power and control. For this reason, the word tool shall serve in this paper as short notation for "tool" in its restricted sense, for "machine" according to the foregoing logic, and for "capital good" is a final, productive, material, economic good other than land. This latter term, capital good, is more fully explained in the following paragraphs.

The preceding dictionary definition of the word tool is incomplete for purposes of this paper. To complete the definition, one must somehow rationalize the working of materials in terms of human purposes or reasons. 
A number of possible reasons come to mind--to occupy human time and energies with mental and physical activities; to destroy other materials; to wear out the tools; etc. Whatever reasons one might conceive, they all appear to resolve into one, and that is: materials are worked, shaped, formed, attached, etc. by tools for the purpose of creating or preserving other goods. And goods are simply material and immaterial things external to man that satisfy human wants.

The goods created by applying tools to materials may be either intermediate or final goods. Intermediate goods are of course not final goods. They are partially processed materials or sub-assemblies which will enter into and lose their identities in final goods. Intermediate goods include lumber that has been cut from trees but which has not yet been used to build urban housing, manufacture furniture, or any other final uses to which the lumber might be put. Intermediate goods also include sheet and tube steel and aluminum, agricultural fertilizer, vegetable and grain seeds, gasoline engines, transmissions, auto bodies, asphaltic cement, crushed rock, crude oil and every other partially processed good which will ultimately be used in some final good.

All final goods have reached the end of whatever processes have gone into their production. They have taken the forms in which they will be used by people. And all final goods are used up in rendering services to people. The services are of two general sorts, consumption services and production services. Final consumer goods include all household and some public properties--furniture, appliances, food, automobiles, clothing, jewelry, art objects, etc. Consumer items render services directiy to the people who use them for their personal comfort and satisfaction. on the other hand, final production goods render services to persons 
who are using the goods to produce both intermediate goods and other final goods of both the consumption and production sort. Final production goods are called capital goods or producers' durables in the national product accounts of most countries. Final production goods are tools within the meaning intended here. They are final goods because they have reached the end of the processes that created them, but they are used to process other goods--not to render personal services directly to the people who use them. The definition of the word tool then is: A tool is a capital good, a producer's durable good, or any implement or machine which is used by human producers to work materials in the creation of other goods and services having human value.

The kind of implement that usually comes to mind when the word tool is used is something held in the hand of a skilled craftsman who is using it to shape or join materials in the production or repair of things used by other people. The carpenter's saw, the plumber's pipe wrench, and the welder's torch are examples of this kind of tool. However, the word is not limited to the implements of a skilled craftsman. Any implement which is itself a final good and is used in the production or repair of other goods is a tool. Thus, a thermostat is a tool for regulating the heat of an industrial power plant or a blast furnace. A calculator is a tool to do mathematical computations. An assembly line is a tool which brings sub-assemblies together in a process that results in the creation of some product. The point is that many different kinds of items fit the description of a tool.

Moreover, tools are tools simply because they make it possible for people to manufacture and repair other things the accomplishment of which would be impossible, or at least very difficult, without tools. That is, 
tools embody technology because they do, by their very natures, reduce human effort in the creation of goods having human value. For example, how long might it take a sawyer to produce a properly shaped and sized wooden beam from a rough $\log$ without the use of a tool? Presumably, he could tear the log apart with his fingernails or his teeth. But it would take a very long time and the work would surely debilitate him in a short time. Rather, a sawyer is a sawyer because he uses a saw to cut wood. It is the technical qualities of his tools that distinguish the sawyer and that enable him to cut and shape wood.

Likewise, tools possess technical qualities which make them suitable for certain uses and unsuitable for other uses. A motor truck is instrumental in transporting its cargo over roads between its starting point and its destination. However, given the present state of automotive science, a motor truck is absolutely useless as a tool for measuring the amount of radiation emitted from a cathode tube. Some tools are also more efficient than other tools at performing the same kind of work. The sawyer can trim out his beam more quickly with a saw than with an adze. And he can do it even more quickly with a power saw than with a hand saw. The power saw therefore embodies greater technology because it enables the sawyer to produce more units of lumber per man-hour than he can produce with an adze or a hand saw.

Finally, tools are future-oriented. While tools are themselves the existential ends of means which were employed to create them in the past, they were produced in contemplation of future use. The sawyer's saw was the end product in a long and complex process commencing with the mining of iron ore and concluding with the shaping and filing of the teeth with which the saw will bite into wooden fibers. The ore was 
deliberately mined with the expectation that it would be smelted, refined, forged, and machined into things for human use. The latter stages of its production were undertaken with the intention of creating a tool for sawing wood. And this expectation was a human vision looking beyond the saw as an end product. It comprehended the existential end, the saw, as a means to on-going human ends. The saw was future-oriented even in its creation.

The future orientation of course extends to the use of tools. Tools are always brought into use for the purpose of creating states of affairs which do not obtain in the present. Just as the mining, smelting, and machine equipment produced a saw in contemplation of future use, so the saw now produces lumber in contemplation of future use. The timbers trimmed and shaped by the saw will be used as forms to shape concrete foundations, as beams, joists, sills, studs, caps, trusses, sheathing, siding, subfloor, door and window trim, base board, and many other components in residential, commercial, and industrial structures. Like all tools, the saw is employed to produce other goods having human value. In this context, use of the saw is future-oriented and it will be instrumental in bringing to fruition states of affairs which exist in the present only as human contemplation.

It is sometimes thought that materials should be included with tools in the definition of technology. Materials are physical substances which are or can be a constituent part of a good. A substance becomes a material in its use or contemplated use in a good. Thus, materials, like tools, are future-oriented. Likewise they do possess technical characteristics and they are used in the creation of goods having human value. However, materials fail to meet the technological criterion of tools for at least 
two reasons. The first reason is that, unlike tools, materials lose their identities in the goods of which they become parts. Whatever technical characteristics they possess are merged with those of the other materials in end products. That is, materials are intermediate goods--not final goods. And they are not used in their intermediate form to shape or attach other materials in the creation of other goods having human value.

The second reason materials fail to meet the technological criterion is that physical substances become materials only in some relationship to the tools with which they are extracted, refined, and combined with other materials to produce goods. That is, raw materials or resources are defined in terms of existing technology. For example, coal, crude oil, natural gas, and uranium all coexisted on earth with men for many centuries before the tools needed to use them came into existence. It was not until the discovery and innovation of coal technology that coal became a raw material. Likewise, it was not until petroleum technology had advanced substantially that crude oil could be refined into gasoline, engine oil, fuel oil, diesel oil, cleaning solvents, lubricating oil, bearing grease, asphaltic cement, plastics, and a host of other intermediate products. Petroleum technology is defined by the tools with which crude oil is extracted, refined, and used in all of its refined forms. Without the tools, crude oil would remain crude; a sticky substance that is more a hindrance than a help to mankind. The point is, that materials reflect only the technology of the tools that shape them.

The foregoing discussion leads by reduction to the conclusion that a tool is a finished good, a capital or producer's durable good, any implement or machine which is used by human producers to work materials in the creation of other goods having human value. Moreover, technology is that

Reproduced with permission of the copyright owner. Further reproduction prohibited without permission. 
quality of a tool which enables it to be substituted for human labors in the production of goods and services.

\section{Tools and Skill}

One often hears the term "labor productivity." The term represents a measure of industrial efficiency stated as "output-per-man-hour." The measure is calculated by dividing the market value of all final goods and services produced in an economy during some period of time (in other words, the gross national product) by the total man hours employed in the economy during that time. On the basis of output-per-man-hour, the American worker is said to be the most productive in the world. That is, the goods and services produced with each hour of American labor is greater than that produced by the labor of any other country.

The terms labor productivity and output-per-man-hour conjure up images of highly skilled men in industrial attire furiously manufacturing goods with crude tools powered by the brawn of their own sinewy biceps. The impression is that industrial efficiency is exclusively the product of the working man. His physical power, individual skill, and personal industry are solely responsible for the efficiency of the system. However, most economists and a good many other people know that the picture drawn above is far off the mark. It is true that these labor characteristics account at least in part for industrial efficiency. And it is true that the efficiency of an industrial system can validly be, and perhaps should be, measured as output-per-man-hour. However, these terms foster certain presuppositions which obscure the nature of industrial efficiency.

The fact is that the cognitive skills of the worker are neither inherited genetically--al though the capacity to learn them may be 
transmitted genetically--nor are they acquired in an environmental vacuum as an intellectual and manipulative tour de force. Rather, the cognitive skills of workers are derived from the tools they use. This is easily observed by contrasting the skills of two workers separated in time. The first is a tribes person in a hoe-culture during the early neolithic period, and the second is an American farmer in the modern, industrial age. Cultivation to the tribes person of the hoe-culture meant simply clearing and digging up a small patch of ground with a stick or hoe. Her motive power was the physical strength of her own body. She seeded the patch and left it to grow and ripen. Her seeds were those of indigenous grasses and other edible vegetation. She added no manure or other fertilizers. She used no insecticides, fungicides, herbicides, or pesticides, and she did not irrigate. At the end of the growing season she harvested whatever her patch produced. Her patch of ground was never fallowed. She cultivated the same plot each year. After a few seasons the soil was depleted and her yields declined. She simply cleared another patch and repeated her technique until that plot was also depleted. After she had exhausted the land near her hovel she simply moved elsewhere and began anew. 5

The technology of the early neolithic tribes person was very primitive. It consisted of her hoe. Her technical skill was in her ability to apply technique to her tool in the creation of goods. Technique is simply the procedure by which her tool--the hoe--was put into operation to perform the productive service for which it was designed. The tribes person's technical skill was, therefore, as rudimentary as her hoe was primitive. It consisted of her ability to manipulate the hoe in turning or stirring the soil sufficiently to create a suitable bed for her seeds.

Reproduced with permission of the copyright owner. Further reproduction prohibited without permission. 
And technique involved her judgments about when, where, and how to employ her hoe. Her skill was derived from her tool.

Likewise, the cognitive skills of the modern farmer are derived from his tools. The modern farmer cultivates his land, plants his seeds, and reaps his crops mechanically. Unlike the primitive farmer who had only her own physical strength as motive power, the modern farmer relies on the mechanical power of his tractor and other farm implements to do the work for him. He is able to increase his yields by using carefully prepared seeds of hybrid and blight-resistant crop strains. He uses engine-powered irrigation systems to protect his crops from the weather vagaries of nature; and he uses insecticides, fungicides, pesticides, and herbicides to protect against crop wastage by vermin, blight, and weeds, because of the chemical technology which supplies him with nitrogen, phosphorus, potash, lime, and trace elements to rebuild his soil.

The tools of the modern farmer are much more complex than the simple hoe of the neolithic farmer. The technique by which the modern farmer employs his tools in the productive functions for which they were designed is likewise much more complex. His technical skill, his ability to apply technique to his tools in the agricultural production of food and fiber, is commensurately greater than that of the neolithic farmer. The modern farmer must not only know how and when to operate his complex pieces of farming equipment, he must also know how to properly maintain them. The point is that his technical skill is concentrated on his tools and their use in producing goods. It follows that the tools are the sources of his technical skill, and his skill is the measure of his mastery of his tools.

To place this in better illumination, one might imagine that the Reproduced with permission of the copyright owner. Further reproduction prohibited without permission. 
mate of the neolithic farmer is all-at-once plucked out of his primitive enironment and is advanced to the present. He and the modern farmer are separated from their tools and all cultural symbols so that they stand bared before their examiners. The question explored by the examiners is: What are the visible differences between them?

If each man is a more-or-less average representative of his era, one difference will immediately stand out. The primitive man will be smaller in all or most of his physical dimensions. This is simply the result of differences in the nutritional and sanitation environments in which the two were raised; which is, incidentally, a technological factor. If the two are from the same racial stock, there will not likely be other physical differences. Each man will have the same external appendages and sensory organs, the same internal structure and functionary organs. Each man is homo sapiens and there will be no generic differences between them.

What is it then that distinguishes modern man from his primitive ancestor? It will surely be stated that modern man is "smarter," and that this will not appear as a physiological or anatomical difference. If, by "smarter," the meaning is that the average primitive man possesses less innate intelligence than his modern descendant, the evidence does not support the contention. ${ }^{6}$ On the other hand, if the meaning is that modern man possesses more acquired knowledge about himself and his environment, then one must agree. It is not that modern man has greater intellect than his ancestor, but that his intellect has been better developed.

The next question is: Why is the modern intellect better developed? The answer is blatant--because modern man has more tools and tools which are technologically superior to those of neolithic man. It can be 
countered that the reason is because modern man possesses more goods of all kinds. One can have no disagreement with this statement because it simply reinforces the original contention. To see this one need only inquire how the goods of modern man came into existence. The answer is that they were produced with tools employed by people. Thus the intellect of modern man is better developed because of the concentrated thought processes required of him to fully master the techniques for productively employing his tools. The skills of both neolithic and modern man are derived from tools. The essential difference between them is therefore the relative quantity and quality of their tools. The physical attributes of man remain essentially unchanged, but the properties and technical attributes of his tools have changed substantially over the centuries.

\section{Tools and Productivity}

The preceding section of this chapter commenced with a discussion of the terms "labor productivity" and "output-per-man-hour." The impression conveyed by those terms is that productivity is a function of the skill and industry of labor. It was demonstrated in the preceding section how the skill of labor is derived from the tools employed with labor to produce goods having human value. Thus, one is left with only one major nexus between labor and productivity, and that is the so-called industry of labor. However, even that nexus is on shaky premises. This section will argue that labor productivity and the productivity of a modern industrial system is only minutely dependent upon the skill and industry of labor. Rather, productivity is mostly determined by the quantity and technical quality of the tools employed in the system.

The preceding section concluded that the essential difference 
between neolithic and modern man is the relative quantities and qualities of their tools. A major significance of that difference is in the productivity of each man relative to the other. The technical quality of the neolithic hoe limits the tribes person to the tillage of a very small plot of land, probably less than a hectare. She simply could not turn enough soil fast enough to bring more land under cultivation in the time available to her. Thus, her crop yield was small in relation to the amount of time she spent in cultivating her land because of the 1 imitations of her tools.

Moreover, the primitive farmer's yield was small because she did not have the modern advantages of supporting technologies. That is, she had no access to seeds of blight-resistant and hybrid strains of crop. She had no sources for fertilizers, insecticides, fungicides, herbicides, or pesticides, and she had no way of irrigating her crop land if she suffered drought during her growing season. She had to rely on the existing fertility of her soil and on the vagaries of season for the right combinations of rainfall and sunlight to bring in a meager crop. And after her losses to insects, rodents, fungus, and weeds, she might have enough harvest to feed her family if she supplemented her larder by hunting game, the game brought in by her husband, and by occupying her family gathering indigenous berries, nuts, and roots. Most assuredly there were few seasons of surplus, and there was rarely enough to simply feed her own family. The primitive farmer's productivity was constrained by the technical paucity of her tools.

The size and richness of human society based on such a primitive technology was absolutely constrained by its abysmally low agricultural productivity. There could be no villages, towns, or cities, or any other 
cohesive human communities which substantially exceeded the family number. The self-sufficient family unit was the principal if not the only institution of the mesolithic and early neolithic periods. While there were undoubtedly intra-family specializations, there was no time for the inter-famity specializations which led to trade and ultimately to the proliferation and agglomeration of the extra-family institutions which comprise urban areas. Such specializations had to await a time when agricultural productivity could support substantially more than the farmer and her family. Urbanization was, at root, an agricultural revolution, and the latter was precipitated by technological developments which increased agricultural productivity.

Like the early neolithic farmer, the modern farmer's productivity is a function of the quantity and quality of his tools. By using mechanically-powered equipment, the modern farmer can farm several thousand acres of land. Indeed, he must usually cultivate at least a thousand acres (approximately 400 hectares) in order to secure enough income to allow him to live moderately (by modern standards) at farming alone. Moreover, he must specialize in one or only a few crops in order to take advantage of the economies in large-scale production. He cannot afford to waste his time on the diverse kinds of farming that characterized the traditional, smal1, family farm--an institutional entity which was relatively self-sufficient.

The modern farmer's yield per unit of land is much greater than that of the neolithic farmer because he has abundant sources of supporting technologies. That is, he can obtain the very best seeds to plant from firms which specialize in developing and producing blight-resistant seeds. And he can assure a verdant crop by applying chemical fertilizers Reproduced with permission of the copyright owner. Further reproduction prohibited without permission. 
that are specially formulated to compensate for deficiencies in his soils in terms of the nutritional needs of his crops. Likewise, he can protect against drought by irrigating, and against crop wastage from insects, rodents, fungus, and weeds by applying appropriate chemicals to his growing crops. Finally, he can multiply his yields by double and sometimes triple cropping his land most years without depleting his soil.

The modern farmer's harvest measured as output-per-man-hour is very great. He and his family could not consume even a small fraction of the crop he produces, and the chances are that they consume none of it at all. Rather, the entire crop is sold to urban food-packing firms which process it and sell it to both urban and rural consumers. Thus the farmer lives off the proceeds of his sales just as urban workers live off their wages and salaries.

Only a fraction of the farmer's net income is spent on agricultural goods, and whatever agricultural goods his family consumes are thoroughly processed, packaged, distributed, and sold to him by business firms operating in urban centers. Rather, the major part of his net income is spent on precisely the same kinds of goods and services consumed by urban dwellers. It is spent on housing, electricity, telephone, heating fuel, transportation, household appliances, television, clothing, and other goods and services manufactured or processed in urban areas. Likewise, he 1 istens to the same radio programs and watches the same television programs as his urban counterparts. His children attend schools in urban areas, and he pays taxes on his properties and his incomes just the same as urban dwellers. In terms of his household style and the consumption pattern of his family, the modern farmer is very much an urban creature. Likewise, the technologies which supply the farmer with mechanical Reproduced with permission of the copyright owner. Further reproduction prohibited without permission. 
equipment, fuel, irrigation pipe, pumps, chemical fertilizers, insecticides, herbicides, fungicides, pesticides, and a host of other goods are products of urban industries. The farmer is, all at once, a buyer of products produced by industries which are essentially urban, and a major supplier of food and fiber resources to urban industries. Indeed, it is precisely the phenomenal productivity of the agricultural sector which has released manpower from the production of primary goods to specialize in urban industrial employments. Urban industries produce the rich variety of relatively low-cost manufactured goods and services which are characteristic of an advanced industrial society. ${ }^{7}$

Farmers today comprise approximately two percent of the population of the United States. And yet, the farm sector is so productive that the U. S. Department of Agriculture must pay the farmer not to farm and must purchase certain agricultural surpluses after the farmer has sold all of his output that the U. S. economy can consume and as much as the international economy can absorb. It has been the innovation of mechanical and chemical technologies in agriculture which has enabled the modern American farmer to produce enough food and fiber to support a great many urban families, while the neolithic farmer with her hoe could barely produce enough to support her own family. ${ }^{8}$

The land and weather patterns of the North American continent have not significantly changed while the transformation in American agriculture occurred. Likewise, the physiognomy of the farmer has changed not at all. He has no new anatomical appendages. On the other hand, he has acquired greater knowledge of himself and his environment. This knowledge derives from his tools, and the tools of the American farmer are the means behind his amazing output-per-man-hour. More specifically, it is that quality

Reproduced with permission of the copyright owner. Further reproduction prohibited without permission. 
of American farm tools which enables them to be substituted for human effort in the production of agricultural goods. In short, like his skill, the American farmer's productivity is essentially a function of the technology embodied in his tools and the tools of those urban enterprises which support him.

Of course, it remains true that the skills and industry of labor are a major source of productive efficiency in a subsistence economy. But even a capital-scarce economy relies heavily on the tools it has. Moreover, the ability of a more primitive economy to improve the welfare of its members comes down to its success in somehow increasing its stock of capital goods or tools relative to its labor force, and in improving the technical qualities of its capital goods at the same time. Improvements in the technical qualities of tools means acquiring and employing new units of capital goods that increase the units of output-per-man-hour for the whole economy--in other words, new units of capital goods which substitute for more units of labor in producing all kinds of goods. It means somehow replacing the sawyer's hand saw with a power saw. It means somehow replacing the Mountagnard's hoe and bush knife with modern agricultural equipment. This is, of course, a tall order, and the issues surrounding it are examined in subsequent chapters.

\section{TOOLS AND HUMAN EFFORT}

What happened between the early neolithic era and the modern times to change man's productivity so markedly? Indeed, what has happened since primeval times before man succeeded in domesticating animals? The simple answer is that tools have been perfected and substituted for human labors to produce goods down through the ages of man. Yet the answer is not as 
simple as that. The complexities of substituting tools, or capital goods for labor in production processes are taken up in the next few chapters. It is sufficient for the moment, however, to deal with the simple statement-tools have been substituted for human labor in the production of goods. Consider a thankfully by-gone era, a primeval time when man stood bare of textile adornment and with only the most primitive stone, bone, and shell tools. Ten thousand years ago, at the end of the pleistocene geological period when the Wurm glaciers of the last ice age receded from Central Europe, neanthropic man, or homo sapiens, emerged probably from the Aurignacian, Solutrean, and Magdelenian cultures of the upper paleolithic period. Human culture was of the food-gathering kind Agriculture, the domestication of animals, pottery, and polished (rather than chipped) stone tools that typified neolithic culture had not yet emerged.

Except for very crude implements fashioned from stone, bone, and shell, one finds that mesolithic man possessed practically no tools. In deed, man himself is the essential tool. There were no domestic beasts to provide power. The motive powers to manipulate his crude implements came from mesolithic man's own anatomy. It was from the dexterity and strength of his own back, arms, and hands that man marshalled the power to slam his stone axe into the skull of a wild beast. More than that, it was his legs that propelled him on the hunt--and it was his sight, hearing, and senses of sme11, taste, and touch that enabled him to navigate, avoid calamity while moving about, track and find the beast, land the killing blow, and return the meat to his abode. Finally, it was his own mind that coordinated the entire episode according to the techniques learned from his tools and his ancestors.

The history of technological development during the millennia that

Reproduced with permission of the copyright owner. Further reproduction prohibited without permission. 
separate modern man from his mesolithic ancestors is one of systematically removing man from the processes by which he produces goods and services. This has been accomplished by substituting tools for human effort in production processes. The first great technological innovations created opportunities to remove the muscles of man's legs, back, and arms as primary sources of industrial power. The second wave of technological advance opened the way for removal of his skeletal frame, his manipulative dexterity, from industrial processes. The third advancement made it possible to remove man's voice and nervous systems, and the most recent advances are opening opportunities to supplant man's brain as a device for coordinating industrial activities. These advances are not so discreetly organized as they appear here. Rather, they overlap one another. For example, research in power technology, the first stated above, continues to produce new and revolutionary tools to the present.

\section{Power Devices}

The first major technological innovations were the initial steps in a long series of advances toward removing man's body as a source of power in industrial processes. They started at the outset of the neolithic period with the first human efforts to gain better control over the food supply. The effort advanced along two lines--the tillage of crops and the domestication of animals. The domestication of animals brought the meat supply under man's dominion. However, as animal husbandry merged with crop tillage, domestic beasts came to be used as work animals as well as for meat. It was soon discovered that the oxen which supplied the primitive meal was also useful as a beast of burden. The ox replaced man at the draw of the plow, a primitive tool that was little more than a pointed

Reproduced with permission of the copyright owner. Further reproduction prohibited without permission. 
stick. The plow replaced the hoe as a tool for turning the soil in preparation for planting. The ox also came into use to draw cargo sleds and wagons. Eventually the ox gave way in western civilization to the horse as the principal draft animal. ${ }^{9}$

The substitution of first the ox and then the horse for man as the source of industrial power had the effect all at once of freeing man for other activities and of increasing the output-per-man-hour for those hours of human labor devoted to production. For example, an average draft horse is capable of exerting 120 pounds of force at a velocity of 3.6 feet per second for 432 foot-pounds per second of power or work. This compares with approximately 18 pounds of force exerted by a man turning a winch at a velocity of 2.5 feet per second for 45 foot-pounds per second of work. The average man can only produce about one-tenth the amount of work as the average draft horse per unit of time $(45 \div 432=.104$ or $10.4 \%)$. The power of the ox or horse pulling the plow simply turned more earth more rapidly than could be done by a single man. The change to a power technology based on draft animals was so significant and prevailed so long that mechanical forms of power continue to be measured today in draw-bar horse power or brake horse power. ${ }^{10}$

The advance of technology did not stop with shifting the power load from human muscular systems to those of domesticated draft animals. Water power and wind power were developed between 150 B.C. and 1500 A.D. to operate grain, textile, and other mills and to propel cargo and passenger vehicles and vessels. Like the ox and the horse, wind and water power have fallen into disuse in the face of power produced by mechanical devices discovered and innovated since the eighteenth century. Water power continues to be significant only in the generation of electricity 
in a few regions of the world. ${ }^{11}$

The next major advance in power technology occurred in England in the eighteenth century when James Watt perfected a steam engine from a reciprocating steam device developed earlier by Thomas Savery and Thomas Newcomen. By the beginning of the twentieth century, the steam engine had been adapted to power pumps, ships, rail locomotives, electrical power generators, and a variety of industrial mills. The widespread innovation of the steam engine made it possible to shift industrial loads from the backs of draft animals and from the more limiting wind and water-power devices to the more powerful and versatile mechanical power units fueled by wood and fossil fuels. ${ }^{12}$

The development and widespread use of internal combustion engines marked the next major advance in power technology. The first of these was the reciprocating, gasoline-powered engine built in 1820 by $W$. Cecil of Cambridge, England. Cecil's engine was improved in 1823 by Samuel Brown, an English scientist. The Brown version was produced and sold in quantity. The reciprocating gasoline engine has since been adapted for use to power automobiles, aircraft, small electrical-generating plants, agricultural equipment and countless other units. The diesel engine, gasoline turbine engine, jet engine, and rocket motor are all internal-combustion engines developed and innovated subsequent to the reciprocating gasoline-powered engines. ${ }^{13}$

Dr. William Gilbert, physician to Queen Elizabeth I, discovered electricity in 1600 A.D. While examining the properties of magnets and amber. There have been many other persons associated thereafter with discoveries built upon electricity--Benjamin Franklin, Luigi Galvani, Alessandro Volta, Hans Christian Oersted, Andre Ampiere, Michael Faraday,

Reproduced with permission of the copyright owner. Further reproduction prohibited without permission. 
and others. It was Faraday who, in 1831, discovered electromagnetic induction, the principle upon which the electric generator and the electric motor are based. These tools--the electric generator and the electric motor--enable power to be transformed from such other forms as fossil fuels, water and wind power, and nuclear energy into electrical energy for transmission over wires to users and for further transformation into usable motive power. For example, electricity might be generated by a generator or dynamo which is powered by water spilling over a dam. The electricity is carried by transmission 1 ines to users who reconvert the electricity to power by use of an electric motor. The electric motor is, of course, connected to other industrial tools used by the recipient to produce goods. ${ }^{14}$

The most recent innovation in power technology is the nuclearfission reactor. The nuclear reactor is coming into wider use for energizing large electrical-power generators. It has also been used to replace steam and internal combustion engines in ocean-going vessels. Nuclear technology remains very much inchoate with additional research pointing toward development of so-called "fast breeder" fission reactors and the possible development of fusion reactors. Finally, a great deal of interest now centers on ways to harness the sun's rays as a power source. Likewise, more attention is given to possible ways of improving wind- and water-power technologies and ways of developing geothermal potentialities. These latter efforts anticipate the eventual depletion of fossil fuels as sources of energy to fuel steam engines and internal-combustion engines.

The practical effect of emergent power technologies has been and remains the extrication of man's muscular system as the source of physical power in industrial processes. As the power requirements of industry in 
agriculture was shifted from the body of neolithic man to the bodies of draft animals, so the power requirements of all industrial activities were systematically shifted from the backs of oxen, horses, elephants, and other draft animals to wind- and water-power devices, to steam engines, internat-combustion engines, and to electric motors powered by electrical generators attached to one or more of the foregoing power sources or by nuclear reactors.

Moreover, the physical power of man's body is less than puny when compared to the physical powers of the various tools devised by man to give motive power to his industrial processes. For example, consider the comparative transportation efficiency between a man on foot and a modern jet aircraft. If the purpose is simply to move one's self and his baggage from Los Angeles to New York, there is clearly no contest. The aircraft will accomplish the feat in a few hours with hardly any human hardship. The man afoot will take several months, and he will endure great physical hardships. The difference is the tool, the jetpowered aircraft, which can move many people and their baggage in one trip between the two cities in a few hours. The powers of the tools substituted for human effort utterly dwarf man's pitiful meagerness by comparison.

\section{Transmission Devices}

The second wave of technological advance could as well be called the first because it originated and developed concomitant with power technologies. Indeed, the devices here allocated to the second wave complemented power devices by translating the forces created by the latter into directed motion. They are known in the realm of physics as simple 
machines--the wheel and axle, the lever and fulcrum, the wedge (or inclined plane), the pulley, the screw, and the gear. These devices might be called transmission or manipulative technologies because they transmit force from the motor mechanism to the working component of a machine or tool--much as man's skeletal structure transmits the force of his muscular system in whatever he is doing. Thus, the simple machines make it possible to remove much of man's manipulative dexterity from production processes.

Evidences of simple machines are found in the works and arts of the ancients. Some simple machines have doubtlessly been in common use at least since the early centuries of ancient Egypt. For example, the principle of the lever is found as a sweep to lift water from a well in Egypt as early as 1550 B.C. The works of Philon of Byzantium and Vitrivius Pollio, the Roman architect, dating from the first century B.C. contain some of the earliest descriptions of simple machines. The Greek scientist, Hero of Alexandria, authored works in mathematics, physics, and mechanics during the third century A.D. Hero's writings contain careful descriptions of the simple machines commonly understood and used in al1 forms of industrial activity today. ${ }^{15}$

A simple machine translates force into directed motion in some combination of force and motion called work. Thus, if a fifty-pound weight is lifted vertically a distance of ten feet, 500 foot-pounds of work have been accomplished ( 10 feet $X 50$ pounds $=500$ foot-pounds). However, one can lift the weight ten feet (ignoring friction; etc.) by employing a force of only ten pounds in combination with any of the aforenamed simple machines having a mechanical advantage of at least five--where mechanical advantage is the ratio of the force exerted to the weight moved, or the 
ratio of the distance over which the force moves to the distance moved by the weight. The simple machine accomplishes this by substituting motion for force, or force for motion. That is, the ten-pound force must move fifty feet to produce 500 foot-pounds of work, or enough work to lift the fifty-pound weight ten feet. The simple machine is an implement which enables this to be done. 16

Taking the wheel and axle as an example, it is found that a draft horse pulling a loaded two-wheeled cart can move 1500 pounds over a level surface at 3.6 feet per second producing 5400 foot-pounds of work per second. Recalling from a previous example that an average draft horse can produce 432 foot-pounds per second of work on a straight draw-bar pul1, it is seen that the wheel and axle under a cargo compartment harnessed to a horse has increased the power efficiency of the horse by more than 12 times. The mechanical advantage of the wheel and axie in this example is probably something between eleven and twelve, taking account of power lost to friction, etc. By comparison, a man can move approximately 225 pounds in a two-wheeled barrow at 1.66 feet per second for work of 372 foot-pounds per second. While this is an improvement over a man simply carrying a burden, note that a man's work capability with a two-wheeled conveyance is only about $6.9 \%$ of that produced by the horse under similar conditions. 17

However, even the power of the horse is dwarfed by the immense power of a diesel engine. Such an engine linked by gears and other drive mechanisms to the wheels of a locomotive can draw fifty or more rail cars, each rolling on steel wheels and carrying a hundred or more tons of cargo over steel rails across the breadth of a continent. The combination of power technology and the manipulative technology of simple machines has 
enormously multiplied mankind's capacity to accomplish work. More than that, these technologies have made it possible to remove the muscular power and the structural dexterity of man's body from many of the productive processes by which mankind produces goods and services having human value.

\section{Control Devices}

The third great advance came with the discovery and innovation of communications technologies. The tools arising from this advance have made it possible to remove much of man's perceptual equipment, his nervous system, and his voice from production processes. Communication technologies have advanced most rapidly since the discovery and development of electricity. More specifically, modern tools of communication are based on the electromagnet and the vacuum tube--or the vacuum tube's modern descendants, the transistor and the integrated circuit. The entire world of electronic communication is built upon these tools.

William Sturgeon, an English electrician, invented the electromagnet in 1823. It is considered by many scientists to be the greatest invention of modern times. And yet it is a simple device consisting of an iron bar around which coils of insulated wire are wound. The bar is not magnetic until electrical current passes through the coil, and its magnetism ceases as soon as the current stops. The magnetic strength of the electromagnet is a function of the size of the coil and the amount of electrical current passing through the coil. It is so sensitive to fluctuations in current that it will precisely reproduce the voice and words spoken into a telephone by a person at one end for a listener at the other end of a circuit spanning many miles.

Reproduced with permission of the copyright owner. Further reproduction prohibited without permission. 
The amazing electromagnet is unconsciously used many times each day by everyone in the modern world. All push-button switches are connected to electromagnets (solenoids or relays) to control door bells, elevators, traffic signals, self-opening doors, automobile starters, automatic washers and dryers, and thousands of other implements in daily use. It is an essential component of all control devices in modern homes and in offices and factories. And it is a technical basis of all electrical communication of sound and symbols by telephone, radio, intercom, and tele-typewriter. ${ }^{18}$

Consider for a moment the use of an electromagnet in a simple, servo-mechanism, the ordinary thermostat used to control heating units in urban households. The heat inside a dwelling was adjusted before the thermostat by a person whose sense of feel detected a drop in the room temperature. When the temperature dropped sufficiently to cause discomfort, the person would place another log or shovel of coal on the fire. If this produced too much heat, the person might open the damper on his fire unit to allow more heat to escape up the chimney. The point is that the person's sensory apparatus was needed to detect the temperature change. His brain recognized the problem and transmitted instructions over his motor nervous system to take appropriate action. The needed physical action was then taken by the person to correct the temperature problem.

But no more. A servo-mechanism has entirely replaced man in this process. The change in temperature is detected by a thermometer composed of pieces of metal held apart by an adjustable plastic device. As the temperature drops, the metal contracts and warps until the pieces touch, closing an electrical circuit wired to a solenoid (or electromagnet) 
in a furnace installed in some unobtrusive place in the home. The energized solenoid turns on a switch to a motor powering a pump and igniter. The pump forces oil through a nozzle, atomizing it in a firebox where the igniter sets the oil afire. The heat builds up in the firebox until another thermostat, sensing the rising temperature in the firebox, activates a fan which distributes the heat through a duct system to the rooms requiring the heat. When the temperature in the dwelling reaches proper levels, the thermostat senses it and reverses the process to extinguish the flame and inactivate the fan. And the human occupants are relieved of the burdens to sense temperature changes and take action to make physical adjustments to the heating unit. Moreover, the thermostat is a slave which never tires and which operates with far greater precision than any human sensory and motor nervous systems.

Impressive as its powers are, the electromagnet alone does not account for the proliferating myriad of communication devices. The electromagnet is essentially a terminal device. It converts transmitted impulses to action. The impulses are transmitted by other means--copper wire, radio waves, etc. Transmission by radio wave was made possible by invention of the vacuum tube and its modern successors, the transistor and the integrated circuit.

Many scientists working over a span of time invented the vacuum tube and its variations. The "Edison effect" was patented by Thomas Edison in 1883. The effect was ignored until 1899 when Sir J. J. Thomson, a British scientist, offered what came to be an accurate explanation of the Edison effect. The effect was achieved by enclosing a small copper plate near but not in contact with the filament inside an electric light bulb. When the plate is charged with positive electricity, the electrons 
emitted by the energized light filament are attracted to the plate. The attraction continues so long as the filament is energized and heated to the correct temperature. The flow of electron current is the means by which the gap between the plate and filament is bridged, closing the circuit in the tube.

It was not until 1904 that Sir John Fleming, a British physicist, produced a vacuum tube from the principles underlying the Edison effect. Fleming's tube is a diode, a two-element device. It is used today as a rectifier to convert alternating current to direct current. It was two years later that Lee DeForest, an American engineer, created the triode or audion tube by inserting a wire grid between the filament and plate of the Fleming diode. It is the Deforest triode that has been the basis of all amplification in radio, television, radar, sound movies, electron microscopes, photo transmission, calculators, computers, X-ray sets, and scores of other electronic implements. ${ }^{19}$

Radio, television, and all forms of wireless transmission occur when sound and light waves are converted to electrical pulsations. Those pulsations are much too weak to be transmitted. The vacuum tube modulates and amplifies the pulsations until they are millions of times more powerful and broadcasts them across the face of the earth and into space. The journey around the world actualiy takes less than a fiftieth of a second. But when the amplified pulsations arrive a continent or more away, they are once again too weak to register on video screens and speaker systems. The vacuum tube in the receiver set once again amplifies the weak pulsations until they are powerful enough to energize the speaker and video systems at the receiver end. ${ }^{20}$

Prior to discovery and innovation of the vacuum tube, industrial

Reproduced with permission of the copyright owner. Further reproduction prohibited without permission. 
data and controlling responses had to be received through the sensory organs and nervous systems of humans located at industrial sites, and had to be transmitted through the motor nervous systems and voices of the same persons. That is, the measurement, recording, and analysis of data, and the formulation and transmission of controlling reactions to the data were al1 manual, immediate, and on site. By the use of electronic sensing devices and radio and television communication equipment, it is now possible for persons on the earth to measure, record, and analyze data from unmanned vehicles traveling millions of miles in space at thousands of miles per hour and to control the vehicle direction, velocity, and much more. The radio and television transmission and reception of data and commands are possible without the sensory and motor nervous systems of man because the vacuum tube--or, more accurately, the transistors and integrated circuits which are replacing vacuum tubes-performs the transmission functions both more accurately and at a tremendously greater range than is capable with man's innate physical endowments alone.

The vacuum tube has taken many forms and was used wherever electrical current had to be rectified, modulated, or amplified. The simple Fleming valve, a diode, was elaborated into the triode, the pentode, the photo-electric ce11, and the many other variations used in electronic devices. However, important as it was to the invention of these significant devices, the vacuum tube is rapidly giving way to the transistor, the discovery in 1948 of John Bardeen and Walter Brattain of the Bell Laboratories in New York. Transistors and integrated circuits are capable of all that can be accomplished by vacuum tubes and much more. Moreover, additional research is exploring the possible use of laser beams as a 
technique for transmitting electrical pulsations. ${ }^{21}$

The invention and development of radio, television, and the plethora of other electronic devices which abound in modern industrial societies depended upon other discoveries by many scientists--men like James Clark Maxwell, Heinrich Hertz, and Marchese Marconi for the radio, and Vladimir Zworykin and Philo Farnsworth for television. Nevertheless, all modern electronic communication and calculating devices are based upon the amazing electromagnet and the vacuum tube, and it was the discovery of these technical implements which opened the way to the latter. ${ }^{22}$

The discovery and innovation of communication technologies based upon the vacuum tube and the electromagnet have revolutionized the production of goods and services by enabling people to coordinate and control complex and widely-separated industrial processes from locations which are mobile and far removed from those processes. But more than that, communication technologies are resident in tools such as telephones, radios, and televisions, which replace human sensory and motor nervous systems in the creation of goods and services having human value. Moreover, those tools and the technologies resident in them are far more durable and much more reliable than the human components which they replace in industrial processes.

\section{Thought Devices}

The most recent wave of technical advance is the innovation of the digital computer, a device that thinks. The computer supplements and in some cases completely replaces man's brain in production processes. The computer, like the servo-mechanism described in the preceding section, receives input and produces output. However, the servo-mechanism simply 
measures a single input against predetermined and rigid parameters and produces a single output as a reaction to the measured input. The servo-mechanism is a simple reaction device within a closed feedback loop. It is a very simple form of an analogue computer. The digital computer, by contrast, can be programmed to process complex bodies of input data from diverse sources and to produce output choices according to the controlling program. Moreover, the program can be written to produce many different combinations of output from a given body of data. The digital computer is a true thinking device.

Electronic data processing (EDP), as it is performed on a digital computer, is based upon the binary numeric system. The system uses a base of two and consists of only two digits--zero and one. The digits translate as no and yes, or stop and go, or on and off, or reject and accept in electronic data processing. The binary system was elaborated in Principia Mathematica, a pioneering work in symbolic logic produced in the early part of the twentieth century by the philosophers Bertrand Russell and Alfred North Whitehead. 23

Application of the binary system in electronic data processing was pioneered in the late 1940s by the Eckert-Mauchly Company. The electronic components of the Eckert-Mauchly computer were vacuum tubes. Eckert-Mauchly was purchased by the Remmington Rand Corporation (now Spery-Rand) in the early 1950s. International Business Machines Corporation, which had an early background in punch-card tabulating machines, entered the field in 1953 and gained a clear and enduring lead in electronic data processing by 1956. The vacuum tubes of the early Eckert-Mauchly computer have Tong since given way to transistors and integrated circuits in modern digital computers. ${ }^{24}$

Reproduced with permission of the copyright owner. Further reproduction prohibited without permission. 
A11 computers consist of input and output hardware connected to central processing units (CPU). Input hardware and software are implements and techniques for translating man-readable data to machinereadable data and for reading the data into the computer's CPU for processing. The input side of the computer is analogous to the perceptual apparatus and sensory nervous system of man. The output hardware are implements for translating data processed by the CPU from machine-readable language to man-readable language for practical application. The output hardware is analogous to the motor nervous system and the communication and action extremities of man's body. The functions of the sensory and motor nervous systems were described under "control devices" above.

The heart of any computer is its central processing unit. The central processing unit is analogous to the brain of man, and it functions to process data read into it through the input hardware and to feed the processed data to the output hardware. The CPU of a digital computer consists of doughnut-shaped, magnetic cores each of which is smaller than the head of a pin. The cores are organized into core planes which are stacked horizontally or vertically. Each core can be placed in two possible states, magnetized or not magnetized. Or they can be magnetized in two possible directions--clockwise or counter clockwise. The magnetized cores therefore operate in a program language like "gates" in a fence system to control the information in the process. The two magnetic states correspond to the two digits of the binary system--zero and one. For this reason, a core state is called a bit--short for binary digit. ${ }^{25}$ The bit can signal no or yes, stop or start, reject or accept, etc. as well as zero and one.

There are, of course, other ways to wire a CPU. A recent innovation 
involves integrated circuits built into silicon, a semiconductor. A single silicon chip small enough to hold in the palm of the hand may contain as many as 30,000 electronic parts. This innovation holds the prospect of revolutionizing electronic data processing because it has increased computer speeds--100,000,000 instructions per second and retrieval times of $1 / 4,000,000$ of a second. It is significantly reducing the size of computer storage units, with an attending reduction in their costs. Whatever the wiring method, computer memories operate on the binary principle, and a core magnetic state is called a bit.

A computer core is analogous to a neuron cell in the human brain. A human brain is estimated to contain approximately ten billion neuron cells which react like computer electronic cores by transmitting excitatory or inhibitory electrical impulses to other neurons. Each neuron cell may be connected to as many as 10,000 others. Most researchers believe that human learning is related in some way to the number and strength of interneuron-cell connections. 26 of course, the number of cores in a computer CPU is only a small fraction of the number of neuron cells in a human brain. The neuron cells are numbered in the billions while computer cores are numbered in the thousands.

Just as neuron cells are connected with one another, so computer cores are further organized in one of several different combinations depending upon the computers and programming systems used. One common system divides the CPU into segments of eight adjacent cores. An eightcore segment is called a byte and can have 256 different combinations of magnetic core states. The various combinations of magnetic-core states-zeroes and ones--in a byte are known as the Extended Binary Coded Decimal Interchange Code (EBCDIC). Each particular code is assigned to an 
alphabetic, numeric, or special character. Each byte, (indeed, each bit) can be addressed separately in a program using the EBCDIC code. It is therefore possible to encode anything known by man, and represented by alphabetic, numeric, or other symbols and to place it in a computer CPU-subject, of course, to the physical core limitations of the computer.

A portion of the CPU cores of any computer is given over to a control unit while other parts are allocated to a main storage unit (memory), and an arithmetic-logic unit (ALU). The control unit contains the computer program, and it functions to interpret the program instructions placed in the computer by the programmer and to direct the actions of other units of the computer. It initiates execution of computer programs. It transmits data into and out of the main storage unit. It applies the arithmetic-logic from the ALU to process data according to program instructions. And it initiates input and output devices.

The arithmetic-logic unit of the CPU is in essence a calculator. It is an electronic calculator in a true digital computer and it consists of a series of electronic storage units (registers) and other circuits capable of performing mathematical operations. The ALU may be a nomographic device in an analogue computer. An analogue computer is to a digital computer as a slide rule is to an electronic calculator. And as the electronic calculator is more precise and more rapid than a slide rule, so the digital computer is both more accurate and more versatile than an analogue computer. The ALU supplies the patterns of logic by which data from main storage are processed according to the program instructions in the control unit of the CPU.

The main storage, or memory, occupies whatever cores remain in the CPU after allocation of cores to the control unit and the ALU. The main 
storage unit is used to hold both reference data required to execute the computer program (tables of constants, codes, etc.) and variable data for processing. Since all information handled by the computer must pass through the CPU, the CPU must have sufficient core capacity to handle control unit and ALU requirements as well as to store all data needed in the program under process.

The relatively small number of cores which may be built into a computer CPU at the present state of technical development poses a restriction on computer use. For example, it requires 40 cores to write a fiveletter word using the EBCDI code described above--one byte per letter and eight cores per byte. Thus, one can effectively store fewer than 25, five-letter words in one thousand cores in the main storage. At the present most computers have less than 1000-K $(1,000,000)$ storage units or bytes in the CPU.

The paucity of core capacity has been partly overcome by creating shorter codes and by devising auxiliary storage hardware. The Binary Coded Decimal (BCD) system uses six consecutive cores to represent 64 different characters. The American Standard Code for Information Exchange (ASCIE) uses seven consecutive cores to represent 128 symbols. Auxiliary or secondary storage of data is achieved by use of sequential access media in the form of magnetic tape, or direct access media in the form of data cel1s, magnetic drums, and magnetic disks. The CPU accesses auxiliary storage through a technique called sequencing so that the auxiliary storage capacity is thought of as "virtual memory" because it is easily accessible to the main storage unit of the CPU. ${ }^{27}$

Whatever the 1 imitations of computers, their powers and potentialities in production activities are impressive. Examples of effective use 
of computers abound in the worlds of business and government. One of many examples that might be cited is the experience of Lockheed, one of the world's leaders in aircraft and aerospace manufacturing. Lockheed had used computers since the early 1950s for such things as calculating trajectories and designing airborne and space vehicles.

In 1958, Lockheed's Missiles and Space Division sought a system capable of controlling its production. The division's production accounted for approximately $40 \%$ of Lockheed's total employment. The plants at Sunnyvale and Van Nuys, California had between 40,000 and 60,000 different items in different stages of simultaneous production. Ranging from miniscule electronic devices to entire space vehicles, each item had its own production schedule. Moreover, the specifications of many items were often altered after they were well into production. A staff of more than 600 expediters was required to monitor and control this complex production maze.

After more than a year of study, Lockheed settled on R.C.A. data gathering components which could be connected with ordinary telephone wire and coupled with computer hardware. The outcome was what Lockheed called its Automatic Data Acquisition system (ADA). The system is a "real time" one, meaning that access to the computer is random and immediate from the 260 input stations located around the plants, and that constantly updated output can be obtained from any enquiry station.

The system works by reading each item of material entering the plants into computer memory. An employee records each time the item is moved or worked by inserting his card and punching appropriate variable data into the nearest input station. The computer, therefore, knows at a11 times where an item is, who has worked on it, and the wage cost of 
the work performed. The computer also controls inventory on common items, calculating control levels and reordering when stocks drop below reorder points. More than simply counting items, the computer acts heuristically, making judgments about usage factors, etc. By 1965, ADA had accomplished the following:

It saved more than $\$ 2,000,000$ per year against an original onetime development and installation cost of only $\$ 2,300,000$. The saving was achieved by the discharge of 400 expediters and 200 clerks who were no longer needed to control production.

It enabled Lockheed to accurately forecast manpower and plant needs by providing timely and accurate production-machine and manpower costs. Supervisors. tended to conceal the real output and capacities of their departments under the old system by averaging out workloads over the work week. With ADA, management knows exactly how long each job takes and how much work a department can perform on any day or week.

Line employees readily accepted ADA because they felt that they were able to communicate directly to the top management without the sometimes prejudiced interpretations of their immediate supervisors. Work in progress could be located immediately to incorporate the frequent engineering changes inherent to the rapidly changing aerospace world. It was not uncommon under the former system to occupy an expediter two or more days simply trying to locate an item subject to engineering change.

. Ready access to the quality and cost of goods purchased in the past enabled purchasing agents to make more rapid and accurate decisions about what, how much, and where to buy. Under the ADA system, inventories could be kept at optimum levels.

Reproduced with permission of the copyright owner. Further reproduction prohibited without permission. 
Finally, ADA relieved top management of superfluous details by compressing data and supplying only "exception information" or information requiring action by top management. ${ }^{28}$

The results obtained by Lockheed's ADA are characteristic of results generally achieved by successful management applications of computer systems in government and business. The surface has only been scratched in the possible uses of computers in planning and controlling production processes. The chief advantages of computers over antecedent manual techniques are speed and accuracy in information retrieval and processing. That is, the computer is superior to the human brain in sifting and evaluating large, complex bodies of data to reach conclusions and make choices. The natural consequence is that computers are being brought into more and more uses to augmer human brain power or to replace it altogether in some cases.

The use of the computer is only the most recent in a series of technological advances commencing at the advent of the neolithic revolution and having the effect of removing the physique of man from production processes. To be sure, man's body has not and perhaps will never be totally unburdened with productive labor. But the millennia between mesolithic man and modern man are witness to an unburdening of fantastic magnitude.

The first advance was the commencement of a revolution in power technology which continues to the present day and which has had the effect of substituting power devices--draft animals, water and wind power, fossilfuel powered engines, electrical energy, and nuclear power--for man's muscular systems in production processes. The second stage of technical advance involved the innovation of transmission or manipulative 
technologies--the wheel and axle, the lever and fulcrum, the inclined plane or wedge, the pulley, the screw, and the gear. The effect of the second stage was to reduce reliance on man's skeletal structure for the transmission of force in production processes. The third great advance occurred with discovery and innovation of control devices based upon the electromagnet and the vacuum tube. This advance shifted much of the control of production processes from man's perceptual endowments, and his sensory and motor nervous systems to electronic tools. And the last perceptible advance has commenced in the last thirty years, and it involves the use of computers in production decision-making. This last advance has only begun, but it holds the prospect of at least partially supplanting man's brain in production processes.

The total effect of these technological advances has been to remove man more and more from the mundane, day-to-day labors of production while substantially increasing the productive powers of society--both as to the quantity and quality as well as the tremendous diversity of goods and services available to all of society. This has been possible because of the technology resident in the tools which have been substituted down through the ages of man for human labor in the creation of goods and services having human value.

It has been the purpose of this chapter to precisely define technology in a new and different way and to justify that definition in terms of institutional economic theory. The conclusion is that technology is that quality of a tool which enables it to be substituted for human effort in the creation of any good or service having human value. This has required a distinction between tools and other artifacts of material culture. And it has made the tool, broadly defined, the repository of 
technology as well as the harbinger of the material progress attributed to technology. It has mandated a distinction between the technologyembodying tool and the human skill applying technique in the employment of the tool. Finally it has been necessary to briefly outline enough history of technical advance to demonstrate that the unique character of technology is its power to facilitate the substitution of tools for human labor in production processes.

While the social consequences of technologies have been broadly implied here and there in the foregoing discourse, they have not been examined in any explicit or systematic way. It has been more than sufficient to deal here with the attributes of technology alone. It remains for the next chapters to briefly examine social questions surrounding technology--How is it discovered? When is it innovated? What are its social consequences? 
END NOTES, CHAPTER VI

${ }^{1}$ The institutional economic theory in this chapter draws from Ayres, Theory of Economic Progress, pp. 98-108.

${ }^{2}$ Cf. Edwin Mansfield, The Economics of Technological Change, (New York: W. W. Norton \& Co., Inc., 1968), pp. 10-11. Fairchi1d, Dictionary of Sociology, p. 317.

${ }^{3}$ In all the works of Commons, Dewey, and Veblen previously mentioned, there is no definition of technology. Ayres is almost as circumspect.

However, he does associate technology, tools, and human skill in at least one place. His definition of technology appears to be skill organized by tools. Theory of Economic Progress, pp. 105-108 ff.

${ }^{4}$ Abbott Payson Usher, A History of Mechanical Inventions, (Boston: Beacon Press, 1959), p. 116.

${ }^{5}$ Childe, Man Makes Himself, p. 64.

${ }^{6}$ Sherwood L. Washburn, "Tools and Human Evolution," Scientific American, CCII (September, 1960).

${ }^{7}$ Fred A. Shannon, The Farmer's Last Frontier; Agriculture, 1860-

1897, (Harper \& Row, Publishers, 1968), pp. 140-47.

8 Wayne D. Rasmussen and Gladys L. Baker, "Programs for Agriculture, 1933-1965," in Agricultural Policy in an Affluent Society; An Introduction to a Current Issue of Public Policy, ed. by Vernon W. Ruttan, ArTey D. Waldo, and James P. Houck, (New York: W. W. Norton \& Co., Inc., 1969), pp. $69-88$.

${ }^{9}$ Childe, Man Makes Himself, pp. 59-86.

10 Usher, History of Mechanical Inventions, p. 156.

${ }^{11}$ Jerome S. Meyer, Great Inventions, (New York: Pocket Books, Inc., 1962), pp. 23-30.

12 Meyer, Great Inventions, pp. 88-98.

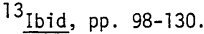

14 Ibid, pp. 131-55.

15 Ibid, pp. 9-22. Usher, History of Mechanical Inventions, pp. 120-23.

${ }^{16}$ See the chapter dealing with mechanics in any high-school physics textbook.

Reproduced with permission of the copyright owner. Further reproduction prohibited without permission. 
17 Usher, History of Mechanical Inventions, p. 157.

18 Meyer, Great Inventions, pp. 155-81.

${ }^{19}$ Ibid, pp. 185-94, 218-29.

20 Ibid, pp. 193-94.

21 Ibid, pp. 270-72.

22 Ibid, pp. 201-217.

${ }^{23}$ Gilbert Burck, The Computer Age; And Its Potential for Management, (new York: Harper and Row, Publishers, 1965), p. 129.

24 Ibid, pp. 81-82.

25 Jehosua Friedmann, Philip Greenberg, and Alan M. Hoffberg,

Fortran IV, (New York: John Wiley and Sons, Inc., 1975), pp. 3-4.

${ }^{26}$ Burck, Computer Age, pp. 126-27.

27 Friedmann, et al, Fortran, pp. 3-19.

${ }^{28}$ Burck, Computer Age, pp. 39-42. 
CHAPTER VII

\section{TECHNOLOGICAL DYNAMISM}

The preceding chapter commenced with the question: What are the underlying causes of institutional instability, change, and discontinuity, and what are the consequences for the city? The tentative answer was that the innovation of new technologies tends to be unstabilizing to institutional environments, and institutions along with their underlying value beliefs change as they react toward the new technologies. And since institutions are principally domiciled in cities, and since cities are creatures of the institutions that populate them, cities also change with the urgings of new technologies.

Chapter VI did not directly address the question or provide an answer. Rather, the chapter laid the foundation for an answer by precisely defining technology, technique, and human skill. The conclusions were that technology is that quality of a tool which enables it to be substituted for human effort in the creation of any good or service having human value; that technique is the procedure or method by which a tool is put into operation or employed to perform the productive services for which it was designed; and that technical skill is the human capability of applying technique to the use of tools in the creation of goods and services having human value.

This chapter starts an elaboration of the suggested answer to the above question. The main ideas are that technologies and the techniques which they mandate are continuous, dynamic, and progressive. By

Reproduced with permission of the copyright owner. Further reproduction prohibited without permission. 
continuous, it is meant that technologies are based on scientific understanding, and current scientific understanding is cumulative and is founded squarely upon all past discoveries. By dynamic, it is meant that the innovation of new technologies is unstabilizing to society because it organizes means (including productive labor) and opens ways of distributing social products in ways differing from the ceremonially prescribed methods descending from the past. By progressive, it is meant that the integration and diffusion of new technologies is forwardurging in terms of the ends-means continuum. The remainder of this chapter expands the first two of these propositions more fully.

\section{TECHNOLOGICAL CONTINUITY}

This section takes up the first stated proposition above--that technology is continuous in terms of the ends-means continuum. The dynamic and progressive qualities of technology are examined in subsequent sections and chapters. Technological continuity relates to where new technology originates and how it is invented, while technological dynamism relates to change or how new technology is innovated. And the progressive nature of new technology has to do with the social integration and diffusion of technology.

\section{Technology and Science}

To say that technology is continuous is simply to say that the discoveries of new scientific insights upon which the invention of new technical means rests is cumulative. New scientific insights involve discovering the existence of something which had been in existence before but had not been previously observed. Invention of new technical means involves 
a deliberate change or adjustment in objects or practices so that a new kind emerges. Invention is always built on the discoveries that precede it. That is, invention of technical means is always based on scientific understanding where that understanding consists of systematized knowledge, and the latter results from the critical testing and verification of hypotheses which purport to link events causally. It is scientific understanding that is cumulative. ${ }^{1}$

It is argued by some that the linkage between technology and science is very tenuous. ${ }^{2}$ According to this view, knowledge is the concern of pure science while use is the concern of technology. Moreover, the discovery of new scientific principles is not an essential precondition to the invention of new technical means. Finally, it is said that early technical discoveries were made by practical men not by men of science, and that little practical use was made of so-called scientific knowledge until the mid-nineteenth century. It can be shown that none of these arguments obviates the nexus between technology and science.

If knowledge is the concern of pure science and use is the concern of technology, it must follow that science has no concern with practical use and technology has no concern with knowledge. Such a view must rest on the notion that knowledge and use are exclusive terms. It might be demonstrated that knowledge may exist independently of its expected uses.

However, past and present practical uses of knowledge is a substantial part of the body of scientific understanding. Therefore, science cannot and does not ignore practical uses because it employs existing understanding to beget additional knowledge, and the uses to which knowledge is put is one form of understanding which science uses in the propagation of so-called new knowledge.

Reproduced with permission of the copyright owner. Further reproduction prohibited without permission. 
Moreover, knowledge is a necessary requisite to practical use or application. Indeed, virtually all knowledge is ultimately used in some practical way. In that sense, knowledge anticipates or even mandates uses. Which is to say that practical uses grow out of knowledge. An important contention in the preceding chapter is that tools which embody technology are important sources of knowledge. Thus, technology is both founded on knowledge and is a significant part of the scientific body of knowledge. It follows that both science and technology are concerned with both knowledge and use or application. Science is concerned with the discovery of knowledge while technology is directed toward the uses or applications of knowledge. Science involves the applications of knowledge to propagate new knowledge, while technology involves the employment of knowledge to new applications.

It is argued that the discovery of new scientific principles is not a necessary precondition for the invention of new technical means, and that technology is therefore not clearly related to science. However, the contention in no way mitigates against the proposition that all technology is founded on scientific understanding. The latter is simply non sequitur to the former. New technological means need not be based on new knowledge. It can merely be a new application of already existing scientific understanding--as, indeed, much new technology is.

Likewise it is argued that so-called practical men (and presumably not the men of science) made the important technical discoveries before the mid-nineteenth century. Here again, the connections between science and technology are supposedly blurred. The argument is apparently based on the unduly restrictive definition of science as only that knowledge which is discovered and systematized through format research employing 
the so-called scientific method. If one accepts that definition, then only those persons who conduct research may be classified as men of science. All others must be placed in other classes.

On the other hand, if one defines science as systematized knowledge, however it comes to be accepted, then the foregoing classification is invalid and the argument is defeated. For example, some systematized knowledge was critically tested and verified by ordinary practice. And yet, such knowledge is accepted by the scientific community without dispute. Is it then less scientific than systematized knowledge that was originally tested and verified by research in a laboratory?

There is no reason why practical men cannot be scientists, or that scientists cannot be practical men. Indeed, the history of science largely ascribes a high degree of practicality to early scientists. And it would seem that modern research scholars achieve greater successes because they also possess practical skills and knowledge of a practical sort. Research skills and knowledge of scientific methods are genuinely practical whether or not one is carrying on scientific research.

Finally, it is argued that little practical use was made of so-called scientific knowledge until the middle of the last century, and that there is therefore no clear connection between science and technology. The argument is based upon the same restrictive definition of science--that only knowledge discovered and systematized through formal research is scientific knowledge. However, if scientific knowledge includes all systematized knowledge, then this argument is also defeated.

Moreover, the enormous acceleration in technical progress since the last century, when scientific understanding became the clear and evident basis of practical applications, further

Reproduced with permission of the copyright owner. Further reproduction prohibited without permission. 
vindicates the notion that science and technology are inextricably and positively related. Thus the nexus between science and technology remains distinct. That is, all technical means are based on scientific understanding. And scientific understanding is continuous and cumulative. It follows that technology is likewise continuous and cumulative.

\section{Cumulative Synthesis}

An example of the cumulative nature of scientific understanding is the history of electrical discovery and the invention of tools based on principles of electricity. Salient features of that history were exposed in the preceding chapter. However, it is useful to draw some of the events out in summary to underscore the continuous nature of technology.

It is recalled that Dr. William Gilbert discovered the existence of electricity in 1600 A.D. While it remained a scientific curiosity for more than 200 years, much was added to the understanding of electricity by other men. It was not until 1823 that William Sturgeon invented the electromagnet. The invention of this little device opened way for the creation of a multitude of tools for control of other implements and for communication. Indeed, all modern communication and control devices use electromagnets in some way.

Eight years later, in 1831, Michael Farraday discovered the principle of electromagnetic induction upon which electric motors and electricpower generators are based. The subsequent invention, innovation, and diffusion of electrical generators and motors has made possible the invention of all kinds of mechanical tools, the development of which would have been impossible without electromagnetic induction.

Thomas Edison invented the incandescent electric-1ight bulb in 1879 . 
While tinkering with his invention he stumbled on the electrical phenomenon which led to the discovery of the vacuum tube. Lee Deforest invented the triode, a variation of the vacuum tube, in 1906. The Deforest vacuum tube led to invention of the radio by Marconi. Subsequent development of the vacuum tube led to the invention of television and digital computers, both of which have become widely used only since World War II.

The discoveries which led to greater scientific knowledge about electricity and its properties were continuous at least from the time of Dr. William Gilbert. Each new discovery was built upon the previous expansions of knowledge. Thus, causal relationships which were discovered in the past became means to future discoveries. Moreover, the knowledge was cumulative insofar as each new generation of discovery made a net addition to the pool of scientific knowledge. Finally, the expansions of knowledge were geometrical in that, like a free electron in a critical atomic mass, each new discovery led to more than one additional invention or application.

All of which says little about the psychological process of invention. There are many theories of invention. One extreme holds that some persons are uniquely endowed with superior intellectual powers and talents which enable them to excel in creative insights. An opposite extreme posits that invention is a coalescing of events which arranges matters so that the invention is inevitable and the inventor was simply fortunate enough to fall into the coalescent situation at a crucial time. Invention is a very complex matter and it is likely that no single, simple explanation will fit every inventive situation.

Nevertheless, persons who have studied the inventive process theorize that it occurs in four distinct steps. The first step is the 
perception of a problem--an unfilled want. The second step involves assembly of the data or elements needed to solve the problem. This must, of course, inciude an individual with the skills needed to manipulate the other elements toward solution. The third step is an act of creative insight in which a novel solution to the problem is conceived. The last step is one of critical revision in which the solution is elaborated and embellished. The solution to one problem leads to new sets of problems so that the process is repeated in what is called a "cumulative synthesis" until a "strategic invention" is developed. ${ }^{3}$

An example of this process, especially novelty in the act of insight, is evident in the words of James Watt. Watt had been studying the Newcomen steam engine for about two years.

I had gone to take a walk on a fine Sabbath afternoon. I had entered the Green and passed the old washing house. I was thinking of the engine at the time. I had gone as far as the Ord's house when the idea came into my mind that as steam is an elastic body it would rush into a vacuum, and if a connection were made between the cylinder and an exhausting vessel it would rush into it and might there be condensed without cooling the cylinder. I then saw that I must get rid of the condensed steam and injection water if I used a jet, as in the Newcomen engine. Two ways of doing this occurred to me: First, the water might be run off by a descending pipe, if an offlet could be got at a depth of 35 or 36 feet, and any air might be extracted by a small pump. The second was to make the pump large enough to extract both water and air .. . I had not walked farther than the Golf house when the whole thing was arranged in my mind. 4

of course, much work remained before Watt could construct a working model of his novel concept. However, the example illustrates how Watt's creative insight was based on elements previously discovered by others-the engine invented by Newcomen, the idea that steam is an elastic body, use of a pump which was the product of novel insights by others, etc. Moreover, Watt's invention produced a practical, working steam engine, but it was only one step in a process of cumulative synthesis which opened 
the way to others who subsequently improved the efficiency of the steam engine by their own inventive insights.

\section{Technological Cross Fertilization}

One additional significance is to be noted. Watt had somehow to gain access to those sundry bits of information. This was no simple feat, since nearly instantaneous communication and enormous banks of information and data did not exist in his day. On the contrary, information which now may be transmitted and received half way around the world in less than a second took several months to travel the same distance under the very best of conditions in Watt's day. Moreover, crucial information was rarely. to be found by simply finding the right book in the nearest library. Where then did the inventors, Tike Watt, of Western Europe gain the information that sparked their ingenuities?

It was a nearly unique conspiration of circumstances which led to the inventions, innovations, and diffusions of technological implements in Western Europe resulting in the renaissance, the reformation, and ultimately in industrialization and urbanization of the Western World. Technological advance emerged in the West from two essential conditions. The first was technological cross-fertilization which introduced diverse technical devices into Europe from other places at crucial times. The second condition was a social climate conducive to innovation. This latter condition is the subject of a subsequent section of this chapter. It is the former condition which is appropriate to the matter at hand.

Technological cross fertilization involves the diffusion of component technologies--somehow bringing together diverse technical devices in the same place and time so that the immediacies and proximities of the devices 
provoke the curious, stimulate their ingenuities, and lead them toward creative insights as to novel technical combinations of the devices. This is accomplished in modern times by the publication of research results which has the effect of communicating new scientific discoveries so they can be critically examined and used by other scholars. However, as noted above, these arrangements did not exist until relatively recent times. How then did it occur in medieval and renaissance Europe? ${ }^{5}$

Technological cross fertilization occurred in Western Europe as a consequence of at least three significant, interconnected series of diffusive events. The first was the repeated invasions from the east, north, and south endured off and on for at least 2,000 years by the peoples of Western Europe. The second was the aggressive responses of the Europeans themselves to threats to their holy places by the Moslem Turks. The third was the resumption of East-West trade during the fifteenth century A.D.

The repeated invasions of Western and Central Europe by the Huns, Turks, and Mongols from the East, the Carthaginians, Romans, and Arabs from the South, and the Vikings from the North brought European tribes forcefulity into contact with widely-divergent cultures. While the Europeans feared and resisted the barbarian invaders, they were brought face to face with both technological and ceremonial aspects of the foreign cultures. They doubtlessly had cause to carefully compare the instrumentalism of the strange technologies with that of their own, and sometimes the tools of the invaders were found to be superior to their own. Occupation of the Holy Land (Palestine) by the Moslem Turks in the eleventh century gave rise to the violent responses of Christendom known as the Crusades. Christianized Europeans responded eight times during 
the 300 years between the tenth and fourteenth centuries to calls by their religious leaders to liberate the Holy Lands from the infidels. More than anything else, the Crusades mark the end of the Dlark Ages and the beginning of the Renaissance in Europe. This time the invading Europeans found themselves immersed in the Oriental cultures of the Middle East, and they acquired tastes for Eastern products and Oriental art which could not be satisfied in their homelands.

The thirst for Oriental culture heightened by the crusades led to resumption and expansion of trade between Europe and the Far Eastern empires. While the commerce was in fine fabrics, spices, and objects of Oriental art, trading brought other aspects of cultures together. Again, the Europeans were able to measure the powers of their own technologies against that of their trading partners. And once again, the Europeans discovered aspects of Oriental technologies complementary or superior to their own. 6

The many centuries of invasions by foreigners, the three centuries of the Crusades, and the resumption and expansion of trade between Europe and the Far East in the centuries following the crusades brought together in Western Europe the conditions needed to launch the mechanical power phase of the industrial revolution. The technological cross fertilization which took place, particularly between the eighth and twelfth centuries A.D. resulted in the diffusion in Europe of many implements and ideas from other areas of the world. The Europeans learned of numerals from the Arabs and zero from the Hindus. They borrowed foot stirrups, the breast harness for horses, paper, moveable type, gun powder, the magnetic compass, and windmills from China. From the Vikings they learned the skill of tacking into the wind with their sailing ships and of rudders 
to steer the ships.

It was immersion in a cross-fertilized technical environment which sparked the ingenuity of inventive men like Watt. And it was their ingenuities operating in such an environment that led to creative insights and novel solutions to the scientific and technical problems of their times. It was the whole process of cumulative synthesis that produced the inventions upon which technological progress was and is founded. Finally, the process of cumulative synthesis demonstrates the cumulative character of science. Since technology is based on scientific understanding, technology is continuous.

\section{TECHNOLOGICAL CHANGE}

This section of the chapter examines the dynamic character of technology. Dynamism is simply the propensity toward motion in anything. It is the opposite of static which is simply the propensity toward rest in anything. To call a body static is to regard it as motionless or changeless. When one refers to the dynamic quality of technology, he is essentially regarding the power of technology to induce çhange.

\section{Tools and Change}

It is recalled once more from the preceding chapter that technology is that quality of a tool which enables the tool to be substituted for human effort in the creation of goods and services having human value. Likewise, it was argued in the same chapter that tools are forward-looking in the temporal and homomensura senses. That is, the use of tools is part of a process of change.

Tools are ends-to-be-reached before they are produced. They exist 
only in human contemplation, and they will not come into existence until there is a deliberate human choice coupled with actions to allocate means to their production. Thus, the creation of tools is forward-regarding in terms of on-going life processes. After tools are created, they are the present effects of the past causes that created them, and they are part of the present means to ends which lie in the future. Finally, they are deliberately brought into use to change existing states of affairs. That is, they are always employed in the present to attain some future end-tobe-reached. Thus the employment of tools is likewise forward-looking in terms of on-going life processes. Tools are therefore implements of change, and their powers of change depend on the technologies resident in them.

It is worthwhile to observe that changes will occur in people and their environments whether or not they possess or use tools. One will starve to death if he does not consume food whether or not he produces the food through tool use. Climates change annually and geological changes occur usually over relatively long spans of time whether or not people use tools. Individuals grow older day by day whether or not they use tools. Iron rusts, copper corrodes, and wood decays whether or not people use tools. All of which is to say that in the very long run there are no truly static situations. Rather, there are only relative states of dynamism, and the dynamism of so-called nature is heavily weighted on the side of what man can only view as decline and decay. To repudiate tools and technology will therefore not stop change. It will only reduce man's ability to influence change in his own interests.

Mankind, like all living creatures, seeks to enhance his own welfare by controlling the direction and magnitude of change. His capacity to 
influence change is obviously related to the quantity and quality of the tools.he uses and the intensities with which he uses them. From this, one can conceive of at least three separate scenarios of change. The first has to do with the intensity with which society uses the existing stock of tools. The second is the rate at which net additions are made to the existing stock of tools, assuming no qualitative changes. The third is the rate at which the technical quality of tools is changed. Technical quality relates, of course, to the ability of a tool to substitute for human effort in production processes. Thus, the third scenario concentrates on technological change.

One can also think in terms of a fourth scenario of change, a composite of the three separate scenarios; the rates at which both the quantity and quality of tools are increased, and the intensity of use of existing tools. This is more realistic because all three scenarios are playing more or less simultaneously most of the time in most societies. However, it is useful to separate the scenarios for purposes of study. The focus of this section is on the third scenario, the one dealing with technological change. It is acknowledged that the preceding two scenarios--intensity of tool use and net increases to the stock of tools-will reflect social changes. The principal changes with scenarios one and two are economic and political adjustments within existing institutional arrangements. That is, they are very unlikely to trigger forces with the power and direction to affect any significant institutional changes. On the other hand, the third scenario reveals the root causes of social revolutions. That is, technical change is most likely to trigger forces with the power and direction to affect significant institutional changes. It is, therefore, technological change which has the 
greatest dynamism.

Focusing then on the third scenario, it is argued that the innovation of new technology--to improve the technical qualities of tools so tools substitute for more units of labor in production--is socially unstabilizing because it organizes means (divides labor) and opens ways of distributing social products differing from the ceremonially-prescribed methods descending from the past. It therefore opens opportunities to change prior existing social statuses and ceremonial systems of rank, and it affords new avenues of social mobility. The roots of social revolution are therefore grounded in the innovation of new technologies--technologies that increase productivity in terms of output per man-hour. Revolutions occur when technological innovation changes interinstitutional relationships such that one or more institutions cease to be wholly complementary within the institutional system. That is, there is a lack of integration and correspondence between interinstitutional ceremonies. Some institutional values and the ceremonies built on them become dysfunctional. The ensuing social instability reflects attempts by the institutional system to adjust itself in the face of the technical change. Social stability is resumed when the new technology is fully integrated and institutions have adjusted their ceremonial systems to account for the technical changes. Integration relates to the progressive quality of technology. Technological integration and diffusion are introduced in the next chapter and described in the remaining chapters of this work.

\section{Technology and Cities}

The foregoing is an abstract and syllogistic argument based on 
several definitional presuppositions which were developed in earlier chapters. Little more need be said at this juncture in explanation of the propositions. However, they require embellishment with concrete examples in the context of institutional economic theory. An example which illustrates the dynamism of new technology in accord with the theory is drawn from the history or urbanization in the Western World.

It is necessary to pause for a moment to consider why cities come into existence at a11. An answer is found in central-place theory and in the theories of location and agglomerative economies. The first has to do with specializations based on the internal economies of large-scale production and the latter has to do with external economies of location and scale. 8

Central-place theory argues that specializations occur because of internal economies of large-scale production, and it is 1 imited by the cost of transporting the resulting products to customers. If, for purposes of illustration, one assumes a featureless plain (a so-called von Thunen plain) on which transportation is as efficient in one direction as in another, and resources are distributed eventy, then there need be no inter-family specialization. ${ }^{9}$ Society might consist of many independent and self-sufficient families evenly distributed over the plain.

According to the foregoing assumptions, each family would grow its own grain, mill its own flour, and bake its own bread. Likewise, it would weave its own cloth and fashion its clothing. In addition to providing its own material needs, it would render needed services. The family would supply whatever medical care its members required, and it would govern itself, educate its young, and provide religious services for the spiritual needs of its members. The quality of goods and services 
would be extremely primitive and the quantity meager, consisting of only that which the family could produce for itself. While there might be intrafamily specializations, there would be no interfamily specializations, and no trade or commerce between families. In short, society would consist of few institutions--perhaps only the family, marriage, and spoken language. One can easily see why the family would loom enormously important in human affairs under such primitive circumstances.

The question is, are there any forces that might operate toward interfamily specializations? The answer is that there might be if families lived close enough to one another that goods and services could be economically transported between them with the prevailing transportation technology. That is, the division of labor (specialization) is 1 imited by the extent of the market. As should soon be evident, the extent of the market is likewise limited by the state of technological development. But this moves ahead of the matter at hand. It is enough now to deal with specialization in terms of the extent of the market--given a state of technological development.

For example, suppose that one family on the plain acquired a particular aptitude for milling flour. Members of the family accordingly developed great skill in milling techniques. That is, they became especially adept at employing the milling tools. They perhaps accomplished this by discovering that the mill stones and other milling equipment employed by them and by their neighboring farmers possessed greater productive capacity than was generally achieved in small-scale operations. That was because the average farmer could not achieve an optimum rate of output for the tools if he milled only for his own family. Thus, economies in the form of lower man-hour costs could be achieved per pound of flour 
milled by increasing the rate of output. Increases in the rate of output necessarily meant changing the milling technique by organizing production around the milling process. That is, the human skills of the efficient miller are organized by the milling tools he uses.

Suppose further that the family decides to offer to mill the flour of several neighboring families if the farming families will supply the miller family with grain. Under what conditions is the miller family enterprise likely to be successful? Clearly, the exchange must prove to be beneficial to all parties if the enterprise is to succeed. Therefore, the neighboring farmers will purchase the miller services only if the man hours gained in not milling their own flour are equal to or exceed the man hours expended to cultivate, harvest, thresh, and transport the grain given the miller family in payment for its service. Likewise, the miller family will find it worthwhile to mill its neighbors' flour so long as the man hours taken in milling the flour are equal to or less than the man hours it would have to expend to cultivate, harvest, and thresh the grain it receives in payment for the milling services.

The miller family would succeed in selling its services under the foregoing circumstances so long as the cost it saved by milling in large quantities exceeded the cost to transport the grain to the mill and the flour back to the neighboring farmers. To illustrate this, suppose that the average farm family can produce one bushel of grain (on the average) with five man hours of labor. Suppose further that the average farm family can mill 33.3 pounds of flour at home from approximately one bushel of grain in one and two-thirds man hours of labor. Thus, the opportunity cost (the grain production that must be given up) to mill 33.3 pounds of flour is one-third bushel of grain, and the opportunity 
cost for the average farmer to produce one bushel of grain is 100 pounds of flour. The average farmer family will be willing to pay up to onethird bushel of grain for milling 33.3 pounds of flour.

Assuming that the prospective miller family is also an average farm family regarding grain production, it can produce one bushel of grain with the average expenditure of five man-hours. However, it finds that it can mill 33.3 pounds of flour in only one hour by milling in large quantities. The opportunity cost (the amount of grain production that must be given up) for the miller family to mill 33.3 pounds of flour is therefore only one-fifth bushel of grain. That is, the family will be willing to mill 33.3 pounds of its neighbors' flour so long as it receives no less than one-fifth bushel of grain in payment. Thus, the prospective miller family has a comparative advantage in the milling of flour because its opportunity cost to mill is less than that of its average farming neighbor. On the other hand, it has a comparative disadvantage in the production of grain because it must forego the milling of 167 pounds of flour to produce one bushel of grain, as compared with only 100 pounds for its average farming neighbor.

Since the miller family has a comparative advantage in milling flour, and its farming neighbors have comparative advantages in producing grain, inter-family specialization is possible as long as the spread between their reciprocal offer prices is sufficient to cover the costs to transport the grain to the mill and to return the flour to the neighboring farmers. It is recalled that the farming families are willing to pay not more than one-third bushel of grain to have 33.3 pounds of flour milled. And the miller family is willing to mill 33.3 pounds of its neighbors' flour for not less than one-fifth of a bushel of grain. Thus, the spread 
between their reciprocal offer prices is $1 / 3-1 / 5=3 / 15$ bushels of grain for milling 33.3 pounds of flour.

Assuming that the most efficient means of transporting cargo is a two-wheeled ox cart, and that the cart can effectively carry 500 pounds of cargo at three miles per hour, who will transport the grain and flour? The farmers? Or the miller? And why? It can be shown that the farm families will transport their grains to the mill and return the milled flour to their farms. This is because the farmer's opportunity cost to transport. goods is less than that of the miller if the latter has succeeded in specializing in milling flour. It is true that the opportunity costs in terms of the bushels of grain foregone to transport goods under the above assumptions is the same for the farmers and the miller (1/5 bushel to carry 500 pounds three miles in one hour). However, their opportunity costs in terms of pounds of flour are different. The farmer must forego only twenty pounds of flour to transport goods subject to the preceding constraints. The miller's opportunity cost is 33.3 pounds of flour (approximately equal to one bushel of unmilled grain). Thus, the farmer will transport both the grain and the flour.

What, then, is the extent of the miller family's market? It is necessary to calculate the maximum allowable transport cost, and then apply that to the farmer's opportunity cost for transporting his grain and flour to and from the mill. It will be found that the maximum allowable transportation under the foregoing assumptions is the spread between the reciprocal offer prices (2/15 bushels of grain per 33.3 pounds of flour) multiplied by the cart capacity (500 pounds of flour). This places the maximum transportation cost the farmers are willing to bear at two bushels of grain. The same results obtain if one calculates the total transport 
cost using the spread between offer prices stated in pounds of flour. However, it is desirable to keep the cost and price stated in terms of bushels of grain since that is the medium in which the farmer will pay the miller.

The total allowable travel distance is then the maximum transportation cost (two bushels of grain) divided by the farmer's opportunity cost for transportation ( $1 / 5$ bushel of grain per three miles in one hour). The maximum allowable travel distance is therefore thirty miles. If it is assumed that four trips (two in and two back) are required to complete the transaction, then the miller's effective market radius is $7-1 / 2$ miles (30 miles divided by four trips). That is, farming families living within 7-1/2 miles of the miller's farm will find it beneficial to use the miller's services, if the miller family charges no more than one-fifth bushel of grain to mill 33.3 pounds of flour, or $3 / 5$ bushel for 100 pounds of flour. Clearly, those families living closer than $7-1 / 2$ miles from the miller place will receive a bargain because of their lower transportation cost. And families living more distant than 7-1/2 miles will choose to mill their own flour.

One can see that the miller family might devote so much time to the milling of flour that it could no longer farm its land efficiently. It would perhaps trade some of its land for the mill stores and other mi11ing equipment no longer used by neighboring families. Moreover, as the miller family became more and more specialized in milling flour, it would gain in skill at milling while diminishing in the skills of farming. And, as the millers concentrated more and more on their tools, they might invent technical improvements in them so as to further increase their productivities. Likewise, the neighboring families could efficiently farm 
the additional lands they acquired from the miller family by simply reallocating the man hours released from milling flour to the cultivation of crops.

The preceding analysis demonstrates how conditions might coalesce to cause interfamily specialization. In the example, the miller place became a central place; a point to which the surrounding farmers brought their grains for milling into flour. This came into being because of the specialization precipitated by the technology resident in tools that led to internal economies of large-scale production, and because the market was great enough to permit expansion to a scale of output that could achieve those economies. But more important, the extent of the market was constrained by the cost of transportation, and this latter cost was a function of the technology resident in the tool of transport-the ox and two-wheeled cart.

Milling flour in this example became an export base industry--an industry that produced a surplus that could only be sold outside the region in which it was produced. The miller family milled a surplus by producing at a rate of output sufficient to achieve maximum efficiency from its tools. And the surplus was exported in exchange for grain which neighboring families could likewise produce in modest surplus. The grain surplus was possible because the neighboring families could more fully specialize in cultivation by reallocating some of their productive labors from milling to farming, and exchanging parts of their surpluses for flour milled by the miller family. Thus, the surpluses behind exportbase activities are found primarily in internal economies of large-scale production.

On the other hand, the extent of the market for the miller's surplus Reproduced with permission of the copyright owner. Further reproduction prohibited without permission. 
was determined by the density of population and the cost of transportation. The cost of transportation was a function of location and the technology resident in the tools of transportation. Both of these economies were external to the miller family. That is, they were external economies of location and scale. They were therefore local base phenomena-economies related to the attributes of locale. The significance of both local-base and export-base activities will be expanded below and in the next chapter.

If one central place for milling flour can emerge because of internal economies of large-scale production and the consequent interfamily specialization, then it will likely occur in other areas by diffusion. Observing the benefits of specialization, other families might also choose to specialize in milling flour. In so doing, they would seek to avoid competition by locating sufficiently distant from the original miller family and any others who might be emulating it so that their market areas were exciusive. That is, they would attempt to create a geographic monopoly. However, as more and more families entered milling, all market areas would be taken and competition would emerge. Eventually, the entire plain would be covered by central miller places so that no farming family was more distant from a miller place than 7.5 miles. Thus, the circles of adjoining market areas would overlap slightly because some farm families would be more distant from a miller place than 7.5 miles if they did not overlap. Therefore, the shape of each miller place would be hexagonal--according to the von Thunen assumptions. And the maximum distance between central miller places would be only thirteen miles ( $2 \times 7.5 \times$ sine 60 degrees) rather than double the radius (or fifteen miles).

The forces that brought forth central miller places will operate in 
time to produce other forms of interfamily specializations. For example, another family might have a particular aptitude for baking bread, and its members may have developed great skill in employing the tools of baking. If the family found that it could reduce its average man-hour cost per loaf of bread by increasing the number of loaves it baked at one time, it likewise found that it had a comparative advantage in baking. If it also found that there were enough neighbors willing to exchange grain for the bread it baked, the family could choose to specialize in baking.

Like the milier family, the family that chose to specialize in baking created a central place--a place where neighboring families could exchange grain for bread, allowing those neighboring families to reallocate their productive labor from baking to those other productions in which they were relatively more efficient. However, the baker family need not necessarily be located at the same place as the miller family. Likewise, the baker family will have a different market area--probably much smaller than that of a miller family. While it might be feasible to make only two round trips per year to the miller, the purchase of fresh bread will obviously require more trips to the baker. Moreover, the opportunity cost to travel any distance simply to purchase four or five loaves of bread is very great, and thus the distance one was willing to travel to buy bread would be commensurately short.

And again, like the diffusion of milling, a successful specialization in baking is likely to migrate to other areas of the plain until the entire plain is covered by a network of small markets, each one surrounding a central baker place. In time, one might also find networks of central places for wagoner families, weaver families, tailor families, 
shoemaker families, cartwright families, seller families, and many more. A11 will have come into existence as specialists in pursuit of increasing returns to scale. That is, they will have taken advantage of the internal economies of large-scale production. And the magnitudes of those economies were determined by the technologies resident in the tools of their trades. Likewise, the extents of their market areas were constrained by the technical qualities of their tools of transport.

However, a central place established around a single economic institution like a flour mill or a bakery does not make a city. It is true that cities might rise simply because of the coincidences of many networks of central places spread randomly over a featureless plain. That is, some central places would assume greater importance than others because the random distribution of networks of miller central places, baker central places, weaver central places, and other central places would coincide at some points. Thus, more than one specialization could be found at the points of coincidence. A hierarchy of central places would eventually emerge in which the first order comprised those central places at which a single specialization was located--say a bakery. Second-order central places would be those at which two or three specializations were found-a baker, a miller, and a weaver. The highest-order central place would be that one on the plain at which the greatest number of specializations was located.

While central-place theory produces a consistent and relevant explanation of urbanization built upon internal economies of scale, it is grossly over-simplified. One can visualize something like the foregoing example occurring near the center of a large, homogeneous mass of flat, arable land. But even under those conditions, there are other 
forces operating to produce urbanization. The example can be brought closer to reality where those other forces can be observed by relaxing its simplifying assumptions. To do so, however, introduces complexities that go beyond the level of analysis desired here. Nevertheless, it is useful to relax the most gross assumptions of the model so that economics of location and agglomeration can be illustrated.

When one departs from the von Thunen assumption, he contemplates a geography on which each site possesses unique spatial and locational qualities. The land possesses peculiar topographic features like forests, rivers, alluvial valleys, hills, coastal reaches, and regions with particular mineral deposits. That is, the land endowment is heterogeneous, absolutely finite, and perfectly immobile so that no one site is a perfect substitute for any other site. Communities in such a world tend to form at those places that confer on their users particular advantages of location or access. Such advantages stern from external economies--cost advantages of location that lie outside the control of individual institutions. The external economies are attributes of local base activities.

External economies may apply to transportation cost or to production cost. Transportation-cost orientation arises when the transportation costs are high in relation to production costs, and productioncost orientation prevails when transportation costs are low in relation to production costs. 10 It can be shown that institutions which are transportation-cost oriented will settle on locations that minimize transportation costs. This will be at either the market locations for their products, or at the resource locations. To locate some place between their markets and their resources will involve higher

Reproduced with permission of the copyright owner. Further reproduction prohibited without permission. 
transportation costs because they must bear two sets of terminal costs-one for resources and one for finished products. One set of terminal costs can be avoided by locating at either the market or the resource end. In general, transportation costs will be lower at the resource end for those institutions which produce goods that lose perishability, weight, or volume in production. For example, the smelting of ore results in the loss of both weight and volume. Likewise, food processing results in loss of perishability. Those industries tend to locate in their, resource areas. On the other hand, transportation costs will be lower at the market end for those institutions that produce goods that gain fragility, perishability, weight, or volume in production. For example, baked goods gain perishability, and automobiles gain volume in production. Those industries therefore tend to locate near their markets. Conversely, some institutions are production-cost oriented. 11 That is, their products possess low bulk-to-value ratios so that transportation costs are low in relation to production costs. Such institutions tend to settle on locations that minimize production-related costs. Thus industries that use labor-intensive processes tend to locate in areas where the wages are relatively low for the skills they employ. Likewise, industries that use power-intensive processes tend to locate where electrical power is relatively less expensive. Finally, those firms that require specialized auxiliary services or regular faceto-face contacts with suppliers or clients tend to locate where those services and contacts can be readily obtained at least cost.

The point is that specializations rising to internal economies of large-scale production produce economic institutions. Those specialized institutions locate themselves so as to take advantage of external

Reproduced with permission of the copyright owner. Further reproduction prohibited without permission. 
economies of location where the costs of transportation or production or both can be minimized. Once established, such locations become central places where human interactions take place according to the character of the institutions located there. And major cities rise at those places where external economies confer abundant cost advantages.

In addition to external economies of location, cities also possess external economies of large urban scale. Such scale economies arise from agglomeration--a balling up of many interdependent institutions at some central place. ${ }^{12}$ External economies of urban scale stem from the progressive specialization of institutions. For example, it is not profitable to invest in expensive equipment to make a single component on a small scale, and production of such a component may be very laborintensive on a small scale. But as the industry expands, a new firm may come into existence to manufacture the component on a large scale and supply it to other firms in the industry. And, of course, those other firms will cease to make the component on a small scale.

The functions delegated by one industry to auxiliary and complementary industries must usually be performed in close proximity. This is a potent factor in the geographic concentration of industries. And the geographic concentration of industries allows an efficient specialization of the local base firms that create the external economies for the industries they serve. Moreover, the external economies involve true reductions in the real costs of social output. They are not just zero-sum savings--savings by one firm at the expense of another firm. Therefore urban agglomeration is a socially-redeemable phenomenon. ${ }^{13}$ Agglomeration may be understood in terms of the example describing internal economies of large-scale production and the specialization of 
millers and bakers. One may consider whether there are any factors that might cause a baker family to locate at or near the site of a miller family. Clearly, the baker family will find economies external to itself operating to cause it to locate near a miller family. It will find some commerce already centered on the miller place, and the miller can supply the flour needed in baking without charging a transportation fee.

In time, perhaps, a wagoner family will locate near the miller place; then a weaver, a tailor, a shoemaker, a cartwright, and a seller. Before long a community of families and other institutions grows large enough to organize itself and to provide public services like a school, hospital, and constabulary. It is when this kind of balling-up occurs at some central place that a city is formed. The process is called agglomeration, and the organizing principle is external economies of urban scale.

The foregoing is an explanation of why cities come into existence. The explanation was found in central-place theory and in the economic theories of location and urban agglomeration. The first had to do with interinstitutional specializations rising to the internal economies of large-scale production, and the latter had to do with the external economies of location and urban scale. Both internal and external economies relate to productivity in terms of output per man hour, and productivity is a function of the technical qualities of tools. Thus, cities are fundamentally creatures of technology--agglomerations of institutions that have come into existence through interhuman specializations developed in pursuit of increasing returns to scale. With this background, one can more clearly understand the forces compelling urbanization in the Western world.

Reproduced with permission of the copyright owner. Further reproduction prohibited without permission. 
Technology and Urbanization

Time and space do not permit any more than a brief summary of the urbanization features salient to the theory at hand. Moreover, the processual details of innovation are left to subsequent parts of this chapter. This section introduces the antecedent technological causes of the urbanization which occurred in Western Europe, particularly, following the medieval period. This was a time of rapid urbanization followed by shifts in political and economic power from Mediterranean regions to northern Europe.

In the way of prefatory background, the first cities were believed to have been founded in Mesopotamia during the fourth millennium B.C. They evolved from quasi-urban communities of less complex social organization. And quasi-urban communities evolved from neolithic folk societies on the order of those described in preceding chapters. The typical folk society is small, illiterate and self-sufficient with a biological division of labor based on the most primitive neolithic technologies. The members are exclusively engaged in collecting food in an unremitting struggle for existence. Norms are highly prescriptive and there are virtually no alternative lifestyles open to members. ${ }^{14}$

Quasi-urban communities arose from preliterate folk societies with the agricultural surpluses produced by the domestication of animals and the merging of animal husbandry with crop cultivation. The oldest known quasi-urban community is prehistoric Jericho at the conflux of the Jordan River and the Dead Sea. Jericho is bel ieved to have been founded sometime in the seventh millennium B.C. The conditions necessary for development of such preliterate communities were a technology capable of producing a surplus of agricultural products, a suitable ecological base, and

Reproduced with permission of the copyright owner. Further reproduction prohibited without permission. 
a social organization extending beyond the family institution.

Technological advance must be great enough to allow the production of a food surplus beyond that needed to sustain the farmers between harvests. The agricuitural surplus must be great enough to free some members from the primary employments of food cultivation and gathering so that they may specialize in skills needed to augment the community in secondary employments--security, transportation, and administration. As noted above, the technological advance that presaged evolution of quasi-urban communities was domestication of animals and the subsequent employment of animals at draught. These technical improvements led to the internal economies of scale that facilitated the specialization and division of labor.

A suitable ecological base is one in which there is an adequate water supply, and the soil and climate are capable of producing sufficient agricultural goods with the prevailing technology to support the population of the community. This accounts in part for the selection of places like Jericho in the Jordan River Valley and Jarmo in the Mesopotamian riverine system as the first sites for quasi-urban communities in the West. It also suggests why cities did not emerge in the northern-most and southern-most reaches of the temperate zones unti1 much later. Weather in those zones was less hospitable and the technology needed to sustain an agricultural surplus in those soils and climates did not exist until much later.

The social organization of a quasi-urban community must be sufficiently advanced to provide an institution of government with enough power and ability to direct the activities of others. Likewise, there must be economic institutions of sufficiently integrated occupations and 
specialized labor skills to provide security for the community and to manage the agricultural surpluses. The crops require planting, cultivating, and harvesting. Harvested products must be transported from the fields to storage. They must be secured from marauders, and they must be rationed out to members of the community at appropriate times.

The chief differences between quasi-urban communities like Jericho and Jarmo and urban Ur and other feudal cities of the Tigris-Euphrates riverine system are technologies, the complexity of social organization, and literacy. It is no coincidence that the first feudal cities were founded pari passu with the invention and innovaticu of copper tools. The technological advances that first produced feudal urbanization was metallurgy--copper mining, smelting, and smithing. The use of copper produced more productive tools and improved means of transportation. These in turn led to larger agricultural surpluses and increased specialization and agglomeration--the movement of more persons from primary to secondary employments.

Likewise social organization in feudal cities had to be much more complex. In addition to the security and management of agricultural sur pluses provided in quasi-urban centers the new urban areas added manufacturing and commercial institutions. The mining of copper generally took place some distance from cities, and ore of semi-processed copper had to be transported back to the city. Some part of the urban population had to be organized as craftsmen and artisans in well-integrated processes for copper smelting and smithing to produce the tools and implements made of the new metal. Finally, the economy had to be far enough advanced to carry on commerce in resources, manufactured goods, and food. 15 Commerce, of course, gave rise to record keeping and thus to 
developments in mathematics and written language. Indeed, most anthropologists distinguish the city from the quasi-urban community on the basis of 1iteracy. According to this idea, a written language is clear evidence of a well-advanced and complex social organization. The folk community had no written language, and the feudal city did. However, one should not miss the point that the social organization is a complex of institutions which have been shaped in part by technology--that quality of a tool that enables it to be substituted for human labor in production processes. 16

The feudal cities of Mesopotamia at the end of the fourth millennium B.C. contained populations estimated between 5,000 and 20,000 persons. By the beginning of the second millennium, the inner city of Ur was believed to domicile upwards to 34,000 persons. Such cities that somehow survived into the 19th century ranged in population from 5,000 to 100,000 inhabitants. ${ }^{17}$

The spatial and institutional arrangements of feudal cities are remarkabiy similar. The center of the city is the seat of governmental and religious activities, and it generally contains the residences of the elite. Lower classes are scattered in descending social order toward the city boundaries. The members of an occupational skill live and work in a particular area of the city. The family unit is patriarchal, and it is the principal socializing institution in the city. One is born into a family in a particular social stratum, and he must usually live out his life according to the norms of his class. Only the elite are literate because only the elite are educated. And the educational system is oriented to transmission of the city's traditions and ceremonial values. For the vast majority communication is by word of mouth, and news is 
disseminated by heralds and criers.

Economic institutions in the feudal city are not well developed as compared with an industrial city. Production is based exclusively on human power and the power of other animals. The division of labor centers on product, not process. The principal production institution is therefore the guild, and the guild functions primarily to set prices and limit competition in its line of commerce. Typically, there is little standardization of weights, measures, and currencies. Credit and thrift institutions are very meager if they exist at all. Each feudal city with its agricultural environs is a self-sufficient entity and there is a minimum of commerce and other friendly intercourse between feudal cities.

The ruling authorities of the feudal city are based on absolutes and tradition. The political and religious institutions are rigidly hierarchical, and decision-making knows no rules beyond the ceremonial status and power of the person in authority. Religion is very prescriptive, and it is a powerful instrument for preserving order and maintaining social stability in the feudal city. In a word, the feudal city "emphasizes ceremonial rigidity and particularism." 18

By contrast with the feudal city, the modern industrial city flourishes because of class fluidity and universalism. Status is based more on achievement than birth, and occupational positions are filled according to universalistic principles rather than particularistic. The family unit is loosely organized and members are relatively free to depart its influences with few restrictions. Many institutions are involved in socialization processes. A particularly important socializing institution is the public-school system. Universal mass education is a necessity in the industrial city. And only an industrial society is economically

Reproduced with permission of the copyright owner. Further reproduction prohibited without permission. 
capable of freeing large segments of $i$ ts population from productive employments to be educated.

The economy of an industrial city thrives on mass-production methods powered by mechanical engines and electric motors. Indeed, the widespread use of mechanical power to replace animal power is the chief technical distinction between industrial and feudal cities. The distinction is crucial because it is the foundation upon which other distinctions are based. Production is carried on by large-scale enterprises in the industrial city, and labor is specialized along process lines rather than by product lines. There is strict standardization of weights, measures, and currencies. The institution of banking is well developed and credit is usually available. Industrial cities are interdependent and they are connected by well-used transportation routes, communication systems, and commerce and banking ties.

While the social organization is complex, the industrial city usually has a weak power structure as compared with the feudal city. Formal rules rather than ceremonial appeals to personal authorities are more used in bureaucratic decision making. Governing authority is based mainly on ceremonial consent of the governed and appeals to scientific experts. Indeed, the scientific tradition is a particular ceremonial mark which distinguishes the industrial city from the feudal city. Finally, religion is usually more permissive than prescriptive in an industrial city. ${ }^{19}$

The foregoing relates to the spatial and institutional characteristics of the societies described. These characteristics are the static elements in society. They are cross-sectional like a photograph snapped at some particular time. They show what apparently existed at the time, but they reveal nothing about how the objects in the photo came to be 
what they were when the picture was taken. The question is, what were the dynamic elements that caused changes over time?

The essential differences in the states of development from a folk society to an industrial city are the productivities of each in terms of product outputs per unit of labor input. Thus they are differences in states of technological development, or the technical qualities of tools used by each. The agent for change in each case was new technology. It was the innovation, integration, and diffusion of draft animals for cultivation and transportation that moved society from the folk stage to the preliterate, quasi-urban community. It was the innovation, integration, and diffusion of metal tools that moved society from the quasi-urban community to the feudal city stage. And it was the innovation, integration, and diffusion of mechanical power and electrical-control devices that moved society from the feudal city to the industrial-city stage.

Turning now to European urbanization, Europe was populated by smal1 tribes organized as folk societies until well into the first millennium B.C. Cities did not appear on the continent of Europe until nearly 3,000 years after the founding of the first cities of Mesopotamia. The first European cities were built by Achaeans, Dorians, and other indo-European tribes who invaded from the north into the Aegean area and by the Etruscans in Italy. The former were masters of iron, and their triumphs over the original inhabitants of the Aegean lands were the triumphs of iron, for the original inhabitants had not yet acquired skill with the new metal.

The new Greeks found the unyielding terrains of the Balkan Peninsula and the Peloponnesus unsuited, with the technologies prevailing at the time, to the production of sufficient agricultural surpluses to support cities. They therefore learned seafaring from their Minoan and Phoenician

Reproduced with permission of the copyright owner. Further reproduction prohibited without permission. 
predecessors, and they produced their surpluses by fishing and by trading and warring with other Mediterranean peoples. The Greeks also learned city building from their southern Mediterranean neighbors, and Corinth, Sparta, Athens, and other Greek cities were established by the eighth century B.C.

At the same time, the Etruscans were building Pisa, Siena, and other cities on the Apennine Peninsula. As already noted in Chapter IV, Rome was founded in the seventh century B.C. at the frontier between Etrusca and Latium. Rome ascended to dominance over Etrusca by 500 B.C. and over Greece, Persia, and Carthage by the end of the Punic Wars. She pushed her borders to the outward limits of the then civilized world by the end of the first century B.C. Indeed, wherever one found Rome, he found at least a veneer of civilization also. Many of the major cities of Europe were established by Rome or because of Rome. They include such cities as Paris, London, Brussels, Cologne, Seville, Bordeaux, Vienna, and Belgrade.

The collapse of Roman power and the recession of her authority from Central and Western Europe in the fifth century A.D. brought chaos and decline in European commerce and trade with the East. It also brought the internal strife and the barbarian invasions from the east, north, and south which merited comment earlier in this chapter. The result was an arrestation and retrogression in European city development. Except for those cities under the influence of Byzantine and Moslem administrations, the cities of Europe declined in population and power.

After nearly five centuries of eclipse, the cities of Europe commenced a vigorous resurgence. Starting in the tenth century A.D., the center of economic and political power shifted gradually northward from 
the Mediterranean to west central Europe. One manifestation of the shift was a rapid increase in both population and urbanization. The old European urban centers revived and the era is distinguished by the proliferaticn of new urban communities in northern Europe. ${ }^{20}$

The question is, why did urbanization resurge in Europe when it did? And how did Western European nations come to possess the powers that accrued to them in the middle of the second millennium A.D.? Some writers attribute the revolution to developments in Christian religious thought. Others believe that it occurred because of charismatic political and military leadership on the parts of some monarchs which enabled them to win diplomatic and military capitulations from lesser adversaries so that kingdoms were expanded and empires formed. Still others believe it was the early seeds of capitalism with its reliance on markets and the expansion of commerce and banking.

In a sense it was all of these phenomena--and in another sense it was none of them. All of these happenings did, indeed, occur at crucial times. But they were the surface conditions of causes that lay much deeper. The roots of the revolution lay buried in the soil of technological change. Moreover, the technological changes occurred between the middle and end of the medieval period preceding the emergence of Europe out of the Dark Ages and into the Renaissance.

The technical changes which lay behind the vigorous resurgence of European cities took place first in agriculture and warfare, and then in transportation. The changes involved the innovation of a heavy plow to replace the ancient scratch plow, innovation of a triennial system of crop rotation, and development and use of the heavy horse first in warfare then in agriculture and transportation. The combined effects of these 
innovations was a substantial increase in agricultural productivity, increased efficiency in overland transportation, increases in populations, and rural to urban migrations.

The next chapter deals with the integration and diffusion of the heavy plow, the triennial system of crop rotation, and the heavy horse, and with the demographic changes and social progress precipitated by innovation of those technical improvements. However, the matter at hand is: why did innovation of these devices first take place in Europe at that time? Most of the technical means were known earlier by other societies in other parts of the world. Why did those other cultures fail to innovate and exploit the technical devices that initiated revolution and social progress in Europe? What was the unique combination of circumstances that caused Europeans to pick up on some technologies that were discovered but not effectively innovated by other cultures?

\section{TECHNOLOGY AND CEREMONIALISM}

The reasons the heavy plow, triennial field rotation, and the heavy horse were first innovated in European agriculture was because of the invention spurred by the technical diffusion and technological cross-fertilization that was taking place there and because ceremonialism had a very tenuous hold on the peoples of Europe at the time. The technological cross-fertilization taking place there was described earlier in this chapter as an element in invention. The reasons ceremonialism was weak in Europe during that period will be described later in this section. First it is necessary to set the ceremonial conditions of pre-renaissance Europe aside to examine the elements of institutional economic theory that impinge upon the innovation of new technologies and its relationship

Reproduced with permission of the copyright owner. Further reproduction prohibited without permission. 
to ceremonialism.

The existence of technological cross-fertilization is necessary for invention and thus for innovation, but it is not a sufficient condition for the innovation of new technologies. It is possible for new scientific discoveries and technical inventions to occur without innovation, integration, and diffusion following. A weak ceremonial system is also required. It is the simultaneous occurrence of technological cross-fertilization--to facilitate invention--and weak ceremonial practices that leads to the innovation and integration of new technologies.

Weak ceremonial practices are necessary to the innovation of new technologies because of the disaccord between technology and ceremonialism. Ceremonialism is tradition-bound and change-resistant while technology is dynamic and change-producing. The remainder of this section examines the nature and conditions of the innovation of new technologies and the relationship of technical innovation to ceremonialism and institutional change. ${ }^{21}$

Innovation of New Technology

New technologies are initiated through a process of innovation. Innovation is simply the production of changes through the introduction of novelties. The novelties are, of course, the new technologies, while the changes are the cultural consequences of the novelties. Innovation is different from discovery and invention. Invention is a deliberate change or adjustment in objects so that a new kind emerges, while discovery is the perceiving of something which had been in existence before but had not previousty been observed. Invention is a condition of innovation as discovery is a condition of invention. It is possible to have discovery without invention, and invention without innovation. It is not possible 
to have innovation without invention, or invention without discovery. ${ }^{22}$ There are no social effects from discovery and invention alone. The social consequences of invention do not commence until innovation takes place and the novelties of invention are introduced. To be sure, invention is a necessary ingredient of innovation. But nothing will happen, whatever is invented, until innovation takes place. Moreover, both discovery and invention in the modern age are largely products of institutional research carried on with the expectation of innovation. Thus, innovation is the centerpiece of technical progress and institutional change.

As invention is the product of the inventor's genius, so innovation is the work of the innovator. The inventor of a technical improvement is rarely its innovator because the motives and tinkering skills of the inventor are not the same as the entrepreneurial skills of the innovator. It is the rare person who possesses genius for both invention and entrepreneurship. For example, DeForest, mentioned earlier as inventor of the triode, went broke several times trying to put his invention to commercial use. Yet others successfully innovated DeForest's important inventions. The same fate has befallen many inventors. Many have tried to be innovators. Few have succeeded. Ironically, the pages of history are covered with the names of inventors, but one finds few names of innovators. Given the central and crucial nature of innovation, it would appear that altogether too little attention has been given to the study of innovation and innovators.

Nevertheless, the innovator is the key to innovation, the centerpiece of technical advance and institutional change. His role is that of entrepreneur. As such, he is forward-10oking in terms of the ends- 
means continuum. He seeks to organize present means in the least costly and most efficient way to achieve future ends-to-be-reached. And since the future cannot be known with certainty, there is risk that the outcomes of present choices will not be as expected. Thus, the function of the entrepreneur is to bear the risks of failure--not to fail, but to make calculated present decisions, the future outcomes of which are inherently uncertain. And the future outcomes are more uncertain, albeit potentially more beneficial, if promising technical novelties are introduced among the means.

The entrepreneurial function is discharged by an elite class in whatever society it is performed. This is a natural consequence of the authoritative nature of allocation. The entrepreneur has been empowered, by whatever means, to make social choices as to the allocation of scarce resources to the attainment of future ends. On the other hand, entrepreneurship has not been the exclusive province of a particular elite. It might sometimes be born by a ruler or a governing body. It might be served by business persons in a market system. or it might sometimes result from a coalition of these and other elite groups. For example, almost the only innovators in electronic data processing have been private corporations like International Business Machines, National Cash Register, National Semi-Conductor, etc. On the other hand, the only innovator in the original development of nuclear energy was the U. S. Army Corps of Engineers, followed by the Atomic Energy Commission, both agencies of the U. S. Federal Government.

Whatever person or group carries out entrepreneurship, the entrepreneur's method is to maximize the net benefits of whatever future ends are sought and hopefully attained. He achieves this by economizing in 
the allocation of present means. That is, he selects and organizes present means in the least-costly fashion consistent with the future ends selected to be achieved. Thus, he is able to improve his allocation if he increases the ends attainable with a given set of scarce means, or if he can secure the usual benefits of future ends at lesscostiy employment of present means. Either way, he may be said to have increased net benefits. The drive to maximize net future benefits therefore leads the entrepreneur to innovate where innovation is rikely to result in economizing in the allocation of scarce means.

The innovation of new technologies is considered successfut and socially redeemable if it produces a sustaining increase in net benefits. That is, an innovation is a worthy one if it increases human welfare, and human welfare is increased any time some persons can be made better off without making anyone worse off. Thus human welfare will be increased, ceteris paribus, any time the output of goods and services having human value is increased per man-hour of input. An innovation is worthless if it fails for any reason to produce the foregoing outcome at some time in the ends-means continuum. Successful innovations lead to diffusion--the spread and integration of the new technologies, and the adjustment of the institutional system to the new technical conditions.

The entrepreneur or entrepreneurial group is rewarded for successful innovations and penalized for failure. Indeed, it is the substantial rewards open to the successful entrepreneur that gives him incentive to innovate. The entrepreneurial reward for a successful innovation is a share in the increase in the net benefits which are created by the innovation. This is known as private profits if the entrepreneur is a private person operating in a market system. If the entrepreneur is a ruler or 
a ruling body, the private benefits may be greater security in office for the ruler or political party stemming from increased approbation of their subjects or political constituents--and, of course, a share of the increase in net benefits accrueing to the office of ruler.

The innovation may fail for some reason to produce the expected increase in net social benefits. Indeed an unsuccessful innovation might result in the diminution of net social benefits under some circumstances. The penalty the entrepreneur must bear for a worthless innovation depends, of course, on the nature and magnitude of the costs involved. If the innovation involves the introduction of an invention through a market process and fails for some reason to increase profits as planned--to increase sales revenues or decrease production costs or boththen the maximum penalty could be business failure for the entrepreneur firm as that firm absorbs some of any net loss in benefits. If the unsuccessfut innovation were carried out by a ruler or governing body, then the maximun private penalty could be a fall from political power along with loss of the benefits available to persons in political office The point is that new technologies are introduced by a process of innovation. Innovation is performed by an entrepreneurial elite that makes decisions about the selection of future ends-to-be-reached and the allocation of present means to attainment of selected future ends. The outcomes of entrepreneurial decisions made in the present therefore repose in the future, and since the future cannot be known with certainty, there is risk that the outcomes will not fulfill the expectations with which the decisions were made. The risks of failure are therefore borne by the entrepreneur who is incentivated to bear the risks by the prospect of rewards for success. He is likewise encouraged to be prudent and 
plan carefully by the possible penalties for failure. The entrepreneurial role is crucial to innovation, and innovation is crucial to technical prograss.

\section{Ceremonialism and Innovation}

The foregoing explanation of innovation was deceptively simple. It sought to explain innovation in the singular dimension of entrepreneurship. Certainly, the entrepreneur is immensely important, but the institutional environment is equally important. Indeed, the institutional dimension makes the innovation and integration of new technologies among the most complex of all forms of social interaction. The institutional system exposes the entrepreneur to ceremonial risk, and ceremonial risk is one of the greatest deterrents to the entrepreneur and innovation.

Ceremonial risk is simply the risk that the institutional system will defeat the innovation no matter how instrumental the technology promises to be. Ceremonial risk arises from the inherent tensions between technology and ceremonialism. That is technology is forwardurging in terms of the ends-means continuum, while ceremonialism is backward-clinging. Technology is dynamic and change-producing, and ceremonialism is static and change-retardant. The innovation of new technologies is particularly dynamic because it opens ways of organizing means (including productive labor) and of distributing social products in ways differing from the ceremonially-prescribed methods descending from the past. New technologies therefore open opportunities to change prior existing social statuses and ceremonial systems of rank, affording new avenues to social mobility.

This character of technology brings it into conflict with tradition-

Reproduced with permission of the copyright owner. Further reproduction prohibited without permission. 
bound and backward-clinging ceremonialism both as to the choices between alternative and competing future ends-in-view, and the alternative ways of organizing means to the attainment of the chosen ends. Ceremonialism prescribes that only those ends be selected that are in harmony with and reinforce the institutional values which descend from the past. Likewise, ceremonialism prescribes that traditional means be employed and that they be organized in traditional ways. Ceremonialism brooks no deviation from antecedent procedures. A rigid and strong institutional structure buttressed by entrenched ceremonialism operates to preserve social stability and perpetuate established cultural traits by opposing anything that threatens institutional changes. It achieves this in part by truncating technical progress--by proscribing the innovation of new technologies.

How much of new technology is actually innovated therefore depends upon the strength of ceremonialism--the strength of institutional values and institutional resistance to change. Insofar as new technologies are innovated, conflicting aspects of institutional value systems--ceremonialism--become redundant, wither, and are forgotten or become quaint cultural vestiges of the past. However, the institutional system does not yield easily no matter how weak it might be. Thus institutions submit to technical progress and change only after anomy and social upheaval. ${ }^{23}$ This part of the paper regards the ceremonial restraints on innovation and the ceremonial conditions necessary to innovation. This latter point resumes consideration of the ceremonial state of affairs that permitted the innovation of the heavy plow, triennial field rotation, and the heavy horse in the agriculture of Western Europe.

It is recalled from Chapter $V$ that ceremonialism is the institutional Reproduced with permission of the copyright owner. Further reproduction prohibited without permission. 
instrument for maintaining social stability by preserving and transmitting the cultural values that descend from the past. And Chapter V illustrated how traditional values are preserved and transmitted by institutions through the powers of ceremony. Ceremony structures society into status systems based on ancient customs. It socializes members into accepting and playing traditional roles within the institutional structure. And it exercises social control by prescribing the correct modes of ceremonial exchange for the periodic validation of status. As noted above, the effect of a strong ceremonial system is a stable institutional environment in which the status quo is rigidly maintained and there is neither desire for nor expectation of change. The state of affairs is static, immobile, unchanging. The practical effect is to perpetuate the ancient customs eternally into the future.

One who is a member of such an environment has invested much of his past in an expected future stability that is founded on the preservation of the traditional values. He finds security--confidence, satisfaction, and tranquility--in the only society he knows or wishes to know, and his security is constantly reinforced by the tribal customs and traditional ceremonies of his father and his people. They give him status and they keep him emotionally and intellectually occupied with his social roles. They involve him in ceremonial interaction with the other members of his society who are likewise involved. One finds peace of mind and tranquility in the certainty that life has always been the way he understands it and that it will aiways be so, generation upon generation. The gods have ordained it and there is nothing he can do to change matters even if he should want to.

Indeed, one who is imbued with such institutional certainty and Reproduced with permission of the copyright owner. Further reproduction prohibited without permission. 
ceremonial security views any deviation from traditional ways with a mixture of fear, frustration, and anger--fear, because it disrupts his sense of security with unfamiliar and thus uncertain elements, and frustration and anger because the deviation is not in accord with the customs that are the sources of his security and that he has learned to respect and love. Therefore, he will eagerly join the other members of his society as they respond to the cries of the high shamans to rise against the abominations that violate their taboos and threaten their tribal tranquility. Man and his society will obey the commands of ceremonialism to defeat technical innovations and to preserve and perpetuate tribal customs. It is the grip of ceremonialism that holds a society in a state of technological retardation and social arrest. It is a well-developed and stable institutional system sustained by a powerful ceremonialism that precludes the innovation of new technologies.

It was precisely the ceremonial fixations of the institutionally advanced Oriental societies that prevented those societies from effectively innovating the heavy horse and its trappings in agriculture and transportation. It was the preoccupation with solidly established traditional ideals reinforced by ancient and powerful ceremonies that arrested technical progress in Oriental cultures and continues to do so in modern times. A similar institutional rigidity derived from Hellenistic beliefs and Roman institutions held the peasant farmers of the Apennine Peninsula in a similar ceremonial transfixion regarding effective innovation of the heavy plow.

On the other hand, it was a very feeble ceremonialism that permitted the heavy plow, the heavy horse, and triennial field rotation to be innovated in Europe. The question is: Why were the peoples of Europe

Reproduced with permission of the copyright owner. Further reproduction prohibited without permission. 
relatively less encumbered by ceremony? Why were custom and tradition so irresolute at the time? The answer is found in the unsettled conditions commencing before the rise of Rome and continuing for at least three thousand years in Western Europe. ${ }^{24}$

The people of Europe have endured more than three millennia of strife. The area was a melting pot of human types unprecedented in historical times. The Europeans have suffered almost continual political and military turmoil either from within or without since before the rise of Rome. Comprised of many small and scattered barbarian tribes, the Europeans knew no common languages or culture. Between periods of intertribal warfare, the people have endured conquest by outsiders. The Carthaginians maintained enclaves in the Iberian peninsula until the defeat of Hannibal at the hand of Proconsul Correlius Scipio in the Battle of Zama.

The European tribes fell increasingly under control of the Romans after the Punic Wars, finally succumbing to Caesar's Legions in the Gallic Wars of the first century B.C. The Pax Romana witnessed a consolidation of Roman hegemony over the European tribes. Roman control continued until the decline and eventual withdrawal of Roman power from Europe during the fifth century. The period was anything but peaceful as Roman power was used in Europe to quel1 disputes between her subject tribes, to extend her influence to peripheral lands, to expel invaders from the East and North, and to put down revolts against her administration.

After the collapse of Rome, the fragmented European tribes lay prey to first the Huns who rode out of the East in the fourth and fifth centuries to plunder and rape most of Europe as far west as Orléans. They drove the Ostrogoths toward the Danube, the Visigoths into Thrace and 
Illyria, the Vandals through Gaul and into Spain, the Burgundians into Savoy, and the Saxons and Angles into Britain. The advance of the Huns finally collapsed in 453 A.D. with the death of their leader, Attila. However, Europe was terrorized again by descendants of the Huns in subsequent centuries interspersed with invasions by other barbarians from the north and the south. The Bulgars invaded from the East in the sixth and seventh centuries, the moslem Arabs--Moors or Saracens--from the South in the first half of the eighth century, the Magyars or Hungarians from the East in the latter half of the eighth century, the Vikings--Norwegians, Swedes, and Danes--from the North in the ninth and tenth centuries, the Turks from the East in the eleventh century, the Mongols from the East in the thirteenth, and the Turks--Ottoman and Tamerlane--again in the fourteenth and fifteenth centuries.

While the Huns and subsequent invaders rushed in to occupy the social vacuum created by the collapse of Rome, a dispute amongst insiders waged over who should succeed and restore the ceremonial glory of Rome. The first contenders were the emperors of the Eastern empire at Byzantium during the sixth and seventh centuries. The Franks, under authority of the Bishop of Rome, claimed power during the eighth and ninth centuries. And the Germans--Teutons and Alamanni--asserted their claims to succession during the tenth and eleventh centuries.

Interspersed all the while between wars of conquest and civil strife were famines and pestilences that delivered even more misery and death upon European tribes. Food shortages frequently followed the disruptions of war and revolution causing starvation and malnutrition. And the latter conduced toward pestilence. Indeed, plague was a constant menace. Verus' troops brought plague from the East to Rome in 166-167, and 
Emperor Claudius II died of the plague barely one hundred years later. Attila's army was afflicted with the plague in 452 . The bubonic plague moved from Egypt to Asia Minor, to Constantinople, and to other parts of Southern Europe in 541-543, and sporadic outbreaks of the disease continued in Europe and along the European periphery during the medieval centuries. The Black Death reduced European population by half between 1346 and 1350. It struck aga in in Portugal in 1436, and in London in $1664-1665 .^{25}$

It was as though Western Europe were the cryptic personification of the Apocalyptic Revelations of Saint John the Divine. ${ }^{26}$ Western Europe was a frontier over which the four horsemen rode rough-shod for many centuries. War, civil strife, famine, and pestilence trampled whatever traditions and ceremonies might rise to stifle the triumph of technical progress. These were cataclysmic events of cosmic proportions to the peoples of Western Europe. Some might believe that the times were ruled by the Prince of Evil and his Demonic spirits bringing down damnation and destruction on the sinful, purging mankind, and preparing the righteous for triumph of the Prince of Peace. Whatever it was, it smashed institutional shackles nearly as rapidly as they were forged in preRenaissance Europe.

How could a sixth century Visigothic scion find tranquility in an existence threatened by Bulgars descending on him and his people from the East, or have confidence in perpetuating a cultural past in which the hovels of his recent ancestors were pillaged and razed by the Huns, their kin raped and slaughtered by the armies of Attila, and their survivors driven into a hostile Thrace or Illyria--inhospitable lands where their descendants eked out less than satisfactory subsistences only to be 
decimated each year by famine, or pestilence, or civil strife, or by all of these calamities together. Opportunities to establish family shrines on the burial grounds of their ancestors were cut short each generation or so by one or another apocalyptic calamity. Indeed, the ancestors were interred all over Europe, if they were buried at all. Stable property and other institutional relationships simply could not rise for very long.

The point is that Visigothic descendant, or the Ostrogothid descendant, or the descendant of the Burgundians or of any other indigenous Western European tribe either knew few ancient traditions instrumentally worthy of descendancy, or experienced disillusionment in most values descended from the past. His recollections of the past were filled with fear, frustration, and anger. Moreover, he was unlikely to assimilate the declining ceremonial traditions of the Romans--an oppressor empire that he neither understood nor trusted. Perhaps the term most descriptive of his temperament is accute anomie--an ideology divided within itself leaving a sense of rootless disorganization, a feeling of pointlessness, or that no certain bounds exist, a lack of strong national identity, and no pervasive notion of ethical constraint. ${ }^{27}$ If he had knowledge of the ancient traditions of his tribe, he had no confidence in their powers to render a future tranquility with certainty.

The only escape open to him were into insanity, or suicide, or some kind of mass movement. Escape into the former was perhaps retreat into the fantasy of a completely fabricated past devoid of causal linkages to the intolerabiy anomic present. Suicide was escape into an unbearable present that possessed no salutary linkages to either the past or the future. Escape into a mass movement could have been an hysterical drive Reproduced with permission of the copyright owner. Further reproduction prohibited without permission. 
into a euphoric future contrived of ends as ends-in-themselves, or of ends toward which there were apparently no adequate means in the present. Societies predominantly populated by persons of the former dispositions were more likely to perish completely.

However, a society substantially populated by persons of the latter disposition possessed somewhat greater prospects for survival. And it was likely to place much more stress on the immediate concerns of survival--but more important, survival by any means that promised ascendancy of a future which was hardly certain of ascendancy. Such a society is unlikely to guide itself by the ceremonialism of a patently bankrupt modicum of tradition. Conditions simply would not permit it the luxury of preoccupation with its past. And those members who spent their time in idle fantasies about the "good old days" perished as surely as the contrived objects of their fantasies. Rather, such a society was most likely to accept any means that were demonstrably instrumental to its ongoing future ends. That is, its preoccupation was predominantiy toward the future, and only incidentally, if at a11, with the past. ${ }^{28}$

In short, the peoples of medieval Europe inherited the sciences and technologies of the Roman empire and the Oriental world without the ceremonial burdens of the latter's institutions. Moreover, there were few opportunities and perhaps fewer incentives for the Europeans of the times to establish their own stable and enduring institutions resplendent with ceremonies founded on ancient customs. Europe was a frontier on which whatever institutions existed were social expediencies with few, if any, commonly understood linkages with antiquity. European ceremonial systems were accordingly weak with a very tenuous hold on the people. ${ }^{29}$

Innovation of the heavy plow, triennial field rotation, and the 
heavy horse in agriculture therefore took place first in Europe because of the spur to invention caused by technological cross-fertilization, and because ceremonialism possessed littie power at the time to prevent the innovation of newly-invented tools. Both of these conditions prevailed in medieval Europe mostly because of the tumultuous conditions that prevailed there during and after the decline of Roman power. The latter condition, weak ceremonialism, resulted from centuries of warfare, civil strife, famine, and pestilence.

A caveat is necessary at this point. The preceding illustration is based on the theory that innovation of new technologies requires a weak ceremonial system, and that the means by which a ceremonial system becomes weak is manifest human misery delivered by warfare, civil strife, famine, and pestilence. This may have been so in the quasi-urban communities of antiquity and in the feudal cities of the pre-industrial ages. It may even be true today of those places in the world where industrialism is not the dominant mode of social organization and the industrial city is not the habitat of the vast majority of the people.

However, it is not entirely so in the lands where industrialism is well established and the people and their institutions have adopted industrial life styles. Indeed, a delicately balanced institutional system is a condition necessary for industrialism to flourish. Thus, a viable industrial system is founded on an institutional base that has essentially internalized innovation and technical change. To be sure, ceremonial restraints are ever present--even in an efficiently functioning industrial city. However, the tenuity of ceremonialism is made deliberately permissive so that it may operate to transmit culture, structure society, socialize people, and control them to the purpose of

Reproduced with permission of the copyright owner. Further reproduction prohibited without permission. 
achieving social stability without unduly impeding the innovation and integration of new technologies. But this discourse moves ahead of the points to be made at this time. The institutional characteristics of industrial societies are analyzed in subsequent chapters.

This chapter has commenced an answer to the question: What are the underlying causes of institutional instability, change and discontinuity, and what are the consequences for the city? The answer given here is that the innovation of new technologies tends to be unstabilizing to institutional environments, and that institutions along with their underlying value beliefs and ceremonial systems change as they react toward the new technologies. Accordingly the institutional compositions of cities change with changes in technology.

The chapter initiates an elaboration of the above theme, the main ideas of which are that technologies and their associated techniques are continuous and dynamic. Technology is continuous because the invention of new technical means is based on scientific understanding, and the latter is cumulative and is founded on all past discoveries. Technology is dynamic because the innovation of new technologies introduces ways of organizing means and distributing social products which differ from the ceremonial methods descending from the past. The innovation of new technologies therefore induces very long-run changes in the institutional system that functions to stabilize society.

The continuous quality of technology was developed in terms of invention. Invention is explained as a process of "cumulative synthesis" in which a problem is perceived, the solution elements are assembled, an act of creative insight conceives a novel solution from the assembled elements, and critical revision elaborates and embellishes the solution. 
The solution to one problem leads to new sets of problems and the process is repeated until a strategic invention is developed. A crucial component of the synthesis process is the assembling of data and elements to solve the perceived problem. This is partly accomplished by technological cross-fertilization--bringing together diverse technical devices in the same place and time, stimulating the ingenuities of inventors, and leading them toward creative insights as to new technical combinations of the devices. Technological cross-fertilization is therefore a crucial element in invention.

However, invention is only one step in technologically induced social change. There are no social effects of discovery and invention until innovation takes place--until the new technical devices are introduced. Technical innovation is the function of entrepreneurs who make choices as to the allocation of present means to the attainment of future ends-to-be-reached. If successful, the entrepreneur's choices result in an economical allocation of means--that is, the greatest total benefits are achieved from the attained ends at the least costly employment of scarce means. The use of new technical devices may improve efficiency of the entrepreneur's allocation if it helps secure the selected ends at less-costly employment of means or if it secures greater benefits from the attained ends with the same means cost as before.

But the outcomes of entrepreneurial choices made in the present lie in the future, and since the future is uncertain, there is risk that the allocation of means chosen in the present will not produce the selected future ends. The risks of failure are borne by the entrepreneur who is incentivated to bear the risks by the prospect of rewards for success. The entrepreneur's rewards are a private share of the net benefits secured 
by the attained ends. The entrepreneur is, of course, admonished to plan prudently by the possible private losses for failure. The entrepreneur is the key person in the innovation process, and innovation is a key feature in technical change.

One of the risks borne by the entrepreneur is that his technical innovation will be defeated by ceremonialism. This is because the dynamic character of technology brings it into conflict with the static character of ceremonialism. New technoiogies are change-inducing and forward-urging in terms of the ends-means continuum, while ceremonialism is changeresisting and backward-clinging. How much of new technology is actually innovated therefore depends on the ceremonial powers of institutions to resist changes. The conclusion follows that a weak ceremonial system is a necessary condition to the innovation of new technologies.

This latter point, weak ceremonialism, was developed in terms of the chaotic institutional conditions leading to the innovation of the heavy plow, triennial field rotation, and the heavy horse in medieval European agriculture. Innovation of those technical means revitalized urbanization in medieval and Renaissance Europe, and it helped set the institutional stage for the Industrial Revolution which rose with and followed on the Protestant Reformation. Some of the social effects of those innovations are described in the next chapter where the integration and diffusion phases of technical change are described.

Reproduced with permission of the copyright owner. Further reproduction prohibited without permission. 
END NOTES, CHAPTER VII

TAyres, Theory of Economic Progress, p. 112.

2 Mansfield, Economics of Technological Change, p. 11.

3 Usher, History of Mechanical Inventions, pp. 56-83.

4 Ibid, p. 71.

${ }^{5}$ Ayres, Theory of Economic Progress, pp. 118-119.

6 An explanation of this in terms of foreign trade is found in Gottfried Haberler, "International Trade and Economic Development," in Expansion of World Trade and the Growth of National Economies, ed. by Richard S. Weckstein, (New York: Harper and Row, Publishers, 1968), pp. 104-110.

${ }^{7}$ Not used.

${ }^{8}$ August Losch, "The Nature of Economic Regions," Southern Economic Journal, XXIX (August, 1963), pp. 71-78. Also see l.osch, The Economics of Location, trans. by W. H. Woglam and W. L. Stolper, (New Haven: Yale University Press, 1954). Brian J. L. Berry, "Cities as Systems within Systems of Cities," Papers and Proceedings of the Regional Science Association, X (1964), 147-63. Edward L. U17man, "A Theory of Location for Cities," in Urban Economics: Theory, Development and Planning, ed. by Will iam H. Leahy, David L. McKee, and Robert D. Dean, (New York: The Free Press, 1970), pp. 105-115.

9. H. von Thunen, Der isolierte Staat, Germany: n.p., 1826.

10 William Alonso, "Location Theory," in Regional Development and Planning: A Reader, ed. by John Friedmann and William ATonso, (Cambridge: The M.I.T. Press, 1964), pp. 78-106. Also see: Edgar M. Hoover, The Location of Economic Activity, (New York: McGraw-Hill Book Co., Inc., 1963). Walter Isard, Location and Space-Economy: A General Theory Relating to Industrial Location, Market Areas, Land Use, Trade, and Urban structure, (Cambridge: The M.I.T. Press, 1956).

${ }^{11}$ Alonso, "Location Theory."

12 Edgar M. Hoover, "The Evolving Form and Organization of the Metropol is," in Issues in Urban Economics, ed. by Harvey S. Perloff and Lowdon Wingo, Jr., (Baltimore: Johns Hopkins Press, 1968), pp. 237-84. Raymond Vernon, Metropol is 1985, (New York: Doubleday, Inc., 1963), pp. 25-26. Benjamin Chinitz, "Contrasts in Agglomeration: New York and Pittsburg," The American Economic Review, LI (May, 1961), 279-88. 
13 George Stigler, The Theory of Price, rev. ed. (New York: Macmillan Co., 1952), p. 146 .

${ }^{14}$ Gideon Sjoberg, The Preindustrial City, Past and Present, (New York: The Free Press, 1965), p. 8.

${ }^{15}$ Ibid, pp. 27-31.

${ }^{16}$ Ibid, pp. 32-34. Childe, Man Makes Himself, pp. 87-112.

${ }^{17}$ Sjoberg, Industrial City, pp. 36-37.

${ }^{18}$ Childe, Man Makes Himself, pp. 112-42. Sjoberg, Industrial City, pp. $323-28,332$.

${ }^{19}$ Sjoberg, Industrial City, pp. 339-41.

${ }^{20}$ Ibid, pp. 56-58.

${ }^{21}$ Ayres, Theory of Economic Progress, pp. 174, 177, 185, 187.

${ }^{22}$ W. W. Rostow, "Technology and the Price System," in Science and Ceremony; The Institutional Economics of C. E. Ayres, ed. by William Breit and William Patton Culbertson, Jr., (Austin: University of Texas Press, 1976), pp. 88-93.

${ }^{23}$ Ayres, Theory of Economic Progress, pp. 174-76. Kuhn, Structure of Scientific Revolutions. The phenomenon is approximately analogous to what Kuhn calls "competing paradigms" (the old paradigm and the new). Childe, Man Makes Himself, pp. 186-87. John Dewey, Liberalism and Social Action, (New York: Minton Ba1ch \& Co., 1935), pp. 74-85.

${ }^{24}$ Suggested by Lynn White, Jr., Medieval Technology and Social Change, (London: Oxford University Press, 1962), pp. 71, 73-74.

${ }^{25}$ Rene Sedillot, The History of the World in Two Hundred and Forty Pages, trans. by Geral Hopkins, (New York: New American Library, 1953), pp. 165-152. White, Medieval Technology, pp. 73-74.

${ }^{26}$ Revelations 6:1-8.

${ }^{27}$ deGrazia, The Political Community, pp. 4, 45-79.

${ }^{28}$ Ibid, pp. 131-83. deGrazia develops these ideas partly in terms of the messianic rise of Adolfh Hitler who promised to deliver the German people from Gesellschaft to Gemeinschaft--roughly from the competitive corporate society that seemed to be the source of pre-World War II German anomie to a cooperative folk community which was presumably reminiscent of an earlier and more stable time in German affairs. While deGrazia's example is unfortunate for his purposes, it is a good one for purposes of this paper because the history of Nazi Germany and the subsequent state of German affairs illustrates the futility of an ideological movement which focuses preponderantly on a fabricated past and that drives hysterically toward ends that are viewed as ends-in-themselves.

Reproduced with permission of the copyright owner. Further reproduction prohibited without permission. 
${ }^{29}$ Frederick Jackson Turner, The Frontier in American History, (New York: Henry Holt \& Co., 1921). Henri Pirenne, Medieval Cities: Their Origin and the Revival of Trade, (London: George Allen and Unwin, Ltd., 1939), pp. 140-44, 147-50, 265-85. Lynn White, Jr., "Technology and Invention in the Middle Ages," Speculum, XV (Apri1, 1940), pp. 141-156. 


\section{TECHNOLOGICAL PROGRESS}

This is the last of the chapters dealing with the technology element of institutional economics. The first, Chapter VI, defined technology as that quality of a tool that enables it to be substituted for human effort in the creation of goods and services having human value. It defined the human component as technical skill in applying technique to employment of the tools embodying technology. And it defined technique as the procedure by which humans employ a tool in the production of goods and services having human value.

The preceding chapter, Chapter VII, argued that technology is continuous because it is based on scientific knowledge, and such knowledge is cumulative and geometrical. That is, the invention of new technology is based on past scientific discoveries and their technical applications. Moreover, the invention of new technology usually opens avenues to a number of possible on-going inventions. Therefore, invention of new technical means depends on technological cross-fertilization--the assembly of diverse tools and technical knowledge at the same place and time, provoking the curious and stimulating their inventive propensities.

The chapter also argued that new technologies are dynamic because their innovation opens opportunities for organizing means and distributing social products in ways differing from the ceremonially mandated methods descending from the past. That is, new technology is forward-urging and change-producing in terms of the ends-means continuum. This brings 
technology into conflict with ceremonialism because ceremonialism is change-resistant. That is, ceremonialism is backward-leaning in terms of the ends-means continuum, requiring that only traditional ends be sought and that traditional means be employed according to customs descended from the past. Thus change-producing new technologies are locked in a struggle with change-resisting ceremonialism as to the selection of future ends-to-be-reached and the employment and organization of means to the ends selected.

How much of new technology is actually innovated therefore depends on the power of ceremonialism. It follows that a necessary condition to the innovation of new technology is a weak ceremonial system. These ideas were developed around the history of early urbanization in the West, and around the surge in urbanization that took place in Western Europe during the medieval era. The cause behind the unprecedented urbanization of this latter period was alleged to be the innovation of the heavy plow, triennial field rotation, and the heavy horse in agriculture. And the reasons these innovations took place in medieval Europe was the technological cross-fertilization that was taking place there as well as the feeble condition of European ceremonialism at the time.

This chapter argues that new technology is progressive. That is, successfully innovated new technology results in technological integration and diffusion, and these latter outcomes increase human welfare. Technology facilitates this by economizing in the employment of scarce means. That is, it reduces the amount of human effort required to secure desirable sets of future ends. In other words, it decreases the man hours of labor input per unit of output of goods and services having human value. It therefore makes possible a more humane society by providing means 
whereby social products may be distributed more equitably throughout society. 1

The first part of this chapter illustrates the foregoing by describing more thoroughly the innovation and diffusion of the heavy plow, triennial crop rotation, and the heavy horse in medieval Europe. It will be argued that these events increased the internal economies of largescale production in agriculture, increasing agricultural surpluses and liberating large numbers of peasants from primary employments so that they could specialize in secondary, or urban, employments. The second part of the chapter illustrates increases in external economies of urban scale initiated by the agricultural surplus and the further integration of the horse as a draft animat in ordinary commerce.

\section{INSTITUTIONAL CHANGE - TECHNOLOGY AND INTERNAL ECONOMIES}

It was argued in the preceding chapter that social revolutions occur when innovations of new technologies first increase internal economies of large-scale production and then increase the external economies of location or scale. Such changes alter interinstitutional arrangements so that some institutions are not entirely complimentary within the system of institutions. Aspects of ceremonialism founded on certain institutional values become hindrances in light of the new technologies. The resulting social tensions reflect efforts of the institutional system to realign itself in accord with the new technologies.

Social stability is resumed when diffusion and integration of a new technology is complete. Complete integration occurs when the technological innovation is fully incatinated across the institutional system, and all institutions are once again complimentary within that system.

Reproduced with permission of the copyright owner. Further reproduction prohibited without permission. 
This does not happen until ceremonies and ceremonial statuses have been changed to account for the new technology. Complete integration and diffusion of major technological innovations often take centuries and sometimes millennia to occur.

Technological diffusion is essentially an inter-culture phenomenon. That is, technological diffusion is the spread of technology from one culture, area, or group to another by borrowing or migration. The borrowing of technology involves acculturation or assimilation. Acculturation is a process by which culture is transmitted through continuous first-hand contacts between groups with different cultures--one often having a more advanced civilization. Assimilation is a process whereby two or more heterogeneous groups occupying a common territory achieve a substantial cultural homogeneity that ultimately results in a national unity. The migration of technology involves convergence in which distinctive culture traits from different areas become similar or merge completely. ${ }^{2}$

On the other hand, technological integration is the variety of social processes whereby the conflicts between newly innovated technologies and ceremonialism are ameliorated, and the institutional system is brought into social harmony with the new technologies. Both innovation and integration are essentially intraculture phenomena. That is, they take place within a culture, vis between cultures. ${ }^{3}$ The remaining content chapters deal with the social mechanics of technological integration in an industrial society.

The result of diffusion and integration is a new social stability in which institutional powers have been redistributed in consonance with the new technological realities. Some institutions will have gained power, and some will have lost power. New institutions will have emerged, and 
some will have disappeared. According to institutional economic theory, it is social revolution precipitated by technological change that accounts for institutional discontinuities. This part of the chapter regards the institutional changes resulting from diffusion and integration of agricultural technologies in medieval Europe.

Kings, clerics, craftsmen, costermongers, and camelots were a tiny fraction of the population in medieval Europe. They were supported by the vast multitude of peasant farmers comprising the rest of humanity. Thus, anything that affected peasant agricultural productivity--weather, soil, or tools--must also affect civilization--population, health, wealth, and stealth. Two paralle] developments brought together the technological means by which the Europeans ascended to dominance in the postmedieval Western World. The first was innovation and diffusion of the heavy plow to cultivate the hard soils of European uplands. The second was introduction of the heavy horse and its accouterment--first in warfare, then in agriculture and commercial transportation. Both developments are traced to events commencing in the first century, A.D., and they merged after the eighth century. Finally, those technical improvements were augmented by a shift from two-field to three-field crop rotation. The initial effect of these events was an increase in internal economies of large-scale production in agriculture, and thus an increase in agricultural output per man hour of labor input.

The Heavy Plow ${ }^{4}$

Al though the age is by no means certain, the first plow is believed to have come into use sometime before 6,000 B.C., no doubt as an adaptation of a digging stick. It is thought to have consisted of a triangular

Reproduced with permission of the copyright owner. Further reproduction prohibited without permission. 
or conical shape for digging the soil and handles for pulling or pushing the plow. Eventually an ox was used to provide the motive power for the plow. Modern adaptations of this prehistoric scratch plow remain in use in some places even today.

The scratch plow does not turn the soil. Rather, it agitates the soil in its trace, leaving a strip of undisturbed earth between its furrows. Cross-plowing is done to further pulverize the soil. Thus, fields tend to be as wide as they are long where the scratch plow is used. Moreover, the scratch plow is onty suitable for cultivating the light, dry, alluvial soils of river deltas. It is useless against heavy upland soils. This restricted early agriculture to the river areas where soils were suitable to the primitive scratch plow.

The soils of Northern Europe are mostly of the latter type--moist, heavy, and upland--and they are much more resistant than the light, dry, soils of Mediterranean and adjacent river deltas. Even when drawn by two oxen, the scratch plow could not handle the richer upland soils. If Europe were to prosper, some way had to be found to efficiently cultivate its upland soils. That way came in part with innovation of the heavy plow.

The heavy plow possesses four technical features which distinguish it from the primitive scratch plow. The heavy plow has a coulter which cuts the soil vertically. The coulter is attached at right angle to a flat share that cuts the earth horizontally below the sod. A mould board is attached to the plow and serves to lay the sod over in a furrow against the previously plowed edge. Finally, the entire plow is equipped with a set of wheels arranged to carry the non-cutting dead load of the plow.

Lineage of the complete heavy plow is not fully known. Some Reproduced with permission of the copyright owner. Further reproduction prohibited without permission. 
components of the heavy plow were known to be used with scratch plow shares. Coulters and wheels are believed to have been in use in the Poe Valley as early as the first century. Likewise, the Goths were known to use coulters in the fourth century. However, the first appearance of the complete heavy plow was in the hands of the Slavs in the latter half of the sixth century. Credit for innovation of the heavy plow therefore appears to belong to the Slavs of Central Europe. The new plow was diffused westward, probably by migration, so that it was in use among the German tribes in the seventh century, among the French tribes in the eighth, and among the British tribes in the tenth.

Integration of the heavy plow involved revolutionary changes in medieval European institutions. The changes stemmed from the increased agricultural productivity and from the techniques required to efficiently employ the plow. The heavy plow had several advantages over the scratch plow. It turned the soil with such force that it could be effectively used to bring the hard soils of European upiands into agricultural production. This, of course, greatly multiplied the amount of arable land in Europe. Moreover, there was no need for cross plowing because the heavy plow pulverized the entire surface of a field with a single plowing. The time saved allowed a peasant to cultivate nearly twice as much land in the same amount of plowing. It was a case of substituting a tool, the heavy plow, for labor in agricultural production.

Finally, the elimination of cross plowing made it more economical to plow land in long strips. Thus, fields tended to be long and narrow, rather than square as with scratch plowing. This latter effect was very important to soil conservation on sloping uplands. The long narrow fields were usually plowed in a clockwise direction with the furrow turned to 
the right. As the years passed the fields tended to become terrace-like, each parallel field containing a low center ridge with a slight swail adjoining adjacent fields on either side with like characteristics. The fields therefore trapped and held water while preventing destructive erosion. Crops could usually be harvested from the depression between fields in drought years, and from the ridge in years with heavy precipitation. And, of course, crops were harvested from both ridges and depressions during normal climate years.

Long open fields also changed the pattern of pasturage for cattle. As long as the population was sparsely settled over the land, animals could be grazed in permanent pastures located on tillable lands. But as population increased and the heavy plow made such lands tillable, less land was available for pasturage on a permanent basis. As long as each farmer cultivated his own small plot, his fallow could not be economically used for grazing. However, strip plowing and open fields permitted crops to be cooperatively sown in several large fields during any particular season, leaving a large community fallow free for grazing cattle. This had the added advantage of allowing the manure to drop on the next season's crop land rather than on open meadows.

Innovation of the heavy plow also brought revolutionary social changes in Northern and Western Europe. Sometime during or just before the seventh century, there was an unprecedented upsurge in population and emigration from the Rhineland and contiguous areas. This correlates with an increase in open fields, and it is believed that use of the heavy plow accounts for both phenomena. According to this theory, the heavy plow increased agricultural productivity supplying the surpluses to support greater fecundity in peasant families and all at once liberating

Reproduced with permission of the copyright owner. Further reproduction prohibited without permission. 
significant numbers of peasants from farming.

At the same time the heavy plow was restricted to use in areas having a relatively dense settlement. A single family could not usually afford to acquire and use it. This was because land was allotted to peasants from a very early time on the basis of that which was needed to support a family and render, tribute to king and deity. The family lands were therefore not large enough to efficiently employ the much more productive heavy plow. Moreover, the new plow was costly to acquire. The suspension and wheels were much more complex than the simple frame of the primitive scratch plow, and they were therefore comensurately more expensive. Likewise, the working parts which were greater in number and size, had to be of metal, and all metals were scarce and costly in sixth and seventh century Europe.

The heavy plow was also more costly to operate, both because it was heavier and because it was used in heavier and more resistant soil. The new plow could not be drawn by a single yoke of oxen. Indeed, it usually required four yoke--in other words, eight oxen. It was rare for a peasant family to own more than a single yoke, and it was necessary for them to pool their plow teams to effectively use the heavy plow.

As already noted, it was more efficient to cultivate long, narrow fields with the new plow. Thus, whenever the heavy plow was placed into use in Western Europe, the village lands were usually reorganized from squarish, fenced fields into large open fields which were plowed in long, narrow strips. The only reasonable way to allocate land was, therefore, to distribute the strips to the peasants who owned the plow and the individual yokes of oxen comprising a cooperative plow team. On that basis, one peasant family might cultivate many small dispersed strips of land. 
Thus, land commenced to be allocated to peasants on the basis of their contributions to their cooperative plow teams. This had immense importance because the criteria of efficient land distribution ceased to be the amount needed to sustain one family. With the right technologies, a peasant family could clearly produce a substantial and enduring surplus. Therefore, the basis of land distribution became the amount that could be effectively tilled by the tool of tillage--the plow and the plow team.

Cooperative agriculture posed problems of control and coordination. Clearly, such dispersed narrow plots of land could not be cultivated at the whim of the peasant to whom they were allocated. They had to be plowed in concert with the adjoining strips that were owned by other members of the plow team if all were to be efficiently cultivated. Inevitably disputes arose. As a consequence, strong peasant tribunals emerged in hamlets to adjudicate disputes and to make decisions on land management for the community. These conditions were one of the bases of a manorial system. And such economies were found only in Northern Europe where the heavy plow was used to cultivate open fields.

Diffusion and integration of the heavy plow in medieval Europe increased internal economies of large-scale agricultural production, all at once multiplying the potential for growth in agricultural output, creating a substantial agricultural surplus, and liberating large numbers of peasants from farming so they could gravitate to secondary and urban employments. In order to secure the significant increase in social benefits, society was recrganized to efficiently employ the heavy plow. This involved realigning real property boundaries, reallocating peasant lands from a basis of family subsistence to a basis of tool productivity, shifting farming from an individual family enterprise to a cooperative 
community enterprise, and creating peasant councils to cooperatively manage the community arable.

\section{Triennial Field Rotations}

An innovation in the eighth century augmented the gains reaped from use of the heavy plow. A system of three-field-crop rotations replaced the two-field system which descended from antiquity. The triennial rotation was initiated in Frank lands between the Seine and Rhine Rivers with rise of the Carolingian Empire. It was quickly integrated in that region, but diffusion to other regions of Europe was very slow perhaps reflecting ceremonial rigidities in land tenures. England abandoned biennial rotation in favor of triennial in the twelfth century following the Norman conquest, while the Slavs in Poland and southern Sweden waited until the thirteenth century following the Mongol sweep across Eastern Europe.

The rotation system allowed land to lay fallow biennially under the two-field system and triennially under the three-field system. The fallow period was to rest the soil and allow it time to replenish nutrients through capillary action, and by plowing under the indigenous cover. The parcels were reversed the next year so that the previously fallowed parcel was cultivated, and the previously cultivated parcel was fallowed. The two-field system was used universally, if not uniformly, throughout Europe. The principal variation involved planting seasons. Main crops were planted in the southern part of the north temperate and sub-tropical zones in autumn and were harvested in late spring or early summer. On the other hand, main crops were originally planted in the early spring and harvested in the late summer or early autumn throughout the northern part of the north temperate zone and in the northern sub-arctic zone. 
Three field-crop rotation recognizes that there are indeed two seasons for planting and harvesting and that significant gains in productivity can be realized by organizing agrarian work around the fact. The threefield system divided the croplands into three equal parcels. One was planted in the fall with winter-growing grains for harvest late the follow ing spring. The second field was planted in early spring with summer-growing crops for fall harvest. The third field was left fallow. The fields were rotated each year so that each would have been once in winter crops, once in spring crops, and once in fallow during any three-year period. A comparison of the two methods of crop rotation illustrates the gains in the triennial system over the biennial. If the total annual plow capacity of a manor is 900 acres, then it is easy to see that a single plowing of the fallow will allow the manor to farm 900 acres under either rotation system. However, 450 acres must be kept fallow under the two-field system leaving 450 acres for crops. On the other hand, only 300 acres are kept fallow under the three-field system leaving 600 acres for crops. Thus the gain of the triennial method in product units per unit of plow input is 33 percent over the biennial system. The gain is even more dramatic if the fallow is plowed twice during the year. Of course, double plowing the fallow reduces the total acres of land tillable by a given plow team. However, this poses no problem as long as the increase in productivity from double plowing is at least equal to the output foregone by reducing the acreage plowed. Indeed, overall efficiency is thereby gained in land use because the output per acre is increased while the units of product produced per unit of plow input remains at least the same. At any rate, the three-field rotation gain is even greater with a double plowing of the fallow. 
For example, assuming the same plow team constraint as before, 900 acres per year, it is seen that 600 acres of that capacity must be allocated to double plow 300 acres of fallow under a biennial rotation. This leaves only 300 acres of capacity for plowing cropland, and the total acres farmed by the manor is 600 . On the other hand, only 450 acres of plow capacity is allocated to double plow 225 acres of fallow under the triennial rotation. This leaves 450 acres of plow capacity for the manor arable. The manor can therefore keep 150 more acres in crop for an increase of 50 percent with the same plow input. Part of that increase is derived from the additional land cultivated by the saving in plow-team capacity. That is, the manor can farm 675 acres $(450+225)$ with triennial rotation, and only 600 acres with biennial rotation.

The three-field rotation system had other advantages over and above the obvious gains in productivity. It increased labor efficiency by distributing peasants' work more uniformly across the year. By enabling crop diversification, the technique reduced the propensity toward famine. And finally, the system resulted in a substantial increase in the production of crops that were particularly important to subsequent events. One was the use of legumes in the spring planting, and the other was the cultivation of oats also as a spring crop.

Commencing in the eighth century, legumes--lintels, peas, broad beans, and chickpeas--were sown in the spring planting because they replaced the nitrogen taken from the soil by the previous year's crops of wheat and rye. They were essential to success of the triennial rotation of crops because of the greater intensity of soil use with that system. An important by-product of that procedure was the infusion of 
protein-rich vegetables into the human diet, and this had a positive effect on both the level of population and the health and vigor of the people. These factors weighed heavily in the outcome of subsequent events. Further consequences stem from the spring crops of the triennial field rotation. Oats, which came to Europe as a weed from Asia Minor in prehistoric times, was a major spring crop. Oats happen to be the prime diet for horses, and Europeans found precisely the correct food among their agricultural surpluses for the proper care and feeding of horses-a fact of considerable future importance to the Franks.

In summation to this point, it is clear that innovation and integration of the heavy plow increased agricultural productivity because it embodied greater technology than its predecessor, the primitive scratch plow. That is, the heavy plow had a greater capacity to substitute for labor in agricultural production. Likewise the change from biennial to triennial crop rotation augmented the greater efficiency of the heavy plow so that the two events worked toward a long-run excess of labor in farming. They did this by releasing peasants from agricultural employments while increasing the food surpluses by which populations could expand. At the same time, the new plow enabled theretofore untillable lands to be brought under cultivation, substantially increasing the longrun potential for the production of a continuing agricultural surplus. Finally, the exigencies of the technology mandated a radical reordering of land tenure and the reorganization of peasant employment from individual to cooperative farming techniques.

This discourse on the heavy plow must be interrupted for a time in order to pick up the other technological means by which the Europeans ascended to dominance in the post-medieval Western World. The other means 
was by introduction of the heavy horse. Like the innovation of the heavy plow, introduction and diffusion of the heavy horse is traced to events which commenced in the first century A.D. And the two means merge after the eighth century.

The Heavy Horse ${ }^{6}$

The horse has seven epochs. It apparently originated on the Steppes of central Asia where it foraged the wilds for native grasses. Its second epoch is as game for the Indo-European savages who hunted the Steppes before the dawn of history. Early domestication of the horse for meat, milk, and hides by the same Indo-Europeans marks its third epoch. The fourth finds the horse drawing a travois loaded with cargo or drawing a chariot in warfare. The fifth equestrian epoch sees the animal bearing a rider with broad sword or spear. The sixth sees the horse replacing oxen drawing a plow and other forms of heavy drayage. Finally the horse becomes a totally ceremonial appendage in the modern industrial world where its technical and productive qualities are completely surpassed by mechanical forms of power.

The domestic horse was exclusively a creature of warfare in the Western World until the early ninth century. It served three successive military masters--the charioteer, the rider without stirrups, and the rider equipped with stirrups. Horse-mounted warriors were used by the Persians, the Greeks, and the Romans, and of course, by the barbarians that periodically swept across Europe during the thousand years following the decline of Rome.

However, combat from the back of a moving horse was a precarious enterprise in antiquity. The warrior sat bare back gripping the horse 
with his knees. At most he had only a blanket or cushion between himself and his horse. He had no pommel or cantle to give front and back support, and no stirrups for lateral support. This severely limited the warrior's ability to wield a sword or thrust a spear or lance from horseback. Moreover, the horse of antiquity was too small to bear an armored warrior or to be armored itself. Thus cavairy was never a decisive arm in those times.

The heavy horse, ancestor to both the medieval warhorse and the draft horse, was introduced to the Western world in the first century. The pedigree of the heavy horse is not clearly known. It is clear, however, the heavy horse opened the way to use of heavier accouterment. The rigid-frame saddle soon made an appearance, and both the horse and its rider could be armored for combat.

The saddle with pomel and cantle but without stirrups appeared also in the first century A.D. The saddle burst upon the Roman Empire under barbarian warriors charging out of the east. While the pommel and cantle improved efficiency of warfare from horseback, the plight of the cavalryman remained precarious without stirrups. And seven more centuries elapsed before the stirrup appeared in Europe.

The stirrup is first found in India during the second century B.C. supporting only the big toe of an unshod rider. Of course, the toe stirrup is unsuitable for the shod rider of colder climates, and the first attempt to support the whole foot appears as a hook stirrup in Pakistan and Afghanistan during the latter part of the first century or the early part of the second. The hook stirrup had a penchant for snagging and dragging a fallen rider. It gave way to the ordinary foot stirrup in China by the fifth century. The foot stirrup found its way to Persia by 
the end of the seventh century. Finally, it was innovated in Europe by Charles Martel, de facto King of the Franks, in sweeping military reforms during the first half of the eighth century.

Significance of the foot stirrup to subsequent institutional changes in Europe cannot be overemphasized. The foot stirrup was the keystone to a radical reordering of Frank arms and warfare, and the logistics of military reorganization mandated revolutionary changes in society itself. At the same time the importance of the horse in warfare led to the breeding and proliferation of more powerful horses, and it eventually opened the way to widespread use of the horse in agriculture and transportation. Finally, the Franks ascended to dominate European political affairs for nearly three centuries. The new horse-based technologies were forcefully diffused throughout Europe during those centuries.

To understand how and why the foot stirrup was so important to European civilization, one must understand its function. While the saddle gave front and back support, it was the stirrup that gave lateral support to the rider. The stirrup therefore fixed the rider to his mount and the combination made for a fighting unit of unprecedented might. The blow was no longer delivered by force of the warrior's arm alone. He could now grip his lance between his body and his upper arm, and guiding it with his hand, he could land the blow on an adversary with the combined force of himself and his galloping mount. Thus, the power of the human body was replaced by that of the horse, and the arrangement made possible a new method of warfare--mounted shock combat.

The advent of mounted shock combat reversed the order of battle and within a generation the mounted warrior ceased to simply support infantry. Cavalry replaced infantry as the principal Frankish arm, and infantry,

Reproduced with permission of the copyright owner. Further reproduction prohibited without permission. 
the traditional queen of battle, became a supporting arm to cavalry. The military import of these events was immediate, but the social consequences were revolutionary and pervasive.

The ceremonial aspects of society had to be reorganized to support mounted warfare. The Frankish army consisted of infantry levies of freemen until the middle of the eighth century. The process derived from the Germanic tradition that every freeman was a soldier. It was a relatively inexpensive way for the monarch to maintain an army. The military potentialities of the foot stirrup changed all of that, and virtually every European institution was ultimately affected.

The new method of warfare was costly. To be effective, a knight needed several mounts. In addition to remounts for horses killed in battle, the knight's squire must be mounted. Additionally, the knight must be armed and he and his mounts must be armored. In al1, the cost to equip one knight was about twenty oxen, the plough teams of ten or more peasant families. The cost to maintain a knight was equally expensive. Each horse had to be maintained in top condition, and horses consume large amounts of grain whether or not they see combat. Here then, is the importance to the Frankish kingdom of a spring planting of oats under the triennial crop-rotation plan.

The monetary and taxing systems of medieval Europe were primitive, and there was no way a monarch could rely on taxation to support a retinue of knights. The most important income-producing wealth at the time was arable land, and land endowments became the method by which mounted warriors could be maintained in suitable number. Charles Martel seized ecclesiastical properties in 732--approximately the time triennial crop rotation was innovated in those lands. He gave possession of the land 
(benefice) to an expanded group of cavaliers with the condition that they serve him (servile tenure) in mounted combat. Failure to discharge the tenure involved forfeiture of the fief. The result of these arrangements was a wide extension of the feudal institution of vassalage.

Thus, European feudalism was a military organization of society to support cavalry. It stressed the breeding and rearing of horses and the training and support of men capable of carrying on the new method of warfare. For this reason, Pippin changed the Saxon tribute from cattle to horses in 758. One can imagine the impact of this requirement on the breeding of cattle and horses. The ceremonial aspects of the agricultural system to support cavalry, manorialism, descended from the Roman proprietary system described in a prior chapter. It needed only to be adapted from pagan to Christian ceremonies and to be wed with the ceremonial system of land tenure and agricultural techniques that were emerging with innovation of the heavy plow.

The knight's personality and his environment were shaped by his mode of fighting, and his mode of fighting stemmed from innovation and diffusion of the foot stirrup. The two distinguishing ceremonial qualities of the cavalier were loyalty to his liege and military prowess based on the new methods of mounted shock combat. And these two qualities were the corner-stones of medieval chivalry.

The new warriors had to be skilled professionals. They had to be in superb physical condition and they underwent long periods of military training. There was simply no time for homey vocations like farming and crafts. And here is one significance of an agricultural surplus--support of a full-time, professional military elite. The institution of knighthood produced a proud and cohesive military caste that ceremonialiy

Reproduced with permission of the copyright owner. Further reproduction prohibited without permission. 
vented its competitiveness and sharpened its prowess in the lethal but pragmatic wargame--the jousting tournament--a series of encounters between mounted knights in which opponents charged and attempted to unseat one another with lances. Military service therefore became a matter of ceremonial class, and freedom became a matter of property tenure sufficient to support a mounted warrior. Like the patriarchal estates of antiquity, feudal tenures soon became hereditary, conditioned always on one's ability to fulfill knight's service.

Wherever the Frankish kingdom extended its realm, it introduced its methods of warfare and its feudal institutions. Mounted shock combat became the practice of the Lombards in Italy by the end of the eighth century--Byzantium by the tenth. And William the Conqueror introduced the technique to the Anglo Saxons at Hastings in 1066. The crusades brought mounted shock combat forcefully to attention of the Moslems, and the Syrians and Egyptians were staging jousting tournaments by the thirteenth century.

Finally, the feudal warrior intentionally created by the Franks to serve their military needs became the ruling class on collapse of the Carolingian Empire. Of course, this perfectly preserved the savage tradition that the elite men of invidious leisure shall eschew the debasing occupations involved with the creation and maintenance of material welfare, and shall occupy themselves with only the ceremonial barbarian vocations--politics, religion, warfare, and maleficent games. Quite the opposite of the vulgar occupations, the feudal warrior's vocation stressed invidious leisure and the ceremonial destruction of goods.

But another consequence of feudal warfare commands attention. That is, of course, the breeding up and widespread diffusion of horses suitable 
for heavy draught. For it was harnessing of the heavy horse to the heavy plow that ultimately accelerated the political ascendancy of Europe in affairs of the renaissance world by further advancing agricultural productivity, increasing food surpluses, and freeing labor from agricultural employment. However, the event had to await two other developments--a suitable harness and a nailed horseshoe. ${ }^{7}$

The Slavs reckoned a unit of plowland in the twelfth century as that which could be cultivated by two oxen or one horse. While a properly harnessed and shod draft horse produces approximately the same pull as an ox, the horse moves more rapidly so that it actually accomplishes one and one-half times the foot pounds per second of work done by the ox. And the horse has more staying power than the ox so that the farmer can work several hours longer each day. In a11, the work advantage of the horse is approximately twice that of an ox.

Horses were harnessed like oxen in antiquity--which is understandable since the draft animal of prehistory was the ox, and it would seem that the yoke harness which worked very well with oxen had simply to be adapted to the horse. However, the yoke did not work well with the horse. The horse could be harnessed to the yoke only with long straps attached to the ends of the yoke and passed around the creature's neck and under its belly. The straps pressed on the windpipe and jugular vein when the horse attempted to pull. Moreover, the yoke rested on the horse's shoulders, a point of traction that is much to high for a horse. The key feature of a modern harness is a padded collar that rests on the withers of the horse so as not to constrict blood and airflow. Traces or shafts attach the collar to the load so that the traction point is near the chest of the horse. This allows the beast to place its entire 
weight into pulling. It has been demonstrated that a horse rigged with a modern collar harness can pull as much as five times the load it can pull with the ancient yoke harness. Clearly, horses could not be used in place of oxen for heavy drayage until the collar harness came into use. Early attempts by the Romans to overcome the defects of the yoke harness produced unsatisfactory variations of breast straps and collars. Likewise, China is known to have had the breast harness in the sixth century. At any rate, the evidence points to a satisfactory collar harness in Germany by the latter half of the eighth century. However, diffusion of the collar harness and use of the heavy horse with the heavy plow did not take place in Europe until the late tenth or early eleventh century.

It is probable that the horse was not harnessed to the heavy plow even though the collar harness had been known for two or more centuries because horse hooves are not very durable in moist climates like those of Northern Europe. After a11, a draft horse is no better than his hooves when it comes to the long pull. While the horse hoof is durable in dry climates, it becomes soft and is easily damaged with moisture. Oxen appear to be better equipped than horses in this regard because their hooves stand up better. The nailed, iron horseshoe remedied the problem of hoof durability for horses. However, nailed horseshoes do not appear in Europe until the latter half of the tenth century. The first archeologically-confirmed evidence of a nailed horseshoe was found in the grave of a Siberian nomad in the Yenisei region dating from the ninth century. Evidence indicates that they were known in Byzantium soon after, and in Europe soon after that. However, widespread use of the nailed horseshoe does not occur until the eleventh century.

It was finally in the eleventh century that the properly-shod draft Reproduced with permission of the copyright owner. Further reproduction prohibited without permission. 
horse was efficiently harnessed to the heavy plow in Europe. The plow had been in expanding use for nearly five centuries, and the collar harness had been in existence for more than two hundred years. The combined effects of the innovation, diffusion, and integration of the heavy plow, the three field rotation, and the heavy horse in agriculture were astounding increases in internal economies of large-scale agricultural production, resulting in equally astounding increases in agricultural productivity and surpluses in agricultural products, the emancipation of significant numbers of peasants from farming, and a radical reordering of institutional arrangements.

Those effects were caused by qualitative improvements in tools. That is, they stemmed from technological advances that permitted the improved tools to better substitute for labor in the production of goods and services having human value. Those results became the means to ongoing ends. Indeed, they served to bring ends into view that had theretofore been beyond human reach. It became possible to organize means in different ways than the traditional methods descended from the past. Thus, the forward-urging new technologies were in conflict with change-resistant ceremonialism. That is, some inter-institutional arrangements were not entirely complimentary within the institutional system, and aspects of ceremonialism based on those institutional values became hindrances in light of the new technologies. This led to social conflicts as the institutional system first struggled to resist, then to realign itself in accord with the new technologies.

Social stability did not resume until diffusion and integration of the new technology was complete. That did not happen until the technological innovations were fully harmonized with the institutional system, 
and a11 institutions were once again complimentary within that system. That happened when ceremonies and ceremonial statuses were changed to account for the new technologies. While the innovation and diffusion of the heavy plow and the heavy horse in Medieval Europe took almost a thousand years, the social adjustments needed to fully integrate those technical arrangements took another four hundred years, give or take a century or two.

\section{URBANIZATION - TECHNOLOGY AND EXTERNAL ECONOMIES}

The preceding part of this chapter described how the innovation and diffusion of the heavy plow, triennial field rotation, and the heavy horse increased the returns to scale in agricultural production in medieval Europe. It resulted in the creation of a substantial and enduring agricultural surplus, the liberation of large numbers of peasants from farming, and the precipitation of revolutionary institutional changes. The changes described in the foregoing part of this chapter related to institutions in a rural setting. Of course, the revolution did not end with the changes in agricultural production. Indeed, the revolution in agriculture had profound effects on all aspects of medieval and postmedieval life.

In addition to first increasing the internal economies of largescale production, the diffusion and integration of the heavy plow, triennial crop rotation, and the heavy horse also affected the external economies of location and urban scale. The distribution and size of urban settlements, rural to urban migrations, and urban growth and form were ultimately affected. This part of the chapter describes the progressive qualities of technological innovation and diffusion by illustrating 
the secondary and urban consequences of integrating the heavy plow and the heavy horse in medieval Europe.

\section{Distribution of Urban Settlements}

Substitution of the horse for the ox in farming led to the same substitution in other uses. The horse replaced the ox as draft animal in overland transportation resulting in reductions in transportation costs and commuting times, and therefore in changes in market areas and the distribution of settlements. That is, use of the horse at draw increased the external economies of certain urban locations and led to profound alterations in the hierarchy of central urban places. The changes obtained because of the greater speed of the horse over the $0 x$. The horse could haul goods and passengers greater distances per hour of drayage than the ox. Moreover, the horse could endure longer periods at the draw, and it was a more efficient converter of forage to work than was the ox.

Use of the horse at draw mandated other technical improvements. The common drayage vehicle of Roman times was an ox-drawn, two-wheeled cart. By the twelfth century, the two-wheeled cart had given way to expanding use of four-wheeled wagons capable of haul ing very heavy loads. Moreover, wagons were improved to take advantage of the greater efficiency of the properly shod and harnessed horse. Among the improvements were turning front axles, singletrees, and brakes. ${ }^{8}$

The benefit of these technical improvements was a substantial reduction in the cost of overland transportation. It is estimated that the cost of transporting grain overland in Roman times doubled its price each 100 miles. On the other hand, water transport was so inexpensive that 
grains shipped to the city of Rome from North Africa undersold grains grown by Romans only a few miles from the city. By contrast, the cost of overland transportation of grains in the thirteenth century is estimated to have doubled its price each 300 miles, a reduction to only 33 percent of the former cost.

The sizes of marketing areas and the distribution of settlements were greatly affected by the reductions in overland transportation costs. The relevant principle is found in the relationship between the radius and the area of a circle. If the radius is doubled, the area of that circle is quadrupled. If the radius is tripled, the area is increased nine times. In other words, the area multiplier is the square of the radius multiplier.

Applying the foregoing principle and assuming a transportation cost reduction of two-thirds, one can see that, ceteris paribus, goods can now be transported three times as far at no additional cost. That is, the radius multiplier is three. Thus, the area served by a market village has expanded by a multiple of nine; in other words, by the square of the radius multiplier. For example, if the distance from the central business district of a market area were three miles, its market area is approximately 28 square miles $\left(A=\pi r^{2}\right.$ ). If the cost of transportation to and from that market town is somehow reduced by two-thirds, then the effective radius of its market area may be increased by as much as three times, or to approximately nine miles. This implies an expansion of that town's market area from 28 square miles to approximately 254 square miles, or by a multiple of nine.

The same effect can be demonstrated using a market theory of land allocation. ${ }^{9}$ For purposes of explanation, it is assumed that the value 
of land is determined by its productivity, and that the central market price per acre of harvested product is the same at any given time for a11 producers. The profit per acre to producers is therefore the central market price per acre of harvested product less all costs per acre to produce the product and deliver it to the market. The costs are the land rent per acre, the transportation cost per acre, and other costs per acre. Other per-acre costs include the cost of seed, fertilizer, etc., and they are approximately the same for all producers. On the other hand, transportation costs are directly related to the distance the land lies from the central market place. The farther the land is from the central place, the greater the transportation cost.

If farmer-producers bid against one another for use of the land in accordance with the foregoing assumptions, it will be found that the emerging bid-rent function is inversely proportionate to the transportation-cost function. For example, if the product price at the central market place for a 11 producers is $\$ 200.00$ per acre of output, the per-acre costs other than rent and transportation are $\$ 25.00$, and the profit normally expected and required to keep farmers cultivating the product is $\$ 75.00$ per acre, there remains $\$ 100$ per acre to cover rent and the cost of transportation. Finally, if annual transportation costs are $\$ 33.00$ per acre per mile from the central place, then the effective radius of the central market place is approximately three miles $(\$ 100 /$ acre divided by $\$ 33$ per acre per mile), and its area is approximately 28 square miles.

It is easy to see that farmer-producers will bid higher rents for parcels of land closer to the central market place because the transportation cost associated with those parcels are lower. That is, rent is a premium paid for access to the central places, and the closer the land 
to the center, the higher the rent. For example, if the distance from the central market place is one mile, the annual transportation cost per acre of product is $\$ 33.00$. Under these conditions, the producer would be willing to bid up to $\$ 67.00$ rent per acre. On the other hand, the transportation cost on a parcel two miles from the central marketplace is $\$ 67.00$ per acre, and the farmer-producer would be willing to bid only $\$ 33.00$ rent per acre. And, of course, the producer would not bid on lands more distant than three miles from the central marketplace.

It is also easy to see that a general reduction in transportation costs will increase the radius of the market arable. For example, if the transportation cost on the last mentioned parcel of land dropped from $\$ 100.00$ per acre of output to $\$ 33.00$ (implying an annual transportation cost of $\$ 11.00$ per acre per mile from the central market place) it would become economically feasible to farm the land, and producers would be willing to bid up to $\$ 67.00$ rent per acre. But more than that, the lower transportation costs make it feasible to bring land lying even more distant from the central market into cultivation, thus increasing the radius of the market arable from three miles to nine, and its area from 28 square miles to 254 square miles.

While this simple explanation demonstrates the point, it ignores other economic variables. For example, a reduction in transportation costs would first increase profits and attract more farmers into cultivating the product. This would increase the number of bidders for the arable lands and force rents up. The increased rents would make the more distant and perhaps less suitable lands more attractive alternatives to the land already under cultivation. Finally, the additional supply of product harvested from the newiy cultivated lands would force product

Reproduced with permission of the copyright owner. Further reproduction prohibited without permission. 
prices downward and restore lower profits. The net result would be a new long-run market equilibrium with normal profits, lower product prices, a larger central market area with rents on farm lands lower than before near the central place and higher than before at the periphery.

Other factors are likely to mitigate against expansions on the order suggested above. Topographic features like mountains, lakes, and rivers, will affect the direction and extent of expansion. Similarly, property and political boundaries may place limits on expansions of market areas. Nevertheless, the point is made that the innovation and diffusion of new technologies (heavy horse, breast harness, horse shoes, improved wagons, etc.) reduced the cost of overland transportation. And the lower transportation costs effected profound changes in urban arrangements in medieval and post-medieval Europe. The size and distribution of settlements, rural to urban migration, urban growth, and many other social arrangements were ultimately affected.

The number and distribution of settlements (the hierarchy of central places) were effected because as transportation costs declined and potential village arables enlarged, the market and commuting areas of adjoining hamlets and villages expanded to overlapping. Each community was affected differently depending on its position in the emerging networks of central places. Assume, for example, that a very long-run stability based on the ox-drawn, two-wheeled cart as the primary transport vehicle located hamlets an average three and one-half miles apart. That is, each settlement consisted of ten or twelve peasant cottages serving an area of a little more than eleven square miles with an outside radius of two miles.

Now assume that the last fifty years witnesses a general change to Reproduced with permission of the copyright owner. Further reproduction prohibited without permission. 
horse-drawn wagons and a resulting reduction in transportation costs of two-thirds. What is likely to happen? According to the foregoing theory, one community in nine will eventually expand and the remaining eight will decline so that the resulting very-long-run distribution locates first order settlements an average ten and a half miles apart. That is, each of the expanding villages serves an area of approximately 100 square miles with an outside radius of six miles. And if the surviving villages absorbed the families of the defunct hamlets, the village populations would expand by one hundred or more families. Something on that order seems to have occurred in Europe between the tenth and fourteenth centuries. The point is that substitution of the horse for the ox in overland transportation had transilient effects on the distribution and sizes of European urban settlements. The horse technology reduced transportation costs, changed the external economies of urban locations, and led to the growth of some first-order settlements and the demise of others. Moreover, growth of some settlements accompanied increases in the specialization of urban employments and in proliferation of the urban institutions staffed by the new specialists.

Rura 7 to Urban Migration ${ }^{10}$

Two of the foregoing occurrences brought about other changes that profoundly affected city development in Europe. The first was the increase in internal economies of large-scale production in agriculture caused by innovation and diffusion of the heavy plow and the heavy horse. The second was alterations in the distribution and sizes of settlements caused by the reduction in transportation cost attributed to substitution of the heavy horse for the ox in overland transportation. Together, the 
two phenomena resulted in increases in the external economies of large urban scale and thus increases in urban agglomeration.

An itinerant merchant made his appearance across Europe in the eighth and ninth centuries. His 1 ineage is not certain, but he and most of his retinue were probably former serfs or sons of serfs whose bondage could not be proven. The itinerant merchant as well as all of the traders involved in medieval and post-medieval European commerce were responding to the emerging economic productivities of Western Europe. However, their responses were themselves instrumental toward several important on-going changes. The first was the economic resurgence of European towns and the founding of new towns as medieval trading centers. The second was the gradual monetization of feudal obligations.

The itinerant merchant was the final link in a chain of commerce that commenced at Constantinople, Alexandria, and other Eastern Mediterranean ports, and made a tortous journey through the great maritime cities of Venice, Pisa, and Genoa to the fair at Champagne and to the smaller trading centers emerging in the European river valleys--Hamburg on the Elbe, Cologne on the Rhine, Paris on the Seine, London on the Thames. From those centers, the itinerant merchant peddled the silks, spices, precious metals, drugs, and finely-worked jewelry from the Orient to the nobility that occupied the castles and manors of Europe. The moneys he acquired in this way were used to purchase furs, honey, fish, wine, salt, timber, iron, and woolens which were returned over the same routes to be exchanged for more Oriental goods.

Wherever a merchant stopped, he encamped his retinue on a site protected by a church, or a castle. In time, a permanent trading place grew outside the walls of those edifices. Such places soon became the nuclei

Reproduced with permission of the copyright owner. Further reproduction prohibited without permission. 
of small trading towns or bourgs, as they were called in France. The free men--burgesses or bourgeois--who inhabited the new burgs remained outside the manorial system, and there were no precedents founded on tradition to regulate their relationships with the fuedal nobility. Thus they formed the market institutions and developed the ceremonial arrangements that would eventually displace the fuedal order. For the first time the cities were not the outposts of central governments, as they had been in previous civilizations. Rather, they succeeded in maintaining their independence outside the main structure of social power.

The second change toward which the itinerant merchant was instrumental was the monetization of feudal obligations. Trade with itinerant merchants gave rise to demands for money as media of exchange. Indeed, much of the money was ultimately supplied through the buying transactions of the merchants themselves. However, the use of money did not end with the merchants. Gradually, over the centuries between 900 and 1400, most economic transactions were placed on a money basis. As a result, feudal servitude gave way to the payment of tallage (or taxes) by the vassal in exchange for the fief. Likewise, rents were paid in money for use of the lord's lands. Finally, the lord commenced to reward serfs with money wages for work performed on the lord's demesne. The resulting monetary reciprocities--wages for labor, rent for land, interest for money, and profit for entrepreneurship--pealed the death knell for the institutions of feudal society, and they were harbingers of a coming system of market institutions.

The increase in agricultural productivity described in the early parts of this chapter drove agriculture prices down in relation to the prices of other goods. In international trade parlance, the commodity 
terms of trade turned adverse to the primary producers. By the thirteenth century, the landed aristocracy found itself pinched between low revenues and high prices. Many of the nobles sought relief by enclosing and farming the common lands, and denying use of those lands as pastures for the peasants to graze their stock. Moreover, the fecundity of peasant families and the practice of dividing and distributing a peasant's arable strips among his sons was making it increasingly difficult for peasants to support themselves, and they were gradually pressed off the 1 and. Entire hamlets were wiped out in England where tenants were sometimes simply thrown off the land. The dispossessed tenants became a landless labor force compelled to work for wages wherever work might be found. These events coincided to produce the food and fiber and the labor resources needed to support an expansion in urban employments. Peasants, finding no gainful opportunities for agricultural vocations, migrated to villages where they became the cadres from which the increasing demands for urban services were supplied, and they eventually specialized in the secondary employments that abound in urban settlements. They became millers, bakers, wagoners, cartwrights, weavers, tailors, shoemakers, sellers, musicians, smiths, carpenters, masons, butchers, teachers, clerics, constables, and the host of other specialists that populate the institutions that agglomerate at urban places.

Not only dispossessed tenants, but peasants who continued to farm found urban living preferable as well. Historical geographers investigating demographic changes in Germany found that peasants were abandoning their settlements but not their fields starting in the eleventh century and continuing with greater frequency into the thirteenth century. The peasants were moving to nearby cities and villages and commuting to their

Reproduced with permission of the copyright owner. Further reproduction prohibited without permission. 
fields each day during planting and harvesting seasons. Clearly, the improved transportation technology was the enabling factor. As long as peasants must rely on the slow and plodding oxen as their means of transportation, they must live close to their fields. However, use of the much faster horse allowed the peasants to commute greater distances in the same amount of time as before.

Thus, the shift from oxen to equestrian-based transportation led to the urbanization of German peasants. The advantages to the peasants were many-fold. Life in a rural hamlet of ten or twelve peasant families was drab, indeed. On the other hand, life in a large village of a hundred or more families gave one access to a large church, perhaps a church school, a tavern, better security against marauders, merchants with a greater variety of goods and services, more frequent and accurate news of national and international events, and other urban amenities. ${ }^{11}$

It is hard to imagine a more revolutionary change in the family institution than occurred with urbanization. A rural family was much more isolated, independent, and self-sufficient than an urban family. This meant that the family produced most of its own food and clothing. Governance, education, and worship were directed by the elders of the family. Child delivery, health care, and burial of the dead were all internal functions of the rural family. The isolation of a rural family in medieval times caused its members to be almost entirely dependent upon the family for their living needs. And the responsibilities of the family elders in such isolation endowed the elders with great paternal authority.

On the other hand, the same family removed to an urban setting finds paternal authorities traumatically eroded. The family is no longer 
isolated, self-sufficient, or independent. It now lives in close proximity with many different families. The goods and services provided for itself by the rural family are provided by other specialized institutions external to the urban family, and the family must pay for the goods and services from money wages earned in employments outside the family. Food and clothing are supplied through retail merchants in the town, and governance is carried on by a municipal administration. Education is provided by schools, and worship is done in a church. Child delivery may still take place in the home, but it is most likely assisted by a midwife who has no blood relationship with the family. Health care is provided by hospitals, medical doctors, and nurses, and burial of the dead is done in a churchyard or other community burial plot.

The point is that the potency of the family as an institution is greatiy diminished in an urban setting, vis a rural setting, because of the plethora of other specialized institutions which exist in urban areas. Those institutions simply take over many of the functions that were performed by the family in isolation. The members of an urban family learn to rely on institutions outside the family, and they are therefore no longer solely dependent on the family for most of their living needs. The paradox is that urban family interdependence leads to intrafamily independence, and to diminution of rural family cohesion and erosion of rural paternal authority. Urbanization of European peasants was indeed revolutionary.

Here again, the external economies of large urban scale and the urban agglomeration it produced in medieval Europe is traced to innovation and diffusion of the heavy plow and the heavy horse in agriculture and to subsequent use of the horse in commercial draught. Those

Reproduced with permission of the copyright owner. Further reproduction prohibited without permission. 
technical improvements led to an agricultural surplus, and, at the same time liberated many peasants from agricultural vocations. The former peasant farmers migrated to urban settings where they specialized in secondary employments and staffed the myriad of institutions that agglomerated there in response to the economic stimulus created by the increased agricultural productivities.

\section{Urban Growth}

While the cultural integration of the heavy plow and the heavy horse impacted initially on the internal economies of large-scale production in agriculture, the secondary and on-going effects had to do with the external economies of location and urban scale, and thus with the sizes and distribution of urban settlements, the rural to urban migrations, and urban growth. The sizes and distribution of urban settlements, and the rural to urban migrations were described above. This section elaborates the phenomenon of urban growth in medieval Europe as an on-going consequence of the new technologies in agriculture.

The fact of urban growth in medieval Europe was, of course, implicit in both of the preceding sections. The villages that survived the redistribution of settlements occasioned by the decrease in overland transportation costs grew by simply absorbing both the populations and the commerces of the defunct hamlets. Likewise, rural to urban migrations further swelled urban populations. Indeed, the populations of medieval urban centers did not grow from within, but expanded because of migrations. However, there had to be more to urban growth than simply population increases. There had to be some kind of economic basis to expand urban employments so that the new urban dwellers could be

Reproduced with permission of the copyright owner. Further reproduction prohibited without permission. 
accommodated.

The explanation of urban growth in medieval Europe is found in the interregional trade and exchange relations in which the itinerant merchant described above was a key figure. A section of the preceding chapter dealt with comparative advantage, interfamily specialization, and trade in the context of central-place theory. Precisely the same principles apply to interregional and international trade. Just as persons possess differential aptitudes and tool-using skills, so regions possess different resource or factor endowments. That is, the quantity, or quality, or both quantity and quality of land, labor, capital, and entrepreneurship are different from region to region.

Even if this were not so with labor, capital, and entrepreneurship--which are mobile in varying degrees and could theoretically be distributed uniformly over the land--variations in the productivity of land resources alone would differentiate regions from one another. This is because land is heterogeneous, absolutely finite, and absolutely immobile. And insofar as labor, capital, and entrepreneurship are allocated at least in part according to land productivities, it is unlikely that they will be uniformly distributed across regions--or, for that matter, uniformly within a particular region.

Each region would, therefore, possess particular advantages and disadvantages as compared to other regions, and each would eventually specialize in the production of those goods and services in which it had a comparative advantage. Moreover, it would trade parts of its specialized outputs with other regions for the goods and services foregone in specializing its own productions. Greater efficiency and welfare are presumably achieved, as international trade theory attempts to

Reproduced with permission of the copyright owner. Further reproduction prohibited without permission. 
demonstrate, by international and interregional specializations based on the principle of comparative advantage. And once the residents of a region seek to improve their efficiency through specialization, they forego self-sufficiency and economic independence. They become one segment of an inter-dependent web of specialized economic regions, each one of which is dependent on all others.

And so it was in medieval Europe and between Europe and the cultures of the Eastern Mediterranean. The itinerant merchants became the burgesses of Europe, and they continued to mark up and sell Oriental silks, spices, drugs, jewelry, and precious metals and stones to the nobility. Moreover, they continued to buy food stuffs, fabrics, and building materials from the manors, and they sold those goods to the oriental cultures at handsome profits. In short, the burgs enjoyed very favorable balances of payments while the Eastern cultures were suffering a net outflow of exchange, and the European nobility were slowly becoming impoverished. It was the net injection of exchange payments that created the economic base for urban expansion in medieval Europe.

The key to understanding why and how interregional trade and exchange resulted in urban growth is to understand the principle of the export-base multiplier in economic-base theory. ${ }^{12}$ According to economicbase theory, productive activities in a city and its hinterlands may be divided into export-base (basic) and local-base (non-basic) industries. Export-base industries produce primarily for export to other cities and regions while local-base industries produce only goods and services that are consumed locally. Local-base industries are therefore those productive activities that generate the externat economies of urban scale which cause agglomeration. On the other hand, it is the export-base

Reproduced with permission of the copyright owner. Further reproduction prohibited without permission. 
industries of a city that generate the revenues from outside the region that cause economic growth of a city, including growth of the localbase industries within $i$ ts boundaries and hinterlands.

The export-base multiplier is the ratio of the change in total regional employment to the change in export-base employment. In other words, it states the change induced in total employment by the addition of one employee to an export-base industry. The export-base multiplier may also be understood solely in terms of regional incomes. The levels of regional incomes and regional employments are directly related, and it matters little which statistic is emphasized. However, it is desired to explain here how rurai-to-urban migrations resulted in part from the rapid and substantiai increases in urban employment opportunities over much of medieval Europe. Thus, the export-base multiplier will be described here emphasizing the employment effects.

The multiplier relates export base to urban growth as follows: For some reason an economic demand is initiated from outside a region for products produced in the region. This gives rise to a demand in the region for the resources needed to produce the products to be exported. This, of course, includes an increase in the demand for units of labor to carry out the production. The increased demand for labor will be met either from unemployed persons in the region or by the migration of labor into the region, or both. The added employee will, of course, receive wages from his employer, and the employer will pay the wages from the revenues he receives from selling the product outside the region. The wages paid the new employee, as well as payments made to other factors involved in the production, are injections of buying power into the region. The new workers will use their wages to pay living expenses, perhaps 
including the purchase of some items imported from outside the region. The payments for imported goods are ultimately made to vendors outside the region, and the moneys so paid are therefore leaked from the region's income stream. The new workers may also save part of their wages, and insofar as their savings do not go directly to merchants inside the region, they too are leaked from the income stream. However, their payments to defray living expenses remain in the region's income stream because they are made to landlords, vendors, and tradesmen within the region, increasing the demand for the goods and services supplied by the local-base businesses and employees.

Each person receiving payments from the new employees will likewise spend part and save part. This process will continue through many spending-saving revolutions until funds equal to the entire original injection have leaked away to savings or to payments for goods imported from outside the region. After all spending and saving initiated by the original injection have ended, it will be found that the full value of additional regional income generated is several times the value of new export revenue. Likewise, it will be found that the new regional income is supporting local-base employees that are several times the number of employees added by export-base industries to meet the new external demands for their goods.

The key element here is what economists call the marginal propensity for local consumers to consume locally-produced goods and services. The greater that propensity is, the greater is the export-base multiplier. In other words, leakages to savings and to payments for imported goods weaken the power of the multiplier. There are, of course, other reasons why communities might wish to have high propensities to save and to import. 
However, those reasons are beyond the matter at hand, and it is sufficient for this analysis to recognize that the latter propensities dampen the expansive effects of new export revenues. Export-base multipliers are found to range from slightly less than three to slightly less than seven in modern times, with the higher multipliers associated with the larger cities. Larger cities have higher export-base multipliers because their citizens have higher propensities to consume local goods. This is apparently because larger cities have well-developed local bases that are capable of producing much of what the residents of such cities consume.

An example of the expansive powers of a vigorous export base is found in Flanders. The usual populations of towns in medieval Flanders-Northeastern France, Belgium, and Southern Holland--was from 2,000 to 6,000 persons. However, the populations of Ypres, Bruges, and Ghent each swelled to more than 35,000 persons. These latter cities gained their prominences from specializing in weaving and exporting fine woolen textiles. Incidentiy, much of the raw wool was imported from England where the nobility had created "sheepwalks" by enclosing and depriving the peasants' use of manorial common lands. Some notion of the rapid growth in export revenues is evident in Ypres where the number of lead seals attached to the fabrics produced by its weavers increased from 10,500 in 1306 to 92,500 in 1313 . Likewise, loanable funds became so abundant in Lubeck, the Hanseatic League city to the north of Flanders, that the rate of interest dropped from 10 to $5 \%$ in the preceding twenty or so years, reflecting a substantial injection of payments made for exported goods. 13

It is perhaps not wise to over generalize on such data. However, economic-base theory suggests a causal relationship between the surge in 
the export of woolen fabrics and the growth in the populations of Ypres and the other major textile-producing cities of Flanders. If one assumes that those cities would have grown to something like the average of other towns in Flanders, their growths would have arrested at populations of only 4,000 . However, their populations grew to nearly ten times that number. And it was growth of the employment opportunities in such exporting cities as Ypres, Ghent, and Bruges that attracted medieval peasants into migration from rural to urban areas.

of course medieval urban growth was much less a blessing than has been suggested here. The warfare, famine, and pestilence that periodically swept across medieval Europe was cited above, and rura1to urban-migration resulted in concentrated populations that were particularly vulnerable to those maladies. Indeed, by the time of the Black Death in 1348, migrations had clearly resulted in the overexpansion of urban centers, and the ensuing retrenchment lasted nearly 300 years. Nevertheless, the urbanization that took place between the tenth and thirteenth centuries in Europe set the stage for the Industrial Revolution that commenced in the nineteenth century. ${ }^{14}$

The argument here runs as follows: Urban agglomeration and growth in medieval Europe was possible because of exchange payments generated by interregional trade. Interregional trade was possible because of regional specializations rising to take advantage of internal economies of largescale production. Regional specializations were possible because of technical improvements that lowered the costs of transportation and widened the markets for specialized products, and because of the agricultural surpluses that allowed some peasants to abandon agricultural employments and specialize in the urban employments on which the trade

Reproduced with permission of the copyright owner. Further reproduction prohibited without permission. 
flourished. And the surpluses were possible because the heavy plow and the heavy horse were innovated in Medieval European agriculture. Thus, the causality is traced once again to the increased productivity attributed to important technical improvements--improvements that allowed tools to more effectively substitute for human labor in the production of goods and services having human value.

\section{TECHNOLOGY AND PROGRESS}

The previous chapter described the dynamic qualities of technology. The innovation of new technology is dynamic because it induces change by permitting means to be organized in ways differing from the traditional methods descended from the past. That is, it enables society to secure future ends with the expenditure of fewer present means, and it sometimes brings desirable future ends within human reach that were previously beyond known means. This ultimately reduces the amount of human effort required to secure future ends. In other words, it decreases the man hours of labor input per unit of output of goods and services having human value. It accomplishes this by enabling the tools embodying the new technology to substitute for more units of human labor in production processes.

It has been argued in this chapter that technology is also progressive. Technology is progressive because it is forward-urging in terms of the ends-means continuum. By forward-urging, it is meant that technology is oriented toward future human ends--but more than that, future ends that improve upon human welfare. Such improvement is possible because of the dynamic quality of technology described above. The great strides in human progress were those sequences of events that produced substantial 
improvements in human conditions, whether the improvements were seen as reductions in human travail, declines in famine and disease, or increases in human longevity. Whatever the gains, the events that produced them were solidiy based on antecedent technological advances. The point is that human progress is ultimately keyed to technical progress, and it is in this sense that technology is progressive.

However, the progressive qualities of technology are not realized until newly innovated technologies are diffused and integrated. It is not enough to simply innovate new technologies. Society itself must be restructured to exploit the new technologies if their full benefits are to be realized. It is the integration process that brings forth the institutional changes involved with social structure. It often takes centuries to achieve full integration of pervasive technologies; to adapt human skills, to embellish the technical devices, to perfect the techniques required to effectively employ the tools embodying the new technologies, and to alter distributional arrangements so that everyone enjoys his full share of the benefits created in the process.

This chapter has been an attempt to illustrate the progressive character of technological diffusion and integration by describing some of the institutional changes resulting from development of the heavy plow and the heavy horse in medieval European agriculture. Those technologies produced internat economies of large-scale production that improved agricultural production, all at once creating a substantial surplus of food and fiber, and liberating many peasants from farming and forcing them to migrate to urban centers where they eventually specialized in secondary employments. The new plow and horse technologies therefore created the environing conditions for urban agglomeration as well. Of course, there

Reproduced with permission of the copyright owner. Further reproduction prohibited without permission. 
were other technical improvements in the medieval period that similarly facilitated craft specializations. Such improvements have only been implied in the preceding descriptions, and while it is not intended to slight the latter it has been enough to trace out the progressive consequences of the heavy plow and the heavy horse.

The point is that the plow and horse technologies that were new to medieval Europe altered interinstitutional relationships so that some institutions were not completely complimentary in the institutional system. Certain ceremonial practices based on particular institutional values became obstacles before the new technologies. Social tensions resulted as the institutional system at first opposed and then adjusted itself to the new technologies. The details of the adjustment process were not explicitly described--indeed, archeology and history do not deliver those details up from the medieval period with any degree of clarity. Those processual details could only be inferred from the circumstances. However, the apparent effects, the resulting institutional changes, could be described with some degree of certainty.

At any rate, the social instability precipitated by innovation and exacerbated by integration of the heavy plow and the heavy horse abated only when diffusion and integration of the new technologies were complete. Integration was not complete until the technologies were accommodated by the institutional system, and all institutions were once again in harmony. That did not happen until ceremonies and ceremonial statuses were altered to account for the new technologies.

Complete integration resulted in a new social stability in which institutional powers were redistributed in congruity with the new technologies. Some institutions acquired greater power while others suffered 
diminished power. Some old institutions disappeared and some new institutions came into being. It was social revolution initiated and carried through by technological change that produced institutional discontinuities in the medieval period--as well as in all other periods. And it was the post-revolution stability in which the full benefits of the integrated technologies were realized. But it was the future generations that based their own progressions on the medieval technologies that achieved the full measure of benefits. It is the nature of technical progress that one generation's technical accomplishments are all at once founded on those of previous generations and become the foundation for technical progress by future generations. As technology is continuous, technical progress is also continuous.

This concludes description of the technology component of institutional economic theory as it is interpreted by this author. Chapter VI defined technology as that quality of a tool that enables it to be substituted for human effort in the creation of goods and services having human value. Moreover, it distinguished technology from technique and human skill. Chapter VII described technological continuity and related it to scientific discovery and invention. Likewise, Chapter VII described technological dynamism--the power to initiate change--and related it to the process of innovation. And the present chapter described the progressive qualities of technology and related them to processes of social diffusion and integration.

This and the preceding two chapters have described technology and its relationship to the ends-means continuum--the continuum of on-going life processes. Likewise, the next preceding two chapters, Chapters IV and $V$, described ceremonialism and its relationship to the continuum, 
and the continuum itself was described in Chapter III. The question remaining unanswered in all of this is how the tensions between forwardurging technology and backward-clinging ceremonialism are resolved. The remaining two content chapters deal with that question. 
END NOTES, CHAPTER VIII

1 Ayres, Theory of Economic Progress, pp. 105-24. Thorstein Veblen, Theory of Business Enterprise, pp. 144-76.

${ }^{2}$ Fairchild, Dictionary of Sociology, p. 94.

3 Ibid, p. 159.

${ }^{4}$ White, Medieval Technology, pp. 39-57.

${ }^{5}$ Ibid, pp. 69-76.

6 Ibid, pp. 1-38.

${ }^{7 \text { Ibid, pp. 57-65. }}$

8 Ibid, pp. 66-69.

9 William Alonso, "A Theory of the Urban Land Market," Papers and Proceedings, Regional Science Association, VI (1960), 149-57.

${ }^{10}$ Carlo Cipolla, Before the Industrial Revolution; European Society and Economy, 1000-1700, (New York: W. W. Norton \& Co., Inc., 1976), pp. 139-45. Denys Hay, The Medieval Centuries, (New York: Harper and Row, Publishers, Inc., 1965), pp. 107-27. Robert L. Heilbroner, The Making of Economic Society, (Engl ewood Cliffs: Prentice-Ha11, Inc., 1968), pp. 47-63.

11 White, Medieval Technology, p. 67.

${ }^{12}$ Charles M. Tiebout, The Community Economic Base Study, Supplementary Paper No. 16, (New York: Committee for Economic Development, 1962). ATso see: Richard B. Andrews, "The Mechanics of Urban Economic Base: Historical Developments of the Base Concept," Land Economics, XXIX (August, 1953), 167-67. Homer Hoyt, "Homer Hoyt on the Concept of the Economic Base," Land Economics, XXX (May, 1954), 182-86. Douglass C. North, "Location Theory and Regional Economic Growth," Journal of Political Economy, LXIII (June, 1955), 243-58.

${ }^{13}$ Cipolla, Before the Industrial Revolution, p. 193.

${ }^{14}$ Ibid, pp. 145-57.

Reproduced with permission of the copyright owner. Further reproduction prohibited without permission. 
CHAPTER IX

URBAN VALUATIONS

Considerable verbiage has been invested to this point in distinguishing the technological aspect of human culture from the ceremonial aspect, and in showing how each aspect relates to the continuum of on-going life processes, the end-means continuum. To repeat once again, ceremonialism is backward-reaching while technology is forward-urging in relation to the continuum. Thus, the ceremonial and technological aspects of culture are pitted against one another regarding the selection of future ends-to-be-reached and the means to be employed to secure the selected ends.

Parts of the preceding two chapters have dealt with the conflict between ceremonialism and technology in the context of urbanization in Western Civilization. Attention was focused on the powers of new technologies to bring about institutional changes in the face of ceremonial practices that were systematically weakened by social calamities. It was possible to infer the social choices from the consequent circumstances--in other words, to reconstruct the probable causes from the observable effects. However, practicaliy nothing was said about the political and economic processes for resolving the tensions between ceremonialism and technology into institutional change and social progress.

And yet it cannot be doubted that the revolutionary changes emerged in the wake of deliberate human choices made after reflections

Reproduced with permission of the copyright owner. Further reproduction prohibited without permission. 
on the costs and probable benefits of the alternatives open to choice. Unfortunately, little is found in the literature to inform the present of precisely what costs and benefits were perceived by monarchs or peasants in arriving at chosen courses of action. Attempting to impute from observable circumstances the particular valuations they made in arriving at decisions would involve the most sheer speculations. Therefore there will be no attempt here to embellish the events described in the preceding chapter with speculations on how medieval decision-makers perceived their alternatives, or how much weight they assigned to the particular benefits and costs they might have considered.

However, much social change has occurred between the medieval and modern eras. The technological progress and institutional changes secured in the Dark Ages formed the base from which the Industrial Revolution was launched. And the Industrial Revolution, which is a stage of the technical revolution that has been underway from the beginning of man, is still in progress. Much has obviously happened between then and now, not least of which is enormous gains in human welfare carried forth by the revolutionary powers of technological change.

Much of the western world has become industrialized during the intervening period. Many of the feudal cities of Roman Gaul have become the industrial cities of Europe. The use of draft animals to power agricultural equipment and commercial transport vehicles has given way to the use of mechanical power devices. Mechanical power equipment and electronic-control devices have replaced men in manufacturing, moving society from reliance on scarce and costly hand-

Reproduced with permission of the copyright owner. Further reproduction prohibited without permission. 
crafted products to an abundance of relatively low-priced goods and services which are mass produced in industrial processes.

Moreover, technical changes occur much more rapidly in the present age than at any other time in the history of man. This is partly because of preceding technological developments that have decreased the costs of communication and therefore the costs of knowledge. One effect has been to spur invention by heightening technological cross-fertilization. Another effect has been to further weaken the powers of ceremonialism to resist technological innovation by raising expectations of change and reducing the fears of technical progress and institutional changes in the minds of persons who will bear the costs as well as enjoy the benefits of change. And yet another effect has been to shorten the time required to achieve the cultural diffusion and integration of new technologies. All of these changes are themselves the effects of technological developments--the most important of which is innovation and integration of electronic communication equipment. ${ }^{1}$

The foregoing effects also result from another feature of industrial societies that distinguish them from feudal societies. The feature is that technical change is at least partly institutionalized in industrial societies. By this, it is meant that members of such societies expect some technological development in the form of technical changes that produce net positive social benefits or a surplus of benefits over costs in the long run. Thus, ceremonial practices in industrial societies are directed more toward controlling technical change than toward stopping it all together. This means neither that ceremonialism is absent under industrialism nor that the 
inherent tensions between ceremonialism and technology no longer exist. Rather, it simply means that ceremonialism is deliberately weakened vis-a-vis the powers of technology in an industrial system.

Since industrial society is a present reality, much more is known about its techniques of social choice, and it therefore serves as a better object for the study of social choice than medieval society. This chapter and the next examine the cultural mechanisms for making social choices in an industrial society--choices that resolve the tensions between ceremonialism and technology into technical change and social progress. This chapter considers the institutionalized criterion of valuation in selecting ends and organizing means, drawing primarily from orthodox economic theory-particularly from welfare economics and the economics of public choice. The next chapter examines the processes of social choice in an industrial society, drawing from elements of pluralist political theory and from institutional economic theory.

The principal idea in the present chapter is that attitudes toward value in an industrial society are as multifarious and disparate as society is pluralistic, and there is no simple or direct method to structure and weigh values in choosing between competing future ends and between alternative methods for employing present means toward whatever ends are selected. The first part of the chapter looks briefly at values and welfare in the context of choosing. The remaining parts examine aspects of benefit-cost analysis in terms of the values described in the first part.

Reproduced with permission of the copyright owner. Further reproduction prohibited without permission. 


\section{VALUES AND WELFARE}

\section{Values}

The concept of value is simple to understand, but its applications lead to inordinate complexities. Value is that quality of a thing or state-of-affairs that distinguishes it as more or less desirable. So-called subjectivists in the philosophy of axiology argue that anything about which anyone has concern possesses value. ${ }^{2}$ On the other hand, so-called metaphysical objectivists claim that things are desired because they have value. ${ }^{3}$ Finally, logical objectivists believe there can be no logical or ontological theory of value, only a theory of valuation. ${ }^{4}$ It matters little which idea one subscribes to because each one allows valuations across an enormous range, and it admits a myriad of competing values and conflicting interests--particularly in the pluralist societies that characterize industria1 nations.

Society is an environment of great contrasts. It is a source of humane compassion and a refuse heap for human dereliction. It is allat-once a source of ecstatic pleasures and excruciating pains, of great creativity and terrible waste, of resounding hope and crushing despair, of glorious successes and dismal failures, of grand and auspicious wealth and abject poverty, of abiding love and vicious hate. In short, it is many diverse things to many diverse people.

Likewise, industrial society is composed of disparate creatures-fat, thin, tall, and short--male and female--young and old--black, white, and almost every variation between--rich and poor--educated 
and not-so educated--a society of creatures common in their humaneness or lack of it. Al1 have aspirations, hopes, fears, and despairs. Each loves and hates and experiences varieties of pleasure and pain. Each is an individual effect of prior causes (deliberate or accidental), and he is a means (1ike it or not) to future ends--though hardly the only means. How he is organized toward the future depends not only on the causes that brought him and his environment into being, but also on the choices made by the pluralistic, institutional society of which he is a part as well as the decisions he himself made on those choices left open to him.

Both individual and collective choices involve the selection of future ends-to-be-reached, and the employment of means toward the attainment of those future ends. Such choices are necessarily structured by the values people hold. And those values are partly functions of the ceremonial causes and effects which transmit culture, socialize persons to their institutional roles, control social interactions, and thereby maintain social stability. In short, the attitudes of people about values and the valuing of competing future ends and alternative ways to employ means are mostly the products of the institutional system described in Chapters II, IV, and $V$ above. Recalling from Chapter II:

An institution is an organized social group that has evolved from and is united with some particular system of cultural values, and it serves through processes of social control to stabilize social interaction by preserving and perpetuating those values in the society of which the institution is a part.

Industrial society is essentially an urban one, and since an urban area is simply one at which many highly specialized institutions 
have agglomerated, it follows that industrial society is a valuecharged environment. It is an environment that is charged with technical values, pecuniary values, ethical values, and aesthetic values-a matrix of values as various and complex as the institutions that agglomerate in urban areas, and as the people who populate the institutions and espouse their ceremonial values.

There may be little argument with such technical values as water freezes at sea level when the temperature drops below zero degrees centigrade. And there may be substantial agreement as to pecuniary or economic valuations ordered out in market places as prices, wages, rents, profits, etc. However, such pecuniary valuations may be challenged as unjust on ethical, moral, or social grounds. Likewise, ethical or social considerations might be challenged on aesthetic or intrinsic grounds. And aesthetic valuations might be condemned on moral or ethical grounds. Industrial society, therefore, abounds with clashes between values, each one vying for preeminence in weighting choices for and against particular sets of competing future ends and alternative ways of organizing means.

The point is that peoples' attitudes about values and valuing in an industrial society are as multifarious and disparate as society is pluralistic, and some method must be found to resolve conflicting interests in a selection of social ends and allocation of means that maximizes social welfare. The method commoniy used is some variation of benefit-cost analysis. Before taking up benefit-cost analysis, however, the question of welfare criteria must be examined in the context of choosing from competing ends and from alternative techniques for employing means.

Reproduced with permission of the copyright owner. Further reproduction prohibited without permission. 
Social Welfare

Welfare is simply a state of being or doing we11, and it applies in this case to conditions of human health, prosperity, and happiness. Thus social welfare has to do with the health, prosperity, and happiness of society as a whole. Economists are preoccupied with a socalled social-welfare function. The social-welfare function is a gross abstraction, the derivation of which is found in orthodox microeconomic theory. Time and space do not allow for a rigorous explication of the underlying microeconomic theory. However, a brief summary of the major premises of the applicable welfare economic theory is necessary and possible. It is necessary because the theories implicitly pervade the thinking of most modern policy-makers.

The entire framework of welfare economics rests on several simplifying assumptions--some explicit and some implicit. The following list of assumptions and deductions therefrom is not exhaustive. 5

1. People achieve satisfaction (or utility, or happiness) in the consumption of goods and services. (Note that "services" admits to happiness in human experiences which are not narrowly construed as material or pecuniary). Persons will therefore attempt to maximize their satisfactions while attempting to minimize the costs (or disutility) to them of securing those satisfactions.

2. The human animal is hedonistic so that, in the long run, his wants are insatiable. Thus, human wants are potentially infinite.

3. On the other hand, most of the resource-means from which human wants are satisfied are finite in nature, and they are therefore scarce. Thus, it is important to allocate scarce resource means in such a way that the greatest possible human satisfactions are attained.

Reproduced with permission of the copyright owner. Further reproduction prohibited without permission. 
4. Efficiency is achieved when a so-called Pareto-optimal allocation of resources is attained. ${ }^{6}$ A Pareto-optimal allocation exists when resources have been allocated in such a way that it is not possible to increase anyone's satisfaction (or improve his welfare) without detracting from some other person's satisfaction (or welfare). A Pareto-optimal allocation cannot be improved in terms of efficiency criteria. However, such an allocation may be improved in terms of equity criteria if goods and services are redistributed in such a way that the gaining persons value their gains more than the losing persons value their losses. ${ }^{7}$

5. The economic system functions to allocate scarce resources to competing human wants. A market economy carries out its allocative function by an exchange system based on the price interaction of the supply of and the demand for goods and services. (The term "price" is generally conceived in a pecuniary or monetary connotation when used in connection with an economic system. However, its use is not restricted to pecuniary applications. The price anyone pays for something is really those other things he gives up or "trades off" to secure the good or service he acquires).

6. Allocative efficiency in the way of Pareto criteria can only be achieved in a perfectly competitive market economy. The conditions necessary for a perfectly competitive economy are: Products must be homogeneous. A11 market agents must be price takers--not price searchers. This is usually thought to exist when there are many sellers and many buyers such that the actions of any one seller or any one buyer wi11 not affect the market price. Moreover, there must be perfect market knowledge on the part of every market agent. Finally, 
there must be perfect factor mobility so that resources may move into or out of the production of any good or service according to market conditions. This also means that there can be no barriers to entry of any firm into any industry.

7. A perfectly competitive market system distributes income on the basis of the supply of and demand for the resource receiving the income. The demand for a productive resource is the marginal revenue product of the resource. The marginal revenue product of a resource is the net addition to the manufacturer's total revenue occasioned by the addition of one more unit of the productive resource. A wage that is simultaneously equal to the marginal revenue product (demand) and the average cost (supply) of a productive resource is an efficient and equitable wage. Thus, an efficient distribution of income is an equitable distribution in such a system. Which is to say that if income is to be redistributed according to some other concept of equity, such redistribution is extra-market.

8. Human satisfactions can be maximized subject to available resources if perfectly competitive conditions prevail and if the entire system is in a state of general equilibrium--that is, if there are no economic incentives for changes anywhere in the system. 8

9. Production is said to be in a Pareto-maximum general equilibrium when the marginal rate of technical substitution between every set of inputs is the same for all producers using the inputs. The marginal rate of technica? substitution is simply the amount by which one productive input must be reduced per unit of increase in another productive input such that a constant rate of productive output is maintained.

Reproduced with permission of the copyright owner. Further reproduction prohibited without permission. 
10. A production possibility frontier (or transformation curve) reflecting the number of units by which the production of one good must be decreased in order to expand the production of other goods, is derived from the foregoing. The production possibility curve shows the maximum attainable output of one commodity for every possible level of output of other commodities, given the finite resource pool.

11. A Pareto-maximum general equilibrium of exchange occurs within the constraint of the production possibility frontier where the marginal rate of substitution between every set of goods is the same for all parties consuming the goods. The marginal rate of substitution is simply the number of units of one good that one consumer must sacrifice per unit gain of other goods so that a constant level of satisfaction is maintained. The marginal rate of substitution for exchange partners must equal the marginal rate of trarisformation on the production possibility frontier. There is one unique exchange equilibrium for every point on the production possibility frontier.

12. A utility-possibility frontier reflecting the maximum level of satisfaction attainable by one exchange partner for every level of satisfaction of other exchange partners is constructed from the above exchange solutions. The outward-most reach of a family of utilitypossibility frontiers is called the grand utility possibility frontier.

13. A social-welfare function is assumed to exist. The socialwelfare function is presumably an aggregation of the individual preference functions of all members of society, and it therefore possesses the properties of an individual preference function (or indifference map). An indifference map is a graphic representation of a family of indifference curves. An indifference curve is a locus

Reproduced with permission of the copyright owner. Further reproduction prohibited without permission. 
of points representing different combinations of goods, each combination of which renders the same level of satisfaction.

14. Maximum social welfare is achieved where a social indifference curve (a component of the social welfare function) is tangent to the grand utility possibility frontier. The point of tangency is called the point of "constrained bliss" because it is the one and only Pareto-optimal organization of production and exchange that maximizes human satisfaction throughout society subject to the availability of resources.

The foregoing is a bare-bones outline of the principal tenets of welfare economics. As the reader can see, the theories involve a high degree of abstraction. However, all theories are abstractional made from reality for purposes of explaining past causes and effects. Such abstractions are theories that can be used to predict future outcomes of present actions, and to prescribe present actions to effect desired future outcomes. The marks of good theory are therefore internal consistency, empirical validity, and relevancy, or predictive accuracy.

It can be shown that welfare economics fares very well in tests of internal consistency. By internal consistency it is meant that a theory is free of contradictions whereby one or more components of the theory are incongruent with the major premises of the theory. Welfare economics and the microeconomic theories upon which it is based are virtual paragons of internal consistency, and no significant defects may be cited from that quarter to sully the theories. What then of the other tests of good theory? Can welfare economics stand the tests of empirical validity and predictive accuracy? It is found that the principal defects with welfare economics stem from a lack of empirical

Reproduced with permission of the copyright owner. Further reproduction prohibited without permission. 
validity, and that such defects render its predictive accuracy very suspect--no matter how consistent the theory might be internally.

Welfare economics suffers from a dearth of empirical verification. The two major defects of welfare economics are the requirement that markets be perfectly competitive, and the assumption of a social-welfare function. Other related difficulties that plague the theory are the high-ievel of abstraction, the static approach to analysis, and the stress of pecuniary valuations. That which follows will deal with the relatively minor defects first and end with discussion of the two major defects.

It has already been noted that a theory is an abstraction from reality made for purposes of explaining and applying causal relationships. Thus, an abstraction is a generalization that is assumed into existence to explain reality. A theory is defective if it is based on abstractions or assumed generalizations that do not, in fact, explain reality, or they describe some empirically verifiable but minute aspect of reality, and they are advanced as a total explanation of reality. No matter how attractive a theory might be intuitively, it is an intellectual exercise of little practical value if it cannot be verified empirically. As will soon be clear, this is a problem with welfare economics. The level of abstraction so removes welfare economic theory from reality that the theory is of 1ittle practical value.

A second and related defect of welfare economic theory is that it is a static form of analysis used to explain an essentially dynamic reality. The whole notion of equilibrium is that of a stable state-a state of being in which there are no operant forces for change. In 
the so-called state of general equilibrium on which the concept of social welfare is partly based, the whole of society is theoretically. at rest. There are no economic incentives for change anywhere. The whole notion is manifestly false because the real world abounds with forces pressing for change. That is, the real world is inherently a dynamic environment. It is constantly, if sometimes slowly, in a state of change. No matter how attractive the general equilibrium abstraction, it is defective because it attempts to relate the real world in purely static terms.

A third defect of welfare economics is the implicit elevation of pecuniary valuations over other forms of valuation. It must be admitted, however, that welfare economics need not be couched solely in the pecuniary frame of reference. But, as a practical matter, the underlying economic theories are most instrumental in explaining human interactions in pecuniary terms. This is no doubt because pecuniary valuations are far and away the easiest to recognize in market terms and to verify empirically. Pecuniary valuations are therefore often used, however imperfectly, as proxies for technical, aesthetic, and ethical valuations. The point, however, is that not all values can be reduced to money prices. Pecuniary valuations, no matter how practical or well substantiated, are very poor surrogates for other forms of valuation. And insofar as welfare economics relies upon pecuniary valuations, it offers a poor explanation of realities that abound in technical, aesthetic, ethical, and other values. This idea is elaborated much more fully under "external benefits and costs" below.

A major defect of welfare economics is the deductive conclusion that a Pareto-efficient allocation can be achieved only in a perfectly 
competitive economy. This is tantamount to declaring that a Paretoefficient allocation cannot be achieved simply because perfectly competitive markets are impossible of achievement in modern, industrial economies. And perfectly competitive markets cannot be achieved because the conditions necessary for existence of perfect competition do not exist.

For example, products are simply not homogeneous. Near perfect homogeneity exists with fungible goods such as wheat, sugar, and crude 0i1. However, even fungible goods are differentiated by qualities and conditions. Moreover, very few goods are of the fungible sort. On the contrary, a mark of an industrial system is its multitude of markets comprising wide varieties of differentiated goods and services. The empirical conclusion is that the real world abounds with heterogeneous goods and services, and that product homogeneity is a somewhat rare exception.

Likewise, many producers are price makers rather than price takers partly because it is possible for them to differentiate their products from otherwise close substitutes. This is accomplished by quality and style variations, brand naming, and advertising. Moreover, some markets are highly concentrated on the seller side so that one or a few producers control the quantity of goods flowing to their markets. To the extent that markets are concentrated or products are differentiated, producers may restrict supplies and thereby raise prices in their markets. In like manner, consumers are often price searchers rather than price takers simply because product differentiation has produced variations in quality and style, and therefore in the prices of close product substitutes. The empirical point is that market 
agents are generally not price takers in the real world.

It is also impossible to meet the necessary condition of perfect market knowledge on the part of each market agent in the real world. As good as communication technology is, it is not yet capable of instantaneousiy and precisely recording, storing, recalling, and processing all transactions in all markets, and immediately transmitting the necessary market information to every agent who needs the information to make informed market choices. The empirical conclusion is that the real world is one of imperfect market knowledge. Finally, there is not perfect factor mobility in the real world. It is not always possible for resources to move into or out of the production of particular goods or services in response to market conditions. In the first place, land resources are absolutely finite and immobile, and while the use of any particular parcel of land might be changed, this can occur only in the economic long run. But the land itself cannot be relocated in response to market conditions. This, of course, applies with nearly equal force to structures and equipment permanently installed on the land.

Labor resources in the real world are only slightly more mobile. It is a major personal disruption to pick up and move a household from one region to another, and persons tend to ignore or resist market incentives to make interregional moves. Massive short-run interregional relocations of labor in response to market differentials are therefore rare. And international labor mobility is even less real because of the added cultural shocks involved. On the other hand, labor resources might be somewhat mobile within a local market where a job change does not involve a family or household relocation. However, there are labor

Reproduced with permission of the copyright owner. Further reproduction prohibited without permission. 
market rigidities even in local areas because units of labor are simply not homogeneous. Units of labor are differentiated by technical skills, and they are not perfect substitutes for one another. For the same reason, there are labor market barriers to entry in the form of labor union restrictions and state licensing requirements. Thus, unfilled shortages and persistent surpluses of particular skills do occur from time to time in labor markets because labor resources in the real world are not perfectly mobile.

In similar fashion, business firms cannot usually enter or exit particular industries in response to market signals. An industrial system is composed of many highly specialized institutions. The institutions employ specialized tools and human labor with particular technical skills. They operate at particular locations, and they supply goods and render services to persons in those and related locations. Technical and locational constraints alone would limit the mobility of such institutions. But the high capital costs required to retool for most new markets may be an even more formidable barrier.

Business firms are further limited by other barriers to entry. Economies of scale in many industries may preclude entry by firms with smal1-scale plants because they cannot produce at high enough rates of output to bring their average total costs of production down low enough in target markets to allow them to compete effectively with established forms of larger scales of plant. This is particularly true if the established firms practice exclusionary pricing techniques whereby they price their goods low enough to limit entry by potential entrant firms, but high enough to enjoy some monopolistic profits. Here again, factor mobility is imperfect because businesses are often barred from

Reproduced with permission of the copyright owner. Further reproduction prohibited without permission. 
entry for one reason or another into many real-world markets even though market conditions might otherwise signal needs for changes.

Perhaps the most mobile of factors is capital, and it is also somewhat more responsive to market forces because of its greater mobility. But factor mobility is imperfect even in capital markets. At least two elements restrict the mobility of capital. The first is the range of problems associated with international exchange. The risks and transfer costs involved with exchanging one national monetary unit for another tend to limit the mobility of capital over national boundaries. Likewise, exchange controls, host government control of profit repatriation, and the problems of taxation of income by host as we11 as home governments tend to further limit the international mobility of capital.

The second element is government controls in the form of domestic monetary and fiscal policies that limit capital mobility within a national economy. Such government policies are pursued for purposes of allocating resources to the provision of public goods and services, redistributing income, and maintaining economic stability. The policies are discharged through the tax and expenditure processes of public budgets and through central management of the monetary stock. Monetary and fiscal policies as well as direct regulation of market activities by governments are inimical to so-called competitive, private enterprise markets for the simple reason that they cause allocational and distributional effects that are different from purely market outcomes. This does not mean that the effects are necessarily better or worse--only that they are different and they involve limitations on the free mobility of capital.

Reproduced with permission of the copyright owner. Further reproduction prohibited without permission. 
The point is that the conditions necessary for perfectly competitive markets to exist simply do not prevail and cannot be brought into existence in an industrial system. Products are not homogeneous and they are therefore not perfect substitutes for one another. Not all market agents are price takers. Some on the demand side are price searchers, while some suppliers are price makers. There cannot be perfect knowledge of market conditions by every agent operating in markets. Finally, not all resources are perfectly mobile, and they cannot always enter or exit industries in response to market forces.

Since the necessary conditions cannot exist, then perfectly competitive markets cannot exist. Since perfectly competitive markets cannot exist, it is impossible to determine whether or not a Paretoefficient allocation of resources exists. Of course, there is the question of whether most, but not all, of the necessary conditions will produce a better allocation than if none of the conditions exists. It has been persuasively argued by others that so-called second-best solutions cannot be demonstrated to be better in any way than other nonoptimal solutions. ${ }^{9}$ The conclusion is then that the requirement that a Pareto-efficient allocation can only be achieved and measured in a perfectly competitive market economy is a major defect in welfare economic theory because perfectly competitive market conditions are not empirically validated characteristics of society. And one is placed in the position of attempting to measure and adjust real welfare outcomes to an unreal and unattainable ideal.

In defense of economists, it must be noted that any economist worth his salt does not believe that the perfectly competitive market 
model is a faithful representation of the real world. One may therefore wonder why economists are so preoccupied with the perfectly competitive model. The answer is that the model is one of two polar models used as ideal states by which market performance in the real world may be measured. The opposite polar model is the so-called pure monopoly model in which there is a single supplier and many buyers and which also is not a faithful representation of the real world. That is, real world markets are simply imperfectly competitive in one degree or another on a continuum that extends from a perfectly competitive pole at one extremity to a pure monopoly pole at the other extremity. Regarding the arguments at hand, it is one thing to acknowledge an ideal state as such. It is quite another to require the actualization of an unattainable ideal state as a necessary condition to forming sound social policy--as welfare economics appears to do with the concepts of Pareto efficiency and perfectly competitive markets.

Another major defect in welfare economic theory is the assumption that a social-welfare function exists and might be disclosed in some way if only a method could be found to continuously reveal and aggregate the individual preference functions for every consumer in the economy. Presumably, a market system accomplishes this in some mysterious way. But, as a practical matter, there is no known way to accurately reveal a social-welfare function if one does exist. Indeed, one economist was awarded a Nobel Prize essentially for rigorously demonstrating that there are common preference patterns which, if held by the individual members of society, will give rise to an inconsistent pattern of social choice. Moreover, no market technique, voting scheme, or system of representation will necessarily produce a rational social choice. 10

Reproduced with permission of the copyright owner. Further reproduction prohibited without permission. 
One is inclined to the view that a social-welfare function does not exist except in the grand assumptions and abstruse abstractions of welfare economists.

All of which is to say that welfare economic theory appears to fail the test of empirical validity. It fails because of at least two major defects--the requirement that markets be perfectly competitive in order to achieve and measure a Pareto-efficient allocative outcome, and the assumption of a social-welfare function. Other related and significant defects include the high level of abstraction, the static approach to analysis, and the stress on pecuniary valuations. Each of these defects and all of them together so remove welfare economic theory from reality that the theory is hardly more than an intellectual exercise of little practical use. And while the theory may possess superb internal consistency, its empirical defects cast serious doubt on its relevancy--or its probable accuracy in predicting future outcomes--and thus on its viability as an instrumentality for policy formulations. In other words, its weakness as a positive analys is casts doubt on its normative powers.

Where does all of the foregoing leave the matter of social welfare? Clearly, it admonishes caution in the normative application of orthodox economic criteria to welfare problems. On the other hand, the theory is the refined product of some of the most learned and scholarly minds of the industrial era. It must therefore possess some compelling and enduring qualities. And, notwithstanding its aforementioned defects, it does indeed possess some redeeming attributes. Perhaps the most attractive component of the theory is the notion of a Pareto-efficient allocation of resources. And next to that are the 
criteria for income redistribution, given a Pareto-efficient allocation. There are no doubt other elements of the theory that are good guides for policy. But it seems to this author that the former two components are ideal states that ought to be as nearly achieved in practice as the frailties of reality permit.

At the same time, there are no delusions about the practical difficulties surrounding the attainment of a Pareto-efficient allocation of resources and an equitable distribution of income within a Pareto framework. The paucity of realistic and operational theories underscores the problem--values are as multifarious and disparate as society is pluralistic, and there is no simple or direct way to measure and weigh competing values and conflicting interests in the selection of ends and the employment of means so that social welfare is maximized. The first aspect of the problem concerns the accurate definition and measurement of values in the form of benefits and costs so that they can be weighed in making choices from among alternative and competing social ends and as to the employment of resource means. The second part of the problem is to reach some consensus on choice or preferredness criteria. And finaliy, the choices must be made and actualized in practice. Benefit-cost analysis is one technique that is employed to these ends.

Benefit-Cost Analysis $^{11}$

Benefit-cost analysis is a structured technique for defining and measuring benefits and costs for purposes of evaluating alternative public investment projects. Indeed, the technique is used by private agencies in arriving at investment decisions, and informal variations

Reproduced with permission of the copyright owner. Further reproduction prohibited without permission. 
of benefit-cost analysis are implicitly involved in the economic and political decisions of many, if not most, private individuals.

Benefit-cost analysis is a logical extension of cost-effectiveness analysis, operations research, systems engineering, systems analysis, and program-evaluation-and-review-technique. Indeed, benefitcost analysis is a natural complement to the latter technique. However, it is more comprehensive than the former. Benefit-cost analysis is probably less akin to other types of analysis that are sometimes applied to policy problems, such as psychological analysis, bureaucratic analysis, and implementation analysis.

The earliest documented efforts of the U. S. Federal Government to explicitly employ benefit-cost approaches were made by the U.S. Army Corps of Engineers in the evaluation of river and harbors projects in the early years of the present century. The technique was expanded in the late 1940s by the Rand Corporation to decide which aircraft should be developed as the next generation strategic bomber for the U. S. Air Force. Benefit-cost analysis was officially adopted by the U. S. Department of Defense in 1961 following publication of a book describing the technique and ca-authored by Charles Hitch, then comptroller of the Department of Defense. The benefit-cost procedure was incorporated into a comprehensive federal budgeting technique called the planning-programming-budgeting system (PPBS). The PPBS approach was extended to all federal agencies in 1965 by President Lyndon Johnson, but the PPBS requirement was rescinded in 1971 by President Richard Nixon. However, benefit-cost analysis continues in wide federal use.

The benefit-cost analys is procedure involves estimating and Reproduced with permission of the copyright owner. Further reproduction prohibited without permission. 
discounting present and future benefits and costs back to present values. Discounting is based. on the principle that future value possesses less present worth than it possesses at the time of future transaction. This is because the future is uncertain, and hence people tend to favor current enjoyment of present values over possible future values, and they therefore tend to save only small amounts of their disposable incomes, if they choose to save at all. Thus, one dimension of interest is as compensation to induce people to save-that is, to forego some current consumption in favor of possible future consumption. And, of course, the interest is paid by those persons who use the money saved by others--in other words, by the persons who forego possible future consumption in favor of current consumption. Using the interest principle, one can see that if he must make some future payment--he can deposit a sum in the present to draw interest until the payment must be made. For example, one can currently deposit $\$ 1000$ at five percent annual interest to make a $\$ 2000$ payment in fifteen years. That is, the future $\$ 2000$ obligation has a present value of only $\$ 1000$ if it is discounted at five percent per year. Likewise, if one is to receive $\$ 2000$ in fifteen years, its present worth is only $\$ 1000$ if it is discounted at five percent per year. At any rate, benefit-cost analysis uses the discounting technique to set a present value on both future benefits and future costs. A benefit-cost ratio is then calculated for each alternative way of achieving a particular future end-in-view. That al ternative rendering the highest benefit-cost ratio is selected as the method to be used in securing that particular end-in-view if the end is selected as an end-to-be-reached. An alternative sometimes used in place of benefit- 
cost ratios is net present values. The net present value of a project is simply the difference between the present value of benefits and the present value of costs. The project method selected under that procedure is the one rendering the highest net present value.

Whichever technique is used, it is applied to every end-in-view, and all ends-in-view are arrayed in descending order according to their estimated benefit-cost ratios (or their net present values). Of course, those projects for which the best benefit-cost ratio is less than one, or the estimated net present value is negative (the present value of benefits is less than the present value of costs) are excluded from the list. Selection of ends-to-be-reached is then made from that prioritized list. The end possessing the highest estimated benefitcost ratio (or net present value) is the first to be initiated. It is followed by the project possessing the next highest benefit-cost ratio and so on down the list until the budget for such projects is exhausted. As one can see, benefit-cost analysis is instrumental both in selecting ends-to-be-reached and in choosing among alternative ways of employing means to the ends selected.

A simple example involving a private investment decision will illustrate the point. Assume that a person has somehow come into ten thousand dollars and is seeking to invest it in a way that will maximize his net present value in the investment. Assume further that he has considered investing in real property, a U. S. Treasury bond, gold, commodity future, and common stocks.

He first eliminates commodity futures because he considers the risk of loss too high in relation to his ability to bear risk, and the duration of his investment would be too short to qualify any possible

Reproduced with permission of the copyright owner. Further reproduction prohibited without permission. 
gain as long-term for tax purposes. He then eliminates gold because he believes that its potential for long-term gain has already been discounted by the market. Finally, he eliminates any kind of bond because the expected return is not high enough, and he believes that he is capable of bearing a greater risk for a commensurately greater return. However, he notes that the coupon rate on the Treasury bond is eight percent, and that he can obtain that rate of return virtually free from risk of solvency loss.

On the other hand, he reasons that population pressures and inflation will place continuing upward pressures on rents and real property prices, and he feels that common stocks are badly under-priced considering their book values and earnings potentials. Thus, his investment choice is between real estate and common stocks.

He first estimated net present values of possible investments in several pieces of real property. He discovered that the highest estimated net present value was obtainable with a three-year-old apartment quadriplex that was well situated for multiple-family dwellings. He determined the net present value by subtracting the present value of present and future costs from the present value of present and future revenues.

(1) $P V_{N}=P V_{A}-P V_{C}$

He calculated the present value of revenues by using the following progression where $P V_{A}$ is the present value of revenues, $A$ is the revenue received in a calendar year, $r$ is the discount rate, $i$ is the initial expression, and $n$ is the number of discount periods--usually the productive duration of the investment in years.

Reproduced with permission of the copyright owner. Further reproduction prohibited without permission. 
(2) $\mathrm{PV}_{\mathrm{A}}=\sum_{i=1}^{n} \frac{A i}{(1+r)^{i}}=\frac{A_{1}}{1+r}+\frac{A_{2}}{(1+r)^{2}}+\ldots+\frac{A_{n}}{(1+r)^{n}}$

He reasoned that his revenues would include annual rents over the duration of his ownership plus the net scale price of the property when he decided to sell it. He chose to ignore the income-tax implications-depreciation tax shelter during ownership, long-term capital gains tax upon sale--of his possible investment. He assumed that his rents would inflate at approximately ten percent per year and that he would experience an average vacancy rate of ten percent. He assumed that the market value of the property would likewise inflate by ten percent per year. He decided to use an eight percent discount rate because he knew that he could receive that return on U.S. Treasury bonds with almost no risk of solvency loss. Finally, he considered holding the property for twenty years, the duration of the mortgage note required to secure it.

Thus, the revenue during any given year except the year of sale would be the following in which $R_{0}$ is the annual rent in the preceding year and $R_{1}$ is the annual rent in the current year.

(3) $A_{1}=R_{1}=R_{0}+.1 R_{0}-.1\left(R_{0}+.1 R_{0}\right)$.

And the revenue during the year of sale would be the following in which $S$ is the sale price less transaction costs.

(4) $A_{n}=R_{n}+S$.

Substituting the latter two expressions into progression (2), renders the following:

$$
\begin{aligned}
& P V_{A}=\frac{R_{1}}{1+r}+R_{1}+\frac{.1 R_{1}-.1\left(R_{1}+.1 R_{1}\right)}{(1+r)^{2}}+. . \\
& \frac{+R n-1+.1 R n-1-.1(R n-1+.1 R n+S)}{(1=r)^{n}}
\end{aligned}
$$

Reproduced with permission of the copyright owner. Further reproduction prohibited without permission. 
Each apartment unit is presently leased for $\$ 325$ rent per month, and the tenant pays all of his own utility charges. The property is offered at $\$ 115,000$. However, the prospective investor believes that he can buy it for $\$ 100,000$ because it is part of an estate liquidation and the heirs do not wish to keep the property. However, they are willing to take back a purchase-money mortgage at 10 percent interest as part of the transaction. Substituting appropriate values into progression (5) produces the following estimated present value of revenues:

(6) $\mathrm{PV}_{\mathrm{A}}=\$ 404,779$

He then calculated the present value of present and future costs by using the following progression in which $\mathrm{PV}_{\mathrm{c}}$ is the present value of costs and $C$ is the costs incurred during a particular calendar year.

$$
\text { (7) } P V_{c}=\sum_{i+1}^{n} \frac{C_{i}}{(1+r)^{i}}=\frac{C_{1}}{1+r}+\frac{C_{2}}{(1+r)^{2}}+\ldots+\frac{C_{n}}{(1+r)^{n}} \text {. }
$$

He reasoned that his annual costs would include acquisition costs (Ca), management and maintenance costs $(\mathrm{Cm})$, and property taxes $(T)$.

(8) $c_{i}=c_{a i}+c_{m i}+T_{i}$

His acquisition costs included his down payment in the first year $(\$ 10,000)$, and the interest and payment on principal each year ( $\$ 5195$ in the first year, and $\$ 10,390$ in each subsequent year). He assumed that his management and maintenance costs would average ten percent of his annual rents each year.

(9) $C_{m i}=.1 R_{i}$.

Substituting expression (9) into expression (8) and the expanded 
expression (8) into equation (7) produces the following progression:

$$
\text { (10) } \mathrm{PV}_{\mathrm{c}}=\frac{\mathrm{C}_{\mathrm{a} 1}+.1 \mathrm{R}_{1}+T_{1}}{1+r}+\frac{C_{a 2}+.1 R_{2}+T_{2}}{(1+r)^{2}}+\ldots+\frac{C_{a n}+.1 R_{n}+T_{n}}{(1+r)^{n}}
$$

And substituting the appropriate values into progression (10) and solving for the present value of costs results in

(11) $P V_{C}=\$ 166,930$.

Finally, substituting results (6) and (11) into equation (1) renders the estimated net present value.

(12) $P V_{N}+P V_{A}-P V_{C}=\$ 404,779-\$ 166,930=\$ 237,849$

The prospective investor followed a similar procedure in estimating the net present values of possible investments in a number of widely traded and promising common stocks. The highest estimated net present value he could find, taking inflation into account, was approximately $\$ 40,000$. By comparison, the net present value of a twenty-year treasury bond with an eight percent interest rate discounted at eight percent is precisely zero if inflation is ignored. On the other hand, the net present value of such a bond is negative if there is consumerprice inflation over the life of the bond. Naturally, the investor purchased the quadriplex.

The foregoing example illustrated the use of benefit-cost analysis in making a private investment choice. The procedure seemed clear and unequivocal. One simply estimates the present value of benefits (revenues in this case) and the present values of costs, and he subtracts the latter from the former in arriving at net present value. Choice is simply a matter of comparing alternative results and selecting the result yielding the highest net present value.

Reproduced with permission of the copyright owner. Further reproduction prohibited without permission. 
Choices in the realm of corporate enterprise are often made employing a procedure similar to the technique illustrated in the example. Likewise, governments use variations of the same technique to tentatively select and proffer alternatives to the public and its elected representatives. However, aspects of the benefit-cost procedure become controversial when it is employed in public decision-making. Controversy centers around at least five questions: What elements are to be classified and included as benefits and costs? What pecuniary values shall be assigned to the benefit and cost elements? What preferredness criteria shall be used? (Preferredness criteria include two elements--the social-discount rate, and the time over which benefits and costs will be discounted back to present values). What shall be maximized or minimized in attempting to improve social welfare? And, finally, who will control the process and decide the foregoing questions? The remainder of this chapter briefly examines each of these questions.

\section{INTERNAL BENEFITS AND COSTS $^{12}$}

Internal benefits and costs are those tangible values that are easily measured in pecuniary terms, and with which orthodox economists are most at home. They are the prices, revenues, costs, wages, rents, interest rates, and profits that occupy both the dreams and the waking hours of businessmen and that fill the pages of sophomore textbooks on economic principles. They are the elemental and divisible stuff of market systems and gross national products. And they are all of the other values that lie behind the money terms that represent them in market affairs. They are the aesthetic, subjective, personal, private, visceral, individual, and intrinsic valuations that lurk behind and are

Reproduced with permission of the copyright owner. Further reproduction prohibited without permission. 
somehow manifested in market behaviors.

Internal benefits and costs are perhaps the least controversial aspects of benefit-cost analysis because they are the easiest to measure with some degree of accuracy. When one makes a personal market choice, he actualizes it with a private transaction in which he either buys or sells something and pays or receives a price in exchange. The good or service is divisible and the agent buys or sells only as much of it as he wishes at the price. He is said to reveal his preference for the good or service by the consummated transaction. Moreover, his preference is recorded in the market, and it will have some effect, no matter how slight, on demand and supply factors in the market. The meaning of this for benefit-cost analysis is that the supply of and demand for private or divisible goods and services can be estimated with considerable precision, and there is usually little controversy surrounding which internal benefits and costs should be included or what money values should be assigned to them.

Most private market decisions explicitly employ only internal benefits and costs. The preceding example illustrating a private investment decision was one explicitly involving only internal benefits and costs. The example was developed to illustrate the procedure for using benefit-cost analysis in arriving at an investment decision. The procedure is essentially the same with minor variations to adapt it to corporate and public purposes. Thus, the reader will be spared additional examples of the same kind to illustrate corporate and public applications of benefit-cost analysis. On the other hand, it is necessary to develop a corporate investment example to illustrate other aspects of benefit-cost analysis that give rise to controversy.

Reproduced with permission of the copyright owner. Further reproduction prohibited without permission. 
Suppose, therefore, that a private, electric utility company serving an area of the Pacific Northwestern part of the United States has forecast its future electrical power generating requirements, and it has found that it must somehow provide more electrical power than it can presently generate and purchase if it is to meet the estimated future demands for $i$ ts power. Suppose further that the company employed some variation of the benefit-cost analysis described above as a way to evaluate alternatives for solving its production problem, and that its investigations also revealed that additional hydroelectric development would not be profitable because all good hydroelectric sites in the area had already been exploited. The profitable options and their expected net future profits discounted back to present values were as follows:

Option A: Construct one high-capacity nuclear-fueled, electricalpower generating plant. Present value of revenues $=\$ 800,000,000$. Present value of costs $=\$ 225,000,000$. Net present value $=\$ 575,000,000$.

Option B: Construct one large-capacity generating plant based on fossil-fuel. Present value of revenues $=\$ 800,000,000$. Present value of costs $=\$ 240,000,000$. Net present value $=\$ 560,000,000$.

Option C: Expand generating capacity by constructing several plants: one central nuclear-powered plant, several dispersed fossilfuel fired plants (to minimize transmission costs), and develop renewable energy (wind, sea, or solar) plants where possible. Present value of revenues $=\$ 800,000,000$. Present value of costs $=$ $\$ 370,000,000$. Net present value $=\$ 430,000,000$.

Option D: Do nothing. Acquiesce in the construction of additional generating capacity by other utilities, and simply purchase

Reproduced with permission of the copyright owner. Further reproduction prohibited without permission. 
the needed electrical power from those other companies, mark the price up, and se? 1 it to the company's customers. Present value of revenues $=\$ 800,000,000$. Present value of costs $=\$ 550,000,000$. Net present value $=\$ 250,000,000$.

Option E: Construct a network of renewable energy-powered (solar, wind, and sea) generating plants at suitable sites. Present value of revenues $=\$ 800,000,000$. Present value of costs $=\$ 680,000,000$. Net present value $=\$ 120,000,000$.

Based on the net present values of the company's estimated future profits, and assuming that the company profit maximizes, it will choose to construct a single, high-capacity, nuclear-fueled generating plant. The nuclear plant, Option A, produces $\$ 575,000,000$, a higher net present value than any other option investigated. The question now becomes, can the company make its choice unilaterally and proceed with its nuclear power project? The answer is that it is very unlikely the company can do so. The reason is that the company has considered onty internal benefits and costs in its estimates, and there are other so-called external benefits and costs to be considered before a decision can be made. Moreover, external constituencies must be involved in the process so that what may seem at first to be a straight-forward private economic matter all at once becomes a public and political matter.

\section{EXTERNAL BENEFITS AND COSTS ${ }^{13}$}

What are the external benefits and costs that must be considered by the electric utility company? Or, at a higher level of generalization, what are externalities, and how do they differ from internal

Reproduced with permission of the copyright owner. Further reproduction prohibited without permission. 
benefits and costs? Simply stated, an externality is said to exist any time an economic gain or loss accrues to one or more recipient agent as a consequence of an economic action taken by an initiating agent, and the gain or loss is not reflected in the price of the resulting economic good or service. Or, stated another way, an externat benefit is said to exist when the marginal social cost of a good or service is less than the marginal social benefit, and an external cost is said to exist when the opposite occurs--the marginal social cost is greater than the marginal social benefit.

Externalities may also be understood as so-called spill-over effects, or neighborhood effects. And external costs might appear in the form of external diseconomies, or negative externalities. Likewise, external benefits might be called by external economies or positive externalities. However they are termed they mean external benefits or external costs in the benefit-cost vernacular.

Social benefits are simply the sum of internal (or private) benefits, and external (or public) benefits. And social costs are the sum of internal (or private) costs and external (or public) costs. Social costs and benefits diverge at the margin because external benefits and costs are non-divisible, and markets deal only in the divisible goods and services that comprise internal (or private) benefits and costs. Thus markets equate private benefits with private costs at some certain price. And if external costs drive social costs above private costs, the good or service involved will be produced and consumed at lower costs and higher quantities than would be so if the external cost were included. Likewise, if external benefits drive social benefits above private benefits, the good or service will be 
under-produced at lower costs because the market will equate only the private benefits and costs involved.

Externalities involve initiating agents and recipient agents. An agent that initiates an externality might be either a producer of goods and services or a consumer. In like manner, recipients of externalities might be either producers or consumers or both together. Three classes of externalities have been identified--public-good externalities, technical externalities, and ownership externalities.

\section{Public-Good Externalities}

Public-good externalities result when the marginal cost of supplying additional units of a good or service is zero, or very nearly so. That is, the product is not divisible, and once it is created, no affected person can be excluded from enjoying the benefits. Likewise, adding an additional person to the affected population will not increase the cost of supplying the product. For example, an efficient police force in a community will result in effective crime prevention and law enforcement. Moreover, all residents share in the benefits once the community is free of crime, and no one can be excluded from those benefits. Even visitors and recent immigrants become recipients of crime prevention benefits, and their arrival in the community and their enjoyment of its crime-free environment will not usually add to the cost of supplying the benefits.

However, goods and services involving substantial external benefits will usually be under produced because such goods and services are not divisible. This means that the good or service cannot be divided into consumer units, packaged, and sold to users on the basis

Reproduced with permission of the copyright owner. Further reproduction prohibited without permission. 
of the satisfactions they experience from the benefit. There is, therefore, no way to discover the true preferences of the recipient agents--the residents of a crime-free community in this case. This results in a so-called free-rider phenomenon in which a recipient will understate the value of the benefits he enjoys in order to avoid paying for their production. He will do this because he knows that he will receive the benefits once they have been created whether or not he pays for them.

For these reasons, the allocation of resources to the production of public goods and services cannot be accomplished solely by market institutions. Indeed, it generally falls to governments to reallocate resources from the private sector to the public sector in supplying public goods. Such reallocation is accomplished through government fiscal processes involving tax revenues and public expenditure budgets. And insofar as governments are of the representative sort, issues surrounding taxes and expenditures are ultimately resolved in the electora? process.

\section{Technical Externalities}

The second class of externalities, technical externalities, result from technologies that cause eventy-increasing returns to the scale of the producing plant. That is, average total costs of production decline with each additional unit of output produced per unit of time, and the firm with the lowest cost per unit of output is ipso-facto, the institution with the largest scale of plant in the industry. The result is that the firm with the largest scale of plant can easily under-price all other institutions in the industry because 
their plants are not large enough to enjoy such low-cost operations. Only the producer with the largest plant can survive in competitive markets, and the outcome is a monopoly industry in which all of the consumers in the industry must buy from a single large seller. Once such a monopoly emerges, the monopolist can control the price of his product by restricting output to that rate per unit of time that produces the greatest profits. That is generally at a significantly lower rate of output and a higher price than would prevail under competitive conditions.

The externality in this case is the loss in social benefits occasioned by the monopoly solution, assuming that there are only technical externalities involved. A competitive solution would produce a price that would equate marginal social benefits to marginal social costs. This is so because there are no technical externalities involved with a perfectly competitive solution, and marginal social benefits are therefore the same as marginal private benefits and marginal social costs are also the same as marginal private costs. However, under monopoly conditions, marginal private benefits are less than marginal social benefits, the difference representing external benefits. The profit-maximizing monopolist will set his output where marginal private (and social) costs equal marginal private benefits (or marginal revenue). This will usually be at a lower marginal cost than with a competitive solution, and it will be at a lower rate of output but at a higher market price. In microeconomic jargon, the monopolist is said to be appropriating a larger portion of the consumer surplus to his profits than he would receive under competitive market conditions where there are no technical externalities.

Reproduced with permission of the copyright owner. Further reproduction prohibited without permission. 
A by-product of this kind of ceremonial behavior is also an absolute loss in social welfare. The loss comprises that portion of consumer surplus that is denied consumers, but cannot be appropriated to the monopolist's profits.

Another feature that distinguishes firms that operate in industries containing substantial technical externalities is that they tend to be high fixed-cost enterprises--meaning that their fixed costs are very high in relation to their variable costs. Such institutions are thought to be natural monopolies because, as noted above, monopolies tend to emerge naturally as a result of the increasing returns to scale occasioned by the technical externalities in such industries. A second reason such firms are considered natural monopolies is because they operate most efficiently as monopolies-which is to say that resources are wasted if society attempts to impose competitive market conditions on the industries.

An example of a natural monopoly is a utility industry. An electrical utility industry possesses technical externalities, and its operating company or companies are high fixed-cost firms. Thus, the necessary conditions for efficiency-fostering competition in the electric utility industry do not exist. One can imagine, for example, how the landscape and skyline of the ordinary city would look with fifty or more duplicate sets of electrical power-distribution lines hanging from fifty or more sets of power poles, and connecting fifty or more transformers, switches, and meters at each structure buying electrical power.

Moreover, each power company would ideally build generating capacity to carry the entire market just in case it could somehow 
entice all of the customers away from its competitors. But more than that, each company woild have to build capacity for expected future load--not just for the existing customers--because of the long lead time required to bring new generators on line. The point is that each competitor would have full capacity to carry the total present and projected load. Thus, the industry would have excess generating capacity that is some multiple greater than the number of institutions operating in the industry.

Finally, cut-throat price competition would eventually eliminate all but a few of the largest, and thus the lowest cost, operating companies. And the surviving companies would find it economically more efficient to consolidate into a single operating company. A monopoly with gross excess capacity would therefore emerge, and the resources allocated to the generation and distribution systems of the defunct competitors would have been wasted because the systems would have to be dismantled and removed to make way for productive uses of the lands they occupied.

Clearly, the market will not allocate resources efficiently where technical externalities pervade the industry. It is for these reasons that utility companies are either operated by governments as public enterprises, or by private corporations under strict government control. Controls of private utility corporations involve exclusive franchises and rate regulation. The utility is granted a license that permits it to serve all of the consumers in its market area free from competition with other institutions supplying the same utility services. In exchange, the company must forego the right to set its own prices in favor of public-rate regulation, and it must serve every customer in

Reproduced with permission of the copyright owner. Further reproduction prohibited without permission. 
its market area who is willing and able to pay the established rate. Government regulation of utility companies' attempts to avoid the economic waste inherent in utility industries under the ceremony of competition, and to bring social benefits into equilibrium with social costs. Thus, rates would ideally be set where marginal (social) cost equals average revenue (or marginal social benefit). However, because of technical externalities--the high fixed cost and the need to build capacity that exceeds average demand so as to accommodate peak loading and meet expected growth in demand--the socially desirable rate may cause a utility company to operate at a loss. This is because the marginal cost will probably be below the average total cost of the firm under such circumstances. Governments must therefore either subsidize the company from taxes of other revenues, or use a so-called "fair-return" pricing technique. A fair-return rate is one that equilibrates average revenue (marginal social benefits) with average total cost. This permits the firm to "break even" without subsidy. The fair return approach is generally used because it is politically more palatable than subsidies from tax revenues.

\section{Ownership Externalities}

The third class of externalities is called ownership externalities. Ownership externalities occur because certain resources are divorced from effective ownership, and their marginal private costs are essentially zero. They are therefore looked upon as free goods, and they tend to be employed so intensely in some cases that they are rendered less suitable for continued human use. In other words external costs drive social costs above private costs so that there is 
a welfare loss even though marginal private costs may be at or near zero.

For example, a producer who pollutes water by discharging his toxic wastes upstream imposes an external cost on downstream recipients whether they be consumers who draw drinking water from the stream, or other producers who require clean water in their production processes. The producer-initiator uses the stream as a means of disposing of his wastes because it is the least costly method open to him, and because the flowing water is owned by no one, or it is owned by the government-which is to say that it is owned by everyone and anyone who chooses to use it. If enough people choose to dispose of their wastes in the stream, it may become so intensely used that it is rendered unfit for any other use. External costs result in lower internal or private costs to initiators, and therefore a greater than socially desirable production and consumption of the good or service for which the external cost was imposed. Moreover, they result in loss of profits for recipient producers and loss of utility for recipient consumers. In any case, there is no market method by which the recipients of external costs can recover their losses from the initiators of the costs.

A similar problem arises when an economic agent initiates external benefits. A private intraturban bus company that covers its internal costs of operation solely on the basis of revenues from trip fares may produce external benefits for 1ocal merchants because the company provides transportation for some of the merchants customers who might otherwise be unable to commute for shopping. The bus company might also be partly responsible for a reduction in traffic congestion 
and for some air pollution abatement in the community insofar as residents are wooed away from their private automobiles to commute by bus. The external benefits initiated by the bus company increase the sales of recipient producers and reduce some dissatisfactions of recipient consumers and producers. But, here again, there is no market mechanism by which the initiating bus company can obtain payment from the recipients of the external benefits because ownership of the benefits are effectively divorced from the initiating institution. Here again, the welfare gains and losses attributable to ownership externalities are not effectively handled by markets. When externai benefits raise social benefits above private benefits, the involved good or service is under-produced because the initiator is not paid for the benefits he produces. Governments attempt to correct this kind of misallocation by paying subsidies equal to the estimated pecuniary value of the external benefit to the initiator of the benefits. Such subsidies are sometimes raised from taxes levied against the recipients of the benefits.

In similar fashion, a good or service is overproduced and overconsumed when external costs raise social costs above private costs. This happens because the internal or private costs of production are lower than they would be if the initiator had to bear the full social costs of production. Governments attempt to correct this kind of misallocation by direct regulation or by taxing the initiator of the external cost. Direct regulation involves establishing and enforcing efficient standards based upon the technical character of the toxic wastes discharged and the capacity of the disposal medium to assimilate the wastes without significant degradation. Taxes may take the form 
of a disposal fee or an effluent charge. Either way, the tax is intended to internalize the external cost so that consumers of the resulting products pay a price that covers all of the social costs incurred in their production.

The foregoing three classes of externalities--public goods externalities, technical externalities, and ownership externalities-possess several common attributes. Each involves either an economic gain or loss accruiping to one or more recipient agents as a result of an economic action taken by an initiating agent, and the gain or loss is not reflected in the price of the resulting economic good or service. In other words, an external benefit will drive social benefits above internal or private benefits, and insofar as the market will equilibrate oniy private benefits and costs, the good or service resulting in the externality will be underproduced. In similar fashion an external cost which drives social costs above private costs will result in over-production and consumption of the resulting good or service because the external cost is not borne by the producer and reflected in the consumer price.

Moreover, there is no simple or direct way of measuring the worth of externalities because they are indivisible, and there is no institutional ceremony for internalizing them. That is, they cannot be divided into user units and sold to individuals on the basis of the personal utilities or disutilities the externalities generate. There is therefore no simple or direct way of discovering the individual preferences of recipient agents. As a result, recipients of externalities tend to free-ride by understating their benefits and overstating their costs because they know that they cannot be excluded 
from the external benefits or avoid the external costs once they are created. Likewise, there is no market method for remunerating initiators of external benefits or for collecting external costs from initiators and paying them to recipients.

For these reasons, the existence of externalities converts what might otherwise be relatively simple economic problems with more-orless direct market solutions into very complex social issues that can only be resolved, if at all, in political arenas. One might say that externalities are the combinations that open Pandora's box releasing the disparate and competing values that plague choices between ends-inview and between means to be employed in reaching selected ends. This is simply because almost anything can be claimed as an external cost by possible recipient agents, or claimed as external benefits by initiating agents. And since such claims are buttressed by one or more of the plethora of non-pecuniary values, it is often extremely difficult to empirically prove or disprove the actual existence of the claimed externality. And even if it can be shown to exist, it is often more difficult to place an accurate pecuniary value on it--all of which opens the way to participation by almost anyone in the decision process, and to political game playing by the groups participating in the process.

\section{Externalities and Benefit-Cost Analysis $^{14}$}

With that explanation of externalities, it is possible to return to the benefit-cost analysis of the alternative ways to increase the electrical generating capacity for the utility company introduced earlier. It is recalled that there were five options that the utility 
company found to be profitable when it considered only internal or private benefits and costs. The first option, and the one found to be most profitable, was (A) to build a single nuclear-fueled, generating plant with capacity to supply the expected growth in demand. The other options in descending order of profitability were: (B) to build one large conventional thermal plant powered by fossil fuels; (C) to build several small plants at dispersed locations and using nuclear fuel, fossil fuel, and solar, wind, or sea energy as appropriate to the site; (D) do nothing, letting other utilities construct the additional generating plants; (E) bui ld many solar, wind, and seapowered plants.

The question was asked, can the company make its choice unilateraliy and proceed with its nuclear power project? The answer was that it is very unlikely that the company could do so because it had not considered external benefits and costs in its evaluative analyses. The next question was, what are the external benefits and costs that must be considered before the company can proceed? Despite its present length, this tome will thankfully not be protracted to a length sufficient to fully explore that question. However, it is possible to trace out the general kinds of externalities that will most likely be involved.

It appears unlikely that there will be any public goods externalities because the company is a private one, and its product, electrical power, is divisible into kilowatts, and it can be sold in individual units on the basis of the satisfactions enjoyed by consumers. On the other hand, technical externalities are clearly involved, and it is very likely that ownership externalities will also be

Reproduced with permission of the copyright owner. Further reproduction prohibited without permission. 
significant.

Technical externalities are a consideration because a private, electric utility corporation precisely fits the definition of a natural monopoly. It is a high-fixed cost institution, and it operates in an industry that enjoys (or suffers) increasing returns to plant scale. The company is therefore subject to government regulation of its operations and rates. If for no other reason, this condition alone would subject the company's expansion plans to public scrutiny, and much of that scrutiny would center on the provable externalities of whatever it planned to do. Anyhow, the technical externalities would likely be a factor in some degree on the benefits side of the analysis for each option considered.

Likewise, some ownership externalities cannot be avoided for most, if not a11, options. Probably the most obvious are the external costs of pollution resulting from gaseous and liquid waste emissions. This is undoubtedly the greatest with the first two options--a single nuclear plant, and a single conventional, thermal plant. However, air and water pollution would also be an external cost of the third option, although the pollution would not be so concentrated and thus not so great a problem as with the first two. On the other hand, air and water pollution would not be a problem under the last two options--do nothing and develop solar, wind, and sea energy sources.

The first two alternatives might also lead to increased traffic congestion and air pollution from auto exhaust emission in the community on which the plant is satellited. This might occur because of population added to the community by the addition of a new exportbase industry, and it could lead to greater public expenditures to

Reproduced with permission of the copyright owner. Further reproduction prohibited without permission. 
widen and maintain streets, as well as other actions to remedy the congestion and adjust to the degradation of its environment. This is not likely to be a problem with any other option.

Ecological disruption would undoubtedly occur with all options except $D$, do nothing. It is difficult to say where such disruptions would be the greatest, but one is intuitively attracted to the first two once again as the options bearing the greatest prospects for ecological damage.

The risk of cataclysmic nuclear accident is, of course, an external cost of the first option. A malfunction that resulted in a reactor me1t-down would no doubt dump radioactive water and gas into the air and streams, contaminating large areas surrounding the plant, and rendering them uninhabitable for a time. On the other hand, the nuclear alternative $\mathrm{m}^{2}$ ght lead to long-run improvements in a promising, inchoate technology, and in that case there may be external benefits involved. Those benefits might apply as well to the solar, wind, and sea options.

The list of ownership externalities is limited only by the bounds of one's imagination. One could go on listing and rationalizing possible external benefits or costs to support whatever outcome he favored. But a comprehensive catalog of such externalities go beyond the purposes at hand--which is simply to show how externalities fit into a benefit-cost analysis, and how they provoke controversy and cast doubt on the outcomes of beneifit-cost analysis if they are not carefully handled.

For purposes of illustrating the latter point, suppose that the utility company prepares itself for the long and tedious hearings and

Reproduced with permission of the copyright owner. Further reproduction prohibited without permission. 
possible litigations by having its benefit-cost analysis expanded to include externalities. Believing that its own staff, while thoroughly competent, would lack credibility before public bodies, the management contracts with an outside consultant to complete the study. The economists and technicians of the consultant firm, working with the utility's planning staff to collect and analyze data and arrive at the results reflected in Table 1 . The data in the external benefit and external cost columns naturally embody the conclusions of an environmental impact statement which is appended to the benefit-cost analysis. 
TABLE I

BENEFIT-COST ANALYSIS OF ELECTRICAL GENERATION ALTERNATIVES

(VALUES STATES IN MILLIONS OF DOLLARS)

\begin{tabular}{|c|c|c|c|c|c|c|c|c|}
\hline \multirow[t]{2}{*}{ OPTIONS } & \multicolumn{3}{|c|}{$\begin{array}{l}\text { Present Values } \\
\text { of Benefits }\end{array}$} & \multicolumn{3}{|c|}{$\begin{array}{l}\text { Present Values } \\
\text { of Costs }\end{array}$} & \multicolumn{2}{|c|}{$\begin{array}{l}\text { Present Values } \\
\text { of Net Benefits }\end{array}$} \\
\hline & Private & External & Total & Private & External & Total & Private & Social \\
\hline A - Nuclear only & 800 & 50 & 850 & 225 & 180 & 405 & 575 & 445 \\
\hline $\begin{array}{l}\text { B - Conventional Fossil } \\
\text { Fuel Only }\end{array}$ & 800 & 170 & 970 & 240 & 160 & 400 & 560 & 570 \\
\hline $\begin{array}{l}\text { C - Dispersed Small } \\
\text { Plants Using Nuclear, } \\
\text { Fossil-Fuel and Solar, } \\
\text { Wind, and Sea }\end{array}$ & 800 & 210 & 1010 & 370 & 55 & 425 & 430 & 585 \\
\hline D - Do Nothing & 800 & 250 & 1050 & 550 & 60 & 610 & 250 & 440 \\
\hline $\begin{array}{l}\text { E - Solar, Wind, and } \\
\text { Sea Energy only }\end{array}$ & 800 & 230 & 1030 & 680 & 30 & 710 & 120 & 320 \\
\hline
\end{tabular}


Armed with the benefit-cost analysis, the environmental impact statement and other appended materials, the electric utility company initiates its permit application expressing its continued preference for the nuclear option and rationalizing it on the grounds that the figures are simply estimates and that the utility staff is confident that actual results will vindicate its choice. The entire process has passed with the application into the arena of public choice. How will it fare in the political realm?

For purposes of examining that question, suppose that the population is evenly divided between five distinct points-of-view. And further assume that those five points-of-view are equally represented on the commission or other body that will act on the application. One hastens to admit that such a diverse body is unlikely to exist for long because the colleague nature of such institutional groups usually brings their members to some kind of consensus about the matters on which they deliberate and rule. Proceeding anyhow on the assumption, the points-of-view are those of private businessmen, fiscal conservatives, economic idealists, fiscal liberals, and environmentalists.

Aside from their titles, the attribute that most separates these views from one another is the implicit goal-orientation of each. This surfaces as that which each constituency believes ought to be maximized or minimized. One can see that the profit orientation of private businessmen leads them to favor maximizing net private benefits--which is the benefit-cost euphemism for private business profits. And, of course, option A in Table I maximizes net private benefits.

The fiscal conservative is the person who religiously votes

Reproduced with permission of the copyright owner. Further reproduction prohibited without permission. 
votes against all money measures in elections. The goal-orientation of the fiscal conservative would therefore lead him to favor the least cost solution--option B in Table I if the person happens also to be concerned about environmental matters, or option A if his concern is only for private costs. These two views, that of the private businessman and the fiscal conservative are not far apart. They are both cut of the same conservative cloth, and they are often sewn into the same cloak surrounding issues.

On the other hand, economic idealists are persons who tend to measure the real world by how far it deviates from their models. This view is usually found abundantly in the economics departments of liberal-arts colleges and business schools, and frequentiy in engineering schools and in the professional constituencies surrounding those schools. Inculcated with the importance of maximizing social welfare, economic idealists are most likely to favor maximizing net social benefits because their theories tell them that maximum net social benefits is the benefit-cost euphemism for maximum social welfare. This just happens to be option C in Table I, the eclectic solution. However, economic idealists are not wed to any particular solution on a priori grounds, and if it can be empirically demonstrated that some other option achieves a higher net social welfare, economic idealists would support that option. Coincidentally, the economic idealist's goal-orientation happens to be the most generally used choice criterion.

Fiscal liberals are very nearly the polar opposites of fiscal conservatives. They religiously vote in favor of every money issue on an election ballot. They tend to feel that private profits are the 
scourge of society, and that the best way to deal with matters is to tax the rich who essentially live on profits and to use the revenues to sustain the poor by income supplements, and to reallocate resources from the private sector to the production of public goods and services. Given his goal-orientation, the fiscal liberal is most likely to favor option $D$ in Table I because it produces the greatest total external benefits, and external benefits are the benefit-cost euphemism for public goods.

Finally, the environmentalist possesses an enormous affinity for zoological and geological nature. He believes that the natural state is an ecologically balanced paradise and that the best of all possible worids is a wilderness that has somehow escaped the fettering touch of man. He therefore implicitly opposes all civilized activities because they are not in accord with his vision of paradise and because they foul natural environments with human artificiality, upsetting the ecological balance and wreaking havoc across the land. Clearly, if the environmentalist must support one of the five options, it will be option $E$ because it involves the lowest external cost, and external cost is a benefit-cost euphemism for environmental degradation. The environmentalist is often found in coalition with the fiscal liberal because he sees the profit motives of private business as an engine driving humanity to degrade the environment and because he feels that the most effective brake on that engine is governmental power.

Assuming that deep in his heart each archetype has faith in the integrity of the consultants who prepared the environmental impact statement and polished the benefit-cost analysis, what inside strategies will each employ to achieve selection of that option that 
best fits his goal-orientation? (For purposes of this paper, an inside strategy is one that does not involve explicit coalitions among the factions that make up the decision group). Since each knows that the choice criterion is to be maximum net social benefits, the strategies must somehow result in increasing the net social benefits of his preferred option, or reducing the net social benefits of alternative options. It may be possible to achieve this by contesting one or more of the following elements of the benefit-cost analysis: the items included either as external benefits or external costs, the pecuniary values assigned to the external benefits or external-cost items, the social discount rate, and the number of years over which the present values of benefits and costs were discounted. The effects of changes in the first two elements will be considered in the next section below. The latter two elements are called the "preferredness criteria" and the effects of changes in them will be considered in a subsequent part of the chapter.

\section{Alterations in Externalities}

One way each of the commissioners can press the ascendancy of his preferred solution is to somehow raise the net present benefits of that solution in relation to the others. As noted above, one way this can be accomplished is to somehow bring about a reduction in the costs or an increase in the benefits of the solution he prefers, or to decrease the benefits and increase the costs of the alternatives that stand ahead of his. He can do these things by raising questions regarding either the inclusion or the exclusion of some particular benefit or cost item, or regarding the pecuniary value assigned to 
any item.

He will, of course, raise questions about any glaring deficiencies in the schedules of internal or private benefits and costs particularly if doing so will enhance his preference. However, he is unlikely to find the best picking among the private benefits and costs because they are the most easily quantified empirically, and they are therefore the least controversial and the least susceptible to challenge. On the other hand, the schedules of external benefits and costs are replete with controversy--controversy about which items should be included and about the pecuniary values to be assigned to the included items. Controversy reigns because there is no simple or direct way of establishing the existences of externalities or of accurately measuring their magnitudes if they are found to exist. In like manner, there is no fool-proof way of placing pecuniary values on whatever magnitudes one perceives for externalities. Thus, the best picking for the antagonist is among the externalities.

On that basis, the private businessman may be expected to initially ignore options $D$ and $E$ in Table $I$ because they pose no immediate threat to his preference. On the other hand, he may be expected to raise questions about possible exclusions and low valuations of external cost items, and about the inclusions and high valuations of external benefits for alternatives $B$ and $C$, the conventional and eclectic options, because they both produce higher net social benefits than his favored nuclear solution. If he fails to bring the present value of net social benefits for those options down below that of his solution, he will then attempt to raise the net social benefits of his preferred solution by posing questions 
about its exclusions and low valuations of external benefit items, and inclusions and high valuations of external cost items. Of course, consistency requires that any changes in standards for either inclusions or valuations must be applied uniformly to all like situations under each alternative. Thus, an advocate must take care that a change he proffers in support of his preference does not also change other solutions adversely to his cause.

For example, an argument the businessman might make is that the schedule of external costs of the conventional option do not include the contribution of that option to the depletion of a non-renewable resource--fossil fuels. This would also apply with less force to option $\mathrm{C}$, the eclectic option. Likewise, he might argue that the inflation factor (an internal cost item) used in determining the operating costs for options $B$ and $C$ is too low in view of the foreseeable depletion of fossil fuels. If either of these arguments carry, the effect will be to increase the present values of total social costs and thus reduce the present values of net social benefits for options $B$ and $C$. If this does not give the edge to the businessman's preference, he will argue further that the external costs of his solution have been grossly inflated by the inclusion of an item for the risk of a cataclysmic nuclear accident, and another for thermal pollution of stream water. If these two items are not removed, he can insist that the pecuniary values assigned to them are much too great.

Each commissioner will similarly support his preferred alternative Thus, the fiscal conservative will initially ignore options $A, D$, and $E$, and he will pose questions that tend toward decreases in the present value of net social benefits for option $C$, and that tend toward 
increases in the net social benefits of his preferred solution, option B. In like manner, the fiscal liberal will ignore option $E$, oppose options $A, B$, and $C$, and support option $D$. And the environmentalist will ignore none of the options, support his preference, option E, and oppose the rest. Finally, the economic idealist will see his role as one of protecting the empirical integrity of the benefit-cost analysis because he does not care which option is finally implemented so long as it is the one truly possessing the highest net social benefits.

The point is that the opportunity for manipulation of possible benefit-cost analysis outcomes is greatly expanded by the tenuous nature of externalities and the often questionable pecuniary values assigned to them. Externalities are so malleable that the benefitcost analysis can frequently be made to come out any way the consensus of a decision body chooses. Indeed, the benefit-cost analysis becomes speculative at best, and implausible at worst when externalities loom so large. All of which underscores the problem: there is no easy or direct way of weighing disparate and competing values in the selection of ends-to-be-reached and in the employment of means such that social welfare is maximized subject to resource constraints.

\section{PREFERREDNESS CRITERIA 15}

Another element that enhances the malleability of benefit-cost analyses is preferredness criteria. Preferredness criteria is generally thought of in terms of social discount rates. However, it also inciudes the time preference, or the period of time over which benefits and costs are discounted back to present values.

Reproduced with permission of the copyright owner. Further reproduction prohibited without permission. 


\section{Social Discount Rates}

A very important choice to be made in every benefit-cost analysis regards what social discount rate to use to discount the benefits and costs back to present values. The choice is important because of the relationship between the rate and the resulting present values. Recalling from a previous part of this chapter, the discounting equation for benefits is

$$
P V_{B}=\sum_{i=1}^{n} \frac{A i}{(1=4)^{\top}}
$$

The equation is the same for costs, substituting $C$ for $B$ and $A$. The social discount rate, $r$, is in the denominator of the term, and it follows that a high discount rate increases the denominator and therefore decreases the resulting present value of the benefit or cost. And the opposite is also true. The lower the social discount rate, the higher the resulting present value. Thus, present values are inversely related to social discount rates.

The relationship between social discount rates and present values opens the way for further manipulation of benefit-cost results. Interinstitutional biases can be introduced when several institutions are competing for the same funds. If the funding authority is deciding which institutions shall receive money for its projects on the basis of net present values, the institution that can justify the lowest social discount rate will have an advantage, other things being equal. For example, if the electric utility company described above was not privately owned, but was an element of government, its 
projects would compete with projects of other government agencies for priority and funding. And it could obtain an advantage for itself if it could justify a lower social discount rate than the rates used by competing agencies.

The same problem occurs with intersectoral allocations as well. Social discount rates for federal projects in the United States have traditionally used some sort of average interest rate conjured up from market interest rates paid on U. S. Treasury bonds. Of course, the treasury rate represents an almost risk-free investment and it is therefore substantially lower than private interest rates in money markets. On the other hand, corporate interest rates reflect al1 of the risks borne by private business, and they are therefore higher. The present values on private projects are usually calculated using some kind of weighted average yield on private investments. The point is that government sector projects often appear more productive than private sector projects because the net present values on government projects are usually calculated using lower discount rates. This can and does lead public policy-makers to believe that money spent in the public sector produces greater welfare than money spent in the private sector. And, of course, this will affect the propensity of those policy-makers to propose higher taxes and higher public expenditure programs.

Moreover, intrainstitutional biases may be introduced by a particular discount rate even if it applies uniformly throughout the institution using it. This is because a low rate favors long-term projects over short-term projects, and a high rate favors shortterm projects over long-term projects. This is simply because lower 
discount rates give greater significance to distant future values than higher discount rates. In other words, one dollar discounted from thirty years in the future at four percent is worth thirty-one cents today. Discounted at 12 percent, it is worth only about three cents. For example, ignore initial construction costs and inflation, and assume that a project produces current net benefits of $\$ 1700$ per year. These values discounted at four percent over ten years yield a net present value of $\$ 13,792$. However, a project producing only $\$ 1000$ per year and discounted at the same rate over a thirty-year life yields a net present value of $\$ 17,295$. Clearly, the longer-term project produces a higher net present value even though its annual net revenue is lower. On the other hand, a twelve percent discount rate reverses the order of preference-- $\$ 9,607$ for the ten-year project, and $\$ 8,508$ for the 30 -year project. The point is that the social discount rate is crucial to the outcome of the analysis.

Similarly, low social discount rates favor high initial cost projects with low operation and maintenance costs, while high rates give the edge to projects with low initial costs and high costs of operation and maintenance. For example, using the preceding ilustration, and assuming a usefur life of 10 years and the same current values of benefits for both projects, the project producing $\$ 1700$ in current net benefits per year is operating at lower operation and mainteriance costs than the project that produces only $\$ 1000$ per year. On that basis, the net present values of the first project are unchanged $(\$ 1700 / \mathrm{yr}$. at $4 \% /$ year for $10 \mathrm{yrs} .=\$ 13,792$, and at $12 \% /$ year $=\$ 9,607$.) However, the net present values of the second project change because of the change in useful life from thirty

Reproduced with permission of the copyright owner. Further reproduction prohibited without permission. 
to ten years. (They become $\$ 1000 / y r$. at $4 \% / y r$. for $10 \mathrm{yrs}=\$ 8,113$ ), and at $12 \% / y r .=\$ 5,651$.)

If it is assumed that the initial construction costs occur only in the first year of each project, then the net present values of the projects will be reduced in each case by the discounted values of their initial costs. If the present values of initial costs of the projects are assumed to be $\$ 7,500$ for the first, and $\$ 2,500$ for the second, then the net present values resulting with a four-percent discount rate are $\$ 6,292$ and $\$ 5,613$ respectively. Clearly, the high initial cost project with low operation and maintenance costs is preferred over the other project at a four-percent discount rate. However, if the discount rate is 12 percent, the outcome is reversed-$\$ 2,107$ in net present values for the first project, and $\$ 3,151$ for the second--and the low initial cost project with high operation and maintenance costs is preferred over the other project. Here again, the discount rate is crucial to the outcome.

The foregoing suggests that there should perhaps be a single social discount rate to be applied to all projects in the entire national economy--public and private, long-term and short-term. A so-called net yield approach is often suggested in which some average of interest rates and rates of return on private investments is adjusted by removing inflation risks, solvency risks, liquidity risks, interest rate or term risks, and all other elements that elevate the rate above the pure cost of money, whatever that is. Under these arrangements, every project in every institution across the country is using precisely the same social discount rate, and that rate is the pure cost of using money. Such an arrangement, if it could be achieved, 
would greatly simplify decisions made on the bases of interproject comparisons of benefit-cost analyses.

A counter argument is that structures of market interest rates and returns on private investments are so varied and complex that any so-called average is almost useless. Moreover, when the resulting average rate is refined by removing the factors that elevate it above the pure money rate, it is like removing the salt, leavening, and spices from bread--one is left with a bland, and unpalatable product. That is, a pure money rate--if such a rate exists--is void of most ingredients that give interest and profit rates any significance. Ideally, the rate used to discount net benefits back to a present value on any given project would reflect at least the cost of the capital funds used to create and operate the project over its productive life. Thus, the rate should incorporate every risk and yield factor involved in the project and in like projects throughout the economy. According to this view, each project would use a social discount rate that was uniquely calculated using the risk and yield factors inherent in the project. ${ }^{16}$

One of many examples that might be cited to justify special discount rates is the term structure of interest rates--the distribution of rates according to the lengths of term for the securities represented. The yield curve in the term structure of interest rates usually (but not always) reflects short-term rates that are lower than intermediate-term rates, and intermediate-term rates that are lower than long-term rates. It is sometimes argued that these variations result from the unwillingness of lenders to give up control of their moneys for longer periods because of inflation 
risks, and that the yield curve can be leveled out by simply removing inflation risk from the rates. However, this argument does not square with a so-called perversion of the yield curve during periods of high inflation. The short-term rates rise higher than long-term rates at such times--perhaps reflecting the expectations that long-term rates are too high and can only decline, and thus borrowers are unwilling to make long-term commitments at such high interest rates. However, the more usual shape of the yield curve suggests that social discount rates should increase with increases in the duration of the useful life of the project.

The discount rate strategies that might be employed by antagonists in the utility company example would depend upon features of the possible solutions that are not revealed in the data of Table I. However, it is apparent from the discussion in this section that an advocate in that example would argue to justify a lower social discount rate if his preferred option were either a longer term project than the competing alternatives, or if it were a high initial cost project with low operation and maintenance costs. On the other hand, he would argue in favor of a high social discount rate if his preferred option were either a short-term project or a low initial cost project with high operation and maintenance costs. All of which demonstrates that the relationship between social discount rates and net present values and the opportunities for manipulation of the former adds to the malleability of benefit-cost analysis.

\section{Time Preferences}

Another important choice to be made in every benefit-cost analysis 
is the duration over which benefits and costs shall be discounted back to present values. The choice is important because the choice can affect the resulting net present values. A long duration with many years over which to discount benefits and costs wi11 project higher net present values than a short duration--other things equal.

Of course, the duration of a project should not be in dispute. It should simply be the productive life of the project. However, that period may be indeterminate at the outset of a project because of factors that do not enter into the physical condition of the capital goods in the project. For example, secondary and tertiary effects might endure much longer than the productive life of the primary physical features of the project. This is also true of externalities. The time over which an external benefit or cost endures may exceed the internal, physical life of the project. For example, nuclear contamination caused by a serious accident at a reactor site might render the site unusable for a number of human generations beyond the estimated productive life of the project. Finally, there is the possibility that new technologies may render the project obsolete before its estimated productive life is expended. Conversely, the project may remain productive long after its estimated productive life has passed.

The point is that the duration of the productive life of a project is not always so certain at the outset of the project. Thus there is some discretion in setting the number of years over which benefits and costs are to be discounted back to present values. This then allows for further manipulations of possible benefit-cost analysis outcomes. And if one wished to gain priority for his preferred 
project, he would argue to increase the duration of its productive life, and thereby inflate the project's net present values in relation to alternative projects of shorter duration but discounted at the same social discount rate.

Some of the foregoing tactics for maniputating time preferences are eliminated if the choice criterion is changed from net present values to benefit-cost ratios. Benefit-cost ratios were described earlier as an alternative technique to net present values for choosing a project methodology and for prioritizing a list of projects. The principal advantages of benefit-cost ratios over net present values are that they discriminate on a basis of net present values, but they screen out manipulations involving time preferences and overall project magnitudes.

The inflation of net present values accomplished by increasing the productive life of the project will not change the project priority if benefit-cost ratios are the criteria of choice. For example, assume that benefits and costs of a project are discounted at four percent over ten years and that the present value of benefits is $\$ 13,800,000$, and the present value of costs is $\$ 8,100,000$. This produces a net present value of $\$ 5,700,000$, and a benefit cost ratio of 1.7. Now assume that the productive life over which the benefits and costs are discounted is changed from ten to thirty years. The present value of benefits is now $\$ 29,400,000$, and the present value of costs is $\$ 17,300,000$. This dramatically increases the net present value from $\$ 5,700,000$ to $\$ 12,100,000$. But notice that the benefitcost ratio remains 1.7 . Thus, the tactic for improving the priority of a project by increasing its productive life and thereby inflating its

Reproduced with permission of the copyright owner. Further reproduction prohibited without permission. 
net present value is overcome by using benefit-cost ratios for prioritizing projects.

Likewise, advantages of project size are eliminated by prioritizing project lists according to benefit-cost ratios. For example, assume two competing projects $X$ and $Y$ are analyzed using the same social rate of discount and the same productive life. And further assume that the present value of benefits for project $X$ is $\$ 20,000,000$, and its present value of costs is $\$ 18,000,000$, yielding a net present value of $\$ 2,000,000$. Now, assume that the present value of benefits for project $Y$ is $\$ 6,000,000$, and its present value of costs is $\$ 5,000,000$, yielding a net present value of on $1 y \$ 1,000,000$. On a project list prioritized solely according to net present values, project $X$ would be listed ahead of project $Y$ because its net present value is higher by double that of project $Y$. This is so even though project $Y$ produces $a$ higher rate of return than project $X$. However, if the 1 ist is prioritized by benefit-cost ratios, project $Y$ is listed ahead of project $X$ because the ratio for $Y$ is 1.2 while the ratio for $x$ is only 1.1. Thus, prioritizing project lists according to benefit-cost ratios eliminates advantages (or disadvantages) of project size.

However, prioritizing projects according to benefit-cost ratios wi1l not have any effect on benefit-cost analysis outcomes that involve manipulations of externalities or social-discount rates. The ranking of alternative project methodologies or the priority of a project can be increased on a project list by strategies to increase its net present value in relation to those of other projects. The 
strategies of change described above involving manipulation of externalities and social-discount rates will also change benefit-cost ratios to enhance project priority. Once again, benefit-cost analysis is a pliant process because of the opportunities to maneuver outcomes by jockeying elements of the analysis.

\section{BENEFIT-COST ANALYSIS AND WELFARE}

This chapter commenced with the question, how are the tensions between forward-urging technology and backward-clinging technology resolved into human progress, where progress is forward movement along the ends-means continuum--the continuum of on-going life processes. Future orientation and forward movement along the continuum also suggests the triumph of technology over aspects of ceremonialism, and the resulting improvements in social welfare.

The linkage between ceremonialism and human values was acknowledged, and it was observed that values in an industrial society are as multifarious and disparate as society is pluralistic. The preceding question was then rephrased to: How are the diverse values in an industrial society structured and weighed in choosing between competing future ends and between alternative methods of employing present means toward the selected ends so that social welfare is maximized. After all, it is in the process of choosing between such a] ternatives that new technologies are or are not chosen to be innovated, diffused, and integrated.

However, since the implicit summum bonum in all of this is maximum social welfare, it was necessary to explore that concept. Social welfare is simply the aggregate of individual welfare, and the 
latter is the sum of one's satisfaction with life subject to technical and ceremonial constraints. The tenets of social welfare were examined from the perspective of welfare economics. While the theories of welfare economics are internally consistent, their predictive and prescriptive powers are suspect because they are empirically weak. That is, the theories are so abstract that there is little correspondence with reality or it is sometimes difficult, if not impossible, to empirically establish the correspondence. As consistent as it is internally, much of welfare economics is simply implausible.

Nevertheless, the welfare economic concepts of Pareto-efficiency, and of equity within a Pareto-efficient system were found to be humanely attractive ideas. A Pareto-efficient system is one in which resources have been allocated such that the welfare of any one person can be improved only at the cost of the welfare of others. Equity within a Pareto-efficient system is improved if income is redistributed such that the gaining persons value their gains more than the losing persons value their losses. These concepts were found to be so intuitively compelling that it was suggested that their conditions ought to be as nearly achieved as possible.

However, operationalizing the Pareto criteria is another matter, given the implausibility of significant aspects of welfare economics. The problem is one of accurately measuring the conflicting and competing values, weighing them in some sort of choice mechanism, making decisions, and actualizing the decisions according to some criterion of choice.

Benefit-cost analysis is a technique by which values measured in pecuniary terms are organized and analyzed to facilitate human 
decision-making. The technique moves decision-makers toward choices that, in theory, should at least enhance, if not maximize, social welfare subject to resource constraints. "Benefits" is the benefitcost jargon for social welfare, while "costs" is the term analogous to resource constraints. The benefit-cost analysis procedure by which only methods and projects that produce maximum net social benefits (or maximum excess of benefits over costs) or the highest benefitcost ratios will be implemented is the element that augurs toward maximum social welfare. As explained above, social welfare is enhanced in Pareto-efficiency terms any time someone can be made better off without making any other person worse off. This has a high probability of occurrence whenever an investment project--private or public--truly produces a net positive present value, and that value is the highest in relation to relevant alternatives.

The decision to innovate new technologies occurs out of the benefit-cost analysis process any time a new technology promises to increase social benefits relative to social costs, or to reduce social costs relative to social benefits, and the increase in net social benefits is great enough to overcome ceremonial resistances to the technical change. When these things coalesce, technology produces or widens the excess of social benefits over social costs, and social welfare is thereby improved. Of course, the successful innovation of a new technology--an innovation that does indeed improve social welfare--is unlikely to happen unless all social benefits and costs are accurately assessed and included in the analysis, and all phantom benefits or costs are excluded from the analysis that led to the decision to innovate the new technology.

Reproduced with permission of the copyright owner. Further reproduction prohibited without permission. 
A good bit of this chapter has been devoted to describing how benefit-cost analyses can be manipulated to produce outcomes that are favored by one or another special-interest group. The production of favored outcomes can be achieved by manipulation of certain elements of the analysis--chiefly, externalities, social-discount rates, and time preferences. Manipulation of the latter two, social discount rates and time preferences, can be done, but it is not so facile in present institutional environments because they may be more effectively dealt with in the pecuniary frame-of-reference. However, this is not altogether the case with externalities.

To be sure, many external effects are very real. There are external benefits initiated by both producing and consuming agents for which the market neither extracts payments from the recipients who enjoy the benefits, nor remunerates the initiators for the external benefits they produce. And there are external costs initiated again by both producing and consuming agents for which the market again neither extracts payments from the initiators, nor sees to payment of the recipients who bear the costs. Real external benefits and costs must somehow be verified, quantified, and included in benefit-cost analyses if social decisions are to lead to efficient allocations of resources and equitable distributions of incomes.

There, however, is the rub. Externalities are ethereal. They are non-divisible, vaporous, and illusory. They are like smoke in a bar, and no person who stays in the room can avoid breathing it if he is to breathe at a11. Or they are like the fragrance of a bouquet in a parlor, and no person who remains in the parlor can be excluded from the pleasant redolence as a way of inducing him to contribute to the 
cost of the bouquet. In many cases, there is no simple or direct way of either verifying the existence of externalities, or of assessing their pecuniary values when they are found to exist. Most techniques for evaluating external effects therefore come down to intuitive opinions on the part of the analyst, and this injects subjective and sometimes unsubstantiated judgments into what may otherwise be a moreor-less objective analysis.

It is the problem of verifying and quantifying externalities that opens opportunities to maneuver the benefit and cost elements of benefit-cost analysis to favor the outcomes preferred by the interestgroups with the greatest influence in the process. Preferred outcomes can be assured by the maneuvering of phantom benefits or costs into the analyses, and it is the spiritual essence of externalities that increases the likelihood that such maneuvering will be successful.

There is a gargantuan preoccupation with external costs under the institutional environment that prevails in the United States in this last quarter of the twentieth century. The preoccupation has risen like a spectre from the past concomitant with the rise of new technologies that promise greater and greater social welfare and at the same time threaten revolutionary institutional changes. The question relevant to the continuum of on-going life processes is, to what extent are phantom ceremonial values cloaked as external costs and maneuvered into benefit-cost analyses simply to prevent the innovations of new technologies? There is little doubt that such manipulations take place. But because of the ethereal quality of externalities, it appears doubtful that it can be prevented.

Benefit-cost analysis possesses important advantages despite the Reproduced with permission of the copyright owner. Further reproduction prohibited without permission. 
weaknesses described above. To the degree that manipulation of its various elements can be controlled, benefit-cost analysis appears to be the most promising technique now available to evaluate alternatives--both as to ends to be achieved and ways to allocate resources to achieve the selected ends. It tends to move issues to the top of the table. It arrays costs along side benefits for analysis, and it forces the examination of spending in terms of goals. It therefore holds forth the prospect for greater efficiency in the allocation of resources and in the distribution of incomes, and thus for improvements in social welfare.

However, the weaknesses inherent in benefit-cost analysis admonish additional research to discover better empirical ways of verifying the existence of true externalities and of quantifying them when they have been established. They also admonish constant vigilance on the parts of all affected groups to detect and prevent the improper manipulation of benefit-cost analys is elements to artificially favor the outcomes preferred by one of another special interest group. 17

It has been the purpose of this chapter to examine the modern economic processes by which the tensions between technology and ceremonialism are resolved into human progress. The process involves choosing goals and ways of employing resources to achieve the goals. Choices are made by weighing benefits and costs and by choosing the alternatives that produce the greatest net of benefits over costs, or the goals that render the greatest increase in social welfare. But because of opportunities for manipulation of elements in the process, 
the outcomes that promise the greatest social welfare may not be selected. The problem remains--there is no simple or direct method to structure and weigh values in a pluralistic, industrial society for choosing between competing future ends and alternative ways to employ resources such that sccial welfare is maximized.

This chapter did not consider the political and other social processes by which decisions are made. For example, it left the question open as to how the power to control or influence the decision processes is distributed in a pluralist society. This and other related points are considered in the following chapter. 
END NOTES, CHAPTER IX

$1_{H}$. Marshall McLuhan, Understanding Media; The Extensions of Man, (New York: McGraw-Hil? Book Co., Inc, 1964). Alvin Toffler, Future Shock, (New York: Bantam Books, 1971).

${ }^{2}$ E.g., Jeremy Bentham, An Introduction to the Principles of Morals and Legislation, (New York: Blackwell's Political Texts, 1948). John Stewart Mill, Utilitarianism, in The Great Books of the Western World, Vol. 43, ed. by Robert M. Hutchins, et al., 54 vols., (Chicago: Encyclopaedia Britannica, Inc., 1952), pp. 443-76. Ralph Barton Perry, General Theory of Value, (Cambridge: Harvard University Press, 1926).

${ }^{3}$ E.g., most philosophers of religion (Theists), and absolutists.

${ }^{4}$ E.g., Dewey, Theory of Valuation.

${ }^{5}$ Ferguson and Gould, Microeconomic Theory, passim.

6 Pareto, Economic Politique.

7 Hicks, "Foundations of Welfare Economics." Kaldor, "Welfare Propositions of Economics."

8 Attributed to Leon Walras, Elements of Pure Economics, trans. by William Jaffe, (Homewood: Richard D. Irwin, Inc., 1954).

${ }^{9}$ R. G. Lipsey and K. Lancaster, "The General Theory of Second Best," Review of Economic Studies, XXIV (1956), 11-32.

${ }^{10}$ Arrow, Social Choice.

${ }^{11}$ Adapted from Mishan, Cost-Benefit Analysis. Prest and Turvey, "Cost-Benefit Analysis." Bernard Herber, Modern Public Finance; The Study of Public Sector Economics, 3d ed. (Homewood: Richard D. Irwin, Inc., 1975), pp. 401-19. Cf, Commons, Collective Action, p. 104.

12 Ibid.

13 Bator, "Anatomy of Market Failure."

${ }^{14}$ Steve H. Hanke and Richard A. Walker, "Benefit-Cost Analys is Reconsidered: An Evaluation of the Mid-State Project, "Water Resources Research, X (1974), pp. 898-908. Robert H. Havemen and Burton A. Weisbrod, "Defining Benefits of Public Programs: Some Guidance for Policy Analysts," Policy Analysis, XX (1975), pp. 169-96.

Reproduced with permission of the copyright owner. Further reproduction prohibited without permission. 
15 Ibid.

16 Harold M. Somers, "On the Demise of the Social Discount Rate," Journal of Finance, XXVI (May, 1971), pp. 565-78. William J. Baumol, "On the Discount Rate for Public Projects," in Public Expenci, ture and Policy Analysis, 2d ed., ed. by Robert J. Haveman and Julius Margolis, (Chicago: Rand McNally College Publishing Co., 1977), pp. 161-79.

${ }^{17}$ Alan Williams, "Cost-Benefit Analysis: Bastard Science? And/or Insidious Poison in the Body Politick?" Journal of Public Economics, I (August, 1972), pp. 199-226. Henry Rowen, "The Role of Cost-Benefit Analys is in Policy-Making," in Public Expenditure and Policy Analysis, 2d ed., ed. by Robert H. Haveman and Julius Margolis, (Chicago: Rand McNally College Publishing Co., 1977), pp. 546-55. 


\section{CHAPTER $X$}

\section{URBAN PLURALISM}

The preceding chapter sought to explain how institutional values are measured in dealing with the tensions between technology and ceremonialism--tensions that frequently lead to decisions to innovate new technologies, and ultimately to the institutional changes precipitated by the new technologies. This chapter takes up the processes by which societies reconcile the social tensions that result in institutional changes. In other words, it addresses the question, how do institutions change in modern, industrial democracies?

The tentative answer, and the central idea in this chapter, is that institutions eventually adjust to the new technologies by diffusing and integrating them across the institutional system through a process called "collective action" by economists, and "interestgroup politics" by political scientists. This does not mean that collective action and interest-group politics are simply different names for the same phenomenon. However, it acknowledges a substantial and complementary overlap regarding the economic and political relationship between technological innovations and institutional changes.

It will help to briefly review appropriate parts of preceding chapters as a way of setting the stage for this chapter. It is recalled that ceremonialism arises from the cultural past, and it 
embodies traditional ways of knowing and doing. Thus, it is the technique by which institutions discharge their social functions of maintaining social stability. Ceremonialism accomplishes this by transmitting culture, structuring society, socializing members of society, and controlling social interaction. Ceremonialism seeks in these ways to preserve the cultural values out of which the institutions have grown. Ceremonialism is therefore static and oriented toward the past in terms of the ends-means continuum. Hence, ceremonialism prescribes selection of only those future ends that are congruent with traditional values, and the employment of means in ways that do not deviate from traditional techniques. For these reasons, ceremonialism opposes selection of any future end or any technique for employment of means that is not established in tradition.

On the other hand, technology is that quality of a tool that enables it to be substituted for human labor in the creation of goods and services having human value. Insofar as the production of goods and services presumes future human uses, technology is future-oriented, continuous, dynamic, and progressive. The innovation of new technology opens ways of organizing means to future ends in different ways than the traditional, and it may also bring future ends into human reach that were previously beyond known means. The dynamic quality and forward-urging of technology bring it into conflict with backward-clinging ceremonialism as to the selection of ends-to-bereached, and as to the employment of means to the selected ends. How much of new technology is actually innovated depends on the powers of ceremonialism to resist change and on the tenacity of the institutional values upon which the ceremonialism is founded.

Reproduced with permission of the copyright owner. Further reproduction prohibited without permission. 
Modern innovations of new technologies arise out of decision techniques in industrial societies. Such techniques presume to evaluate alternatives by defining, quantifying, and weighing social benefits and costs. And they usually involve selection of the alternatives that yield the highest net present values (or excess of the present value of social benefits over the present value of social costs). The decision to innovate a new technology is reached when the analysis reveals that use of the new technology will so increase net present values (by increasing present values of benefits, or decreasing present values of costs, or both) that ceremonial resistance to the ensuing change is overcome.

The actual innovation of a new technology is destabilizing to institutional environments because it opens opportunities for social mobility in which traditional social statuses and ceremonial systems of rank may be changed. It is this institutional feedback from technological change that precipitates social revolutions. Such revolutions occur when the innovation of new technology changes interinstitutional arrangements so that one or more institutions are no longer fully complimentary to the institutional system. Certain ceremonies founded on the incongruous institutional arrangements become dysfunctional within the system. The resulting social instability reflects institutional responses to the technical change-first to oppose, and then to adjust itself to the change.

Social stability resumes when the new technology is fully integrated into the institutional system, and ceremonial arrangements have been altered to accommodate the technical change. Some institutions may have gained, and some may have lost social power.

Reproduced with permission of the copyright owner. Further reproduction prohibited without permission. 
New institutions may have come into existence, and some established institutions may have disappeared. It is this process of diffusion and integration of technology that produces institutional change and is the subject of this chapter. The process involves what economists call collective action, and aspects of collective action involve what political scientists call interest-group politics.

\section{COLLECTIVE ACTION}

Institutional economic theory possesses two main branches. The first has to do with institutional instability and discontinuity, and the second with institutional adjustments to change. That is, the first branch deals with the disequilibrating social elements that lead to revolution, and the second branch deals with the equilibrating social elements that lead to adjustment and stability. The seminal works in the first branch were produced by Thorstein Veblen and Clarence E. Ayres, and Chapters III through VIII above are an attempted summary restatement and embellishment of the applicable portions of their works.

The seminal works in the second branch, the one dealing with institutional adjustments and stability, were produced by John R. Commons. The first part of this chapter is an attempted summary and restatement of applicable portions of Commons' institutional economic theory. The reader is placed on notice that many of the terms developed in Chapters III through VIII according to the Veblen and Ayres lexicon are called by different names in the Commons vernacular. As in the translation from one language to another, there is not perfect literation between words in the two branches. However, there

Reproduced with permission of the copyright owner. Further reproduction prohibited without permission. 
are terms in each branch that have approximately synonymous counterterms in the other branch. Appropriate interpretations will-be made in the applicable parts of the following text.

It was Commons' view that institutions adjust in the face of technological change and social stability is restored through collective action. Indeed, his clearest and most complete, and yet concise, statements of theory are found in a monograph he titled The Economics of Collective Action. Collective action deals with conflicts of interests between institutions, and the ceremonial modes of behavior by which the conflicts are resolved. And it purports to explain how the ceremonial norms are changed in the resolution process.

\section{Conflicts of Interests 1}

Conflicts of interests arise between going concerns because of the volitional or purposive nature of mankind and because of the material scarcities induced by the institution of property. The purposive nature of humans gives rise to the uses of goods and services while the institution of property limits the availability of the same. In other words, it is the disparity between the demand for and the supply of goods and services that causes conflicts of interests between going concerns.

Purposiveness, the central feature of volitional psychology, represents the behavioral qualities that inhere in humans and enable them to think and act in the longitudinal dimension of the ends-means continuum, the continuum of on-going life processes that was described in Chapter III above. They are descriptive of the traits that allow humans to visualize their wants and conceptualize them 
in terms of distant future goals, and to plan and develop complex organizations of means to reach those goals. The goals are, of course, finished goods and services of both the producer and consumer kinds. The organization of means involves marshalling both the human and the nonhuman resource components. The former leads to the creation of one or more going concerns and a consequent demand for human labors. The latter leads to demands for material and other nonhuman resources. And the outcome of volitional motives is to secure the expected stream of future incomes as present values.

Commons uses the term "going concern" to mean approximately what Veblen and Ayres calls "institution." The former is a legal term used in courts of law that are trying civil litigations involving economic matters. In that context, a going concern is a lawful, solvent, whole, and viable economic unit. Thus a Commons' "going concern" is an "institution" in the Veblen-Ayres vernacular, but the latter appears to have a somewhat broader meaning than the former. Nevertheless, going concern will be used interchangeably with institution in this chapter.

As noted, going concerns came into being because of human purposiveness. Possible future ends are brought into view, and when one is selected as an end-to-be-reached, a going concern is employed or organized to secure it. A going concern is an institutional organization composed of "complimentary factors" which, when organized correctiy, enable the going concern to accomplish the goal or goals for which it was created. People are transitory in going concerns, but going concerns persist generation upon generation in one institutional form or another. It is the going concern that 
discharges human purposiveness according to volitional psychology.

Going concerns use material things, and the uses of material things are regularized by the institution of property. Private property rights are nothing more than the interests of owners that the state will enforce against non-owners. ${ }^{2}$ It is recalled from a previous chapter that property was fused with sovereignty during the European feudal era, and it was gradually separated with the monetization of feudal obligations. The separation of sovereignty and property institutions came to be founded on the natural rights doctrine of John Locke. The doctrine justified certain common liberties on the ground that one gained a property right independent of the sovereign when he created a good by mixing his personal labors with nature's materials. This followed because one must certainly have a right to the fruits of his own labors.

The property rights severed from the institution of sovereignty included the private ownership and use of corporeal properties. Corporeal properties are tangible things such as land (or realty) and physical commodities (or personalty) other than land and features attached to the 1 and. The expectation that the sovereign would enforce the owner's quiet enjoyment of his private properties against trespass by non-owners gave rise to the English Common Law, specifically:

As distinguished from law created by the enactment of legislatures, the common law comprises the body of those principles and rules of action, relating to the government and security of persons and property, which derive their authority from usages and customs of immemorial antiquity, or from the judgements and decrees of the courts recognizing, affirming, and enforcing such usages and customs; anci, in this sense, particularly the ancient unwritten law of England. 3

Reproduced with permission of the copyright owner. Further reproduction prohibited without permission. 
Incorporeal private property came into being when the courts commenced to enforce so-called obligations of contracts. This consists of a debtor's duty to pay his just debt to a creditor. The creditor's right to receive future payment is a property right conveyed by contract. The contract is an intangible private property because it came into being only in connection with some other property matter, and the right conveyed is an incorporeal property because it involves no tangible, material thing. However, the contract and its rights can be exchanged for other property rights, rights to both corporeal and incorporeal properties as well as to both tangible and intangible properties. Such private rights are preserved against public meddling by the "obligations of contracts" clause of the U. S. Constitution.

The constitutional meaning of property was enlarged by courts and legislatures in the United States during the last quarter of the nineteenth century to include other forms of intangible properties. These properties consisted of business goodwi11, patents, trademarks, copyrights, franchises, etc. They were effectually laws proscribing unfair competition, and they created duties of avoidance and forbearance in others. They give the owners of intangible properties the economic power to withhold from others, until an agreeable price is negotiated, certain rights the non-owners might use and may need.

The modern property distinctions result in proprietary scarcity as distinguished from biological and psychological scarcity. Biological scarcity relates to the Malthusian notion of scarce resources because of poor natural endowments, and psychological scarcity arises from the so-called hedonistic nature of man described by utilitarians like Bentham. The former contemplates resource

Reproduced with permission of the copyright owner. Further reproduction prohibited without permission. 
availability in terms of the past, and the latter in terms of the present. Both are based on a ceremonial concept of corporeal and tangible properties. The concept of tangible property is the holding of corporeal things for one's own use and enjoyment, and it fosters a sense of individualism and economic independence.

Proprietary scarcity, on the other hand, relates to institutional present and contemplated future uses of resources to secure on-going future ends. It is therefore based on a ceremonial concept of incorporeal and intangible properties--ceremonial rights that give persons and institutions status in the form of present claims on future incomes. Such rights are ceremonially conveyed by contracts, and they give the owners the power to ceremonially withhold from others present and future uses of properties the non-owners need until the owners and non-owners can ceremonially negotiate working rules, the prices, and other terms of future exchange. Thus, proprietary scarcity is enforced by a set of ceremonial arrangements involving a concept of intangible properties. Finally, proprietary scarcity ultimately fosters interdependence of interests as opposed to the independence of interest embodied in a concept of tangible property.

However, proprietary scarcity leads to conflicts of interests between going concerns. One institution has legal title and physical possession of the property or the document or other evidence of the property, while another lacks legal title and possession but needs present or probable future use of the property to achieve the institutions' planned future ends. The resolution of such conflicts is the subject matter of collective action, as Commons believed,

Reproduced with permission of the copyright owner. Further reproduction prohibited without permission. 
"in control, liberation, and expansion of individual action." 4

\section{Ceremonial Norms}

Conflicts of interests are resolved by transactions that are structured by working rules and, at the same time, are concerned with creating and changing the working rules. "Working rules" is the Commons term for that aspect of ceremonialism that has so far been called traditional ways of knowing and doing. Working rules are the ceremonial modes of behavior that are expected of persons occupying institutional positions. They are the ceremonial role patterns that descend from the cultural past and inform the present of customarily acceptable forms of human interaction. They are the taboos that cement institutions together internally and that bind them to one another externally. They are all the laws of the nation as well as the conditions of every private contract or other agreement hammered out by bargaining. And they are the managerial decisions and rules promulgated by every executive officer across the land.

In short, they are ceremonialism, the instrumentality of the institutional system for maintaining social stability. Working rules will be used interchangeably with ceremonial ways of knowing and doing (taboos) and with ceremonial modes of behavior.

Working rules are the institutional guidelines for transactions, and the "transaction" is a Commons term approximately meaning "ceremonial exchange" in the language of Veblen and Ayres. Transactions are the ceremonial methods for acknowledging rank and validating status. They are therefore the varieties of ceremonial interactions that bind persons together with flurries of activities within the 
institutional system, and they thereby maintain the system and preserve social stability. The word transaction will be used interchangeably with ceremonial exchange in this chapter. Taking place according to working rules, transactions dissolve conflicts of interests into interdependencies of interests by providing legal forums for the exchange of property rights.

The exchange of property rights between going concerns is, of course, economic activity. Any economic activity takes place in three stages--a negotiation stage, a transaction stage, and an administration stage. The negotiation stage ends with agreement on the values to be exchanged. It is approximately the offer and the acceptance in contract parlance. The transaction stage lays down the working rules that culminate in a binding contract which will govern the exchange. And the administration stage discharges the exchange according to the conditions or working rules laid down in the transaction stage. This includes the lawful alienations and acquisitions of ownerships, the physical transfers of the rights exchanged, and the future payments if any. The transaction stage is the crucial stage because it is the apex of economic exchange where the working rules are established that will govern the activity during its future existence.

A11 transactions are collective action in practice. There are three kinds of transactions--bargaining transactions, rationing transactions, and managerial transactions. Bargaining transactions are the most recent to rise out of custom in the western world. The going concerns in a bargaining transaction are private institutions that are legal equals. They employ persuasion and sometimes coercion as inducements in the negotiation stage to buy and sell commodities or

Reproduced with permission of the copyright owner. Further reproduction prohibited without permission. 
other property rights. The working rules of the transaction stage produce collateral debts - a debt of performance by the seller and a debt of payment by the buyer. The debts are discharged in the administration stage as the seller alienates the property right sold to the buyer and acquires payment of consideration by the buyer, and the buyer alienates the consideration to the seller and acquires the property right purchased from the seller.

Bargaining transactions are collective actions because at the outset each bargaining transaction has not two, but at least five potential parties. There are at least two competitors on each side of the transaction--two potential buyers offering the two best opportunities for the seller, and two potential sellers offering the two best opportunities for the buyer. The buying and selling parties will, of course, be narrowed to the actual buyer and seller by the end of the negotiation stage. Finally, there is at least one judge who stands ready to hear any disputes and to issue decrees in the name of the state to an actual seller or buyer. The judge represents the sovereign power of the state enforcing custom and law. It is this arrangement that makes bargaining transactions juridicial in character.

Rationing transactions are the oldest in point of time, and they are the commands of a governing body allocating property rights among the governed. They take place between legal superiors and legal subordinates, whether or not there is perfect agreement on the parts of subordinates. The negotiation stage involves command as an inducement to obedience, and the working rules of the transaction stage have to do with budgetary commitments that affect the future distributions of wealth, assets, and incomes. The budgets are

Reproduced with permission of the copyright owner. Further reproduction prohibited without permission. 
discharged in the administration stage through the collection of revenues and the disbursement of funds.

Obvious examples of rationing transactions are the taxation and expenditure programs of governments. Dictatorships are the more primitive and autocratic superiors in rationing transactions. However, taxes are no less onerous to the citizen of a democracy in which the tax laws are enacted by legislatures composed of elected representatives. The citizen is nevertheless compelled by law and the possible sanctions of the state against his person and properties to pay his taxes. Moreover, the state will use the tax revenues to pay for whatever public programs emerge from the legislative consensus whether or not all taxpayers agree with that consensus. Other less obvious examples of rationing transactions are the allocations of rights made by boards of directors to the operating officers of private institutions like business corporations, labor unions, and churches. As one can see, the central stage of such activity, the rationing transaction, is legislative in character.

Finally, managerial transactions arise out of bargaining transactions or rationing transactions, or both. The working rules emerging from bargaining and rationing transactions may contain areas of discretion. Those areas of discretion are filled by managerial transactions during the administration stage of the bargaining or rationing transaction out of which the discretion emerged. Managerial transactions are executive in nature, and they take place between legal superiors (the managers) and legal subordinates (the persons managed). Thus, the negotiation stage involves command as an inducement to obedience. The commitments and rules of future actions resulting 
from the transaction stage are to the output of goods and services. Discharge of the commitment takes place in the administration stage by the actual combining of inputs to produce the outputs.

For example, the general manager of an enterprise may be empowered by the rationing transactions of the board of directors to manage the company's resources in the production of commodities for sale through retail merchants to consumers. The working rules will no doubt give the manager substantial discretionary authority to discharge the production commitment in the administration stage. The discretionary authorities will be exercised through additional transactions of the bargaining and managerial sort.

In pursuit of his responsibilities, the manager may hire an employee. The hiring involves a bargaining transaction because it takes place voluntarily between legal equals. And, in cases of employment, the commitment to render future labor services is consensual under the working rules (custom and law) that govern such commitments in the western world. The commitment may therefore be terminated at will by the employee and under collective bargaining provisions by the employer. However, once the employment commitment is made, and as long as it remains in force, the status relationship between the employer and employee is one of master and servant. And, as long as that relationship obtains, the servant is obliged to obey the commands of the master in their productive enterprise. Thus, the transactions that thereafter ensue between them are managerial transactions which are corollary to the bargaining transaction that initiated the master-servant relationship.

The three forms of transactions--bargaining, rationing, and 
managerial--resolve conflicts of interests between going concerns by providing ceremonially-sanctioned methods for exchanging property rights. The exchange of property rights is necessary to permit going concerns access to the scarce resources needed for the institutions to achieve their future ends-to-be-reached. The transactions are governed externally by working rules (custom and 1aw), and they are concerned with the creation of the internal working rules to govern the on-going features of the exchanges with which they deal. It is therefore transactions that maintain the institutional system by binding persons together with collective activities within the system-activities that reinforce human interactions by ceremonially acknowledging ranks and validating statuses.

\section{Changing Ceremonial Norms ${ }^{6}$}

The key to understanding institutional changes is in understanding how ceremonialism changes--how changes are brought in the ceremonial totems and taboos, in the ceremonial systems of status and rank, and in the methods of ceremonial exchange that validate institutional statuses. In short, it is changes in the panoply of the ceremonial canons of taste and the ceremonial modes of behavior that perpetuate institutions and the cultural values on which they are founded. It is changes in the very forces that operate against change.

And the key to understanding how ceremonialism changes is to understand the nature of transactions and their relationships to customs and laws. The simplest statement of those relationships is: transactions are structured by customs and the law, while laws are 
slowly changed to conform to underlying customs, and customs evolve out of the routine practices of transactions. In other words, customs are little more than routinized working rules, and they therefore rise out of working rules that have become routinized by transactions. And the laws are slowly changed to bring them into accord with certain evolving customs. Changes in the law involve interest-group politics and they are the subject of the next part of this chapter.

This section deals with the causal relationships between transactions, working rules, and customs that lead to changes in ceremonial norms. A summary of those relationships follows:

(1) Assuming a very long-run social stability based on a mature technology--one which has been fully diffused and integrated--going concerns are found to be operating with complimentary factors which include firmly established working rules, and the transactions between going concerns are completely routine.

(2) The discovery of a pervasive new technology will open opportunities to increase benefits (increases in quantity or quality or both of goods or services or both) proportionately more than the increases in corresponding costs.

(3) However, innovation of the new technology will be difficult and maybe impossible under some of the established working rules. While those working rules were complimentary factors in the established environment, they become limiting factors with the new technology.

(4) Human purposiveness will cause some going concerns to attempt to innovate the new technology and to realize the profits or other social gains from doing so. They will therefore search for ways to bring the limiting factors under control and to convert them to 
complimentary factors in terms of the new technology. The efforts will take the form of strategic transactions which have the functions of changing the working rules in terms of the new technology. Strategic transactions are simply bargaining, rationing, and managerial transactions that introduce neoteric working rules.

(5) If the strategic transactions are successful, they wi11 produce revised working rules that prove themselves instrumental toward innovation and integration of the new technology, and the revisions will be routinized by repetitive transactions if the innovation is fruitful.

(6) Finally, the limiting factors will have been converted to complimentary factors when the revised working rules have been fully routinized, and fully routinized working rules are, after a11, customary ways of doing things.

An example that illustrates the foregoing process is the innovation of the motor vehicle and some of the very long-run changes in urban affairs that are attributable to the diffusion and integration of automotive technology. It must be admitted at the outset that only a few of the more obvious effects can be described here because the effects are so pervasive that there is hardly an aspect of human existence that has not been significantly touched by that technology. Likewise, it is not possible to describe even a small fraction of the immense profusion of transactions that were somehow involved with the innovation, diffusion, and integration of automotive technology. The transactions must surely number in the billions, and perhaps in the trillions. With this in mind, it is only possible to savor the essence of what occurred.

Reproduced with permission of the copyright owner. Further reproduction prohibited without permission. 
The self-propelled vehicle is a creature of the twentieth century. To be sure, automotive technology is continuous with other technologies, and its genesis extends back in time before the twentieth century. But the innovation, diffusion, and integration of automotive technology are very recent phenomena. Working rules centering on transportation arrangements were based on horse and rail technologies at the turn of the present century. The innovation and diffusion of horse technology was described in Chapter VIII above.

The distribution of settlements, the patterns of interurban and interregional trade and exchange, and the differential rates of urban development and growth described in Chapter VIII were changed again in the nineteenth century by the innovation, diffusion, and integration of railroad technology. The use of horse-drawn, rail transport reaches well back before 1800 , particularly in mining operations and in intra-urban transportation. However, inter-urban transportation remained unaffected by railroad technology until the innovation of steam locomotion. 7

The first inter-urban railroad, the Stockton and Darlington Railway, opened passenger and freight service in England in 1825. The Baltimore and Ohio commenced rail service in the United States in 1828 using horse-drawn cars. The $B$ and 0 converted to locomotives in 1830 using the "tom thumb," a locomotive built by Peter Cooper. The superiority of railroads in the cross-country transportation of freight and passengers was demonstrated during the U. S. Civil War, and that war gave impetus to railroad construction in the United States. Acts of the U.S. Congress in 1862 and 1864 provided public lands for construction of a transcontinental railroad. The Union Pacific

Reproduced with permission of the copyright owner. Further reproduction prohibited without permission. 
Railroad was built westward from Illinois, and the Central Pacific Railroad was built eastward from California. The two met at Promontory, Utah on May 10, 1869.

Railroad construction proved to be a boon to the westward expansion of the United States, and construction proceeded throughout much of the remaining nineteenth century until the entire country was served in one way or another by railroads. The U. S. Interstate Commerce Commission was created in 1887 to regulate the expanding private railroads. By the end of the century routine working rules based on inter-urban rail technology and intra-urban horse technology were well established, and the routine working rules were substantially integrated with social customs and traditional beliefs.

Likewise, physical arrangements had been changed to accommodate the railroad technology. After all, railroad construction included more than simply laying track between two cities. It also involved the construction of terminal facilities for freight and passengers. Thus, cities like New York, Chicago, New Orleans, and San Francisco, that were major ports for water-borne cargo and passengers, had to be partially rebuilt to link rail terminal facilities to water terminal facilities so that argoes could be transshipped without double and triple handling. Other cities like Omaha, Kansas City, Indianapolis, Oklahoma City, and Denver that were developing during the era of railroad construction were expanded around a rail terminal.

This feature of railroads, the central terminal for inter-city transportation, and the relatively high cost of horse-drawn intra-city transport caused cities to be monocentric with high population densities at and adjacent to the central core. All commerce and

Reproduced with permission of the copyright owner. Further reproduction prohibited without permission. 
industry took place at a central business district, and people resided in or immediately next to the central business district. Everything tended to center on the railroad terminal in order to minimize the cost of transportation. Land rents, wages, and net income were accordingly higher in the core area, and they declined with distance from the core area. On the other hand, transportation costs and thus the prices of goods increased with distance from the core area. There were no suburbs as they are known in the latter quarter of the twentieth century. 8

This was the situation, then, at the outset of the automobile era. Cities were generally monocentric and centered on inter-city railroad terminals. The intra-city transportation of cargo was by horse-drawn vehicles, and the intra-city transportation of passengers was by the same means and by electric-powered trolleys. Working rules based on horse and rail technologies were routinized and were reconciled with traditional beliefs and social customs. In other words, the ceremonial norms had been changed sufficiently to accommodate the technologies, and the technologies were integrated with the institutional system so that all affected institutions were congruent with the system.

However, the first fity years of the twentieth century witnessed first a peak in railroad prosperity and then a decline in the significance of the railroads. There were many factors contributing to the changes, but the chief factor was innovation of the selfpropelled vehicle. The first record of a self-propelled vehicle dates back to 1769 when Nicholas Joseph Cugnot demonstrated a steampowered three-wheeled carriage in Paris. Cugnot's invention was

Reproduced with permission of the copyright owner. Further reproduction prohibited without permission. 
treated as a curiosity, and it was not produced for sale to users. 9 However, a similar vehicle built in 1801 by Richard Trevithick in England gave rise to the production and use of both steam- and electric-powered vehicles in England during the nineteenth century. Even so, the self-propelled vehicles did not come into full use there until their worth was demonstrated in the United States during the first quarter of the present century. This was because the British did not find it possible to change the existing working rules to allow the full diffusion and integration of self-propelled vehicles with the existing institutional system. For example, such vehicles were limited to a four mile-per-hour speed, and they were subject to discriminatory bridge and road tolls. Likewise, a so-called Red Flag Act was passed in England requiring that each self-propelled vehicle be preceded by a man on foot carrying a red flag by day and a red lantern by night to warn approaching teamsters and carriage-masters so they might control their horses as the vehicles passed. The requirement remained in force from 1836 to 1896.

Ceremonial powers and institutional resistance to change were simply too great in England to permit the full integration of selfpropelled vehicles there. The British experience demonstrated that innovation of the new automotive technology was difficult, and full integration was impossible under some of the established working rules. While those working rules were complimentary factors in the established environment, they were limiting factors with the new technology. The same ceremonial situation prevailed with more or less intensity elsewhere in the world.

In the meantime, it was becoming clear to other enterprising 
people that the self-propelled vehicle held great potential for substantial improvements in overland transportation. Under the correct circumstances, such vehicles could provide personal portal-toportal passage commencing at any moment of the owner's choosing, and they could do so with unprecedented privacy, speed, comfort, and hauling capacity. Moreover, the costs of maintenance and operation could be far less than the same costs using teams of horses for motive power. There were no extensive preparations required before the trip, as with horses, and there were no special livery requirements at the end of the trip. Al1-in-a11, the potential gains in human welfare seemed impressive to those persons with the vision to look ahead.

Karl Benz and Gottlieb Daimler were two such visionaries. Benz introduced a three-wheeled carriage powered by an internal combustion engine in Germany in 1885. In the same year, Daimler produced an internal combustion engine that was better suited to self-propelled vehicles, and the Daimler Company brought out the "panhard car" in France by 1894. So-called "horseless carriages" were introduced on the other side of the Atlantic during the 1890s in various power and size configurations by Charles and J. Frank Duryea, Ramsom 01ds, Henry Ford, Elwood Haynes, Alexander Winton, and others.

It was the work of entrepreneurs like Benz, Daimler, 01ds, Ford, Winton, and others that led to the creation of going concerns for the purpose of innovating the new automotive technology and realizing the private profits and other social gains for doing so. Their strategies involved searching for ways to bring the limiting factors under control and to convert them to complimentary factory in terms of the new technology. Their methods took the form of strategic transactions 
by which working rules were changed to facilitate diffusion and integration of the new technology. The strategic transactions were rationing, bargaining, and managerial transactions that introduced novel working rules. The novel working rules might apply to creation and organization of the going concern, purchases of inputs, production arrangements, or marketing the final product.

Perhaps the most successful and best-known innovator in the automotive field in that era was Henry Ford. It is therefore possible to draw from Ford biographical materials to illustrate the employment of strategic transactions that changed working rules, and to illustrate the routinization of working rules into customary ways of knowing and doing. Ford was born on a farm near Dearborn, Michigan in 1863. He was employed by the Edison Company as a machinist and engineer from 1890 to 1899. Working in his spare time, he completed his first automobile in 1892 . $^{10}$

Resigning from the Edison Company in 1899, Ford and others formed the Detroit Automobile Company. However, eventual disagreement with his associates caused Ford to withdraw, and in 1903 he formed the Ford Motor Company in association with James Couzens, the Dodge brothers, and others. Ford had bought out his associates by 1907, and the Ford Motor Company has since remained under control of the Ford family. Each of these actions involved strategic bargaining transactions in the creation of a going concern for the purpose of producing and selling automobiles. The first attempt proved fruitless, but the second set of transactions culminated in the Ford Motor Company, perhaps the most successfut pioneering automobile producer in the world.

Reproduced with permission of the copyright owner. Further reproduction prohibited without permission. 
Success of the Ford Motor Company is attributable to many things. However, three novel and revolutionary arrangements stand out because they eventualiy became the models for other successful manufacturers. The first was to adapt the conveyor belt principle to the mass production of automobiles. The second was to gain control over the supply of inputs. And, finally, Ford established control over the distribution and sale of his automobiles.

Undoubtedly the most revolutionary of Ford's novel arrangements was adaptation of the conveyor-belt principle to the mass production of automobiles. This was accomplished by strategic rationing transactions that committed the Ford Motor Company to the assemblyline principle, and allocated internal resources to company managers to carry out production according to that principle. On-going strategic bargaining and managerial transactions further shaped the working rules to actualize the novel concept. Strategic bargaining transactions involved hiring units of labor and buying other resources, and strategic managerial transactions involved integrating the labor and other resources into the assembiy-line process. The result was a manufacturing process that substantially reduced the unit cost of automobiles by taking advantage of increasing returns to large-scale production. And the Ford assembly-line process became a model of production efficiency that was ultimately copied and adapted to the manufacture of nearly every product in modern industrial systems.

The other two novelties initiated by the Ford Motor Company, gaining control over input supplies and over distribution and sale of the final products, resulted in much the same way. Strategic rationing transactions committed the company and allocated its

Reproduced with permission of the copyright owner. Further reproduction prohibited without permission. 
resources to those ends, and company agents secured the ends, largely through strategic bargaining transactions with other going concerns. Because of the advantages Ford Motor Company realized from those arrangements, it soon became the largest and most profitable automobile producer in the world. Ford introduced the Model-T in 1908. The Model-T was an inexpensive, mass-produced, standard car that sold $15,000,000$ before it was discontinued in 1928. The initial success of the Model-T enabled Ford to expand in the 1920s with branches in England and other countries.

The mass-production technique and the vertical consolidations that gave Ford Motor Company control of its automobile distribution and sales as well as many of its input supplies became prototypes for other successful automobile producers and other manufacturers. Thus, Ford's strategic transactions successfully adapted the traditional working rules, converting them from limiting factors to complimentary factors in terms of automobile manufacturing, distribution, and sales. And continuous repetition of the transactions by ford and the other going concerns that copied Ford routinized the novel working rules so that they became customary ways of knowing and doing.

This section has described how changes in ceremonial norms are brought about through collective action to adapt the institutional system to technological changes. This involves changes in ceremonial tastes and in the ceremonial modes of behavior that perpetuate institutions and the customs and traditional beliefs around which institutions are formed. The changes derive from the nature of transactions and their relationships to custom and law. Transactions are guided by customs and the law, while laws slowly change to conform 
to customs, and customs evolve out of the routine practices of transactions. That is, customs are simply working rules that have been routinized by transactions, and customs change as working rules are changed and routinized by transactions.

\section{INTEREST-GROUP POLITICS}

The previous section described how ceremonial norms are changed by collective action through the medium of transactions between going concerns. Transactions are governed by customs and the law, while customs evolve out of the routine practices of transactions, and laws slowly change to conform to evolving customs. The section described how transactions change and routinize working rules, and routine working rules are customary ways of knowing and doing. And, since ceremonial norms are also customary ways, they change as novel working rules are routinized by transactions. Since laws are little more than codification of certain customary beliefs, they are slowly changed with changes in the underlying customs. However, the section did not elaborate on this latter point, noting that changes in the laws involve interest-group politics. This part of the chapter deals with interestgroup politics and changes in the laws.

The main idea in this part is that laws are founded on customs, and they are enacted and changed in a pluralist democracy by interestgroup interaction in which persons are free to form, join, quit, and dissolve interest groups, and interest groups are free to form, join, quit, and dissolve coalitions in support of or opposition to the enactment of new laws and changes in old laws. Consensus can be reached and human welfare enhanced in this way through interest-group

Reproduced with permission of the copyright owner. Further reproduction prohibited without permission. 
interaction alone. Moreover, a public-interest equilibrium results and can be maintained solely by the interaction of opposing interest groups and interest-group coalitions. The first section examines the relationship between law and sovereignty, and the second section describes how interest-group interactions bring about changes in the law.

\section{Law and Sovereignty}

Laws are based on customary ways of knowing and doing. They are codifications of the traditional beliefs that descend from the ancient past. They are all of the rules of ceremonial conduct of a nation-state in which the rules are enforced by a sovereign authority with powers to impose punishments for violations of the rules. There is, therefore, no systematic development of law until the appearance of a sovereign state with centralized police authority. The state rises in response to what appears to be a universal tendency for the institutions of a society to produce a legal order to preserve and enforce their ceremonial mandates. Thus, governments come into existence with social activities which threaten certain taboos that are held sacred by the more powerful institutions in a society.

Any social activity involves at least two groups, one composed of those persons who are directly involved in the activity, and others composed of those persons who are indirectly affected for good or bad by the activity. Those groups which are indirectly affected and who perceive their interests involved in the activity will organize to preserve their customs and to protect their interests. The resulting organized interest is a public, and insofar as the public commissions agents to operate in its behalf to control the activity, the 
institution of government comes into being. 11

The power to control is coercive power--the power to compel people to do things they would not otherwise do, and to desist from doing things they would otherwise do. And since the ultimate in coercion is physical violence, sovereign government is, at base, institutionalized violence--that is, violence that enjoys the sanction of law. This is so whether the form of government is monarchic or democratic, albeit that the coercive powers may be more restrained by custom and law in the latter than in the former.

The earliest governments were monarchical in which all sovereign powers--legislative, executive, and judicial--were vested in a single ruler who was supreme in ceremonial power, rank, and authority. The earliest surviving legal codes were nothing more than collections of ancient beliefs regarding ceremonial behavior that were assembled by such monarchs in discharge of their legislative powers. Much of what is now known of the governments and traditions of antiquity survives in the form of legal codes--the Code of Hammurabi (Babylonia), the Laws of Manu (India), the Mosaic Code (Palestine), and the Law of the Twelve Tables (Rome). Indeed, Roman law developed from the latter of these, and was summarized in the Corpus Juris Civilis at the time of Justinian. While the Roman law was eclipsed for a time by Germanic Codes after the decline of Rome, it was later revived and became the basis of most Continental European laws. ${ }^{12}$

However, development of the law in England followed a different course. Revolt of the barons against King John led to sealing the Magna Charta at Runnymede in 1215 . The document was sealed under duress, and the king repudiated it as soon as he was free from baronial 
coercion. Nevertheless, certain aspects of British law trace their origins to the Magna Charta. Among these are the right to trial by jury and the guarantee of habeas corpus which are traced to the clause against the oppression of subjects. Likewise, some have traced the House of Lords, and thus the British parliamentary system, to the Magna Charta provisions that secure certain feudal rights, privileges, dues of the barons against encroachment by the king. This and other matters led the king to convene a Curia Regis, or Great Councit, to consider judicial matters of the realm that affected baronial prerogatives. The chief effect of Magna Charta was to limit the sovereign powers of the monarch. ${ }^{13}$

Royal courts were created in partial response to the Magna Charta limitations on royal prerogatives, but also on the medieval theory that the laws administered by the King's Courts (King's Bench, Exchequer, and Court of Common Pleas) represent the common customs of the realm as opposed to the customs of local jurisdictions that were applied in baronial courts. The King's Courts served to undermine the local administrative powers of the landed aristocracy as against the sovereign powers of the monarch in England by providing recourse to litigants that was less partial than the often capricious judgments handed down in the local courts under baronial control.

Common recourse to the King's Courts gave rise to the Common Law that is now a basis of law in most English-speaking countries and other countries that were colonized by the British. ${ }^{14}$ The Common Law gave supremacy to the customs or judicial precedents over the administrative edicts of local aristocracies. This led to the doctrine of "supremacy of the law" under which not even the sovereign is above 
the law. It also led to the presumption of innocence under which a defendant is presumed to be innocent until his guilt is proven beyond a reasonable doubt. This, of course, placed the burden of proof on the plaintiff in civil litigations and upon the state in criminal trials. Finally, it led to common trials by jury in which matters of guilt and innocence must be decided on the evidences by panels of peers rather than by the aristocracy or by officers of the sovereign. The result of all of this was to separate and distinguish judicial powers from other forms of sovereign power.

Representative government emerged in England concomitant with but ostensibly separate from rise of the Common Law. It was a long, slow process that commenced in the thirteenth century with the Curia Regis, the kernel from which the House of Lords evolved. The House of Commons also originated in the thirteenth century with the convocation of knights and burgesses to report the consent of counties and towns to taxes imposed by the kind. However, the legislative powers of Parliament were not fully secure until the Glorious Revolution of 1688 which saw James II deposed and William III subject to great limitations on the powers of the crown. Moreover, it was not until the late nineteenth and early twentieth centuries that the House of Commons secured its ascendancy in British government. Likewise, it has only been. in recent times that the lower social classes have secured the franchise and have enjoyed full representation in the House of Commons. ${ }^{15}$

Because of the long history and continuity of its laws, the British Constitution is unwritten and flexible. The fundamental laws and principles of government that make up the British Constitution 
implicitly include the whole body of common and statutory laws of the realm as well as the practices and traditional workings of government. It can therefore be changed simply by acts of parliament, by judicial construction, or even by changes in customs. 16

On the other hand, many nations made sharp political and economic departures from the past in revolutions over the last two or more centuries. They have therefore had little in the way of indigenous legal customs on which to rely in constituting their new governments. Thus, they have used written constitutions to initiate governments and to specify the fundamental laws and principles of government by which they will be governed. For this purpose they have drawn largely from political philosophy or from legal precedents successfully applied by other nations, or from some combination of these two.

The Constitution of the United States is of this Tatter form-specific, written, and having superior sanction to the ordinary laws of the land. It is rigid insofar as it is subject to specifically prescribed processes of amendment which make it difficult to change by amendment. It consists of a preamble, seven articles, and presently, 23 amendments. It is based on the natural-rights doctrine formulated by John Locke, and eloquently restated in the Declaration of Independence. The delegated powers were constructed largely from so much of the Commentaries on the Law of England by Sir William Blackstone as deal with the sovereign powers of nation states. 17

The U. S. Constitution serves to delegate powers from the several states to the federal government. This is because powers of sovereignty reposed originally and solely in the states, and the states acquired their powers from the colonial charters granted by royal

Reproduced with permission of the copyright owner. Further reproduction prohibited without permission. 
decrees and by acts of the British Parliament. It was therefore ceremonially impossible for a federation to take place until the states relinquished some of their sovereign powers to the new republic. However, those powers not specifically delegated elsewhere in the Constitution were reserved to the states by the Tenth Amendment. As will soon be clear, these provisions no longer have much meaning because statutes and judicial constructions have preempted the powers of the various states and have opened them to invasions by federal authorities.

Article One delegates the legislative powers to a Congress composed of a House of Representatives with representation apportioned by population, and a Senate with representation apportioned by states. Each representative must stand for election biannually, and each senator every six years. Article Two delegates certain executive powers to an office of President. That office is filled by election every four years. Article Three delegates judicial powers to a Supreme Court composed of justices who are appointed for life by the President, and their appointments are confirmed by the Senate. The remaining articles deal respectively with relations of the states, amendments to the Constitution, supremacy of the federal Constitution, and the conditions under which the Constitution was to be ratified.

The separation of powers into three branches is thought to create a system of checks and balances that will so diffuse sovereign powers as to preclude the concentration and usurpation of power by any one branch. For example, the legislative powers of the Congress are limited in three ways. First, both houses must pass each bill before it can be sent to the President for signature. Second, any bi11 passed 
by both houses may be vetoed by the President before it becomes law. However, a presidential veto may be overturned by a two-thirds majority in both houses. Finally, the constitutionality of any statute may be tested in the courts by any person who wishes to bring legal suit to that end, and if the statute is found to be unconstitutional, it will be set aside by the courts.

The executive powers of the President are likewise limited in three ways. First, he can generally take no actions without the statutory authority of Congress. Second, in those few areas in which he is empowered to initiate action his actions are subject to ratification by the Senate. And third, the constitutionality of any presidential action may be tested in the courts by any person who wishes to bring legal suit to that end, and if the action is found to be unconstitutional, it will be set aside by the courts. Finally, the Supreme Court and all of the lesser federal courts are limited to hearing only those cases that are properly brought before them through judicial process. The courts cannot initiate legislative and executive actions, nor can they undertake review of such actions upon their own initiatives.

The U. S. Constitution also places other limits on the sovereign powers of the federal and state governments. These limitations are contained chiefly in the first nine amendments, the so-called "Bill of Rights," and the fourteenth amendment, the equal protection of the laws amendment. The essence of these amendments is to secure individual civil liberties from invasion by sovereign powers.

The U. S. Constitution with its various amendments is a very brief but vastly important statement of the fundamental laws and 
of government for the United States. Beneath the constitutional veil lurks an enormous body of statutory, admiristrative, and case law. Statutory law embodies all of the enactments of the Congress and the legislatures of the various states that have been signed into law by the President and the state governors. Administrative law embodies all of the rules promulgated by all of the regulatory agencies created by the federal and state governments. And case law embodies all of the judgments rendered by all of the courts in the land.

Despite the difficulties in making formal amendments, the federal Constitution has been elaborately embellished to extend and increase the sovereign powers of the federal government into what was formerly the constitutionally sanctified domain of the states and the realm of individual freedoms. This has been accomplished by statute and judicial construction relying chiefly on the interstate commerce and implied-powers clauses of Section 8, Article one of the Constitution. The interstate commerce clause delegates to the federal government the exclusive power to regulate international and interstate commerce. The implied-powers clause gives Congress the power to enact whatever laws are necessary to execute the other powers expressly delegated to it. $^{18}$

Until the late 1930s, Congress exercised its powers under the interstate commerce clause exclusively with the regulation of transportation that crossed state boundaries. The agency for regulation, the Interstate Commerce Commission, was created by statute in 1887 to regulate the private railroads that were ascending at that time to dominate the economy. Case law generally affirmed a strict, literal interpretation of the interstate commerce clause that limited 
federal regulation to those activities that literally and physically crossed state boundaries.

However, the depression that plunged the country into economic chaos during most of the 1930s spawned a rash of recovery legislation during the pre-World War II administrations of President Franklin Rooseve1t. The resulting statutes constituted a massive expansion in the federal regulation of private business whether or not the business activities physically crossed state boundaries. Hardly any aspect of American economic life remained free from federal regulation. This likewise constituted a massive invasion of the states' domains and a federal preemption of their sovereign powers.

The courts, relying on the precedents of strict and literal interpretations of the commerce clause, responded by declaring crucial recovery statutes unconstitutional. However, the Supreme Court slowly came to a more liberal interpretation, one that simply confirmed a social trend already established in practice. In 1937, the Court handed down a landmark judgment that effectively removed any constitutional bar to the expansion of federal control of private social activities, economic or otherwise. The case was the National Labor Relations Board vs Jones and Laughl in Steel Corporation, and it was the constitutional test of the National Labor Relations Act. In order to uphold the statute, the Supreme Court had to so.broaden its interpretation of the interstate commerce clause that virtually any activity that can be shown to affect the general welfare may now be construed as in interstate commerce for purposes of exercising federal sovereign powers.

The Jones and Laughtin case laid to rest any serious question of 
states' $^{\prime}$ rights, and it opened the way to the unbridled proliferation of federal regulatory agencies. The federal structure is literally plastered with acronyms representing the institutions that have since been created by congressional statute to regulate nearly every aspect of human existence in the United States. The problems of regulation and regulatory standards had become so acute by the end of World War II that Congress found it necessary to enact the Federal Administrative Procedures Act in 1946. The Act simpiy standardized and codified the customary procedures that had evolved out of the rationing, bargaining, and managerial transactions involving regulatory practice and that had proven to be ceremonially viable in the institutional system.

There are no expressly stated constitutional provisions for the creation of federal regulatory agencies. Hences they have been created under the implied powers clause, and they are generally considered to be parts of the executive branch of government. Their governing boards and chief administrators are therefore appointed by the President and their appointments are confirmed by the Senate. Even so, most such agencies function with a high degree of autonomy under the statutes that created them. This is because they are presumed to be staffed with persons possessing a high level of technical expertise in the areas of their regulatory powers. And they function to provide expert control over social matters in which neither the Congress nor the courts possess technical competence.

For these reasons, the statutes under which regulatory agencies are established generally delegate legislative, executive, and judicial powers to be exercised in the technical realm in which the agencies 
are to operate. Thus, such agencies make the rules by which they wi11 regulate, and under which the regulated going concerns will operate. Moreover, the agencies enforce the rules, adjudicate in the prosecution of going concerns that are suspected of being in violation of the ruies, and impose sanctions on those institutions found guilty of rule infractions. All of these matters are subject to review through appropriate appeals to the federal courts. However, the court system will not hear an appeal until all administrative remedies have been exhausted. Likewise, it will not exercise original jurisdiction, hear new evidence, or place itself in the positions of agency hearings officers in exercising judgments on evidence.

The emerging system of federal regulation of heretofore private activities has been criticized on several grounds. An important criticism argues that Congress has abdicated its legislative authorities and has wrongly delegated its legislative powers to autonomous agencies that are directed by officials who are appointed and who are not accountable back to the electorate. On the other hand, the agencies are accountable to congress. They are subject to audit by the General Accounting Office, and they are dependent on Congress for funding of their operations. Congress may eliminate an agency or change its operations either by statute or by fiscal controls. And since Congress is accountable to the electorate, it is argued that regulatory agencies are 1 ikewise accountable through Congress.

Another important criticism argues that endowment of a single agency with legislative, executive, and judicial powers blurs the tradition of separation of powers that is supposed to characterize the federal government. On the other hand, it is argued that so long as 
Congress retains the legislative power to change or eliminate an agency, and so long as going concerns that are subject to agency rules have appellate recourse to the federal court system, the integrity of the checks and balances principle is preserved. The point is that there does not now appear to be any further constitutional or commonlaw ground for turning back the ever-deepening waves of federal regulation of private social activities in the United States. It has become a solid fact of American life and nothing short of cataciysmic revolution is likely to change it--if, indeed, even that can change it. The whole body of administrative law, and a substantial body of case law has grown out of the regulatory process both at the federal level and at the state level. These laws along with the bodies of statutory and constitutional laws that make up the American legal system represent the institutional responses to the technological changes that have thrust humanity into the twentieth century. They are codifications of traditional beliefs that descend from the past. They are based on customary ways of knowing and doing, and they raise ceremonialism and institutional rigidities to their zenith by giving them the force of law--the power of rules that can and will be enforced by the institutionalized violence of sovereign government if necessary.

Interest Groups and the Law

The first part of this chapter described how institutions are adapted to technological changes through collective action. According to this idea, the customs and traditions, the ceremonial norms around which institutions are formed, are changed by transactions between going concerns in which the transactions change and routinize working 
rules regarding the new technologies. And since customary ways of knowing and doing are simply routine working rules, the customs change with routinization of new working rules.

This part of the chapter considers how the laws are slowly changed in accord with certain evolving customs. The immediately preceding section described the relationships between 1 aw and sovereignty--that laws raise ceremonialism to its greatest tenacity by placing it within the enforcement powers of sovereignty. Thus, customs that are given the force of law are more difficult to change than those that do not possess that force. And to change working rules that are specified in law sometimes requires first changing or relaxing the applicable laws. Laws are enacted and changed in a pluralist democracy by interest-group interaction in which persons are free to form, join, quit, and dissolve interest-groups, and interest-groups are free to form, join, quit, and dissolve coalitions in support of and in opposition to the enactment of new laws and changes in old laws.

A pluralist democracy is founded on the principle of process democracy, ". . .that institutional arrangement for arriving at political decisions in which individuals acquire the power to decide by means of a competitive struggle for the people's vote." 19 While the "process" in process democracy is related in terms of inputs and outputs, the struggle for the people's vote is group process in which the struggle is carried on inside and between groups--institutional groups like labor unions, trade associations, business corporations, universities, political parties, units of government, churches, etc., and factions and splinter or subgroups of institutional groups.

Reproduced with permission of the copyright owner. Further reproduction prohibited without permission. 
Chapter II above described the attributes and functions of institutions generally in terms of the social sciences, and Chapters IV and V expanded on the description in terms of institutional economic theory. The contents of those chapters generally apply to the interest-group politics of pluralist theory. It is, therefore only necessary to summarily relate key aspects of the former to the latter.

It was explained in Chapter $V$ how all of society is a network or structure of interlocking and interrelated institutions. The social values commonly cherished by individuals are a product of socialization carried on by institutions, and they are realized through memberships in institutions and institutionally-related groups. Individuals commonly occupy positions in several institutions--some voluntary and some involuntary. Involuntary memberships result from chance of birth and the like over which the individual has no control. However, the point is that individuals are simultaneously members of several potential interest groups (surrounding institutional values that are so universally held that they are not actively politicised), and one or more organized interest groups.

An organized interest group is a politicized interest group-one which actively seeks to influence political decisions to affect particular outcomes regarding the selection of ends-to-be-reached and the employment of means toward the selected ends. Again, from Chapter $V$, it is recalled that such institutional groups are structured by ceremony, and persons occupy positions within the structure that equip them with ceremonial roles to play. The rank, status, and power to wield influence both within and without the organization is a function of both one's position in the organization, and the position 
of the organization in relation to other institutions in the system. Which position one acquires in an organization is the product of a number of ceremonial factors that depend on the nature of the institution involved. However, the matter generally comes down to how meticulous one is in adhering to the ceremonial taboos and in employing the ceremonial totems of the group, and of the positions one seeks within the group. In the final analysis, it is how well the image one projects compares with the ceremonial expectations specified in the institutional norms. In the terms of elite theorists, it is the range of skills and resources one possesses--knowledge of organization, ability to manipulate word symbols, and professional competence. It is one's connections--schools, church, social clubs, other institutional connections--or lack of connections that determine one's access to positions of institutional power, rank, and prestige. ${ }^{21}$

All organizations are controlled under their ceremonial norms by the few persons who occupy the highest positions in the organization, the positions that bestow the highest rank and status on their incumbents. Those persons speak for the organization, and they wield whatever external influence and power the organization enjoys. That is, all organizations are under the titular directions of ceremonial elites. The range of discretionary powers enjoyed by an elite is a function of the ceremonial constraints of the organization it directs. As noted in Chapter IV above, this is chiefly a matter of the traditional values and customary ways of knowing and doing that descended from the past.

The obvious individual inequalities under these arrangements may appear to be inherently undemocratic in terms of the classical liberal 
concept of democracy. However, democracy is preserved, according to a pluralist concept of democracy, so long as the inequalities are dispersed and not cumulative. That is, so long as the persons who occupy positions of influence in one organization do not enjoy the same advantages in all organizations, and so long as such positions are not all occupied by persons from the same ethnic or social strata. Dispersed and noncumulative inequalities are evidences of social mobility in a society by which it is possible for almost anyone who seriously seeks a position of influence to attain it. This is most likely to result in societies in which organizational memberships are predominantly voluntary, and pluralist societies are generally of that sort. 22

Organized interest groups will attempt to influence political decisions regarding the outcomes of social activities. The usual approach is to seek the enactment of laws that will increase the proportionate, incremental share of the benefits more than the increase in the proportionate, incremental share of the relevant costs--or, conversely, laws that will decrease the proportionate, incremental share of benefits less than the decline in the proportionate, incremental share of costs--that accrue to its constituents in any authoritative distribution of benefits and costs. And since the law is concerned with the distribution rather than the creation of benefits and costs, the success of one interest-group will be at the expense of other interest groups, both potential and organized. ${ }^{23}$

Assume, for example, the successful innovation of a new technology for which new working rules are being routinized by transactions to integrate the technology into the institutional system. 
Some indirectly-involved institutions may find their interests adversely affected by the customs evolving from the transactions. Assuming further that there are no private counter-measures open to the indirectly-involved institutions, they may either acquiesce in the activities and silently suffer the adverse effects, or they can press for laws that protect their interests. If they seek relief through the enactment of new laws or the changing of old laws, they may seek either prohibition of the new technology or proscription of the new working rules, or public compensation for their losses. Failing the prohibition, they would seek proscription. And failing proscription, they would seek compensation.

Access to changes in the $l a w$ is through the agents of sovereignty- the interest groups that make up the executive, legislative, and judicial branches of government, and whose interests are the laws themselves and the preservations and expansions of their own power bases. The executive interest groups are addressed by counsel to seek changes in administrative laws. The legislative interest groups are plied by lobbying to obtain desired statutory changes. And, failing both of these, the judicial interest groups may be petitioned for judgments that affect changes through case law. ${ }^{24}$

of course, any effort to initiate changes in the law will precipitate counter actions by interest groups that will be adversely affected by the proposed legal change. Moreover, each opposing faction will en1ist support from other interest groups that can be convinced that their interests are likewise affected or that can be induced into a coalition by other means. The point is that there will be at least three factions surrounding any proposed change in the law-- 
a coalition of interest groups supporting the change, one or more coalitions of interest groups that either oppose the change outright or stand ready with alternative changes, a coalition of the interest groups that are competing for the people's votes.

The most likely outcome of these ceremonial processes of legal change is one that either departs as little as possible from antecedent customs and laws or that produces more votes than it loses for the interest groups in the vote-conscious coalition. Judiciaries are more inclined to the former, and legislatures to the latter. Either way, no change is likely to occur until the aggregate size of the constituencies behind the interest groups favoring the change is greater than the aggregate size of the constituencies behind the interest groups clearly opposing the change. And that division will depend on how each group perceives and evaluates its alternatives in terms of its proportionate benefits and costs. ${ }^{25}$ Finally, how each group evaluates its alternatives will depend on the ceremonial values that are weighted into the applicable benefits and costs.

An example that illustrates many of the foregoing points is urban renewal in the United States. To understand the institutional explanation of that program, one must pick up the thread in the preceding part of this chapter that described the transactions dealing with innovation of the automobile. It is recalled that integration of railroad technology had left urban form essentially monocentric around a central railroad terminal. Commerce and industry took place in a central business district in order to minimize transportation costs. People tended to live in and immediately adjacent to the central business district for the same reasons, and the central core therefore 
had high population densities. Land rents, wages, and net income were higher in the core and declined with distance from the core, and transportation costs and the costs of goods increased with the distance from the core.

It is also recalled that innovation of the automobile succeeded because of the expectation that, under the right conditions, it could provide personal portal-to-portal passage for its owner commencing at any time of the day or night, and it could do so with unprecedented speed, comfort, privacy, and hauling capacity. Finally, it could provide these services at less operating and maintenance cost than a stable of horses. The expectations that fostered innovation of the automobile were largely realized by the end of World War II, and the corollary improvements in the automotive technology since that time have simply extended and consolidated the social gains attributable to the automobile.

It was these two social phenomena that led to the urban redevelopment program in the United States--the monocentric urban form centered on a railroad terminal, and the passenger automobile with its cargo counterpart, the truck. As the horse changed the distribution and composition of settlements from the time of the ox, and the railroad changed them again in the nineteenth century, so the automobile and the truck changed them in the twentieth.

Railroads continued to dominate intercity transportation of passengers and freight until the end of World War II. However, intracity transport of freight was shifted from the horse-drawn wagon to the motor truck commencing after World War I. Likewise, both engineand motor-driven trolley systems were expanded so that these two 
events made it possible for some residents to move farther away from city core areas. Thus, the first waves of suburbanization commenced in some American cities as early as 1920. Of course, this did not particularly affect central business districts that continued to be dominated by intercity railroad terminals. However, it did affect the core residential arrangements, and upward pressures on residentia] rents were arrested as population growth was largely absorbed by the first suburbs. 26

A trend toward moving passengers between cities by automobile, bus, and aircraft was clearly evident at the end of World War II, and the drop in rail passenger traffic was so great that many railroads simply ceased to carry passengers. The personal private automobile was more convenient, and the bus less expensive for short intercity trips. And the aircraft was no more expensive than the train, but it was much faster on long intercity trips. At the same time, the intercity transportation of certain kinds of goods was shifted from railroads to motor trucks and aircraft. The trucks could eliminate transshipment costs by moving goods directly from a seller in one city to a buyer in another--something the railroads could not generally do. And air freight is much faster than rail freight even though it is also more expensive. Finally, private automobiles were putting intraurban trolleys out of business as people increasingly drove their family cars to and from work and shopping.

The effects of these changes were many. The changes accelerated the move of upper- and middle-income residents to suburbs followed by the commercial businesses that served them and by the large-scale enterprises that were liberated from central rail terminals and high 
rents by the shift to intercity truck transportation. The metropolitan area was becoming polycentric with a large central city surrounded by many smaller suburban centers. Indeed, cities like Los Angeles, California that experienced their most expansive growth after the initial integration of automotive technology have developed without one large central city, and they consist mainly of many small centers connected by highway corridors and patchworks of residential housing. However, the suburban dispersal of housing and business reduced the economic functions of older metropolitan core areas to producing highly specialized regional services and providing agglomerative economies for certain kinds of high-risk enterprises. ${ }^{27}$

The decline in demands for core-area sites were felt in lower rents for both residential and commercial properties in those areas while rents and incomes were increasing in the suburban rings that were developing around central cities. And since the suburban rings were beyond the central-city boundaries, the corresponding loss in core real-property values meant a shrinkage in property-tax bases, and thus an increase in tax rates or a reduction in urban-tax revenues to finance urban services. In many cases it meant both.

The continued diffusion and integration of automobile technology was also producing a further revolution in agriculture. The mechanization of farming was increasing the returns to large-scale agricultural production at the same time that agricultural lands in war-torn European countries were being restored to production. The result was a decline in foreign demands for American agricultural goods while rises in American agricultural productivity were increasing the supplies of those goods. Thus, farm incomes were held down during

Reproduced with permission of the copyright owner. Further reproduction prohibited without permission. 
a period in which other incomes were rising. Families were finding it increasingly difficult to subsist on small acreages, and they were more and more inclined to abandon farming in favor of urban employments.

The natural refuge for the recently unemployed rural-to-urban immigrants was the now low-rent housing left in the core areas of central cities by upper- and middle-income families. The cultural shocks of life-style changes and the lack of skills and urban employment opportunities made adjustments for the new wave of immigrants difficult. Moreover, many of the immigrants were southern negroes, and their plights were further complicated by the racial prejudices that confronted them in their new environments. Many found it difficult, if not impossible, to subsist in their new homes, and their landlords found it impossible to collect rents high enough to cover all taxes and maintenance costs. The result was a rapid depreciation in the quality of affected neighborhoods, and an enormous increase in the demand for urban services at precisely the time when urban property-tax revenues to finance such services were shrinking with declining real-property values. ${ }^{28}$

The myriad of transactions that integrated the automotive technology and secured the social gains from that technology changed inter-institutional arrangements so that many institutions experienced substantial gains in net present values. But some institutions found it impossible to adapt, and those institutions suffered reductions in net present values. It was clearly too late to prevent innovation of the automobile or to proscribe the working rules that had already been routinized surrounding that technology by the end of World War II.

Reproduced with permission of the copyright owner. Further reproduction prohibited without permission. 
The only relief open to the adversely affected going concerns was public compensations to eradicate or ameliorate the adverse effects.

Affected going concerns, therefore, organized interest groups and the interest groups formed coalitions to press for laws that would compensate them at the expense of others for the losses they suffered. And other persons and institutions that saw their interest adversely affected by the proposed redistributions likewise formed interest groups and coalitions to protect their interest. The list of going concerns and interest groups is much too long to examine here. However, over the years, it has included such luminaries as the National Urban League, the Federal National Mortgage Association, the National Association of Home Builders, the AFL-CIO, the Bureau of the Census, the Federal Reserve Board, the National Association of Real Estate Boards, the U. S. Conference of Mayors, and the Ford Foundation. The list also includes an imposing number of private companies-predominantly banking and insurance corporations. ${ }^{29}$

Likewise, the details of their opposing views as well as the impressive list of resulting statutes, regulations, and legal decisions go beyond the scope of this treatise. However, the result was a plethora of laws that created more federal and state agencies and authoritative redistribution programs for the agencies to manage. Among the agencies created to date to deal with the automobile effect were the cabinet-levei, federal executive departments of Health, Education and Welfare (HEW), and Housing and Urban Development (HUD), and all of the existing and new federal administrative agencies that fell within their statutory areas of concern were organized under them for program coordination and funding. of course, the redistribution 
programs are managed by the administrative agencies. ${ }^{30}$

One such program, Urban Redevelopment, was initiated as Title I to the Housing Act of 1949. The name was a euphemism for slum clearance, and the latter a euphemism to some people for eliminating what they considered to be undesirable residents. The naive saw the program as a way to restore the older and decaying central cities to their former and rightful eminence. The practical-minded found the program to be a way of acquiring or preserving income at public expense. Still others found that the program imposed substantial costs on them by disrupting their life-styles and forcing them to move from the low-cost housing in familiar neighborhoods populated by friends to housing they could not afford in unfamiliar surroundings populated by strangers. Moreover, the initial program foreseeably reduced the standing stock of urban housing for those low-income families that could least afford to arrange other accommodations. ${ }^{31}$

The name was later changed to Urban Renewal, and the program became the umbrella for a number of subsequent laws of a similar sort. Despite the detractions implied by the above remarks, the accomplishments of the program are as impressive as they were costly. The program did assist the cities that completed urban-renewal projects to make many needed physical adjustments to the automobile effect described above. Likewise, the skylines of many cities are now adorned with stately public structures where once stood only dilapidated older houses. Finally, some high- and middle-income families have found the renewed urban core an attractive place to make their homes, and they have moved back to the city from the suburbs. Even so, the modern, industrial city is not and perhaps never can be 
what it was before the automobile.

The conclusion of this section concludes the chapter. The chapter has attempted to describe how institutions adapt to technological change through collective action. The principle of adaptation is found in the relationships between transactions, customs, and law. Transactions are structured by custom and law, while customs evolve out of the routine practices of transactions, and laws are slowly changed to bring them into accord with the evolving customs. Transactions between going concerns change and routinize working rules, and since customs are simply routine working rules, they change with the routinizing transactions.

Since laws are little more than codified customs, they are changed to bring them into accord with the evolving customs. This last section has attempted to illustrate how laws are changed in a pluralist democracy by interest-group interaction in which persons are free to form, join, quit, and dissolve interest groups, and interest groups are free to form, join, quit, and dissolve coalitions in support of or opposition to the enactment of any new law or change in any old law. Consensus can be reached and human welfare enhanced through interest-group interaction, and a public-interest equilibrium can be maintained solely by the interaction of opposing-interest groups and interest-group coalitions. 
END NOTES, CHAPTER $X$

${ }^{1}$ Adapted from Commons, Economics of Collective Action, passim.

${ }^{2}$ An idea expanded by Gordon C. Bjork, Private Enterprise and Public Interest; The Development of American Capitalism, (Englewood Cliffs: Prentice-Hal1, Inc., 1969).

3 Henry Campbe11 Black, Black's Law Dictionary: Definitions of the Terms and Phrases of American and English Jurisprudence, Ancient and Modern, 4th ed., (St. PauT: West Publishing Co., 1968), pp. 345-46.

${ }^{4}$ Commons, Institutional Economics, p. 902.

${ }^{5}$ Adapted from Commons, Economics of Collective Action, passim.

6 Ibid.

${ }^{7}$ Adapted from R. W. Howard, The Great Iron Trail, (New York: Putnam, 1962).

8 Leon Moses and Harold F. Williamson, Jr., "The Location of Economic Activity in Cities," American Economic Review, LVII (May, 1967), pp. 211-22.

9 Adapted from B. G. Elliott, and E. L. Consoliver, The Gasoline Automobile, (New York: McGraw-Hill Book Co., Inc., 1932).

10 Adapted from Allan Nevins and F. E. Hill, Ford: The Man, the Times, the Company, (New York: Charles Scribner's Sons, 1954). Ford: Expansion and ChaTlenge, 1915-1933. (New York: Charles Scribner's Sons, 1957). Ford: Decline and Rebirth, 1933-1962, (New York: Charles Scribner's Sons, 1963).

${ }^{11}$ Dewey, Public and Its Problems, pp. 34-35.

${ }^{12}$ The Columbia Encyclopedia, 3d ed., (New York: Columbia University Press, 1963), p. 1186.

13

Ibid, pp. 1280-81.

${ }^{14}$ Ibid, p. 460.

15 Ibid, pp. 1604-1605.

${ }^{16}$ Ibid, pp. $479-80$.

17 Ibid, p. 480.

Reproduced with permission of the copyright owner. Further reproduction prohibited without permission. 
${ }^{18}$ Ibid, p. 18. Ronald A. Anderson, Government and Business, 4th ed., (Concinnati: South-western Publishing Co., 1965), pp. T-14, 233-39.

${ }^{19}$ Joseph Schumpeter, Capitalism, Socialism and Democracy, 3d rev. ed., (New York: Harper and Row, Inc., 1962), p. 269. Anthony Downs, An Economic Theory of Democracy, (New York: Harper and Row, Publishers, 1957).

${ }^{20} \mathrm{Cf}$, Truman, Governmental Process, pp. 501-25, 534-35.

${ }^{21}$ Cf, Michels, Political Parties, passim.

${ }^{22}$ Pitirim Sorokin, Social Mobility, (New York: Harper and Brothers, 1927), pp. 8-9. Robert Dah1, Who Governs? Democracy and Power in an American City, (New Haven: Yale University Press, 1961), pp. 85-86.

${ }^{23} \mathrm{Cf}$, Latham, Group Basis of Politics, passim.

24 Ibid.

25 James M. Buchanan and Gordon Tullock, The Calculus of Consent, (Ann Arbor: University of Michigan Press, 1962).

26 Moses and Williamson, "Location of Economic Activity."

27 Raymond Vernon, The Changing Economic Function of the Central City, (New York: Committee for Economic Development, 1959), pp. 40-46. David L. Birch, The Economic Future of City and Suburb, (New York: Committee for Economic Development, 1970), pp. 1-15.

${ }^{28}$ A Decent Home, (Washington, D. C.: U. S. Government Printing Office, 1969), pp. 7-36. Building the American City; Report of the National Commission on Urban Problems, (Washington, D. C.: U. S. Government Printing Office, 1968), pp. 40-55, 355-61.

29 Decent Home, pp. 232-34.

30 Basic Laws and Authorities on Housing and Urban Development:

Revised through January 37, 1971, (Washington, D. C.: U. S. Government Printing Office, 1971), passim.

${ }^{37}$ Otto Davis and Andrew Whinston, "Economics and Urban Renewal," Law and Contemporary Problems, XXVI (Winter, 1961), 106-17. Jane Jacobs, The Death and Life of Great American Cities, (New York: Random House, Inc., 1967). A. H. Schaaf, "Public Policies in Urban Renewal: An Economic Analys is of Justifications and Effects," Land Economics, XL (February, 1964), 67-78. Martin Anderson, The Federal Bul1dozer, (New York: McGraw-Hi11 Book Co., Inc., 1964). 


\section{CHAPTER XI}

\section{CONCLUSION}

This work commenced with the contention that progress toward a more complete theory of urban affairs might be made by integrating institutional economic theory and elements of the more orthodox economic theory with aspects of pluralist theory from political science and relating the resulting whole in an urban context. This is the last and concluding chapter in the work that attempted that synthesis. The chapter briefly summarizes key elements of the intervening chapters, and it suggests possible on-going implications that might be deduced from the work.

\section{SUMMARY OF MAJOR POINTS}

The synthesis commenced with an exploration of selected social sciences literature to establish a definition of the word "institution" that would serve throughout the remainder of the work. The definition finally settled out of Chapter II was that:

An institution is an organized social group which has evolved from and is united with some particular system of cultural values, and it serves through processes of social control to stabilize social interaction by preserving and perpetuating those values in the society of which the institution is a part.

Equipped with the foregoing definition, the work examined institutions in light of selected elements from institutional economic theory, orthodox economic theory, and pluralist political theory. Following is a brief summary of the major points made in the preceding chapters. 


\section{Institutional Economics}

There are two main branches of institutional economic theory. The first branch deals with the forces in society that tend toward instability and revolution. The second branch deals with the forces that tend toward adjustment and stability. The former is the product of Thorstein Veblen and Clarence Ayres, and the latter is that of John R. Commons. The former branch has been described as institutional economics in this treatise. The second is properly the same, but it has been called the economics of collective action, and it was described along with interest group-politics in the chapter on pluralism.

Institutional economics views economic phenomena as products of institutional systems in which markets will exist subject always to institutional constraints. It concentrates on the institutional milieu in which markets exist, and the feed-back effects of market activities on institutional arrangements--the ways in which society's uses and changes in uses of material devices structure and restructure society itself. These effects occur only in the very long run, and institutional economic time periods are therefore anthropological time periods, periods of sufficient duration to study the institutional changes that result from economic and quasi-economic activities.

The very long run is a longitudinat dimension in time, according to John Dewey and Clarence Ayres, called an ends-means continuum--a continuum of on-going life processes. The present is a constantly changing instant of time which divides the past from the future. Everything that exists in the present is the effect of causes from the past, and those same effects are the means to ends that lie in the future along the 
the continuum.

Lying in the future along the continuum, possible future ends exist only in human contemplation, and they will not become actual states of being unless man chooses to bring them into being and actuates choices by organizing and employing means to attain his chosen ends. Ends-in-view are alternative and competing, and the selection of one set of ends may preclude the possible achievement of competing ends because means are either too scarce to permit the attainment of all sets, or the alternative sets of ends may be incongruous.

Ends are not ends-in-themselves. Once they are secured, ends become means to on-going ends that lie even farther in the future along the continuum. Ends have value because people, through institutions, set them out as desired, while the value of means is partly determined by their instrumentalism in securing desired future ends. The questions raised by this concept of an ends-means continuum are: Why and how are particular ends-to-be-reached chosen from among alternative and competing ends-in-view? And what determines how means are chosen and organized toward achievement of the ends selected?

According to Thorstein Veblen and Clarence Ayres, the practice of ceremonialism supplies part of the answer. Ceremonialism is the instrument of the institutional system for discharging its social control functions, and it is the subject of Chapters IV and V. Ceremonialism transmits culture and achieves the social control required to maintain social stability by conferring and validating status upon members of society.

Ceremonialism is founded on the beliefs of tradition that inform the present from the past. Ceremonial values are transmitted by the 
legends and myths that pervade the literature and drama of a culture and that describe the mystical powers of ancestors and the tribal triumphs of the past. Such myths transmit the totems and taboos of the culture. They promote cultural status systems and social order by teaching persons the correct ethical and aesthetical values to hold.

Ceremonialism socializes members of society by teaching and reinforcing them from birth until death with the ancient systems of social status and rank. They come to understand and accept their positions and the roles they must play in society. They accept the mystical potency of each social rank, and they come to recognize and respect the distinctions of rank that distinguish themselves from others both above and below them in the institutional hierarchies of society. Ceremonialism also teaches people how to acknowledge ranks and validate statuses through ceremonial exchange, ceremonial gift-giving and ceremonial destruction of goods. And it teaches them of the serious consequences of failure to know and abide by the ceremonially-sanctioned modes of behavior. Lastly, the cultural ways of knowing and doing, the taboos and the mana of rank and status are reconstructed and reinforced by mystical ceremonies--awe-inspiring religious liturgies, graphic arts, literature, and dramas that extol the tribal values of culture. A11 of this ceremonial activity augurs social stability by involving persons in webs of institutionally-sanctioned social interaction. It is a result of socialization and social control accomplished by institutions that are attempting to preserve and perpetuate traditional value systems. Ceremonialism is therefore backward-clinging in terms of the endsmeans continuum. It rationalizes present euphorias in terms of the powers of mystical past causes, and it brooks no departures from 
customary techniques. It measures the desirability of possible future ends in terms of the values that descended from the past, and it prescribes antecedent techniques as the best methods for employment of means toward attainment of future ends. The ceremonial dimension of society attempts to extend the past forever into the future.

On the other hand, institutions are not always successful in perpetuating cultural values and preserving social stability. Indeed, new institutions rise, some institutions decline, and some disappear a)together. Why does this happen in the face of the powerful ceremonial hold on the past? According to Thorstein Veblen and Clarence Ayres, the answer is found in the social consequences of new technologies. Chapter VI above distinguished technology from human skill and technique. Technology is that quality of a tool that enables it to be substituted for human effort in the creation of goods and services having human value. Human skill is the propensity and ability to apply technique to the use of tools, and techniques are the methods by which humans employ tools in production. Technique is therefore the procedure by which ends are converted to means as an on-going process. Technology is continuous, dynamic, and progressive. The continuous and dynamic qualities of technology were described in Chapter VII. Technology is continuous because the invention of new technologies is based on scientific knowledge, and such knowledge results from empirical verification and critical testing of hypotheses that purport to link events causally. Scientific knowledge is continuous because it is based on scientific discoveries, and such discoveries are cumulative in the sense that they are founded on the reservoir of scientific knowledge that has been built up from prior discoveries. Insofar as

Reproduced with permission of the copyright owner. Further reproduction prohibited without permission. 
the invention of new technologies is founded on scientific understanding, technology is likewise continuous.

The innovation of new technology is dynamic because it opens opportunities to allocate resources (employ means) in ways that are different from the ceremonially prescribed methods that descended from the cultural past. It may also change the ends selected to be attained because it brings ends into view that were previously beyond available means. The innovation of new technology will therefore also open opportunities to change traditional social statuses and ceremonial systems of rank, affording new avenues of social mobility toward higher relative statuses for some persons and lower relative statuses for others.

The progressive character of technology was described in Chapter VIII. Insofar as new technology succeeds in substituting tools for human effort in the production of goods and services having human value it will produce a social dividend in the way of a greater surplus of social benefits over social costs. And since those benefits are distributed to enhance human welfare, the new technology will contribute to human progress. The distribution of the social dividend is a function of the institutional system in society, and the progressive quality of new technology is realized by the diffusion and integration of the technology throughout that system. In the integration process the institutional system is changed to bring it into accord with the new technology.

The dynamic and progressive features of new technology make it forward-urging in terms of the ends-means continuum, that of on-going 1 ife processes. However, these features bring technology into tension with tradition-bound ceremonialism, and the resulting environment is filled with conflicts between those persons whose ranks and statuses are

Reproduced with permission of the copyright owner. Further reproduction prohibited without permission. 
threatened, and those persons who stand to gain in position and status by the innovation, diffusion, and integration of the new technology.

To what extent new technologies are actually innovated and integrated depends upon the strength of ceremonialism in relation to the forward pull of the potential net social benefits expected from the new technology. In other words, it depends on the relative strength of institutional values and ceremonial resistances to changes. To the extent that new technologies are innovated, diffused, and integrated with the institutional system, some of the ceremonial norms and modes of behavior will become redundant and fade, causing some institutions to decline in influence, power, and importance. The question raised by the relationship between technology and ceremonialism is: How does society reconcile the tensions between new technologies and ceremonialism into social change and human progress?

Valuations

The answer to the foregoing question is found in methods for valuing social benefits and social costs, and in techniques for making social choices. Valuation methods are found in orthodox economic theory, and social-choice techniques are the concerns of political pluralist theory and of that branch of institutional economics called the economics of collective action. Chapter IX is concerned with the former and Chapter $X$ with the latter. This section of the summary covers Chapter IX.

The first step in reconciling the tensions between tradition-bound ceremonialism and forward-leaning new technologies is to accurately measure the benefits and costs of alternative courses of action. However, the values perceived by individuals and institutions are as multifarious

Reproduced with permission of the copyright owner. Further reproduction prohibited without permission. 
and disparate as society is pluralistic, and there are therefore a myriad of competing and conflicting values. Moreover, there is no simple or direct way to structure and weigh competing values in selecting ends-to-be-reached, and to organize and employ means to whatever ends are selected such that social welfare is enhanced.

Indeed, it is not always clear what social welfare is or how it should be measured. Nevertheless, orthodox economists argue that welfare can somehow be maximized if resources (means) can be allocated optimally. Vilfredo Pareto describes an efficient allocation as one in which means have been allocated such that it is impossible to improve anyone's welfare without adversely affecting the welfare of others. J. R. Hicks and Nicholas Kaldor maintain that, even though a Paretooptimal allocation of means exists, social welfare can be improved if social product is redistributed in such a way that gaining persons value their gains more than losing persons value their losses.

The "possibility theorem " of Kenneth Arrow holds that there are some conditions of choice under which neither market nor political arrangements will define a social-welfare function by which Pareto-maximum welfare can be measured or achieved. Notwithstanding Arrow's convincing arguments, the Pareto criterion remains a very compelling ideal to be as nearly achieved as possible. But, again, any movement toward that idea needs to be founded on empirically accurate valuations--valuations that weigh costs and benefits, where benefits are human satisfactions attained by achieving the most desirable sets of future ends, and costs are the alternative ends foregone to secure the benefits.

Both benefits and costs may possess internal attributes and external attributes. Internal attributes involve divisible (private, 
personal, visceral, aesthetic) values, while external attributes involve nondivisible (public, ethical, collective, institutional) values. Economists argue that goods and services that possess only internal (divisible and private) attributes may be provided through the pricing mechanisms of private markets.

Some economists have argued with conviction that goods and services possessing substantial externalities cannot be efficiently provided through private markets. This is because such goods and services are not divisible, and no one can be excluded from enjoying the benefits once they have been produced. Since they cannot be divided, such goods cannot be packaged and sold in consumer units. Persons therefore tend to "free ride" with such goods by understating their benefits and overstating their costs because they know that, once the goods have been created, they cannot be denied the benefits. Goods possessing substantial externalities are collective or public goods, and they must be provided by other institutional arrangements than private markets.

The alternative to private markets is, of course, the variety of governments in which public goods are said to be provided through the electoral process. Whatever the institutional process, the technique that is gaining currency is benefit-cost analysis--a technique in which annual benefits and costs are estimated and net social benefits are discounted back to a net present value. Several issues surrounding the technique raise questions about its viability as a means of valuing alternatives. The issues involve the following problems:

- Which external benefits and costs will be included?

--What pecuniary values are to be assigned to external benefits and costs?

Reproduced with permission of the copyright owner. Further reproduction prohibited without permission. 
--What social discount rate will be used to discount future benefits and costs back to present values?

--Over what useful life will the benefits and costs be discounted?

--What is to be maximized or minimized in the outcome?

--Which institutional values will dominate the process?

The benefit-cost analysis of social alternatives can lead to many different outcomes depending on how the foregoing questions are answered. And since each one can be answered a number of ways, benefitcost analyses can be manipulated to yield outcomes favored by one or another special-interest group. The problem in terms of the ends-means continuum is that the innovation of an otherwise justified new technology may be defeated through such manipulations by the forces of ceremonialism. Despite these obvious limitations, benefit-cost analysis may be the best available method for valuing social alternatives.

Which underscores the problem--values as perceived by individuals and institutions are as multifarious and disparate as society is pluralistic, and there is no simple or direct way to structure and weigh competing values regarding ends and means. The question remains: How does society reconcile tensions between ceremonialism and technology in selection of ends-to-be-reached and in employing means to the ends selected?

\section{Pluralism}

The answer to the foregoing question is found in the economics of collective action and in pluralist theory, particularly theories of interest-group politics. These bodies of theory and their relevance to urban affairs were described in Chapter $X$ above. Together, the two sets of theory help explain how institutions adjust to the disequilibrating 
influences of new technologies through changes in customs and laws. According to the theory of collective action advanced by John R. Commons, conflicts of interests occur between going concerns (or institutions) over the present and future uses of scarce resources. Resource scarcity is caused by intangible property rights--claims on streams of future incomes arising from the expected future employment of material things. The conflicts of interests are resolved by transactions (or ceremonial exchanges) that bring about exchanges of property rights between institutions. Transactions are limited by working rules (or ceremonial norms cloaked as traditions) in the form of custom and law, and each transaction is concerned with settling the particular working rules governing its own exchange. Customs evolve out of working rules that are changed and routinized by transactions.

There are three kinds of transactions--bargaining, rationing, and managerial. Bargaining transactions take place between going concerns with approximately equal bargaining powers. Bargaining transactions are voluntary arrangements and they tend to be juridical in nature. On the other hand, rationing transactions take place between legal superiors and legal subordinates. Rationing transactions are therefore involuntary arrangements, and they tend to be legislative in character. Finally, managerial transactions are likewise involuntary, and they concern the organized uses of properties and other rights established out of prior bargaining or rationing transactions. Managerial transactions tend to be executive in nature.

A11 transactions involve at least three elements--conflicts of interests caused by proprietary scarcity, interdependence of interests arising from the need for exchange, and order stemming from the need for 
working rules to facilitate exchange. Transactions function to convert conflicts of interests to interdependencies of interests. Transactions a]so create and change working rules where necessary to meet the needs of exchange.

The relevance of collective action to institutional changes, and thus to the resolution of tensions between ceremonialism and technology, is found in the relationship between transactions, working rules, customs, and laws. Transactions are structured by the working rules in customs and laws; working rules are changed by transactions to fit the needs of exchange, while customs evolve from new working rules that are routinized by transactions, and laws are slowly changed in accordance with the evolving customs.

Laws are customs that have been set apart by placing the coercive powers of the state behind their enforcement. Law does not come into being, therefore, until there is a sovereign state with centralized police authority. And such an authority rises in response to what is apparently a universal propensity for institutions to produce a legal order to enforce their ceremonial norms. Governments are therefore the institutional agencies for making, enforcing, and adjudicating laws. Making and changing laws are legislative functions, while enforcing laws is an executive function, and adjudicating violations and disputes under the law is a judicial function. Customs that have been given the force of law, are of course, more difficult to change than other customs.

The way laws are made and changed to conform with evolving customs in a pluralist democracy is explained by theories of interestgroup politics. The main idea is that laws are made and changed through interest-group interaction in which persons are free to create, 
join, quit, and dissolve interest groups, and interest groups are free to form, join, quit, and dissolve coalitions in support of or opposition to the enactment of any new law or the change of any old law. According to this idea, consensus can be reached and political stability maintained through the interaction of opposing interest groups while laws are in a perpetual state of adjustment.

This ends the summary of the key points that were expanded and illustrated in the preceding chapters. The summary has shown how the component theories--from institutional economics and political pluralism--were integrated in the main work. However, several additional points must be stressed. The first is to underscore the places where the component theories converge and overlap, and the possible normative relevance of that. The second is to point out the places where the theories appear to have import for urban affairs, and to consider the possible normative relevances in each case.

\section{INSTITUTIONAL FCCNOMICS AND PLURALISM}

One aspect of the contention in the first chapter of this work was that institutional economic theory, and selected elements of orthodox economic theory might be brought into productive synthesis with political pluralist theories. This part of the concluding chapter points to the places in the main text where it seems to this author that the component theories converge and overlap, and to the possible normative relevance of the results.

There were many places throughout the main text at which the component theories overlapped. However, ignoring the introductory and concluding chapters, the chapters in which institutional and other 
economic theories were significantly in union with political theories were Chapters II, IV, V, IX, and X. The institutional essence of those chapters was predominantly ceremonialism, vis technology. Chapters II, IV, and V related institutions to groups, and group activities to ceremonial activities. Chapter II defined institutions in part as human groups organized around particular sets of cultural values, and it sought to expand the definition by exploring the origins of institutions, social functions of institutions, the structure of institutions, and the nature of institutional influence and power. While Chapter II was a wide-ranging examination of the social-sciences literature on institutions, much of the literature was consistent with institutional economic theories, and the latter theories were consistent with some ideas espoused by political theorists like David Truman at one extreme, and C. Wright Mills at the other.

Chapters IV and $V$ explored ceremonialism and the social functions of institutions, noting that ceremonialism is the social mechanism by which institutions discharge their functions--in particular, to stabilize society by transmitting culture, organizing society, socializing members of society, and exercising social control. These aspects of institutional economic theory from the works of Thorstein Veblen and Clarence Ayres have good correspondence with political theorists like Harold Lasswell and David Truman, to name only two.

Chapter IX brought together the distilled works of many orthodox economists, and several other social scientists to examine the matter of human welfare, and of valuing social alternatives for improving on welfare. While the material in that chapter was not explicitly from institutional economics, the tone of the economic content was

Reproduced with permission of the copyright owner. Further reproduction prohibited without permission. 
institutional in character. Moreover, the institutional tone of the chapter was consistent with the interest-group theories of David Truman and Earl Latham.

Finally, Chapter $X$ combined the economics of collective action, a branch of institutional economic theory from the works of John Commons, with theories of interest groups from the works of political scientists like David Truman, Earl Latham, and Robert Dahl to explain how institutions adjust to technological change. Commons described how the customs around which institutions are organized are changed through what he called collective action. The works of Truman, Latham, and Dahl complemented that of Commons by offering an explanation of how laws are changed through interest-group interaction to conform with evolving customs.

of course, the fit between institutional economic theory and contemporary political theories is not perfect. For that matter, neither is the correspondence perfect between the two main branches of institutional economic theory. However, there are many points on which one or another aspect of institutional theory parallels, overlaps, or complements contemporary political theory. The opposite is also true, and drawing from political theory, it has been possible to augment and expand the body of institutional economic theory.

One might conjure up a great many possible implications from these conclusions. However, it seems that the principal relevance of this part of the tome lies in the essentially provincial nature of the social sciences in a real world that is inherently diverse, varied, and heterogeneous. The understanding of social phenomena is rarely achieved by attempting to explain it within the limits of a single discipline. If it is to be understood at all through the application of social 
theories, the theories must at least be eclectic--drawn from as many sources and disciplines as necessary to render a consistent explanation that has empirical validity and is relevant to real-world problems.

\section{INSTITUTIONAL ECONOMICS AND URBAN AFFAIRS}

Another contention at the beginning of this work was that progress toward a more complete theory of urban affairs might be possible by relating the synthesis in terms of urban affairs. The examples used to illustrate the component institutional and political theories were therefore directly related to cities, or they had a reasonably clear relationship to urban affairs. That is, they were either non-urban consequences of causes that were clearly urban, or they were urban consequences of causes that were non-urban.

of course, it was not possible to include every urban matter that might be meaningfully related to the synthesis. Thus, the urban phenomena usedwere selected on two bases. The first was according to how well the material could be adapted to the component theories, and the second was according to a time line that extended roughly from antiquity to the present. The theme that seemed to be most amenable to these bases was urbanization. Aspects of both technology and ceremonialism were accordingly illustrated by selected urbanization topics.

\section{Technology and Urbanization}

Chapters III, VI, VII, VIII, and X contain technology-related examples from the history and related theories of urbanization. The underlying notion in those chapters was that modern industrial cities represent the highest achievements of civilization and that they are 
the products of technological developments. Those developments commenced before recorded history and they continue to this very moment. As long as man progresses along the continuum of on-going life processes, technological development will provide the means of progress and increased urbanization and the embellishment of urban life will be one of its products.

The means-ends continuum, the continuum of on-going life processes, was illustrated in Chapter III by discussion of the Roman establishment of the City of London, England. The main idea in Chapter III was that a city is the effect of causes that lie in the past, and it is a collection of means to ends that lie in the future. It is the product of human deliberations and choices, and usually deliberations and choices that extend backward for many centuries in time.

Chapter VI employs a discussion of technological developments in agriculture as a way of deriving a definition for the word "technology." The urban relevance of agricultural development is that urbanization is, in the first instance, a product of improvements in agricultural productivity, and agricultural productivity is a function of technological developments in agriculture. The concluding part of Chapter VI describes how anatomical parts of man have been replaced in production processes by tools embodying successively more complex and instrumental technologies. These developments both improved agricultural productivities and enhanced human existence in modern industrial cities.

The economic principle of comparative advantage was used in Chapter VII to explain central-place theory, and central-place theory to explain the effects of internal economies of large-scale production in 
bringing about urbanization. Technology is a central feature in this chain of causes because it is improvements in technology that bring about increases in internal economies of large-scale production. And insofar as economies of scale bring about increased specializations, there are increased pressures for urbanization for it is in cities that specialization, the division of labor, reaches its highest level.

The invention and innovation of new technologies and effects of those innovations on urbanization was also described in Chapter VII. It was argued that the underlying factor in the change from prehistoric folk society to the pre-urban folk community was the change from the use of humans for motive power in agriculture to the use of oxen as draft animals. The technological change that moved society from the prehistoric and pre-urban folk community to the truly urban feudal city was the discovery of metallurgy, the subsequent improvements in tools, and the consequential increases in productivities. Finally, urban society moved to the era of the industrial city with the substitution of mechanical power technologies for animals in productive processes.

The progressive qualities of technology were illustrated using central-place theory again in Chapters VII and VIII to show how increasing degrees of specialization leads to agglomeration of institutions at central places in response to increasing external economies of large urban scale. Likewise, changing technologies that lowered costs of transportation were shown in Chapter VIII to effect changes in the distribution of urban settlements within hierarchies of central places. History of the diffusions and integration of the heavy plow and the heavy horse in agriculture and the horse in overland transportation in Medieval Europe lent empirical weight to the theories in Chapter VIII. 
Export-base theory was used in Chapter VIII to illustrate the ongoing effects of technological integration on urban growth in Medieval and Renaissance Europe. Increasing first the internal economies of large-scale production, and then the external economies of urban scale, the diffusion of technology promoted productive surpluses that were used as exports in interregional trade and exchange. The net revenues realized from the trade were used to expand local urban bases and were thus responsible for urban growth.

Finally, how collective action and interest-group politics bring institutional norms into accord with changing technologies was described in Chapter $X$. One aspect of that adjustment was illustrated by the changes in urban form precipitated by changes in transportation technologies. That part of the chapter explained how the railroads produced monocentric cities in the nineteenth century, and how the later diffusion and integration of automotive technology produced suburbanization, polycentric cities, and a plague of urban problems that are a part of the on-going institutional adjustment process. Urbanization as a theme to describe the dynamic and progressive effects of technology according to institutional economic theory seems to be a useful approach. It appears to add both color and dimension to institutional economics, political theory, and explanations of urban affairs. And insofar as advances in social theory are incremental at best and are based upon insights drawn from antecedent theories, it may be said that the work at hand has advanced urbanology toward a more complete theoretical base--albeit ever so slightly.

The normative implications of this aspect of the work appear to center on the very long-run relationship between technological

Reproduced with permission of the copyright owner. Further reproduction prohibited without permission. 
development, urbanization, and the quality of urban life. The significance of this relationship is often and unfortunately lost in a labyrinth of what can only be called short-sighted ceremonial concerns that appear as traditional values, the preservation of which is most likely to retard technological development, inhibit urban development, and impair the quality of urban life. In the very long run, improvements in the quality of urban life are keyed to urban development, and urban development is keyed to technological development. And since human progress points toward continued urbanization, progress is likewise tied to technological development--just as it has always been.

Urbanization and Ceremonial ism

Urban-related examples were employed to illustrate the ceremonial aspects of institutional economics in Chapters II, IV, V, IX, and X. The central urban-related idea is that institutions agglomerate at urban places to take advantage of the external economies of large urban scale. Thus urban areas are simply domiciles for institutions, and they provide the physical forums for ceremonial interaction. Any reference to institutions or ceremonialism, the instrument for discharging institutional functions, is therefore related to urban affairs. An important related idea is that ceremonialism is traditionbound and backward-clinging in terms of the ends-means continuum.

Chapter II was given over to exploring the ontological meaning of the word "institution" in order to devise a definition that would serve throughout the work that followed. Chapters IV and V expanded on the institutional functions gleaned from the review of literature in Chapter II. A product of those expansions was to show how institutions 
evolved as social mechanisms to reduce human uncertainties and to stabilize human interactions. The legendary establishment of the city of Rome, Italy, by Romulus was described in Chapter IV to show how the institutional system of antiquity finally adjusted to the modest urbanization that was occurring in those times.

Finally, Chapters IX and $X$ are devoted to explanations of how institutions adjust to technological changes in modern pluralist democracies--societies that are both industrialized and urbanized. It was demonstrated in Chapter IX how ceremonial influences might defeat the innovation or the integration of new technologies by manipulating benefit-cost analyses to favor outcomes that were preferred by reactionary institutional groups that were bent on preserving their traditional values.

Chapter $X$ described how the institutional system adjusts itself through collective action and interest-group politics. Collective action brings about changes in customs by transactions (ceremonial exchanges) between going concerns (institutions) in which working rules (ceremonial norms) are adapted to new and different circumstances. The routinization of such adapted working rules produces changes in customs. The chapter also demonstrated how laws are changed to bring them slowly into agreement with evolving customs. Customs that have been given the force of law are much more difficult to change than other customary ways; the process of change in a pluralist democracy is through interest-group politics.

Once again, urbanization as a theme around which to unify the synthesis and describe the ceremonial dimension of institutional economics has been a useful approach. The theme has highlighted the 
ceremonial aspect of urban existence by first demonstrating the agglomerative linkage between cities and institutions and thus the domiciliary role of the former for the latter, and second by expanding on the functional influences of ceremonialism toward the maintenance of social order in all places that institutions exist. This is, of course, predominantly in urban settings where the external economies of large urban scale have attracted an agglomeration of institutions.

The normative implications that might be drawn from the relationship between urban affairs and ceremonialism appear to center on the tradition-orientation of ceremonialism. The first concern is with the maTheability of benefit-cost analysis by which it may be possible for reactionary institutions to defeat the innovation, diffusion, and integration of new technologies that would otherwise advance human welfare in terms of the continuum of on-going life processes. It can only be hoped that persons will become wary of such strategies as they become better informed on the essential character of ceremonialism and its role of preserving traditional values $k$ opposing innovations that threaten the mythical foundations on which those values are based.

The second concern is with what appears to be the modern tendency to declare more and more human interaction as subject to law and thus to the coercive enforcement powers of governments. Over and against the need for stability is an equally important need for flexibility, and expansion of the rule of law, vis the reign of customs aloiie, is to forfeit the latter for the former. Laws are much more rigid and more difficult to change than customs that do not have the force of law. The more a society gives its customs the force of law, the more inflexible that society becomes. And the more inflexible a society, 
the less likely it will be to realize the progressive powers of new technologies in expanded human welfare.

\section{INSTITUTIONAL ECONOMICS}

Another purpose in the foregoing work was to make a contribution of sorts to institutional economics--although that purpose was not expressed in so many words. The question raised in this part of the concluding chapter is whether that implicit purpose has been fulfilled. Finally, this part will compare the institutional works of a selected group of contemporary economists with the interpretations made here of the seminal works in institutional economic theory.

\section{Economic Theory}

Viewed exclusively from the economic perspective, description of the two foregoing relationships may be considered a contribution to institutional economic theory. That is, the parallel augmenting and complementary relationships between aspects of pluralist political theory and institutional economic theory may be said to enhance both bodies of theory, and thus to be a contribution to the latter as well as the former. Likewise, describing urbanization and urban development in terms of institutional economic theory is a contribution to the latter as well as to a better understanding of the former.

It appears to this writer that the work at hand makes several other contributions to the field of institutional economics as well-albeit they are minuscule ones. The main contributions are: Designation of a fourth economic time period, the "very long-run." Expanded redefinition of the words "institution," and "technology." Giving 
more precise description to the institutional relationships between discovery, invention, innovation, integration, and diffusion as they relate to science and technology, and reorganization, and embellishment of institutional economic theory as it is interpreted from the seminal works by this author.

Chapter I above designates the relevant institutional economic time period of analysis as the "very long run," and defines it as a period of sufficient duration to study the institutional changes that result from economic and quasi-economic activities. To be sure, other economists have acknowledged the anthropological and evolutionary nature of institutional economic theory, but none have distinguished its time period of analysis from other economic time periods. ${ }^{6}$ The institutional time period differs from the three time periods of orthodox economic theory in that the latter are concerned primarily with elasticities of resource supply, given a state of institutional arrangements. As the name implies, and the definition confirms, the institutional time period is much longer than the longest orthodox economic time period. Indeed, the essential distinction of institutional economic theory is this time period dimension and the evolutionary perspective it connotes.

Chapter II sought an operational definition of the word "institution." Previous definitions were generally found deficient because they were not sufficiently inclusive. Selected topics of social sciences literature were surveyed, and the definition quoted in the beginning of the summary at the head of this chapter was adopted. The definition describes the institutional components (human group and cultural values), the social function of institutions (to preserve 
social stability), and the institutional methodology (by perpetuating

- cultural values). Chapters IV and V further elaborated on the adopted definition in terms of the ceremonial nature of institutional functions and methods. ${ }^{7}$ Thus this work has produced a definition of the word "institution" that is more complete and more suited to the purposes of institutional economic theory.

Considerable verbiage has been produced by others about technology. However, this writer could find no adequate definition in all the literature dealing with the word. Most previous definitions are deficient because they either confuse technology with technical skill-which is a nonmaterial, human quality--or with all culture without distinction. Chapter VI attempts to sort out these issues and to derive an operational definition of the word. The resulting definition is: Technology is that quality of a tool that enables it to be substituted for human effort in the creation of goods and services having human value. Moreover, the chapter distinguished technology from technique and technical skill. Technique is the method by which tools (embodying technology) are employed by humans. And technical skill is the ability of persons to apply technique to the employment of tools. This work has therefore produced definitions of the word "technology" and of related terms that are more clearly delineated than previous definitions and that appear to be better suited to the purposes of institutional economic theory.

Building on the definition of technology from Chapter VI, Chapters VII and VIII offered a more exacting explanation of the institutional relationships between scientific discoveries and the invention, innovation, integration, and diffusion of new technologies.

Reproduced with permission of the copyright owner. Further reproduction prohibited without permission. 
Scientific discoveries and the invention of new technologies relate to technological continuity while the innovation of new technologies relates to the dynamic qualities of the latter--to the powers of technology to induce social change. The integration and diffusion of new technologies relate to improvements in human welfare, and the latter to social progress. ${ }^{8}$

Finally, this work has produced a new interpretation of the seminal works in institutional economic theory and has reorganized and embellished the theory with historical examples. It was noted in the beginning chapter that institutional economic theory is in a state of disarray with unreconciled inconsistencies between its main branches. It is therefore not clear how institutional economists can claim a coherent body of theory, or justify it as a discreet field within the economics discipline. Indeed, it is not at all clear how institutional economics fits within the discipline of economics. ${ }^{9}$ Thus more orthodox economists tend to treat the field with disdain and to escape completely into the fairyland of mathematical economic models.

The preceding chapters have attempted to demonstrate that there is a coherent body of institutional economic theory, and that the field serves a number of important functions within the economics discipline. Institutional economics adds a dimension and a perspective all its own by which economics may be more closely related to and more nearly integrated with other social science disciplines, and it functions to criticise, augment, and complement other fields within the economics discipline.

While no exhaustive effort was made to reconcile the inconsistencies in institutional economic theory, the theory was 
organized and rationalized along particular lines so that the major premises of this work might be developed. As noted in Chapter I, the criteria used to achieve consistency between the fragments of institutional economic theory were to use those parts that are in essential agreement, to use those parts that this author believes are most valid where there is conflict and where the material is needed to systematize the theory, and to ignore remaining parts that do not appear to be particularly applicable.

There are points on which the seminal institutional writers are clearly in agreement. They all shared an evolutionary outlook--what this writer characterizes as a very long-run perspective. They all were concerned with the position and nature of institutions in society. And they were all critical of orthodox economic theory for its static method of analysis. Notwithstanding these points of agreement, certain inconsistencies persist to plague the field.

By now, the reader knows very well that the theory is organized in this work around the idea of an ends-means continuum and the choices surrounding the selection of future ends and the employment of means toward achievement of the ends selected. 10 Likewise, the reader knows about the past-clinging of tradition-bound ceremonialism and of the forward-urging of new technology. These ideas were described in Chapters III through VIII, and they were taken from The Theory of Economic Progress by Clarence Ayres.

Ayres combined the concept of ceremonialism from The Theory of The Leisure Class by Thorstein Veblen with the progressive technologies from The Theory of Business Enterprise and other works also by Veblen to describe the ceremonial-technology dichotomy. Further, he related 
the dichotomy to a continuum of on-going life processes, a concept that he drew from Theory of Valuation by John Dewey. However, the original Ayres rendition of these ideas did not follow the form described here. Indeed, his work was so difficult for some scholars to understand that he had to clarify it in a protracted foreward to his second edition. 11 Even there, his organization does not seem to this writer to be a good one. The reorganization given in this work to these aspects of the theory has hopefully given it better clarity and coherence.

The Veblen-Ayres branch of institutional economics sees institutions and their ceremonial practices as villains in the play of human progress. Institutions serve to stabilize social interaction, and this means placing restraints on individual actions that contravene institutional norms. It means preclusion of technological innovation, proscription of change, and inhibition of human progress where the former are instrumental toward progress. The Veblen-Ayres branch sees progress as the triumph of its hero technology over the villain institutions. It explains institutional discontinuities in terms of technological continuities. In short, the Veblen-Ayres branch of institutional economics concentrates on the unstabilizing forces that cause social revolutions. It gives practically no explanation to how stability is maintained while social change is under way.

On the other hand, the John R. Commons branch views institutions as the heroes in the piece. After all, institutions are "collective action in control, liberation, and expansion of individual action." The Commons view proceeds on the premise that at least some level of certainty and stability in human interaction is necessary in any civilized society. It is, of course, institutions that maintain social 
stability before, during, and after social changes. Moreover, the Commons branch attempts to explain institutional changes in terms of collective action, and it succeeds thereby to shed light on the area of economic interaction left murky from the Veblen-Ayres point of view--the social processes whereby the tensions between ceremonialism and technology are resolved into human progress.

The inconsistencies related above stem, in this writer's opinion, from differences in points-of-view. The Veblen-Ayres view concentrates on the technology and the social forces that tend toward change, and thus toward social instability. Conversely, the Commons view concentrates on the forces of society that tend toward stability--on what Veblen and Ayres call ceremonialism, and Commons thinks of as working rules and transactions. At any rate, the interpretation in this work sees the two views as complementary, and it has been expedient to develop this idea in Chapter $X$ above as a partial reconciliation of the two branches of institutional economics. ${ }^{12}$

The apparent inconsistencies between the Veblen-Ayres branch and the Commons branch of institutional economics are complicated by problems of vocabulary. This difficulty is further complicated by modern writers who tend to coin their own terms for phenomena on which there is not wide-spread semantical agreement. At any rate, an understanding of the synonymity of terms is useful in seeing that Veblen, Ayres, and Commons were, indeed, comprehending and writing of the same things. Chapter $X$ above attempts to clarify this by translating certain terms from Commons to the verbiage of Veblen. For example, the Commons "going concern" is approximately synonymous with the Veblen "institution." Likewise, Commons" "working rules, custom, and law" are 
approximately synonymous with Veblen's "ceremonialism," and the former's "transactions" may be viewed as the latter's "ceremonial exchanges."

This part of the chapter attempts to justify the claim that substantive contributions to the field of institutional economics have been made in this monograph. The supposed contributions are:

Demonstrating a parallel, augmenting and complementary relationship between political pluralist theory and institutional economic theory. Showing the relevance of institutional economic theory to urbanization and urban development. Designating the "very long-run" as the institutional economic time-period of analysis. Redefining the words "institution," "technology," and related terms. And reorganizing and expanding institutional economic theory as it has been interpreted from the seminal works by this writer.

\section{Contemporary Institutional Economists}

Until now, this writer has adhered closely to the seminal writers in institutional economics. Indeed, even this was very selective, and only the writings of Thorstein Veblen, John Dewey, C. E. Ayres, and John R. Commons were seriously consulted. This was done to assure that the original works were interpreted with fidelity. Curiously, none of the seminal writers were economists in the orthodox sense. Veblen, Dewey, and Ayres were educated in the discipline of philosophy, and Commons failed in his efforts to complete a doctorate in economics. This might account for what no doubt appears to other economists as the former writers' contrariwise approach to economic orthodoxy. And it might also account in part for the apparent lack of interest shown in the field by most traditionally-trained economists. Nevertheless, each 
man made one or more substantial and significant contributions to the field that is known today as institutional economics, and it is on their works that the field is founded.

Are there any contemporary scholars in the field today? If so, who are they? How shall they be distinguished from other economists? What is the nature of their work? And how do their writings relate to this work? There are, of course, contemporary scholars of institutional economics that are distinguishable from other economists, although some contemporary institutionalists might resist their inclusion in that classification. Moreover, many contemporary institutional economists are distinguished in other fields of economics as well. Interestingly, contemporary institutional economists are some of the most widely read in the economics discipline today.

The attributes of institutional works that distinguish them from those of other economists include the characteristics described above as unique to the field of institutional economics. The essential attributes that are common to the works of all institutional economists are employment of the very long-run time-period of analysis along with the evolutionary perspective that the time-period involves, and the concentration on institutional arrangements.

Other corollary attributes that may indicate an institutional linkage are tendencies to niggle and criticise economic orthodoxy on the bases of empirical and historical examples drawn from other disciplines and theoretical views, and preoccupations with economic development and growth.

A good many economists who are much better known for their contributions to orthodox economics might incidentally be classified 
as institutional economists on the foregoing bases. ${ }^{13}$ However, the contemporary scholars selected for inclusion here as institutionalists have, in the opinion of this writer, distinguished themselves by producing works that are substantial contributions in the field. The works of these men defy easy subclassification. Some survey the past and are descriptive. Some look to the future and are predictive. Some deal with normative values and are prescriptive. And some are all three. Some of their works deal with contemporary problems, and others with very long-run developmental problems. Some tend to stress technological aspects of socio-economic problems, and others stress the ceremonial.

At any rate, the best-known contemporary institutional economist, in this writer's opinion, is John Kenneth Galbraith. Galbraith has been a prolific commentator on the American and world economies since the early 1950s. Spiced with a smidgen of prescriptive exposition, his works have been primarily descriptive. Moreover, he tends to take the phenomenon of technical change as given, and he concentrates his analysis on the problems of ceremonialism and institutional adjustment. His contributions to vocabulary include the concept of countervailing power, dependence effect, conventional wisdom, social balance, industrial state, technostructure, revised sequence, educational and scientific estate, planning system, and more.

Galbraith's first work of institutional significance is American Capitalism, subtitled "The Concept of Countervailing Power." The work applied the interest-group politics of Dewey, Truman, and others to economic interaction, holding that ". . .private economic power is held in check by the countervailing power of those who are subject to

Reproduced with permission of the copyright owner. Further reproduction prohibited without permission. 
it." By which, Galbraith means that "In the typical modern market of few sellers, the active restraint is provided not by competition but from the other side of the market by strong buyers." 15 Moreover, each side will attempt to enlist public opinion in its cause and to influence the enactment of laws that will enhance its bargaining power. Galbraith illustrates the operation of countervailing power with examples drawn from the history of labor and farm legislation, among others.

As well as coining a new term, "countervailing power," American Capitalism is a criticism of economic orthodoxy for concentrating on imaginary competitive markets while ignoring the very long-run institutional changes that have rendered the orthodox paradigm ever less relevant. In this sense, the work is more in the tradition of John $R$. Commons. Indeed, one can almost imagine Commons! "collective action" operating as Galbraith's "countervailing power."

Perhaps Galbraith's most influential work is The Affluent Society which, along with American Capitalism lays a foundation of theory on which most of his subsequent works are erected. Indeed, Affluent Society is the first volume in a trilogy, the remaining volumes of which are reviewed below. The book is also a social criticism that became a favorite conversation piece of the liberal dilettanti, and it topped the best-seller lists for six months or so. Moreover, the work has so far had a lasting effect on recent generations of policy makers and scholars.

Approximately the first third of Affluent Society is, of course, an introduction, and it states the historical context in which the remainder of the work is developed. The center piece of the 
introduction is "the Concept of the Conventional Wisdom," ". . .the ideas which are esteemed at any time for their acceptability." 16 Acceptability is tested by familiarity, and the wider the familiarity, the less changeable the ideas. It is, of course, the conventional wisdom that rules the lives of men and is therefore the basis of social policies. Galbraith traces the roots of the conventional wisdom from the fundamental ideas of modern Western Civilization--the notions of rational economic man, competitive markets, consumer sovereignty, the liberal state with limited powers, etc.--to the present flowering of high consumption in modern industrial life. That ties economic security to employment, employment to production, and production to consumer demand.

The center third or so of Affluent Society is devoted to an attack on the institutional fruits of a conventional wisdom that is sadly out of touch with the economic realities of industrial times. The pièce de résistance of that section and perhaps the entire book is the "dependence effect," which Galbraith describes thus:

As a society becomes increasingly affluent, wants are increasingly created by the process by which they are satisfied. . . Increases in consumption, the counterpart of increases in production, act by suggestion or emulation to create wants. Or producers may proceed actively to create wants through advertising and salesmanship. Wants thus come to depend on output. In technical terms it can no longer be assumed that welfare is greater at an all round higher level of production than at a lower one. . the higher level of production has, merely, a higher level of want creation necessitating a higher level of want satisfaction. . . this is not true of all goods, but that it is true of a substantial part is sufficient. It means that since the demand for this part would not exist, were it not, contrived, its utility or urgency, ex contrivance is zero. 17

The notion embodied in Gaibraith's dependence effect is, of 
course, not affirmed in the conventional wisdom which believes the opposite, that production is called up by consumer demand. The disparity :.: between the illusions that people hold (the conventional wisdom) and Galbraith's reality (dependence effect) is responsible for serious misallocations of resources and a variety of socioeconomic i11s. It results in a lack of "social balance," and social balance is defined by Galbraith as ". . . a satisfactory relationship between the supply of privately produced goods and services and those of the state, .. . ${ }^{18}$

The dependence effect results in social imbalance because "advertising operates exclusively, and emulation mainly, on behalf of privately produced goods and services. Since management and emulative effects operate on behalf of private production, public services will have an inherent tendency to lag behind." In amplifying this, Galbraith writes:

The scientist or engineer or advertising man who devotes himself to developing a new carburetor, cleanser or depilatory for which the public recognizes no need and will feel none until an advertising campaign arouses it, is one of the valued members of our society. A politician or public servant who dreams up a new public service is a wastre1. Few public offenses are more reprehensible. 19

The theory of social balance is the heart of the prescriptive portion of Affluent Society. Galbraith devotes the last third of his book to matters that should be changed to correct the misallocations, bring the economy into social balance, and remedy other social ills traceable to the dependence effect. Finally, the book ends with a prediction of the benefits that might be expected if his prescriptions are followed.

Reproduced with permission of the copyright owner. Further reproduction prohibited without permission. 
Affluent Society was a popular conversation piece on the academic circuit as well. The avant garde scholars delighted in its implied criticisms of conservatism. But, understandably, not all of Galbraith's colleagues agreed with him. Some attacked his dependence effect, arguing that there is much more to advertising than want creation, that advertising also conveys all sorts of information needed by consumers if they are to make intelligent economic choices. Others raised questions about the theory of social balance, arguing that many of the goods and services designated as so-called public goods by Galbraith might be provided more efficiently by private markets. Finally, others called Galbraith to task for what they saw in Affluent Society as a sellout to socialism. 20

But what about the relationship of Affluent Society to the interpretation of institutional economics exposed in this work? Galbraith's contribution in The Affluent Society is in the very best tradition of institutionai economics. One can see Veblen's influence, and perhaps that of Ayres, in the work. Indeed, conventional wisdom is Galbraith's term for ceremonial beliefs a la Veblen, or for custom in the Commons vernacular. Likewise, the emulative quality of the dependence effect is straight out of Veblen's Leisure Class. Finally, the work is a scholarly social criticism of the first order. Nevertheless, there are some disquieting reservations of Galbraith's normative pronouncements that will be reserved for the end of this review of his works.

At this writing, Galbraith has produced two more works that merit comments as institutional economics. Indeed, the two selections complete the trilogy that commenced with and evolved from The Affluent 
Society. The New Industrial State is a carefully delineated description of the corporate system and the relationship of the corporation to the state and the individual. While it is an overstatement to say that New Industrial State is simply a restatement of The Affluent Society, the reader has little trouble seeing the influence of the latter in the former even though Galbraith has taken some pains to attire phenomena in the former in different idiomatic regalia.

What Galbraith is describing has long since been described by others. However, at least two things distinguish this work. The first is that he has brought a considerable mass of scholarship togetrer in a single volume to support his contentions. The second is that he has in some ways disclosed his own ideological preferences more openly and thus more clearly--with reasonable scholarly reservations, of course.

The dominant feature of the industrial state is the industrial system comprising large producing organizations, planning, discipline, and economic growth as the principal measure of success. The large producing organizations are, of course, corporations. Galbraith describes how the "technostructure" has largely replaced traditional management in controlling the modern corporation. The technostructure consists of "those who, as participants, contribute information to group decisions." Galbraith describes this group as very large--

. . it extends from the most senior officials of the corporation to where it meets, at the outer perimeter, the white and blue collar workers whose function is to conform more or less mechanically to instruction or routine. It embraces all who bring specialized knowledge or experience to group decisionmaking. This, not the management, is the guiding intelligence-the brain--of the enterprise.21

Everything in the industrial state is harnessed to the needs of the technostructure. Members of the technostructure "adapt the goals of 
the corporation to their own; by extension, the corporation seeks to adapt social attitudes and goals to those of the members of the technostructure." Thus the accepted sequence is revised. The accepted sequence is founded on the notion of consumer sovereignty--"the unidirectional flow of instruction from consumer to market to producer..."

Galbraith explains the revised sequence: "Instead the producing firm reaches forward to control its market and on beyond to manage the market behavior and shape the social attitudes of those, ostensibly, that it serves." 22

The technostructure, through its management and control, have brought the state itself into line so that the state serves the former by "regulation of aggregate demand, maintenance of a large public. . . sector on which this regulation depends, underwriting of advanced technology and provision of an increasing volume of trained and educated manpower. "23

The latter of these state functions in service to the technostructure--provision of an increasing volume of trained and educated manpower--is discharged by state and corporate support of higher education, what Galbraith calls the "educational and scientific estate." The traditional antagonisms between the latter and the corporate world have 211 but vanished since ascendance of the technostructure, the members of which are products of the educational and scientific estate. The estate has expanded enormously to meet the needs of the technostructure, and it is gaining in political influence at the same time that organized labor is declining in sich influence. ${ }^{24}$

Most of The New Industrial State is given over to description of the present economic condition of modern American society and of the 
institutional changes that have brought it to that condition. However, in the last chapter Galbraith speculates on the probable future of the industrial system. His predictions suggest a convergence wherein any nation that achieves mature industrialization will, irrespective of its professed ideology, become an industrial state in service to its citizens. Thus, the state enterprises of the professed communist nations will be indistinguishable from the mature, modern corporations of the professed capitalist nations. And the states in both cases will be serving their industrial systems in the same ways. ${ }^{25}$

What Galbraith calls the industrial system in New Industrial State he roughiy translates to the "planning system" in Economics and the Public Purpose. The planning is, of course, carried on by the technostructure which, by the way, survived the transition from the former volume to the latter without perceptible change. The planning enables the technostructure to maintain its control of the entire economy and thereby to assure an unending continuation and growth of its prestige, power, and income.

However, Galbraith contrasts the planning system with the market system, the less than half of the economy that continues to serve the American consumer. This is essentially the noncorporate, proprietary part of the business world, and it is composed of many small enterprises that tender services, vis the supply of goods or things that are manufactured by the large corporations. The important differences are that members of the planning system are able to control their environments while members of the market system remain subject to their environments. These circumstances lead to exploitation of the market system by the planning system. Moreover, such economic ills as 
recession and inflation fall heavily on the market system, but leave the planning system little affected, or perhaps even better if than before. $^{26}$

Economics and the Public Purpose is Galbraith's major prescriptive work. The last third of the volume is given over to an agenda of reform that seems remarkable in light of the institutional problems Galbraith has so assiduousiy sketched out. Some of the most conservative persons might consider his reforms radical while the most liberal constituency might feel they were on the conservative side. Indeed, as he is careful to point out, many of the reforms were well under way before the book was published in the early 1970s.

Interestingly, Galbraith rejects the tired liberal palliatives of the past that attacked market power. He argues correctly, in the opinion of this writer, that: "The central problem of the modern economy is unequal development. The least developed is where there is the least monopoly and market power; the greatest development is where there is the most." 27

He therefore rejects anti-trust enforcement both because it has been ineffective and because it proceeds on the classical theory that monopoly power leads to inefficient allocations of resources. He rejects regulation in its present form because the state is essentially a captive of the planning system and regulation simply leaves the technostructure to regulate itself. Placing so-called public-interest members on corporate boards of directors is a toothless remedy because corporate boards are almost as powerless before the technostructure as the corporate stockholders. Finally, he rejects wholesale public ownership of corporate business because the evidence faits in many cases 
to demonstrate that public ownership is an improvement over private ownership--and, indeed, some evidence suggests the contrary in some kinds of enterprise. ${ }^{28}$

What Galbraith argues for is emancipation; emancipation of belief, emancipation of women, emancipation of the state, and emancipation of the market system. The agenda calls first for emancipation of belief by jettisoning the worn-out baggage of the conventional wisdor and its classical economic contents. It means leaving hold of the accepted sequence and grasping the revised sequence in all of its ramifications. Only with those new understandings can the state be emancipated from the technostructure and its planning system. And onty then can the state become the agency for carrying forth the remainder of Galbraith's agenda of reform.

The remaining Galbraith agenda calls for the emancipation of women from the menial household competitions that occupy suburban populations. Among other things, this means equal educational opportunities, equal employment opportunities, equal pay for equal work, choices of work week and work year, and child-care centers. The agenda calls for enhancement of the power and competence of the market system, vis that of the planning system. Likewise, it calls for disciplining the purposes and methods of the planning system, and seeing to a more equitable distribution of income both within the planning system and between that system and the market system. It calls for better social balance in the allocation of resources between the private and public sectors. Finally, it calls for a new socialism--public provision of housing, medical care, and transportation based on need. ${ }^{29}$ What then of Galbraith's institutionalism in the last two Reproduced with permission of the copyright owner. Further reproduction prohibited without permission. 
volumes of his trilogy? First, it needs be noted that Galbraith is guilty of the infamous style change procedure he so deplores among oligopolistic manufacturers. The reader will recognize the "conventional wisdom" of The Affluent Society attired as "accepted sequence" in New Industrial State. Thus, like the conventional wisdom, the accepted sequence is an aspect of ceremonial knowledge in VeblenAyres terms. Likewise, the reader will recognize the "dependence effect" of The Affluent Society disguised as the "revised sequence" in New Industrial State. Thus, like the former term, revised sequence relates to the human propensity to emulate that was a central theme in Veblen's Theory of the Leisure Class. Finally, as al ready noted, Galbraith has dressed up the "industrial system" of New Industrial State as the "planning system" in Economics and the Public Purpose. Like Veblen, Galbraith shines as a great popularizer of new expressions. Style changes aside, New Industrial State looks in many ways like an update of Veblen's Theory of Business Enterprise. Additionally, one can almost read the sequel to Veblen's Engineers and the Price System in Galbraith's treatment of the "technostructure." And the technostructure sounds very much like the "power elite" of C. Wright Mi1ls. Likewise, Veblen's lamentations in the Higher Learning in America are reaffirmed with a special twist in Galbraith's description of the "educational and scientific estate." 30 Final1y, Galbraith's treatment of the state in relation to the industrial system is strikingly similar to that of Marx in his critique of capitalism--and Marx is, after all, a superb institutional economist when his work is measured by the criteria stated above. One must, of course, avoid the logical fallacy-that since Marx was an institutional economist, all institutional 
economists are Marxists.

In addition to restating a good many old institutional themes

Galbraith's work possesses other qualities that mark it as

institutional economics. It involves a very long-run dimension, and it deals with institutional change. It recognizes, but does not dwell upon, the function of technology in inducing social change. Moreover, it expands incrementally on an understanding of modern techniques for innovating new technologies in what Galbraith calls "process innovation" or the institutionalization of innovation through the research and development programs carried on for the technostructure and its planning system by the state and the educational and scientific estate. He correctly notes that this is done to insulate the technostructure and its planning system by controlling the unstabilizing effects of new technologies. ${ }^{31}$

Finally, Galbraith's work might be viewed as a modern and carefully argued restatement of Say's Law--that market demand is created by the forces of supply. ${ }^{32}$ That is, the supply of goods and services give rise to returns of income (rent, wages, interest, and profits) to the factors of production that were employed to produce the supply. There could, therefore, not be an insufficiency of demand resulting in unemployment because the recipients will, in the aggregate, spend their incomes on the consumer goods they were employed to produce. Say's Law was more or less up-ended by the so-called new economics of John Maynard Keynes. ${ }^{33}$ Keynes argued that the end of production is consumption, and that the level of aggregate consumption may be insufficient, resulting in unemployment, if the level of aggregate saving is greater than the level of aggregate investment. Thus, 
production is called forth by market demand. Galbraith's version of Say's Law takes the form of the dependence effect. Given institutional arrangements to maintain buying power (employment compensation, transfer payments, government subsidies, etc.) demand is created by producers through advertising.

Notwithstanding its institutional virtues, Galbraith's work possesses some disquieting features. First, the entire Galbraithian edifice hangs on the dependence effect, and the dependence effect is founded on a fallacy of composition--because a part of the economy conforms to his model, then his model explains the entire economy. He alludes to this in the early pages of The Affluent Society when he writes: "This / the dependency effect $\bar{T}$ is not true of all goods, but that it is true of a substantial part is sufficient." 34 And he proclaims it loudly in the front two-thirds of Economics and the Public Purpose where he acknowledges the existence of a market system that is more or less explained by orthodox economic theory. Moreover, a substantial part of the goods produced by the manufacturing sector (the industrial or planning system) are important subsistence items and they likewise escape Galbraith's classification as goods subject to the dependence effect. Finally, even the advertising that is intended to create demand for goods that would otherwise have no apparent demand has information value over and above demand creation. Thus, the dependence effect might actually apply to as little as one-tenth or less of the goods and services consumed in the United States in any given year. If the dependence effect cannot stand, then a good bit of that which follows in The Affluent Society and in the remaining volumes of Galbraith's trilogy may be subject to serious doubt. 
Second, Galbraith takes orthodox neoclassical economic theory to task for its supposed failure to adequately deal with market imperfections--that is to deal with them according to the Galbraith world view. In fact, a good bit of Galbraith's polemic, including the phenomenon he calls the dependence effect, is taken out of contemporary neoclassical economic theory or applied economics fields that are founded on such theory. More specifically, it is taken from the economics of market or industrial structure. The field branches into the economics of anti-trust and the economics of regulation. And those applied fields are founded on the microeconomics of imperfect competition.

Regarding Galbraith's agenda for reform, it is not entirely clear how the state can be, or whether it should be, emancipated from the institutional system of which it is, like all other institutions, a component part. As the earlier chapters of this essay attempted to demonstrate, and Galbraith faithfully acknowledged in the early chapters of The Affluent Society, there is a large and commonly held body of received (conventiona1) wisdom that, right or wrong, binds a stable society together. And all of the institutions--the state, the economy, the family, the church, etc.--are, for good or bad, in near unanimous affirmation of those ceremonial beliefs. Moreover, the various components of the institutional system are interrelated and interdependent. They constantly reinforce one another through the ceremonial exchanges of their respective members. And those members occupy positions in not one, but a number of the interdependent institutions. It is difficult to see how the state can be severed from the institutional system and still remain effective in its 
dealings with that system--particularly if the state is to be a representative democracy.

Moreover, Galbraith's approach to reform comes down essentially to handing over the power to a sovereign state that is "emancipated" from what may be its most important constituency and expecting the state to effect redistributions of economic and other institutiona 1 powers on the basis of some higher kind of wisdom--apparently the unconventional wisdoms flowing from Galbraith's pen. It seems to this writer that such an expectation is uncommonly naive. If history demonstrates anything, it is that there is no tyranny more oppressive than that of an all-powerful sovereign, and no attribute more corruptible and corrupting than unrestrained political power.

Even if the state could be emancipated and it did altruistically embark on the mission of bringing Gaibraithian reform to fruition, the probable outcomes deserve closer examination. Galbraith's prescription for redressing an skewed distribution of institutional powers appears to be the creation of countervailing powers in the weaker institutional sectors. It seems to this writer that this could be jumping from the institutional frying pan into the ceremonial fire. It could lead to the escalation of countervailing (and counter-countervailing, etc.) powers, and thus to a proliferation of institutions and successive layers of ceremonial crust over a society already burdened with oppressive ceremonialism.

Whether or not one agrees with either his descriptions or his prescriptions, Galbraith is to be applauded for presenting relevant, timely, controversial, and provocative issues and views in words the general public can understand. He is perhaps the most literary of 
contemporary economists. He is lucid and articulate. He is sometimes satirical, often humorous, always witty--al1 of which no doubt accounts for his popularity with the reading public.

A seemingly disproportionate amount of space has been given over to reviewing the principal institutional works of John Kenneth Galbraith. This was done because, in the opinion of this author, he is the best known and most read institutional economist in the world today. His works are also among the best examples of social criticism in the field. However, there are a good many other solid institutional economists on the contemporary scene. Unfortunately, space does not permit them to be given the same treatment accorded here to J. K. Galbraith. However, some clearly deserve more than passing mention.

Two other important institutional economists who, like J. K. Galbraith, tend to concentrate their works on problems of ceremonial adjustments, are Gordon C. Bjork and Robert L. Heilbroner. Bjork, who is the least pub7ished of the two, picked up a thread from John R. Commons and has attempted to weave it into whole cloth. The Commons thread is an observation that private property is nothing more than those assets the personal possession of which the state recognizes and stands ready to defend. Bjork develops this notion into a theory of institutional change based in part on interest-group politics.

\footnotetext{
. . sets of institutional arrangements are worked out by men and survive as long as they are perceived to be useful in contributing to such individual and social goals as security, provision of the material means of existence, and opportunity for individual advancement. The arrangements are changed when technological advances create new opportunities for economic improvement or when they create a demand for protection by groups who are able to exercise political power to win protection of their interests from other members of society. 35
}

Reproduced with permission of the copyright owner. Further reproduction prohibited without permission. 
The argument about the logic and development of capitalism presented in this book, then, is one which emphasizes the social utility of capitalist arrangements for a-society interested in maximizing economic growth while retaining the security of the individual. It does not depend on any belief in the "natural" or " "moral" " rights of men to property in assets or freedom from social control of their use. It emphasizes that institutions have been changed as individuals have been able to convince the rest of society that the rest of society would be better off by recognizing certain rights to freedom and property than it would be if it did not recognize them. 36

Bjork develops these ideas in the remainder of his work. Chapters III through $V$ describe the origins of his ideas in political and economic thought and in the so-called "logic of property." Chapters VI through IX develop the freedom and property aspects of his thesis in a more or less historical context looking at developments from antiquity, through the medieval period, and into modern times. Chapters $X$ through XIV examine public regulation of market activities--or limitations on the unconstrained uses of property--first by comparisons with medieval markets, then in a description of Soviet economic organization, and finally with an examination of anti-trust policies, labor legislation, and monetary controls in the United States. Chapter XV examines the United States record of income distribution and shows that the distribution of income is determined by institutional factors and that such factors must change if the distribution of income is to change. Bjork's work closes in Chapter XVI by encouraging a "capitalist ethic" patterned on the philosophy of the commonwealth adopted in Massachusetts by its founding fathers. Bjork observes:

Reproduced with permission of the copyright owner. Further reproduction prohibited without permission. 
In his economic transactions with other members of society, each individual was to be free to enrich himself as long as his actions also enriched the rest of society. Transactions which merely redistributed existing wealth or income were not to be socially condoned. The analysis of property and freedom of exchange elaborated in preceding chapters have been informed with this ethic. This writer believes such an ethic does provide a reconciliation between private enterprise and public interest, between individual ism and community. 37

Bjork's work is a superb look at the history and development of the institution of private property and the role private property has and is playing in the stabilization of social interactions in a capitalist system. The work is therefore devoted to the aspects of ceremonialism surrounding the institutions involved with private property--private markets, the state, the family, etc. This is a different, but fruitful, way to study economics, and Bjork is to be applauded for expanding knowledge and understanding in this way.

However, it seems to this author that Private Enterprise and Public Interest possesses some weaknesses in terms of the institutional theories described in this work. First, it appears to this writer that Bjork assumes by implication "rational economic man." Such an assumption seems unrealistic, and it does not fit well with the concept of ceremonialism developed in this essay--unless, of course, one defines rational behavior to be any behavior that is ceremonial. Finally, Bjork appears to have an inadequate concept of the tensions between ceremonialism and technology in the selection of ends and the employment of means. Perhaps this is because, like Commons before him, Bjork is more concerned with the institutional powers that augur social stability than the technological factors that tend toward instability-even though he does acknowledge the dynamism of technology in inducing social changes.

Reproduced with permission of the copyright owner. Further reproduction prohibited without permission. 
Robert L. Heilbroner has been a prolific writer with contributions to a number of fields in economics. His first publications were very popular selections in economic biography and history. He later turned his attentions to economic theory, and several of his works were eventually gathered together into a somewhat popular textbook for beginning economics students. He gradually shifted his attentions toward institutional economics, seemingly in respite from his work in theoretical and applied economics.

Heilbroner's first major journey into institutional economics resulted in the publication of The Future as History, subtitled "The Historic Events of Our Times and the Direction in Which They are Taking America." 38 The essay explores what Heilbroner calls the "inertia of ideologies," or what Veblen and Ayres refer to as "ceremonial resistance to change." Heilbroner claims that one's ideology is a product of what he calls a "philosophy of historic expectations," and he describes that philosophy as one of optimism in the United States. He argues that a philosophy of optimism tends to equate the movement of historic forces with the idea of progress, and to obscure the historic possibilities and impossibilities regarding freedom and necessity.

Thus, Americans possess an unrealistically rosy image of what is actually a dismal world existing and developing around them. They are lulled into complacency by such an ideology, and the complacency leads to inertia and the failure to respond with needed change. This eventually leads to frustration and disillusionment because of what Heilbroner calls the "ambiguity of events"--people are confounded when they achieve goals only to find that their achievements have 
unexpectediy produced new and different sets of problems. The challenge for the West is to somehow produce the fortitude and understanding to maintain an outlook of humane optimism.

Between The Future as History and his next contribution to institutional economics, Heilbroner wrote The Great Ascent; The Struggle for Economic Development in Our Time. ${ }^{39}$ of course, one might argue that Great Ascent was a contribution to institutional economics because one can hardly write on the subject of development without taking the very long-run view and applying institutional economic analysis. However, the book is one in an established field of applied economics even though it contains much in the way of institutional theory. Like most other writers in the economic development field, Heilbroner makes the point that "economic" development is too narrow a term. Development actually involves all aspects of society, of which the economy is only a part. He also observes that the outlook for significant improvements in the less developed nations in this generation is very gl um.

Heilbroner's next piece of institutional writing is The Limits to American Capitalism, which is well described by the title. ${ }^{40}$ The book contains a superb discourse on the relationship between technology, productivity, and social change. Heilbroner argues that technology has pushed society to the "boundaries of the business system," and he predicts that capitalism will survive well into the next century, but that it will ultimately yield to a very different kind of social order. One aspect of that change will be the rise of a "scientific elite." Heilbroner produced another title in applied economics between Limits to American Capitalism and his next and most ambitious

Reproduced with permission of the copyright owner. Further reproduction prohibited without permission. 
institutional scholarship. This time, his work was in what is called "comparative economic systems," another field that is akin to institutional economics. The work, Between Capitalism and Socialism, is a collection of essays written since 1966, and, like Great Ascent, is important to Heilbroner's metamorphosis to institutional economics because his study in the applied fields obviously helped shape some of his thoughts for his major contribution to institutional economics. 41 Heilbroner's most ambitious piece of institutional scholarship to date is An Inquiry Into the Human Prospect. ${ }^{42}$ The inquiry is in the vein of his previous institutional works. However, where the latter tend to be more descriptive--Future as History dealing with the inhibitive effects of ceremony, and Limits to American Capitalism dealing with the unstabilizing effects of new technologies--the former is more predictive. Heilbroner's institutional writings have always had a significant international flavor, but Inquiry is cast in the international mold, albeit that he views international events from the Western vantage point. That is, while his previous institutional works dealt primarily, but not exclusively, with internal matters over which the United States has some control, Inquiry deals primarily with the external challenges over which the U. S. may have very little if any control.

He argues that the United States and all of Western Civilization is gravely threatened by external challenges, or challenges from the Third World that will multiply over the years and that cannot be met or overcome with the usual industrial solutions. Indeed, it is precisely the efforts and successes of the less developed nations in achieving industrialization that is and will continue to exacerbate 
the problems. Moreover, the West cannot morally deny the peoples of those countries their fair share of world resources and of what has come to be viewed as the materially good life in the West.

The external challenge, then, is a combination of affluent liestern life styles and continued industrialization of the economically depressed nations in the face of dwindling world resources and burgeoning populations in the latter nations. Obviously, increasing populations alone will place insufferable strains on already scant resource pools. And each improvement in the livelihood of the povertystricken part of the world will multiply the resource drain.

Moreover, each improvement for the poverty-stricken will be accomplished by expansion of industry, and each expansion of industry will add to the technology-induced pollution already choking the biosphere. Finally, industrialization must eventually make nuclear materials available to all nations, and this can only lead to widespread access to the most gruesome of "obliterative" weapons. According to Heilbroner, such weapons will be great equalizers in a world of otherwise unequal nations.

What, then, is the human prospect? Several scenarios occur to Heilbroner. The most dismal is a cataclysmic end a few generations hence after mankind has integrated and diffused enough technology to completely overload and perhaps destroy the life-support capacity of the earth. The next and equally dismal scenario is widespread nuclear warfare between nations attempting to acquire or preserve parts of the shrinking resources for themselves. The least dismal is a continuing series of convulsive changes forced on the West and the rest of humanity by the foregoing external forces. Clearly, the meritorious

Reproduced with permission of the copyright owner. Further reproduction prohibited without permission. 
Western ceremonies of peace, democracy, freedom, individualism, etc. cannot fare well under such circumstances.

What does Heilbroner see as the nature of future society if, indeed, humanity somehow manages to survive? Heilbroner calls such a society "post industrial." He describes it as one in which the institutions will stress parsimony over profligate consumption, quality of life over quantity of goods, and rendering services over production of material wealth. He sees a decline in scientific endeavor and a return to preindustrial introspection and speculations about ultimate values. People will be better educated, and they will look upon resource consumption and heat generation as necessary evils.

Heilbroner's most recent works are Business Civilization in Decline and Beyond Boom and $\mathrm{Crash}^{43}$ The former is essentially an expansion on The Limits of American Capitalism in light of his revelations in An Inquiry Into the Human Prospect, and the latter is little more than a progress report on the former in light of the oil crisis. Heilbroner attempts to construct a time-table for his predicted decline in industrial capitalism in the United States and the West, and for the rise of the so-called post-industrial society. He sees little change except in the growth of planning in the near future. However, he prophesies the advent of "trans-systemic" challenges during the middle range (25-50 years) in which the external challenges he described in An Inquiry will start producing institutional changes in both the capitalist and socialist economies of the Western World. Finally, those same challenges will lead to post-industrial society 100 or 150 years hence.

Reproduced with permission of the copyright owner. Further reproduction prohibited without permission. 
What can be said of Heilbroner's institutional economics? The least is that he has a good comprehension of ceremonialism--the inertia of ideology as it applies to American capitalism. However, he does not appear to understand that the same forces are working in every other system, be it democratic socialism, Marxian socialism, fascism, tribalism, or any other ism that afflicts a people. The less developed nations are in a state of deplorable misery today (by Western standards) because their peoples vehemently oppose any technological influence that may require them to abandon their cherished tribal traditions. While there may be emulative pull to development, development will not take place without considerable push to overcome institutional barriers as well.

Moreover, Heilbroner appears to be trapped in an embrace between straight-line extrapolations and unilinear causality. He has bought into the Neo-Malthusian Meadows study--the original study of the socalled Club of Rome that the Club itself repudiated in recent sequels. ${ }^{44}$ It nevertheless appears that Heilbroner has seated himself firmly with other doomsday seers who are neurotical1y searching for the ends of the earth from atop the environmental band wagon. Most of those passengers suffer the same myopic afflictions. They are straightline extrapolators who reason unilinearly.

The error in this approach is that it overlooks the progressive qualities of technologies. The difficulties with modern technology are mainly transitory institutional maladjustments in the integration and diffusion processes. There is no reason to believe that the needed adjustments will not be made, or that the quality of life on earth will not be immeasurably improved for more people in the outcomes.

Reproduced with permission of the copyright owner. Further reproduction prohibited without permission. 
Moreover, the quality of life will be improved precisely because of substantial increases in per-capita quantities of goods. And all of this will occur directly with the pace at which people disabuse themselves of mysticism and false notions of mythical supernatural powers in control of their lives.

Heilbroner is certainly not the first person to overlook the progressive qualities of new technologies. That oversight afflicted both Malthus and Marx and caused their most dire predictions to fail. ${ }^{45}$ Likewise, it accounts for the intellectually bankrupt "stagnation thesis" of Alvin H. Hansen a generation or so ago. 46 Indeed, Hansen achieved fame in large part for the publications he ground out to first rationalize his mistake, then to repudiate it, and finally to erect new theories on diametrically opposite assumptions. Finally, the gloomy prophesies of the such recent harbingers of doom as Rachel Carson, Paul Ehrlich, and the Meadows family have not and are extremely unlikely to materialize for the same reasons. ${ }^{47}$

Heilbroner's assumptions aside, this age is not perfectly unique. The present human condition is different in at least one absolute dimension. It is enormously superior to other ages because of technological developments. But problems facing present man are the same in substance as those facing other ages even though they are different in kind. In substance the problem is to reconcile the tensions between tradition-bound ceremonialism and dynamic technologies in the selection of future ends and the employment of means so that progress results in the enhancement of human welfare.

What then can be said of Heilbroner's foreboding descriptions and ominous predictions? Certainly, he has made the dismal science 
dismal indeed. Although he seems to admonish otherwise, his implied prescription appears to be that Western man must substitute a philosophy of pessimism for his inherently optimistic outlook. Such a change does not seem warranted. Heilbroner is undoubtediy correct in predicting a different social order in the very long run because institutional change follows inevitably when mankind has the courage to innovate new technologies. However, this writer cannot agree, and history does not affirm that the induced changes are likely to result in diminished human welfare.

This review cannot end without mention of a number of economists who have expanded understanding of the social significance of technology. Not all of them can be considered to be institutional economists because their analyses ignored institutional arrangements and they dealt with technology in terms of the usual orthodox time periods. Interest in the economic effects of technology were stimulated by revelation in 1928 of the "Cobb-Douglas Production Function," the technical characteristics of which need not concern this study. 48 There foilowed a period of speculation and additional research on the Cobb-Douglas findings, but the matter of technical change was subordinated to other factors because of certain economic characteristics of the aggregate production function.

After a much too respectable interval (1957), Robert M. Solow produced an article dealing with "Technical Change and the Aggregate Production Function." 49 Solow's work greatly heightened interest in the economic effects of technology, and the economic vocabulary concerning technical change was greatly expanded by Solow and other economists who carried on the research. Finally, Edwin Mansfield 
produced a book on the subject that summarized and integrated much of the work done by others on the economic effects of technical change. 50 While none of this work was institutional in character, it was important to institutional economics because it was giving empirical substantiation to pronouncements made previously by Veblen and Ayres about technology.

In the meantime, W. W. Rostow produced The Stages of Economic Growth; A Non Communist Manifesto in which he posited a theory of traditional society and five stages through which such a society must pass in the process of developing itself into a mass-consumption eccnomy. 51 Rostow drew an analogy between the developing country and an aircraft. One of Rostow's stages is therefore called the "take-off," the period during which the country makes itself airborne in terms of economic growth. The so-called take-off stage is crucial because it is the period in which the country is at full throttle, so to speak, making heavy investments in the capital goods that will turn it into an industrial nation. The capital goods, of course, embody technologies, and the effects on the country are unstabilizing.

Rostow's take-off stage captured the imagination of every economist who had an interest in economic development and much attention focused on the matter of innovation or diffusing new technologies in developing countries. One such economist was Simon Kuznets who did a survey of the quantitative knowledge of economic growth. ${ }^{52}$ Part of Kuznets' survey recapitulated data on rates of technical change and their effects on gross national product and on other variables. Kuznets produced his own writings on economic development in which he stressed the importance of technological diffusion and the resulting 
institutional changes to economic development. Finally, Gerald M. Meier wrote The International Economics of Development in which he integrated orthodox theories of technical change with international trade and exchange theories to show the relationship between those factors in the matter of economic development. ${ }^{53}$ While these economists were working in applied fields of orthodox economic theories, their works shed more light on the nature of technology and the relationship between technical change and institutional change.

This review would not be complete without mention of at least one more scholar. Donald A. Schon has produced several works with significance for institutional economics. The first of such works published in the United States is Technology and Change; The New Heraclitus. Schon explored the nature of invention and innovation in terms of risk, uncertainty, and decision-making in corporations. He reviewed the history of American technical change, and examined what he believes to be the ethical issues surrounding national policies devised to enhance technological advance. ${ }^{54}$

Schon's next title is Beyond the Stable State in which he examines the role of "dynamic conservatism"--what he calls a tendency to fight to remain the same--in institutional resistance to change. He argues that the stable state (institutional constancy and predictability) is eternally lost because the innovation of new technologies has made continuous institutional transformation a central feature of modern society. He asks how institutions can become effective "learning systems" so that the exponential growth in information can be managed. He dismisses the so-called rational scientific modes of understanding because they depend on the 
predictability and continuity that are lost in the on-rush of technology. He advocates an "existential strategy" for managing the flow of information and the rapid rate of change. ${ }^{55}$

Schon's stable state is the epitome of institutional rigidity, and his dynamic conservatism is yet another term for ceremonia! ways of knowing and doing. However, his term is a contradiction of sorts because conservatism is not dynamic in the usual sense. Nor is dynamism conservative. The words are diametrically opposite in their general tenor. Conservative, the adjective form, describes resistance to change, while dynamic describes forces in motion, that is, movement or change of position.

Semantics aside, Schon is good on the tensions between ceremonialism and technology. Even so, his solution to instability is to let the institutions manage the flow of information and thereby the rate of change. While there can be no other solution--because that is the modus operandi anyhow--it is like letting the wolf tend the flock. In short, Schon does not appear to understand the nature of institutional change in terms of Commons' "collective action."

This somewhat lengthy review of selected literature from contemporary institutional economics was accomplished to show how the contemporary work relates to the seminal works in the field, and how this essay relates to the contemporary. literature. As with all scholarship, there is not perfect agreement among scholars. However, it is hoped that the reader has been able to detect sufficient agreement among contemporary scholars and between them and the works of Veblen, Commons, and Ayres to see a consistent and relevant body of institutional economic theory.

Reproduced with permission of the copyright owner. Further reproduction prohibited without permission. 
Most contemporary institutional writers have limited themselves to the application of institutional economics to current problems. They have been commentators who describe and explain modern events in terms of institutional causality, and who criticise their colleagues and public policy-makers in the light of institutional theory. Some few institutional scholars have sought to expand or to deepen the theory by synthesis and testing. These latter scholars have confined their works to one or another component of the theory. None have attempted to bring the elements of theory into a consistent whole.

As noted above, a necessary step in achieving the stated purpose of this paper was to interpret and give some organization to the components of theory heretofore loosely known as institutional economics. While this was done with care, the work remains the author's interpretations, and whether or not the outcome is satisfactory remains for others to judge. However, the point is that this work differs from other work in the field insofar as it is an attempted organization of the essential body of institutional economic theory known at this time.

This review was also made to demonstrate how institutional economic theory relates to orthodox economics and to other socialscience disciplines. It seems to this writer that institutional economics is solidly established in the economics discipline because both the field and the discipline share a common concern--the selection of future ends from competing possible ends, and the alternative employments of resource means to attainment of those ends so that human welfare is best served. Moreover, institutional economics adds an important dimension--the very long-run--to the understanding of 
economic phenomena. The field therefore augments both the positive and the normative powers of the discipline.

Finally, it is hoped that this review will so stimulate the interest of other scholars that at least some of them will turn their considerable research talents to furthering understanding in institutional economics. 


\section{END NOTES, CHAPTER XI}

${ }^{1}$ Authors mentioned in this summary were cited in the end notes of the summarized chapters, and they will not be cited again here.

2Truman, Governmental Process. Mills, Power Elite.

3 Harold Lasswel1, The Analysis of Political Behavior; An

Empirical Approach, London: Routledge \& Kegan PauT, Ltd., 1948. Truman, Governmental Process.

${ }^{4}$ Latham, Group Basis of Politics. Truman, Governmental Process.

5 Latham, Group Basis of Politics. Truman, Governmental Process. Dahl, Who Governs? Robert A. Dahl, After the Revolution: Authority in a Good Society, (New Haven: Yale University Press, 1970). ATso see critics of "interest-group politics." Theodore J. Lowi, The End of Liberalism; Ideology, Policy and the Cris is of Public Authority, (New York: W. W. Norton \& Co., Inc., 1969). Grant McConne11, Private Power and American Democracy, (New York: Random House, Inc., 1966). Robert PauT Wolff, The Poverty of Liberalism, (Boston: The Beacon Press, 1968).

${ }^{6}$ Allan Gruchy, Modern Economic Thought; The American Contribution, (New York: Prentice-Ha71, Inc., 1947), pp. 3-4. Note that this is similar to Marshall's so-called fourth time period, "secular movements of normal price, caused by the gradual growth of knowledge, of population, of capital, and the changing conditions of demand and supply from one generation to another." However, also note that Marshail's definition is directed toward the usual concerns of orthodox economics. It omits any explicit mention of technology and institutional change. Alfred Marsha11, Principles of Economics, 8th ed., (London: Macmillan \& Co., Ltd., 1920), pp. 78-79.

${ }^{7}$ John Gambs, Beyond Supply and Demand, (New York: Columbia University Press, 1946), p. 13.

8 Rostow, "Technology and the Price System," pp. 88-96.

${ }^{9}$ The place of institutional economics in the economics discipline is a question that recurs in American Economic Association meetings every decade or so. However, the discipl ine has no discrete classification for institutional economists at this time. See The American Economic Review, LXVIII (December, 1968), 425.

${ }^{10}$ The choices between competing ends and alternative employment of means are the grounds common to all economics, and it is this concern as much as any in institutional economics that weds it to the economics discipline. 
${ }^{11}$ Ayres, Theory of Economic Progress, pp. v-xxv.

${ }^{12}$ David Hamilton, "Veblen and Commons: Theoretical Convergence," Southwestern. Social Science Quarteriy, XXXIV (September, 1953), 43-50.

13 particularly in the applied economics fields of labor economics, public finance, economic development, economic history, and comparative economic systems.

${ }^{14}$ Aside from those listed above in footnotes (Gambs, Gruchy and Hamilton), other contemporary economists who come to mind as making contributions to institutional economics, but whose works will not be reviewed here, include: William Breit, James Buchanan, Neil W.

Chamberlin, A. W. Coats, William P. Culbertson, Jr., Joseph Dorfman, S. Herbert Franke1, R. A. Gordon, Gardiner Means, Gunnar Myrdal, Macur 01 son, and Gordon Tullock-- to name a few.

${ }^{15}$ John Kenneth Galbraith, American Capitalism; The Concept of Countervailing Power, (Boston: Houghton Mifflin Co., 1952), pp. 177-12.

${ }^{16}$ John Kenneth Galbraith, The Affluent Society, (New York: The New American Library, 1963), p. 18.

17 Ibid., pp. 128-30.

18 Ibid., p. 201.

19 Ibid., p. 204.

$20 \mathrm{~F}$. A. Hayek, "The Non Sequitor of the 'Dependence Effect'," Southern Economic Journal, XXVII (Apri1, 1961), 346-48. Henry C. Wallich, "Public vs Private: Could Galbraith be Wrong?" in Private Wants and Public Needs, ed. by Edmund S. Phelps, (New York: W. W. Norton \& Co., Inc., 1962), pp. 51-62.

${ }^{21}$ John Kenneth Galbraith, The New Industrial State, (Boston: Houghton Miff? in Co., 1967), p. 71.

22 Ibid., pp. 211-12.

${ }^{23}$ Ibid., p. 320.

${ }^{24}$ Ibid., pp. 282-95.

25 Ibid., pp. 388-99.

26 John Kenneth Galbraith, Economics and the Public Purpose, Boston: Houghton Miffl in Co., 1973), pp. 179-212.

27 Ibid., p. 276.

28 Ibid., pp. 215-22.

Reproduced with permission of the copyright owner. Further reproduction prohibited without permission. 
${ }^{29}$ Ibid., pp. 223-324.

${ }^{30}$ Thorstein Veblen, The Theory of Business Enterprise. The Engineers and the Price System, (New York: Harcourt, Brace \& World, Inc., 1963). The Higher Learning in America: A Memorandum on the Conduct of Universities by Business Men, (New York: Sagamore Press, Inc., 1957). Mil1s, Power Elite.

${ }^{31}$ Galbraith, Public Purpose, pp. 146-54.

32 Jean-Baptiste Say, Treatise on Political Economy: Or the Production, Distribution, and Consumption of Wealth, (Boston, We1 $1 \mathrm{~s}$ and Li17y, 1821), pp. 83-93.

${ }^{33}$ John Maynard Keynes, The General Theory of Employment, Interest and Money, (New York: Harcourt Brace \& Co., Inc., 1936).

${ }^{34}$ Galbraith, Affluent Society, p. 130.

$35_{\text {Bjork, Private Enterprise, }}$ p. 20.

${ }^{36}$ Ibid., p. 28.

37 Ibid., p. 236.

${ }^{38}$ Robert L. Heilbroner, The Future as History; The Historic

Events of Our Time and the Direction in Which They are Taking America, (New York: Harper and Row, PubTishers, 1959).

39 Robert L. Heilbroner, The Great Ascent; The Struggle for Economic Development in Our Time, (New York: Harper and Row, Publ ishers, 1963).

${ }^{40}$ Robert L. Heilbroner, The Limits of American Capitalism, (New York: Harper and Row, Publishers, 1965).

${ }^{41}$ Robert L. Heilbroner, Between Capitalism and Socialism; Essays in Political Economics, (New York: Random House, Inc., 1970).

${ }^{42}$ Robert L. Heilbroner, An Inquiry Into the Human Prospect, (New York: W. W. Norton \& Co., Inc., 1974).

${ }^{43}$ Robert L. Heilbroner, Business Civilization in Decline, (New York: W. W. Norton \& Co., Inc., 1976). Beyond Boom and Crash, (New York: W. W. Norton \& Co., Inc., 1978).

${ }^{44}$ Donella H. Meadows, et al. , The Limits to Growth; A Report of the Club of Rome's Project on the Predicament of Mankind, (New York: Universe Books, 1972). For an important, different view, see H. E. Goeller and Alvin M. Weinberg, "The Age of Substitutability," American Economic Review, LXVIII(December, 1978), pp. 1-11. 
${ }^{45}$ Thomas Robert Malthus, An Essay on the Principle of Population, (London: Macmillan \& Co., 1895). Karl Marx, Capital; A Critique of Political Economy, ed by Friederick Engels, Trans. by Samuel Moore and Edward Aveling, (New York: Random House, Inc., 1906).

${ }^{46}$ Alvin H. Hansen, "Economic Progress and Declining Population Growth," American Economic Review, XXIX (March, 1939), pp. 1-15.

${ }^{47}$ Rachel Carson, Silent Spring, (Boston: Houghton Mifflin Co., 1962). Ellu1, Technological Socjety. Paul R. Ehrlich, The Population Bomb, (New York: Ballantine Books, 1968). Meadows, Limits to Growth.

${ }^{48}$ C. W. Cobb and Paul H. Douglas, "A Theory of Production," American Economic Review, XVIII (1928), pp. 139-65.

49 Robert M. Solow, "Technical Change and the Aggregate Production Function," Review of Economics and Statistics, XXXIX (August, 1957), pp. 312-20.

${ }^{50}$ Mansfield, Economics of Technical Change.

51 W. W. Rostow, The Stages of Economic Growth; A Non Communist Manifesto, (London: Cambridge University Press, 1960).

52 Simon Kuznets, Modern Economic Growth; Rate, Structure, and Spread, (New Haven: Yale University Press, 1967).

${ }^{53}$ Gerald Meier, The Economics of Development, (New York: Harper and Row, Publishers, 1968).

${ }^{54}$ Donald A. Schon, Technology and Change; The New Heraclitus, (New York: Delacorte Press, 1967).

${ }^{55}$ Donald A. Schon, Beyond the Stable State, (New York: W. W. Norton \& Co., Inc., 1973). 
SOURCES CONSULTED

Alonso, William. "A Theory of the Urban Land Market." Papers and Proceedings Regional Science Association, VI (1960), 149-57.

"Location Theory," Regional Development and Planning; A Reader. Edited by John Friedmann and WiTliam Alonso. Cambridge: The M.I.T. Press, 1964.

"American Economic Association Charter and Bylaws, 1978 Survey of Members Including Classification Listings, Supplementary Information and Statistical Summaries." American Economic Review, LXVIII (December, 1978).

Anderson, Martin. The Federal Bulldozer. New York: McGraw-Hill Book Co., Inc., 1964 .

Anderson, Ronald. Government and Business. 4th ed. Indianapolis: South-Western Publishing Co., 1965.

Andrews, Richard B. "The Mechanics of the Urban Economic Base: Historical Developments of the Base Concept." Land Economics, XXIX (August, 1953), 161-67.

Annals of America, The. Chicago: Encyclopaedia Britannica, Inc., 1968.

Arrow, Kenneth J. Social Choice and Individual Values. 2nd ed. New Haven: Yale University Press, 1963.

Arrow, Kenneth J.; Chenery, H.; Minhas, B.; and Solow, R. "CapitalLabor Substitution and Economic Efficiency." Review of Economic Statistics, XLIII (August, 1961), 225-50.

Ayres, Clarence E. The Theory of Economic Progress: A Study of the Fundamentals of Economic Development and Cultural Change. 2nd ed. New York: Schoken Books, 1962.

Bachrach, Peter, and Baratz, Morton S. "Two Faces of Power." American Political Science Review, LVI (December, 1962), 947-52.

Bator, Francis M. "The Anatomy of Market Failure." Quarterly Journal of Economics, LXXII (August, 1958), 351-79.

Baumol, William J. "On the Discount Rate for Public Projects." Public Expenditure and Policy Analysis. 2nd ed. Edited by Robert J. Haveman and Julius Margolis. Chicago: Rand McNally College Publishing Co., 1977.

Reproduced with permission of the copyright owner. Further reproduction prohibited without permission. 
Becker, Gary. Human Capital. New York: National Bureau of Economic Research, 1964.

Be11, Daniel. "The Power Elite--Reconsidered." American Journal of Sociology, LXXIII (November, 1968), 238-50.

Bellush, Jewel, and Hausknecht, Murray, eds. Urban Renewal: People, Politics and Planning. Garden City: Doubleday \& Co., Inc., 1967.

Bentham, Jeremy. A Fragment on Government and an Introduction to the Principles of Morals and Legislation. New York: Blackwell's PoTitical Texts, 1948.

Bentley, A. F. The Process of Government. Chicago: University of Chicago Press, 1908.

Berry, Brian J. L. "Cities as Systems Within Systems of Cities." Papers and Proceedings of the Regional Science Association, $X$ (1964), 147-63.

Bibie.

Birch, David L. The Economic Future of City and Suburb. New York: Committee For Economic Development, 1970.

Bjork, Gordon C. Private Enterprise and Public Interest. The Development of American Capitalism. Englewood Cliffs: Prentice-Hall, Inc., 1969.

Black, Alan. "The Comprehensive Plan." Principles and Practice of Urban Planning. 4th ed. Edited by William I. Goodman and Eric C. Freund. Washington, D. C.: International City Managers Association, 1968.

B1ack, Henry Campbel1. Black's Law Dictionary; Definitions of the Terms and Phrases of American and English Jurisprudence, Ancient and Modern. Revised 4th ed. St. Paul: West Publishing Co., 1968.

Book of Common Prayer and Administration of the Sacraments and Other Rites and Ceremonies of the Church According to the Use of the Protestant Episcopal Church in the United States of America, Together With the Psalter or Psalms of David. Greenwich: The Seabury Press, 1952.

Breit, William, and Culbertson, William P., Jr., eds. Science and Ceremony; The Institutional Economics of C. E. Ayres. Austin: University of Texas Press, 1976.

Buchanan, James M., and Tullock, Gordon. The Calculus of Consent. Ann Arbor: University of Michigan Press, 1962.

Bunke, Harvey C. A Primer on American Economic History. New York: Random House, Inc., 1969. 
Burck, Gilbert. The Computer Age; And Its Potential for Management. New York: Harper and Row, PubTishers, 1965.

Carrington, Richard. The Mammals. New York: Time, Inc., 1963.

Carson, Rachel. Silent Spring. Boston: Houghton Miffl in Co., 1962.

Chapin, F. Stuart. Contemporary American Institutions. New York: Harper Brothers, 1935.

Childe, V. Gordon. Man Makes Himself. New York: New American Library, 1951.

Chinitz, Benjamin. "Contrasts in Agglomeration: New York and Pittsburg," American Economic Review, LI (May, 1961), 279-88.

Cipolla, Carlo M. Before the Industrial Revolution; European Society and Economy, 1000-1700. New York: W. W. Norton \& Co., Inc., 1976.

Cobb, C. W., and Douglas, P. H. "A Theory of Production," American Economic Review, XVIII (1928), 139-65.

Cochran, Thomas C., and Miller, William. The Age of Enterprise; A Social History of Industrial America. New York: Harper and Row, Publishers, 1967.

Codere, Helen. "Fighting with Property; A Study of Kwakiut1 Potlatching and Warfare, 1790-1930." Monographs of the American Ethnological Society, XVIII (1950), 63-91.

Columbia Encyclopedia. 3rd ed. New York: Columbia University Press, 1963.

Commager, Henry Steele, ed. Documents of American History. 5th ed. New York: Appleton-Century-Crofts, Inc., 1949.

Commons, John R. Legal Foundations of Capitalism. Madison: University of Wiscons in Press, 1957.

- Institutional Economics; Its Place in Political Economy. 2 vols. Madison: University of Wisconsin Press, 1961.

. Economics of Collective Action. Madison: University of Wiscons in Press, 1970.

Coulanges, Numa Denis Fustel de. The Ancient City; A Study of Religion, Laws, and Institutions of Greece and Rome. Garden City: Doubleday \& Co., Inc., n.d.

Dahl, Robert A. "A Critique of the Ruling Elite Mode1." The American Political Science Review, XLVII (June, 1958), 463-69.

Reproduced with permission of the copyright owner. Further reproduction prohibited without permission. 
- Who Governs? Democracy and Power in an American City. New Haven: Yale University Press, 1961.

- After the Revolution? Authority in a Good Society. New Haven: Yale University Press, 1970.

Darwin, Charles. The Origin of the Species by Means of Natural Selection, and The Descent of Man and Selection in Relation to Sex. VoT. XLIX of Great Books of the Western World. Edited by Robert M. Hutchins, et al. 54 vols. Chicago: Encyclopaedia Britannica, Inc., 1952.

Davis, Otto, and Whinston, Andrew. "Economics and Urban Renewal." Law and Contemporary Problems, XXVI (Winter, 1961), 106-17.

Dewey, John. Essays in Experimental Logic. Chicago: University of Chicago Press, 1917.

- Experience as Nature. New York: The Open Court Publishing Co., 1925.

- The Public and Its Problems. Denver: Alan Swallow, n.d.

- Characters and Events. 2 vols. Edited by Joseph Ratner. New York: Henry Holt \& Co., 1929.

- The Quest for Certainty. New York: Minton Balch, 1929.

- Human Nature and Conduct; An Introduction to Social Psychology. New York: Random House, 1930.

- A Common Faith. New Haven: Yale University Press, 1934.

Liberalism and Social Action. New York: Minton Balch \& Co., 1935.

- Experience and Education. New York: The Macmillan Co., 1938.

- Logic: The Theory of Inquiry. New York: Henry Holt \& Co., 1938.

- Intelligence in the Modern World; John Dewey's Philosophy.

Edited by Joseph Ratner. New York: Random House, Inc., 1939.

- "Theory of Valuation," International Encyclopedia of Unified

Science. Vol. II. Chicago: University of Chicago Press, 1939.

Doeringer, Peter B., and Piore, Michae1 J. Internal Labor Markets and Manpower Analysis. Boston: D. C. Heath \& Co., 1971.

Dorfman, Joseph; Ayres, C. E.; Chamberlin, Neil W.; Kuznets, Simon; and Gordon, R. A. Institutional Economics; Veblen, Commons and Mitchel1 Reconsidered. Berkeley: University of California Press, 1963.

Reproduced with permission of the copyright owner. Further reproduction prohibited without permission. 
Downs, Anthony. An Economic Theory of Democracy. New York: Harper and Row, Publishers, 1957.

Druker, Peter F. The Age of Uncertainty. New York: Harper and Row, Publishers, 1969.

Ehrlich, Paul R. The Population Bomb. New York: Ballantine Books, 1968.

Elliott, B. G., and Consoliver, E. L. The Gasoline Automobile. New York: McGraw-Hi11 Book Co., Inc., 1932.

Ellu1, Jacques. The Technological Society. Trans. by John Wilkinson. New York: Random House, Inc., 1964.

Encyclopaedia Britannica. 15th ed. 30 vols. Chicago: Encyclopaedia Britannica, Inc., 1974.

Fairchild, Henry Pratt, ed. Dictionary of Sociology and Related Sciences. Paterson: Littlefield, Adams \& Co., 1964.

Farb, Peter. The Insects. New York: Time, Inc., 1962.

Ferguson, C. E., and Gould, J. P. Microeconomic Theory. 4th ed. Homewood: Richard D. Irwin, Inc., 1975.

Fraser, Sir James George. Folk-Lore in the 01d Testament; Studies in Comparative Religion, Legend and Law. Abridged ed. New York: Tudor Publishing Co., 1923.

Freud, Sigmund. The Basic Writings of Sigmund Freud. Edited by A. A. Bri17. New York: Random House, Inc., 1938. . An Outline of Psychoanalysis. New York: W. W. Norton \& Co., Inc., 1949.

Friedmann, Jehosua; Greenberg, Philip; and Hoffberg, Alan M. Fortran IV. New York: John WiTey \& Sons, Inc., 1975.

Galbraith, John Kenneth. American Capitalism; The Concept of Countervailing Power. Boston: Houghton Mifflin Co., 1952.

- The Great Crash, 1929. Boston: Houghton Miffl in Co., 1954.

- Economics and the Art of Controversy. New York: Random House, Inc., 1955.

- The Affluent Society. Boston: Houghton Miffl in Co., 1958.

- Economic Development. Boston: Houghton Miffl in Co., 1962.

- The New Industrial State. Boston: Houghton Mifflin Co., 1967.

Reproduced with permission of the copyright owner. Further reproduction prohibited without permission. 
- Economics and the Public Purpose. Boston: Houghton Mifflin Co., 1973 .

Gambs, John. Beyond Supply and Demand. New York: Columbia University Press, 1946.

Gard, Richard A. ed. Buddhism. New York: Washington Square Press, 1963.

Gibbon, Edward. The Decline and Fall of the Roman Empire. Vols. XL and XLI of Great Books of the Western World. Edited by Robert M. Hutchins, et al. 54 vols. Chicago: Encyclopaedia Britannica, Inc., 1952 .

Goeller, H. E., and Weinberg, Alvin M. "The Age of Substitutability." American Economic Review, LXVIII (December, 1978), 1-11.

Grazia, Sebastian de. The Political Community; A Study of Anomie. Chicago: University of Chicago Press, 1948.

Grigsby, William G. Housing Markets and Public Policy. Philadelphia: University of Pennsyivania Press, 1963.

Gruchy, Allan. Modern Economic Thought: The American Contribution. New York: Prentice-Ha17, Inc., 1947.

Haberler, Gottfried. "International Trade and Economic Development." Expansion of World Trade and the Growth of National Economies. Edited by Richard S. Weckstein. New York: Harper and Row, Publishers, 1968.

Hacker, Louis M., ed. Major Documents in American Economic History. 2 vols. Princeton: D. Van Nostrand Co., Inc., 1967.

Hamilton, David. "Veblen and Commons: Theoretical Convergence." Southwestern Social Science Quarterly, XXXIV (September, 1953), 43-50.

Hanke, Steve H., and Walker, Richard A. "Benefit-Cost Analysis Reconsidered: An Evaluation of the Mid-State Project," Water Resources Research, X (1974), 898-908.

Hansen, Alvin H. "Economic Progress and Declining Population Growth." American Economic Review, XXIX (March, 1939), 1-15.

Haveman, Robert H., and Margolis, Julius, eds. Public Expenditure and Policy Analysis. Chicago: Rand McNally College Publishing Co., 1977. , and Weisbrod, Burton A. "Defining Benefits of Public Programs: Some Guidance for Policy Analysts." Policy Analysis, XX (7975), 169-96. 
Hay, Denys. The Medieval Centuries. New York: Harper \& Row, Publishers, 1965.

Hayek, F. A. "The Non Sequitur of the 'Dependence Effect. '" Southern Economic Journal, XXVII (Apri1, 1961), 346-48.

Heilbroner, Robert L. The Future as History; The Historic Events of Our Times and the Direction in Which They are Taking America. New York: Harper \& Row, Publishers, 1959.

- The Great Ascent; The Struggle for Economic Development in Our Time. New York: Harper and Row, Publishers, 1963.

- The Limits of American Capitalism. New York: Harper \& Row, Pub7ishers, 1965.

- The Making of Economic Society. 2nd ed. Englewood Cliffs: Prentice-Ha71, Inc., 1968.

- Between Capitalism and Socialism; Essays in Political

Economics. New York: Random House, Inc., 1970.

An Inquiry Into the Human Prospect. New York: W. W. Norton \& Co., Inc., 1974 .

- Business Civilization in Decline. New York: W. W. Norton \& Co., Inc., 1976.

- i 1978 .

978 Beyond Boom and Crash. New York: W. W. Norton \& Co., Inc.,

Herber, Bernard. Modern Public Finance; The Study of Public Sector Economics. 3rd ed. Homewood: Richard D. Irwin, Inc., 1975.

Herring, E. Pendleton. Group Representation Before Congress.

Baltimore: Johns Hopkins University Press, 1929.

Herskovits, Melville J. Economic Anthropology; The Economic Life of Primitive Peoples. New York: W. W. Norton \& Co., Inc., 1965.

Hertzberg, Arthur, ed. Judaism. New York: Washington Square Press, Inc., 1963.

Hicks, J. R. "The Foundations of Welfare Economics." Economic Journal, XLIX (September, 1939), 699-712.

Hoover, Edgar M. The Location of Economic Activity. New York: McGrawHill Book Co., Inc.

"The Evolving Form and Organization of the Metropolis." Issues in Urban Economics. Edited by Harvey S. Perloff and Lowden Wingo, Jr. Baltimore: Johns Hopkins Press, 1968.

Reproduced with permission of the copyright owner. Further reproduction prohibited without permission. 
Howard, R. W. The Great Iron Trail. New York: Putnam, 1962.

Hoyt, Homer. The Structure and Growth of Residential Neighborhoods in American Cities. Washington, D. C.: U. S. Government Printing office, 1939.

. "Homer Hoyt on the Concept of the Economic Base." Land Economics, XXX (May, 1954), 182-86.

Hunter, Floyd. Community Power Structure. New York: Doubleday, 1963.

Hyman, Herbert H. Political Socialization; A Study in the Psychology of Political Behavior. New York: The Free Press, 1969.

Isaacs, Reginald R. Community Renewal Program, San Juan Metropolitan Area, 1964-65. San Juan: Puerto Rico Urban Renewal and Housing Administration, 1965.

Isard, Walter. Location and Space Economy; A General Theory Relating to Industrial Location, Market Areas, Land Use, Trade, and Urban Structure. Cambridge: The M.I.T. Press, 1956.

Jacobs, Jane. The Death and Life of Great American Cities. New York: Random House, Inc., 1967.

James, Wi11. The Will to Believe. Introductory Readings in Philosophy. Edited by Marcus G. Singer and Robert R. Ammerman. New York: Charles Scribner's Sons, 1962.

Johnsin, Carey C. ed. Institutional Adjustment; A Challenge to a Changing Economy. Austin: University of Texas Press, 1967.

Kaldor, Nicholas. "Welfare Propositions of Economics and Interpersonal Comparisons of Utility." Economic Journal, XLIX (September, 1939), 549-52.

Keynes, Edward, and Ricci, David M. eds. Political Power, Community and Democracy. Chicago: Rand McNalty Co., 1970.

Keynes, John Maynard. The General Theory of Employment, Interest and Money. New York: Harcourt, Brace \& Co., Inc., 1936.

Kornhauser, William. "'Power Elite' or "Veto Groups, '" Culture and Social Character. Edited by Seymour Martin Lipset and Leo Lowentha1. New York: The Free Press, 1961.

Kuhn, Thomas S. The Structure of Scientific Revolutions. 2nd ed. Chicago: University of Chicago Press, 1970.

Kuznets, Simon. Modern Economic Growth; Rate, Structure, and Spread. New Haven: Yale University Press, 1967.

Reproduced with permission of the copyright owner. Further reproduction prohibited without permission. 
Lasswe11, Harold. The Analys is of Political Behavior; An Empirical Approach. London: Routledge \& Kegan Pau1, Ltd., 1948.

Latham, Earl. The Group Basis of Politics. Ithaca: Cornell University Press, 1952.

Latouche, Robert. The Birth of Western Economy; Economic Aspects of the Dark Ages, Trans. by E. M. Wilkinson. New York: Harper \& Row, Pub7ishers, 1966.

Lippman, Wa7ter. The Phantom Public. New York: Macmillan Co., 1929.

Lipsey, R. G., and Lancaster, K. "The General Theory of Second Best." Review of Economic Studies, XXIV (1956), 11-32.

Locke, John. Concerning Civil Government, Second Essay. Vol. XXXV. Great Books of the Western World. Edited by Robert M. Hutchins, et a]. Chicago: Encyclopaedia Britannica, Inc., 1952.

Losch, August. The Economics of Location. Trans. by W. H. Woglom and W. F. Stolper. New Haven: Yale University Press, 1954.

. "The Nature of Economic Regions." Southern Economic Journal, XXIX (August, 1963), 71-78.

Lowi, Theodore J. The End of Liberalism; Ideology, Policy and the Crisis of PubTic Authority. New York: W. W. Norton \& Co., Inc., 1969.

McConne11, Grant. Private Power and American Democracy. New York: Random House, Inc., 1966.

MacIver, Robert M., and Page, Charles H. Society; An Introductory Analysis. New York: Holt, Rinehart and Winston, Inc., 1949.

McLuhan, H. Marsha11, Understanding Media; The Extensions of Man. New York: McGraw-Hil1 Book Co., Inc., 1964.

Madison, James. "Number 10." The Federalist. Vol. XLIII of Great Books of the Western World. edited by Robert M. Hutchins, et al. Chicago: Encyclopaedia Britannica, Inc., 1952.

Malinowski, Bronislav. Argonauts of the Western Pacific. New York: E. P. Dutton \& Co., 1932.

- The Dynamics of Culture Change. New Haven: Yale University Press, 1945.

- Magic, Science and Religion, and Other Essays. Garden City: Doubleday \& Co., 1948.

- Crime and Custom in Savage Society. Paterson: Littlefield, Adams \& Co., 1962.

Reproduced with permission of the copyright owner. Further reproduction prohibited without permission. 
Malthus, Thomas Robert. An Essay on the Principle of Population. London: McMillan \& Co., 1895.

Mansfield, Edwin. The Economics of Technological Change. New York: W. W. Norton \& Co., Inc., 1968.

Mantoux, Paul. The Industrial Revolution in the Eighteenth Century; An Outline of the Beginnings of the Modern Factory System in England. Revised ed. New York: Harper \& Row, Publishers, 1961.

Marshall, Alfred. Principles of Economics. 8th ed. London: Macmilian \& Co., Ltd., 1920.

Martindale, Don. Institutions, Organizations and Mass Society. Boston: Houghton Miffl in Co., 1966.

Marx, Karl. Capita1; A Critique of Political Economy. ed. by Fried-rich Engels. Trans. by Samuel Moore and Edward Aveling. New York: Random House, Inc., 1906.

Mead, George Herbert. Mind, Self and Society. edited by Charles W. Morris. Chicago: University of Chicago Press, 1934.

Meadows, Donella H.; Meadows, Dennis L.; Randers, Jordan; and Behrens, William W. III. The Limits to Growth; A Report of the Club of Rome's Project on the Predicament of Mankind. New York: Universe Books, 1972.

Meehan, Eugene J. The Foundations of Political Analysis; Empirical and Normative. Homewood: The Dorsey Press, 1977.

Meier, Gerald. The Economics of Development. New York: Harper \& Row, Publishers, 1968.

Merton, Robert K. Social Theory and Social Structure. Revised ed. New York: The Free Press, 1957.

Meyer, Jerome S. Great Inventions. New York: Pocket Books, Inc., 1962.

Michels, Robert. Political Parties; A Sociological Study of the 01 igarchical Tendencies of Modern Democracy. Trans. by Eden and Cedar Paut. New York: Dover Publications, Inc., 1959.

Mi11, John Stuart. Utilitarianism. Vol. XLIII. Great Books of the Western World. Edited by Robert M. Hutchins, et al. 54 vols. Chicago: Encyclopaedia Britannica, Inc., 1952.

Mills, C. Wright. The Power Elite. New York: Oxford University Press, Inc., 1956.

Mishan, E. J. Cost-Benefit Analysis. New and expanded edition. New York: Praeger Publishers, 1976.

Reproduced with permission of the copyright owner. Further reproduction prohibited without permission. 
Moses, Leon, and Williamson, Harold F., Jr. "The Location of Economic Activity in Cities." American Economic Review, LVII (May, 1967), 211-22.

Murdock, George P. Rank and Potlatch Among the Haida. New Haven: Yale University Press, 1936.

Musgrave, Richard A. The Theory of Public Finance; A Study in Public Economy. New York: McGraw-Hi77 Book Co., Inc., 1959.

Nevins, Allan, and Hil1, F. E. Ford: The Man, The Times, The Company. New York: Charles Scribner's Sons, 1954.

Ford: Expansion and Challenge, 1915-1933. New York: Charles Scribner's Sons, 1957.

- Ford: Decline and Rebirth, 1933-1962. New York: Charles Scribner's Sons, 1963.

Nietzsche, Friedrich. A7so Spake Zarathustra. Trans. by Thomas Common. n.p., 1883.

North, Douglas C. "Location Theory and Regional Economic Growth." Journal of Political Economy, LXIII (June, 1955), 243-58.

Packard, Vance. The Status Seekers; An Exploration of Class Behavior in America and the Hidden Barriers that Affect You, Your Community and Your Future. New York: D. McKay Co., 1959.

Pareto, Vilfredo. Manuel d'Economie Politique. 2nd ed. Paris: Girard, 1972.

Park, R. E., and Burgess, E. W. The City. Chicago: Chicago University Press, 1925.

Parsons, Talcott. The Social System. Glencoe: The Free Press, 1951.

Perry, Ralph Barton. General Theory of Value. Cambridge: Harvard University Press, 1926.

Peterson, Roger Tory. The Birds. New York: Time, Inc., 1963.

Pirenne, Henri. Medieval Cities: Their Origin and the Revival of Trade. Princeton: Princeton University Press, 1925. Mohammed and Charlemagne. London: George Allen \& Unwin, Ltd., $193 \overline{9}$.

Polsby, Nelson W. "How to Study Community Power: The Pluralist

A7ternative." Journal of Politics, XXII (August, 1960), 478-84.

Reproduced with permission of the copyright owner. Further reproduction prohibited without permission. 
Prest, R. A., and Turvey, R. "Cost-Benefit Analysis: A Survey." Economic Journal, LXXV (December, 1965), 683-735.

Protagoras. "Fragments." Treasury of World Philosophy. Edited by Daggobert D. Runes. Paterson: Littlefield, Adams Co., 1959.

Rasmussen, Wayne D., and Baker, Gladys L. "Programs for Agriculture, 1933-1965." Agricultural Policy in an Affluent Society. Edited by Vernon W. Ruttan, Arley D. Waldo, and James P. Houck. New York: W. W. Norton \& Co., 1969.

Remmling, Gunter W., and Campbell, Robert C. Basic Sociology; An Introduction to the Study of Sociology. Totowa: Littlefield, Adams \& Co., 1970.

Renou, Louis, ed. Hinduism. New Yorn: Washington Square Press, Inc., 1963.

Robbins, Lionel C. An Essay on the Nature and Significance of Economic Science. 2nd ed. London: Macmillan \& Co., 1935.

Rodwin, Lloyd. "The Theory of Residential Growth and Structure." The Appraisal Journal, XVIII (July, 1950), 295-317.

Rostow, W. W. The Stages of Economic Growth; A Non Communist Manifesto. London: Cambridge University Press, 1960. . "Technology and the Price System." Science and Ceremony; The Institutional Economics of C. E. Ayres. Edited by WiTliam Breit and William Patton Culbertson, Jr. Austin: University of Texas Press, 1976.

Rowen, Henry. "The Role of Cost-Benefit Analys is in Policy-Making." Public Expenditure and Policy Analysis. 2nd ed. Edited by Robert $H$. Haveman and Julius Margolis. Chicago: Rand McNally College Publishing Co., 1977.

Runes, Daggobert D. ed. Treasury of World Philosophy. Paterson: Littlefield, Adams \& Co., 1959.

Samuelson, Paul A. Economics. 9th ed. New York: McGraw-Hill Book Co., Inc., 1973.

Say, Jean-Baptiste. Treatise on Political Economy; Or the Production, Distribution, and Consumption of Wealth. Boston: We17s and Li17y, 1821.

Schattschneider, E. E. Politics, Pressures and the Tariff. New York: Prentice-Ha11, 1935.

Schon, Donald A. Technology and Change; The New Heraclitus. New York: Delacorte Press, 1967. 
Beyond the Stable State. New York: W. W. Norton \& Co., Inc., $197 \overline{3}$.

Schreiber, Arthur F.; Gatons, Paul K.; and Clemmer, Richard B.

Economics of Urban Problems; An Introduction. Boston: Houghton MiffTin Co., 1971.

Schumpeter, Joseph A. Capitalism, Socialism and Democracy. 3rd ed. New York: Harper and Row, Publishers, 1962.

Shannon, Fred A. The Farmer's Last Frontier, Agriculture, 1860-1887. New York: Harper and Row, Publishers, 1968.

Sédillot, René. The History of the World in Two Hundred and Forty Pages. Trans. by Gerald Hopkins. New York: New American Library, 1953.

Sjoberg, Gideon. The Preindustrial City, Past and Present. New York: The Free Press, 1965.

Smith, Len Young, and Roberson, G. Dale. Business Law; Uniform Comercial Code. 3rd ed. St. Paul: West Publishing Co., 1971.

Solow, Robert M. "Technical Change and the Aggregate Production Function." Review of Economics and Statistics, XXXIX (August, 1957), 312-20.

Somers, Harold M. "On the Demise of the Social Discount Rate." Journal of Finance, XXVI (May, 1971), 565-78.

Sorokin, Pitrim. Social Mobility. New York: Harper \& Brothers, 1927.

Spencer, Herbert. The Principles of Sociology. Vol. I., 3rd ed. New York: D. Appleton \& Co., 1885.

Stigler, George. The Theory of Price. Revised ed. New York: Macmillan Co., 1952 .

Sumner, William Graham. Folkways: A Study of the Sociological Importance of Usages, Manners, Customs, Mores, and Morals. New York: the New American Library, 1960.

Teithard de Chardin, Père Pierre. The Phenomenon of Man. Trans. by Bernard Wall with an introduction by Julian Huxley. New York: Harper \& Row, Publishers, 1965.

Thompson, Carey C. ed. Institutional Adjustment; A Challenge to a Changing Economy. Austin: University of Texas Press, 1967.

Thünen, Johann Heinrich von. Der Isolierte Staat in Beziehung auf Landwirtschaft und Nationalokonomie. 3rd ed. Berlin: Schumacher-Zarchtin, 1875. 
Tiebout, Charles M. The Community Economic Base Study. Supplementary Paper No. 16. New York: Committee for Economic Development, 1962. . "Exports and Regional Economic Growth." Journal of Political Economy, LXIV (Apri7, 1956), 160-69.

Toffler, Alvin. Future Shock. New York: Bantam Books, 1971.

Truman, David B. The Governmental Process. New York: Alfred A. Knopf, Inc., 1951.

Turner, Frederick Jackson. The Frontier in American History. New York: Henry Holt \& Co., 1921 .

UT Iman, Edward L. "A Theory of Location for Cities." American Journal of Sociology, XLVI (May, 1941), 853-64.

Unger, Maurice A. Real Estate. 5th ed. Cincinnati: South-Western Publishing co., 1975.

U. S. Department of Labor, Bureau of Labor Statistics. A Brief History of the American Labor Movement. 1970 ed. Washington, D. C.: U. S. Government Printing Office, 1970.

U. S. House of Representatives, Committee on Banking and Currency. Basic Laws and Authorities on Housing and Urban Development, Revised Through January 31, 1971. Washington, D. C.: U. S. Government Printing Office, 1977.

U. S. National Commission on Urban Problems. Building the American City; Report of the National Commission on Urban Problems to the Congress and the President of the United States. Washington, D. C.: U. S. Government Printing Office, 1968.

U. S. President's Committee on Urban Housing. A Decent Home; The Report of the President's Committee on Urban Housing. Washington, D. C.: U. S. Government Printing Office, 1969.

Usher, Abbott Payson. A History of Mechanical Inventions. Boston: Beacon Press, 1959.

Veblen, Thorstein. The Theory of the Leisure Class. New York: The Macmillan Co., 1899.

- The Portable Veblen; The Essence of the Work and Thought of One of America's Great Original Minds. Edited by Max Lerner. New York: The Viking Press, 1948.

- The Higher Learning in America; A Memorandum on the Conduct of Universities by Business Men. New York: Sagamore Press, 1957.

Reproduced with permission of the copyright owner. Further reproduction prohibited without permission. 
- The Theory of Business Enterprise. New York: The New American Library, 1958.

- The Engineers and the Price System. New York: Harcourt, Brace \& World, Inc., 1963.

Vernon, Raymond. The Changing Economic Function of the Central City. New York: Committee for Economic Development, 1959.

- Metropolis 1985. New York: Doubleday, 1963.

Wallich, Henry C. "Public vs Private: Could Galbraith be Wrong?" Private Wants and Public Needs. Edited by Edmund S. Phelps. New York: W. W. Norton \& Co., Inc., 1962.

Walras, Leon. Elements of Pure Economics. Trans. by William Jaffe. Homewood: Richard D. Irwin, Inc., 1954.

Washburn, Sherwood L. "Tools and Human Evolution." Scientific American, CCIII (September, 1960), 62-75.

Webee, Max. The Theory of Social and Economic Organization. Trans. by A. M. Henderson and T. Parsons. New York: Oxford University Press, 1947.

Webster's New Twentieth Century Dictionary of the English Language. Unabridged 2nd ed. New York: The World PubTishing Co., 1970.

Went, Fritz W. The Plants. New York: Time, Inc., 1963.

White, Lynn, Jr. "Technology and Invention in the Middle Ages." Speculum, XV (Apri1, 1940), 141-56.

- Medieval Technology and Social Change. London: Oxford University Press, 1962.

Williams, Alan. "Cost-Benefit Analysis: Bastard Science? And/Or Insidious Poison in the Bcdy Politick?" Journal of Public Economics, I (August, 1972), 199-226.

Winsborough, Hal H. "City Growth and City Structure." Journal of Regional Science, IV (1962), 35-49.

Wolff, Robert Paul. The Poverty of Liberalism. Boston: The Beacon Press, 1968.

Reproduced with permission of the copyright owner. Further reproduction prohibited without permission. 